

\section{ETHNICITY AND MOBILIZATION IN SAMI POLITICS}

\section{Tom G. Svensson}
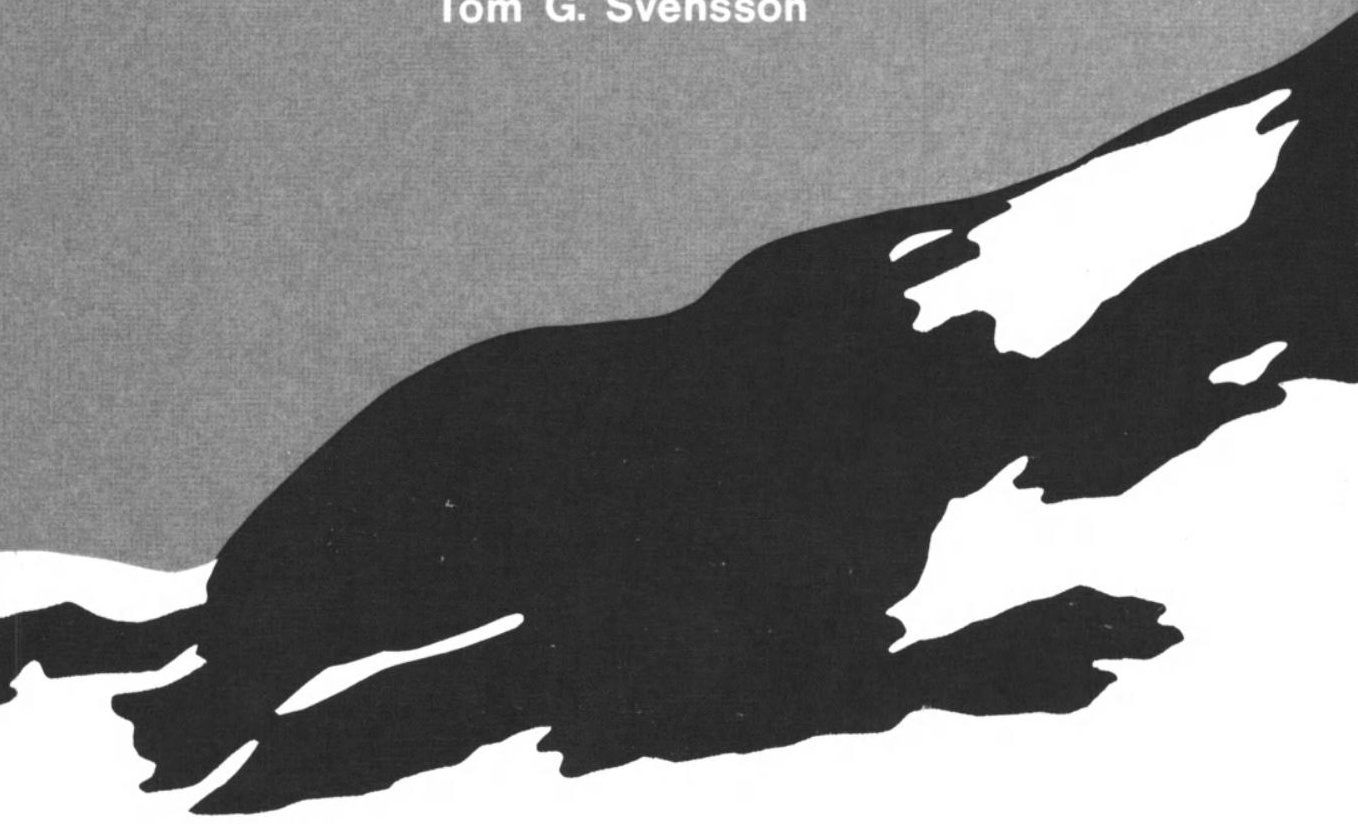



\section{ETHNICITY AND MOBILIZATION IN SAMI POLITICS}

Tom G. Svensson 
LiberTryck S tockholm 1976 
STOCKHOLM STUDIES IN SOCIAL ANTHROPOLOGY $\cdot 4$

(C) Tom G. Svensson 1976

Department of Social Anthropology, University of Stockholm

All rights reserved. This book, or parts thereof, may not be reproduced in any form without written permission of the author. 
C O N T E N T S

Page

Preface

1. Introduction

2. The ecological situation

3. Structural premises

4. The local political form

5. The developed political form

6. Cases of exploitation

7. Samish pasture rights in Norway

8. Revision of the legal framework

9. Conclusions

Appendices

List of abbreviations

References 


\section{Preface}

The present work is a completely revised version of a $\mathrm{Ph} . \mathrm{D}$. thesis presented at the University of Stockholm, Autumn 1973. Some of the chapters have been completely re-written while others, with the exception of minor changes, have been retained in their original form. In the original Swedish version I felt that it was important to give as many source references as possible, with the result that the number of notes and appendices was considerable. These have been reduced in the English version for the simple reason that a non-Scandinavian readership cannot be expected to have the same interest in this predominantly Scandinavian source material as would Scandinavian and Samish readers. However, interested readers should consult this thesis. (Svensson, 1973a)

This study is also the fruit of research carried out for a long period of time. I first became interested in political problems, and in particular those of minority groups, when I was a new student of anthropology. It was Tomas Cramér, who in Autumn 1962 gave a stimulating lecture on the legal and historical aspects of Sami problem to the Anthropological Association of the University of Stockholm, who first aroused my interest in the particular minority situation of the Samis. A few months earlier Cramer had been appointed as legal ombudsman to the Samis. His lecture made me consider the contemporary situation of the Samis in Sweden and it was after this that I was able to formulate a relevant social anthropological research problem. As is apparent from the following study, the Sami ombudsman plays a key role in terms of illustrating the changing minority status of the Samis. The consideration I have received from both Cramer and his staff during the thirteen years that have passed since this study commenced has been invaluable. In this 
context the Samis have exhibited an unusual openness to official examination, and I therefore owe a great debt of gratitude to the Sami ombudsman.

I also include here all those Samis in the field, without whose patient help this study would never have been accomplished. I have learnt a great deal from them, not only about their culture and the problems of their daily life, but also about their wisdom of life, and for that I am deeply indebted. Their hospitality, so invaluable for a non-established researcher, was extremely great, and time was always available for questions and long discussions. It is impossible to name everyone to whom I am indebted for their invaluable friendship. The unbroken contact I have had with Per Idivuoma, the foremost Sami politician, has been of great importance. Per Bertil simma and his family are very close friends of mine in Karesuando. Gustav Heikka, Johannes Simma and the Pilto siblings have also given me invaluable help with this study. In Kiruna my thanks are due in particular to the brothers Johan and Erik Kuhmunen and their families, as well as Nikke Stenberg and his wife. All those persons that I have named here have shown me great hospitality, and have also taken great interest in the problems with which I was dealing.

Among Samis outside the actual area where this study was carried out, I would particularly like to thank Nikolaus Kuhmunen in Gällivare who has read through the entire manuscript and made many invaluable suggestions.

In a study of this sort, considerable information must be obtained from official bodies that deal with Sami affairs. I would therefore like to record my gratitude to the regional authorities in Luleå for their readiness in meeting all my requests.

At a professional level particular thanks are due to Professor Karl Eric Knutsson who has supported me in this task in every possible way and whose criticism has been essential. Thanks go also to Docent Ulf Hannerz who made valuable comments on an earlier draft of this study.

At the Ethnographic Museum, University of Oslo, where I have been employed during the last seven years, everyone has supported me in different ways. The former Head of the Museum, Professor 
Gutorm Gjessing, and in particular his successor Professor Fredrik Barth, have created working conditions at the department that has greatly facilitated this study to be completed. In addition I am especially grateful to $\mathrm{Dr}$. Johs. Falkenberg who has encouraged me in the completion of this monograph. Professor Jan Brögger and Professor Arne Martin Klausen, former colleagues at the Ethnographic Museum, have also contributed valuable points of view at an earlier stage of this work as have Fredrik Barth and Harald Beyer-Broch. I am very grateful for all the suggestions and comments that have been made, but the responsibility for the conclusions that have been drawn remains solely my own.

Another colleague who I would especially like to mention in this context is Harald Eidheim, University of Oslo, who has followed the progress of my work virtually from the beginning, and who has been of great intellectual inspiration.

I would also like to emphasize the importance that Professor Fredrik Barth and the stimulating environment of the University of Bergen have had for me. During the academic year 1965-66 I had the pleasure of being a student in Bergen and the foundation of social anthropological theory and method that I acquired during this period are, no doubt, evident in this study.

I would also like to extend thanks to my good friend and colleague Björn Ranung, Stockholm who has drawn the illustration on the cover, the vignettes at the beginning of each chapter and the maps.

Chapters 1 - 6 have been translated by Elisabeth Seeberg, Oslo and the remainder by Martin Percivall, Stockholm, and to both I extend my thanks for excellent work. Nancy Frank has always been helpful in necessary language consultations for which I am very grateful. I am also indebted to Unn Tangevald-Jensen, Asker, who, in the very short time available, has transformed the manuscript into a typographically finished product.

Each chapter begins with a vignette illustrating a Sami objet d'art. Each vignette, illustrating different aspects of modern Sami handicraft, is accompanied by a short quotation from different Sami literary works. In this way I have attempted to 
show the vitality of the culture the political struggle of which forms the core of this study.

In this context I should like to comment on the use of the word Sami. The usual term in English usage is Lapp. Since the Samis have now begun to carry out their activities on an increasingly international scale, they have agreed to use the name Sami with all its derivatives. Both the Nordic Sami Institute in Kautokeino and the Swedish Sami Union have recently adopted this viewpoint. The time is now ripe to introduce this term also into an anthropological literature.

Finally I would like to thank my parents and my wife Annette. They have encouraged me in more ways than one, in particular Annette who has acted as an indispensable proof-reader. Without her loyalty and great patience as well as her unfailing help this study would never have been accomplished; I can think of no other more fitting tribute than to dedicate this study to Annette as an expression of my gratitude.

The publication of the final manuscript has been aided by the Swedish Research Council for the Social Sciences. 


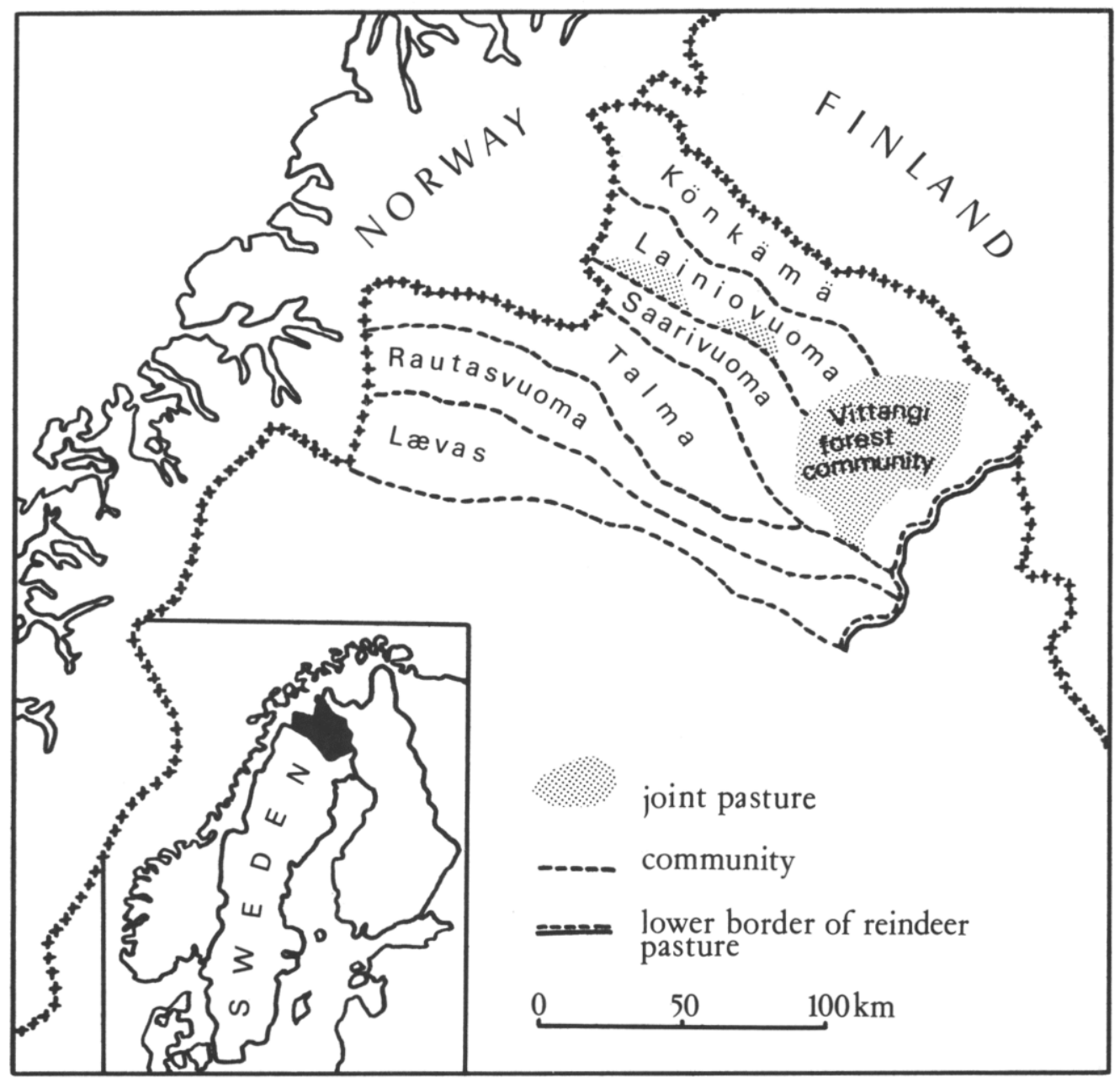




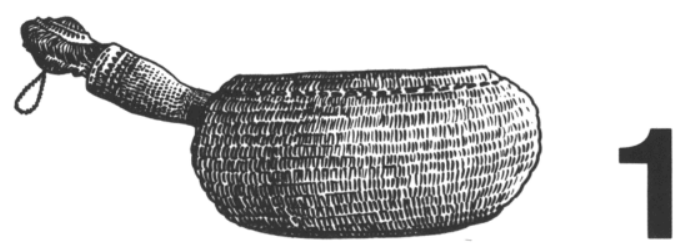




\section{Introduction}

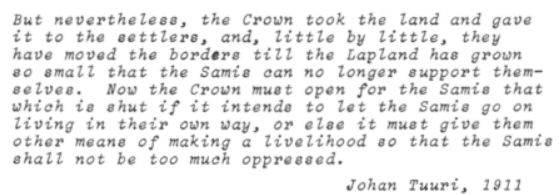

Many branches of Social Science are beginning to take an increasing interest in the problems of ethnic minority groups. A study of the third world must of necessity be a study of poly-ethnic contexts: not only does this apply to macro-disciplines such as national economy, political science and sociology, but social anthropology, traditionally emphasizing the micro-perspective, now tends increasingly to extend the field of its research with studies of the relationship between micro and macro-levels. The relational contexts on which these studies are based are, as a rule, poly-ethnic. But as anthropology has occupied itself with this aspect of investigation for a comparatively short time, the formulation of new and tentative theoretical advances available to date cannot compare with that offered by other aspects of investigation.

However, we may assume relative agreement on certain fundamental features which are characteristic of an ethnic minority situation. The first point is that of the form of social relationship, i.e. an ethnic minority can be understood only in terms of its relationship to another ethnic group. Next - an ethnic group is a minority in terms of the distribution of power. As a rule, a minority has little or no influence on its own affairs: the entire institutionalized power is controlled by the dominant group.

A concept of this sort goes back, in part, to Louis Wirth's discussion in The science of Man in the World Crisis. (Wirth, 1950). This discussion then formed the theoretical basis for the first detailed analysis of minorities in anthropology, namely wagley and Harris's joint work Minorities in the New World, (Wagley and Harris, 1958). More recently we find similar theoretical approaches being 
taken by, amongst others, Tobias and Woodhouse as well as Banton. (Tobias and Woodhouse, 1969, and Banton, 1972).

In order to find more general theories for studies of minorities we have to turn to Blalock's sociological work Toward a Theory of Minority-Group Relations. This study aims at a relatively high level of theoretical abstraction, and with the aid of formal modes of expression, tries to formulate definitive propositions concerning different aspects of the discrimination of minorities. The section on power in relation to discrimination has the greatest relevance to this study. (Blalock, 1967).

The relationship between different ethnic groups within polyethnic contexts is certainly the most fruitful approach also for the study of ethnic minority situations. The continuous interethnic interactions should according to Barth be viewed as a form of social organization. In this way we are able to focus on the relative power relations between the groups as well as the problem of boundary maintenance, a most significant aspect of all ethnic minority studies. In the volume edited by Barth, Ethnic Groups and Boundaries, these theoretical viewpoints have been spelled out very clearly. (Barth, 1969). Although the book primarily concentrates on the general problem of ethnicity, ethnic minority situations are seen as a special variant of inter-ethnic relations, a case which is illustrated by Eidheim's article in the same book, When Ethnic Identity is a Social Stigma. (Eidheim, 1969). In my analysis of the Sami minority situation I have adopted the theoretical framework advanced by Barth et.al. (Barth, 1969).

The foundation of the power of Swedish society is based on legal statuses and institutions. This institutionalized power is based on legislation, a legislation controlled by the majority alone. Thus the wider society must be conceived in terms of certain status positions such as, for example, certain high offices within the political and bureaucratic system, and also in terms of various laws and regulations. The Samis are a part of this society; in interaction, they can only make use of statuses and institutions defined and controlled by the majority. If the Samis are to be able to stress their own, unique rights under these circumstances, they must choose a strategy aimed at moral 
conviction. On this basis one may assert the Samis' traditional right to a territory, and one may further stress the fact that they are an ethnic group, a group which Swedish society cannot ignore. Such a strategy can enable them to realize certain specific aims during conflicts - partly in the form of economic compensation, partly by means of a relocation of projects of exploitation, so that they may be better adapted to the Samis' conditions of life. But this strategy is based on sources of power which have not been legally codified.

In other words, the Samis - unlike the majority - lack an institutionalized foundation for their own power. This difference in the distribution of power is manifested in the concrete interaction between the two parties, and as a result of this inequality the Samis are always the inferior part, the eternal loser. Such interaction is always subject to a greater or lesser degree of conflict. And in time, this relationship of conflict results in extensive cultural consequences which affect the interethnic relations.

A discipline within Samish research which has for many years dealt with the minority problem is that of cultural geography. Here we should especially mention Erik Bylund and Filip Hultblad, whose works deal particularly with the Swedish colonization of Lapland, and with its consequences for the Samish population. During recent years, sociologists and political scientists have also taken up problems concerning the minority aspect. (See, for example, E.Dahlström, 1967a, 1967b and 1974, and Per Otnes, 1970). of social anthropologists, Harald Eidheim has studied this complex of problems at particularly great length (Eidheim 1963, 1966, 1968, 1969 and 1971), and Robert Paine and Ottar Brox are among those who also touch on similar questions in their works. (Paine, 1965, Brox 1966 and 1969). Guttorm Gjessing being primarily an archeologist has studied the process of change among the Samis using a great historical depth for his analysis, oscillating from pre-historic times to the present. (Gjessing, 1954). In a recent study with the provocative title Norge $i$ Sameland he has followed up some of his most important ideas. (Gjessing, 1973). The present work is most clearly related to Eidheim's studies. This study is primarily dealing with social change, with 
special emphasis on the political aspect of this change. The position of the Samis in Sweden has undergone a radical change during recent decades. Our aim is that of accounting for this change. We approach the problems by studying the relationship between a dominant ethnic majority (the Swedes) and an ethnic minority (the Samis). Thus the following analysis may be said to comprise two foci - that of elucidating social change, and that of elucidating the minority situation. Regardless of the particular aspects or matters with which the various chapters deal, these intentions are always present.

It is very difficult to assess how many Samis actually comprise the ethnic group, as we have no current census. Usually the number of Swedish Samis is put at around 10.000, but this is a very rough estimate, and probably 15.000 come closer to the real number. It is easier to assess the number of reindeer Samis, as the larger society has established criteria for their definition. The special Reindeer Pasture legislation defines who, by virtue of their status, belongs to this group or not. According to these official stipulations, the number of reindeer Samis does not exceed 2.500. We must generally regard the Samis of Sweden as a fairly heterogeneous group. Because of varying ecological adaptation, different categories of Samis pursue different forms of life. These differences affect the organisation of their day-to-day lives, but they are often regarded as being irrelevant in inter-ethnic interactions.

Without going into too much detail, we may differentiate between six different types. As a result of their way of life, the ethnic boundary between the Samis and the wider society is most evidently shown by the reindeer Samis. Their regular pattern of behaviour, verbally expressed through the Samish idiom, leads to a definite we-identification. The demarcation shown by the mountain Samis in this respect is somewhat more apparent than that of the forest Samis. ${ }^{1)}$ The way of life of the latter is in many ways more akin to that of the settled forest farmer, even though their primary occupation is reindeer herding. Their reindeer pasture is located at the same topographical level - the pineforests all the year round, and therefore these Samis do not need to move about as much as the mountain Samis. 
Along the great rivers of northern Sweden we find small groups of fishing Samis. Fishing, like hunting, is an ancient occupation among the Samis - it predates reindeer herding. These Samis are often in contact with the reindeer Samis, and many of them own a few reindeer for their own use. This contact between the two groups has helped to keep the Samish language alive.

The remaining groups of Samis manifest their membership of their ethnic group less clearly in their daily lives than the above categories, and they have also become more assimilated than the above. They include those Samis who still live in the local communities primarily populated by reindeer herders, even though they themselves now have some other occupation. They therefore still share to an appreciable extent the way of life typical of the reindeer Samis. Then there are the so-called urban groups of Samis in the region; these are persons who have chosen an occupation typical of the Samish region, such as mining, and who are thereby enabled to manifest a limited form of ethnic identity. They spend much of their leisure time in their original environment. - Finally we have the type with the loosest cultural connections - the urban Samis of southern Sweden. This group consists of those Samis who have chosen to make use of the free choice of occupation characteristic of the wider society. They are naturally widely spread throughout the country, and thus they can express their ethnic identity only to a very limited extent. I consider ethnic identity as the way in which people experience and manage their membership of an ethnic group. It is a kind of imperative status which conditions the definition of the situation in all inter-ethnic interactions. (Barth, 1969 and 1971).

The ethnic boundary between the Samis and the majority can, in an analytical sense, be regarded as a form of social organisation. In the present work I attempt to show how the ethnic boundary between the majority and the Sami minority group is expressed in terms of organisation, and also how it has changed.

The internal, cultural differences which was related above are usually undercommunicated by the Samis in the minority-political process. As the ecological adaptation of the reindeer samis is the most vulnerable as concerns conflicts between them and the interest of the wider society, the reindeer Samis - and of these 
perhaps mainly the mountain Samis, who are definitely in the majority - act as the principal part in political processes. I have therefore chosen to concentrate on the situation of the mountain Samis, and to this end I have selected a number of local units - Sami communities (samebyar) which, together with all the other Sami communities of Sweden have, under the organisation of Svenska Samernas Riksförbund (SSR - Swedish Sami Union) gone into political struggle against exploitation by the dominant group. Such an empirical delimitation has to do with the problem of choosing one's unit for analysis. By selecting that group of Samis which is most seriously affected by the encroachment of the wider society, we at the same time show this problem in the sharpest possible light.

The reindeer Samis of Sweden, like those of Finland and Norway, are classified according to a specific legal and administrative framework. Sweden has altogether 44 Sami communities ten of which are inhabited by forest Samis. These Sami communities are social and geographical units, with a clearly administrative purport. Like the Reindeer Pasture Law and the special administrative apparatus, these units have been imposed on the reindeer samis by the wider society. For this reason, the Sami communities form a suitable point of departure for our attempt to elucidate the complex of problems with which we are here concerned. We have chosen one connected area, consisting of the six Sami communities of Laevas, Rautasvuoma, Talma, Saarivuoma, Lainiovuoma and Könkämä, in the municipalities of Kiruna and Karesuando respectively; this area is large enough to be fairly representative for the purpose of the present investigation. ${ }^{2}$ ) (See also map I).

Six Sami communities may seem to be too small a unit of investigation, considering that the Swedish Sami region consist of 44 such communities. However, most of our six are large communities, and together they account for $28,5 \%$ of the total rein-deer herding group in Sweden. Moreover, our area also includes c. $20 \%$ of the total number of reindeer. ${ }^{3)}$ Also from the point of view of the variations of form which de facto exists within the reindeer herding region, the chosen area may be regarded as being fairly homogenous: for instance, the border between the North Samish and the Central Samish dialects runs in the south of our area. Further, we find great ecological variations, for example 
much pressure from the wider society in the south, as compared with considerable isolation farther north. North of lake Torne, we meet the vital problem of the right to pasture in Norway. This problem is quite essential due to the present line of the national frontier.

These variations are important to an understanding of the situation of the minority within the wider society.

Our intention is that of showing conditions as they prevail today. A fairly narrow delimitation of time is justifiable for this purpose: the year 1950 is a mile-stone in the history of the Samis, for it was then that SSR was established. This led to vital changes in the possibilities for action enjoyed by the minority. Tracing this change in minute detail will help us to gain an understanding of the present situation. Even though the period of time is short, it includes processes of change which are so essential that they may certainly be treated in a generative perspective. Conditions prior to 1950 are touched upon only in as far as they are relevant to our purpose.

The field work, which took altogether eight months, was carried out during the years 1963-1969; a couple of additional short stays during the summer of 1971 and 1973 were also required. This work may be divided into two categories: that comprising participant observation, and that of observing the various forms of meetings relevant to our problem. The field work covered all the activities important to reindeer herding - reindeer herding in summer in the high mountains (marking of calves, castration, etc.), in early autumn slaughtering of bucks, later on the big roundup of herds for the primary yearly slaughtering and separation of reindeer between the different herding groups before migration to the winter pasture. Reindeer herding during winter and various spring activities have also been observed. Thus all the months of the year were included, except April and May, the least active months for the reindeer herder. ${ }^{4}$ )

The most important types of meetings are those which are held annually between the administrators and the members of a local community, of which I attended six, and the national meeting of SSR, which I also attended six times. Other meetings are internal community meetings, meetings of the Board of SSR, legal proceedings concerning disputes about water, and various meetings 
between the legal counsellor and the local communities. It is characteristic of all these meetings that they are fora of political activity.

Social change must, according to Barth, be studied as an ongoing process. The empirical material on which such an analysis is based consists of specific events of change. (F. Barth, 1968). In the present work I shall attempt to demonstrate which factors determine social change, and also, by means of a number of political case studies, to illustrate the consequences of such change.

As my theoretical frame of reference I have employed a generative model for analysis. (F. Barth, 1966). Change of social form can be explained by means of an investigation into which premises of action generate regular social behaviour i.e. social form. Social change is brought about by a change in these premises. Premises, in this context, are all the incentives and constraints which canalize and shape human interaction. As I have chosen to concentrate on the political aspect of social change, the discussion must necessarily centre on the main premises for such a change.

Apart from the ecological premises and those which refer to the administrative framework we shall also discuss the particular set of values that generate specific forms of action. The Samish ideology of ethnic pluralism, which has developed during the years after the Second World War, constitutes an incentive for politically conscious actions intended to redefine the foundation of power enjoyed by the minority. It is concerned with the viability of Sami culture, with its ability to maintain its own ethnic uniqueness even during our modern times. Provided the Samis are successful in these matters, the system of values will continue to be positively affected. But the Samis must also pay due regard to the set of values on which the wider society is based. Characteristic of Swedish society is an advanced ideology of welfare and equality. Nor must the idea of economic effectivity, predominant in the industrial countries of the west, be ignored. As the Samis are Swedish citizens, they have the same opportunity as all other such citizens to utilize the benefits of the welfare state. Therefore their special interest must not predominate once those of the Swedish common weal. In many cases, exploitation is there- 
fore considered essential in parts of the country which had previously been used exclusively by the Samis. Such exploitation contributes to a general economic expansion, it increases the gross national income, a fact from which all members of society profit. The Samis therefore pay due attention to this set of values, which thus acts as a constraining factor on their strategies. Moreover, the wider society also holds a generally-accepted view about the moral rights of ethnic groups. The Samis, as an ethnic minority, can make use of this view in order to reduce, to some extent, the negative effect of the exploitations. Thus there is a definite discrepancy between the values of the Swedish majority and those held by the Samis. This affects the continuous interethnic relations to a large degree, and the ethnic boundary is to some extent marked by these diverging sets of yalues.

Apart from the above, I would also emphasize that the collection of data has not been restricted to politics. I have taken pains to observe the total sphere of articulation between Samis and Swedes as closely and comprehensively as possible.

Politics I regard as a game of influence, power. The competitive game of which we are concerned in this study cannot be regarded as a normal political game, analysed according to the principles of the theory of games, because the rules characteristic of the game of power are not accepted by both parties. This particular game is a form of conflict, in which the Samis claim a traditional right which has been confiscated by the dominant party. This is characteristic of the situation of ethnic minorities in states of this kind. Conflict, in our context, refers to confrontations in which two parties at one and the same time make divergent claims to the same object, and where one of the parties incur heavy losses. As the Samis do not have the right of veto against, for instance, exploitation effected by the wider society, the conditions essential to maintain their way of life are changed as the result of every such confrontation, regardless of whether they are rewarded any kind of compensation or not. The loser is always the same in minority situations, because of the difference in the sources of power available to the two parties. In this study we shall attempt to show how a more developed political form can lead to political gains for the minority in this conflict 
- this is also the most important generative condition for social change and for cumulative political movements on the part of the Samish population.

Finally, political organisation comprises those manifestations which, formally and informally, are expressed in conflicts about resources of power; recurrent social behaviour aimed at the realization of the more or less autonomous position of the ethnic group. (A. Cohen, 1969).

Most of the material underlying our investigation - that illustrative of the way in which Sami politics are conducted, as well as of the political successes the Samis have met - consists of political case studies, which are here analysed in a processual perspective. This is not a study of political institutions per se, but one of specific forms of action or strategies, which are expressed in this continuous conflict about resources of power. This aspect of social life is manifested in concrete cases, which will be regarded as sequences of events covering a short or a long space of time. Several important works have recently argued for a similar methodical point of view. (See, especially, Schwartz, Tuden, Turner, eds., 1966 and Schwartz, ed. 1968). In a recent article about the Creek Indians Anthony Paredes has also argued for the significance of specific historical events when it comes to initiate such processes as shaping the ethnic identity and cultural revitalization. (Paredes, 1974:64).

The theoretical frame of reference should in other words, be regarded as an attempt at processual analysis. The complex character of the problems studied may at times render it more difficult to fulfil this aim. However, a study of social change must always be based on a theoretical point of departure of this kind.

As every ethnic minority situation must of necessity imply the study of a continual interaction between macro-levels and micro-levels, the macro-level - in this case the wider society cannot be regarded exclusively as a given factor, a niche, of the micro-level - the Samis. These two levels constitute two extreme points of the social field analytically determined for the purpose of this investigation. Ulf Hannerz is among those scholars who have argued in favour of such an analytical oscillation. (Hannerz, 1973). 
The processes of change which we here discuss, i.e. the struggle for a redefinition of the distribution of rights within an ethnically plural society, are not without parallel. It may suffice if we mention the various organisational manifestations of the North American Indians, and their more loosely built up Red Power Movement, inspired by the Black Power Movement. (See, e..g., Swadish and Simons, who present two American Indian case studies in Tobias \& Woodhouse, 1969). We may also refer to the Inuit of the North American continent and to those of Greenland, as well as to such different cultural groups as certain numerically strong Latin American Indian groups, and the Australian aborigines. Many ethnically very different minority groups may jointly try to coordinate their strategy and actions, as illustrated by the conference of the Arctic minorities in Copenhagen in November 1973. The delegates at this conference included representatives of the Inuit (Eskimoes) from Canada, Alaska and Greenland (Greenlanders), Indians from Canada and Samis from Finland, Norway and Sweden. This was the first conference of its kind. (Minutes of the first International Arctic People's Conference, 1974).

When we consider the question of generally increasing cultural consciousness, we must not forget Europe; many ethnic minorities here, for example the Bretons, are setting forth claims identical with the Samis' ultimate political aim: that of attaining an ethnically plural situation. The political situation accounted for below should therefore be viewed in relation to these general processes of social change. 
1. I am not trying to suggest that the Mountain Samis constitute an ethnic group, but I still want to emphasize the fact that they represent that group of Samis which exhibit the greatest number of criteria that are characteristic of such a group. This view also coincides with what Barth wrote in 1971 on Sami groups: But even for this category of Samis (reindeer nomads) it seems that their opportunities for existence are somewhat too narrow for them to be fully regarded as an ethnic group with a pluralistic relationship to the surrounding world, and their relative sovereignty depends more on their territorial and ecological situation than on the social situation as is defined by the dominating group. (Barth, 1971:68). The material that this study presents wholly supports this interpretation.

2. Since this study was carried out, it must be noted in this context that Karesuando has ceased to exist as an independent municipality and as a result of the re-organization of local government boundaries it has now become part of Kiruna.

3. This figure is based on the 1965 reindeer estimates.

4. For the most part the abbreviations L. R. T. etc. are used for the Sami communities. In instances where the identity is not to be disclosed the communities are referred to as $X, Y, Z$. Personal names have also been changed. 



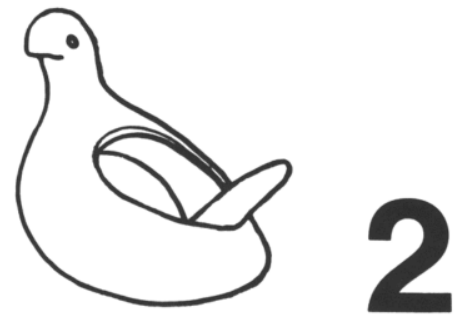




\section{The ecological situation}

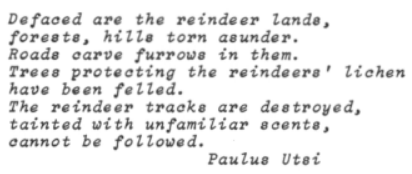

The ecological niche of a people can be said to encompass all natural prerequisites for the maintenance of the particular way of life of the group concerned.

The ecosystem we are concerned with in this study contains two basic niches for human adjustment. First the niche of the Samis which comprises reindeer pasture, fishing and hunting grounds together with the utilization of other resources, i.e. all that make up the living conditions for this particular way of life. The second niche contains all the resources exploited by the industrial society such as ore, forest, waterfalls and so on. In other words the concept of ecological niche is here used to distinguish the doings of one ethnic group from the other within the same environment. (Hardesty, 1972:465). The two ethnic groups are not competing for the same ecological niche, but the exploitation of the niche of the larger society will to a large extent affect the other niche, and consequently have a bearing on the Sami way of life. We have to consider the environment as consisting both of natural resources and of other groups of people with whom you both compete and cooperate. Fredrik Barth, who has made this distinction clear, adds to technology other adaptive responses which are utilized in this environmental adjustment such as politics, property and demographic forces. (Barth, 1964). In this study I will put particular emphasis on the political aspect of this adaptation.

The increased rate of industrial exploitations has forced the Samis to mobilize politically and in that sense the relation between the two ethnic groups using different niches within the same environment has consequently become competitive to a certain degree. When the Samis enter the political arena every 
time their environment is subject to new encroachments they participate in a political game. The Samis are striving for more influence when it comes to protect their ecological niche and for the wider society the Sami minority group frequently represents an obstacle causing extra costs when completion of exploitation projects are at hand. One of the main themes of this study is to demonstrate how political mobilization on part of the Samis caused by environmental encroachments has developed towards resource competition of a certain kind within the same environment.

The ecological perspective in this study will outline the framework of physical as well as social incentives and constraints which affect the people's adaptation to a way of life as advantageous as possible qua reindeer samis. In this chapter the natural premises for action predominate whereas the social premises will be given a fuller account in the subsequent chapter. The conditions of pasture, the possibilities for hunting and fishing, and the opportunity to combine reindeer husbandry with other types of occupations are all important to such an adjustment. There are also various ecological constraints which render an adjustment considered desirable by these people difficult or even impossible. climatic restrictions may be included here, but social restrictions such as pressure from densely populated places, e.g. the town of Kiruna, must also be considered. In the following account, we are particularly concerned to show the variation in ecological conditions which obtains in the region investigated.

The main feature of the Samis' ecological niche is the reindeer pasture. Mountain herding is based on the natural migrations of the reindeer, moving as they do between the different types of pasture. In summer, these animals graze in the high mountains, in spring and autumn further east on the lower mountain plateaus, and their winter pasture is situated in the pine forests. The activity pattern typical of this ethnic group first and foremost involves the adaptation to the traditional grazing habits of the reindeer. In organizational terms this adaptation may be described by means of three concepts: sii'da, sami community and district. $S i i$ 'da is the genuine, Samish institution, which now exists only 
in the form of the regular winter separation of the Sami community into smaller herding units. Sami community refers to the collective community all of whose members jointly take part in the tending of the reindeer during the period of pasture on ground free from snow. The district, finally consists of certain areas of pasture in Norway, restricted in time, space and number of animals pastured; thus the personnel is also limited. The two latter institutions have been forced upon the Samis by the wider society, and they may be regarded as the social ecology to which the Samis must also adjust.

Reindeer pastoralism, in the way the Samis conduct it, is a high.ly specialized form of ecological adaptation and is also quite expansive. (Cf. Ingold, 1974) Modern reindeer management ideally aims at economic expansion and maximum gains for the household units. These aims are, however, as will be shown, curtailed by various encroachments made by the wider society. And in general we may state that the higher degree of such encroachments the less likely are the Samis to realize these expansive aims.

A. The Samis' ecological niche, primarily reindeer pasture The gross area of the entire region, including Norwegian pasture, is $28.815 \mathrm{~km}^{2}$, or $22,5 \%$ of the mountain reindeer area of Sweden.

The decisive factor in reindeer husbandry is the availability of sufficient winter pasture. The net area of lichen land thus indicates very nearly the total capacity of each Sami community. We find particularly low figures for Rautasvuoma and Lævas, while Talma is in only a very slightly better position. We should note that only one of the 21 mountain communities north of the county of Jämtland has produced lower figures yet. The three northern communities have a much higher carrying capacity, i.e. higher proportion of lichen.

From the point of view of pasture the region for this investigation is divided at Lake Torne. Most of the summer pasture of the four communities north of this lake lies in Norway. As a result of the national frontier, the entire mountain range lies in 
Norway. The greater part of the mountain area of the other two communities lies on the Swedish side of the border. However, the national frontier is not a natural border, and for this reason a certain amount of border pasturing on the Norwegian side of the frontier is permitted. The district pasture in Norway is essential for the reindeer herders north of Lake Torne, but border pasture is not of the same vital importance. It is of particularly great moment during hot summers. District pasturing is permitted for 153 days a year ranging from lst May to the end of September. The maximum amount of reindeer totals 22.700 for the six districts, still in use during the time of this study.

Border pasture on the other hand, is permitted for 77 days only, and the area thus utilized by the two communities covers $335 \mathrm{~km}^{2}$. Several of the Norwegian pasture areas - as defined by the 1949 convention - have since been voluntarily relinquished, while others have been lost. Nordnesset, Lyngsdalen, Marknes and Stordalen have all been surrendered since the beginning of the 1960's. In addition, Dividalen has only been partially utilized during recent years (see chapt. VII). These districts cover a total of $2.072 \mathrm{~km}^{2}$, a considerable pasture area, particularly in view of the fact that the remaining districts amount to $3.367 \mathrm{~km}^{2}$. Certain other districts may, in consequence, be overexploited. The entire region has around 35.000 reindeer. If we calculate the number of reindeer per active man within the age group 20-59 years, we shall find that two of our communities have the lowest values of all the mountain communities outside Jämtland, two are very close to tha mean, while the remaining two have the highest values in northern Norrbotten. Thus the six Sami communities here discussed vary considerably with regard to the economic position - in terms of reindeer husbandry - of each household. These variations are due partly to ecological reasons, partly to the demographic situation.

official investigations carried out by various experts during recent years have yielded different sets of figures, ${ }^{1)}$ giving the supporting capacity of the reindeer pasture of each Sami community as well as providing a margin for economic expansion. In calculating the optimum number of reindeer in practice, various 
limiting factors have been taken into account, including such factors as those resulting from the increasing contact with the wider society. These comprise various forms of encroachments into the pasture region. These factors will be accounted for in more detail in the following section.

According to these estimations the rational number of reindeer are in $\mathrm{Kä} 12.000$, La 10.500, S 7.000, T 9.000, R 5.000, and L 6.000 .

As the number of reindeer belonging to a Sami community is affected by the conditions of pasture, it varies considerably over a period of time. The conditions of pasture are first and foremost a result of climatic factors: mild weather followed by the formation of ice, or large amounts of snow packed hard make winter pasture extremely difficult. At times lichen pasturing becomes impossible, and then the Samis are forced either to herd their reindeer on the lower slopes of the mountains - which means that the autumn/spring pastures will be overtaxed - or to resort to emergency feeding, an expensive and laborious process. Hot, dry summers also have an unfavourable effect on the pasture. Because of varying ecological conditions, some of the Sami communities are more vulnerable to these problems, and the frequency of emergencies also varies. The northernmost communities are, as a rule, in a more favourable position as concerns winter catastrophes than the Kiruna communities. This is due partly to considerably more extensive pasture areas on the lower slopes of the mountains, and partly to a greater isolation from the wider society, as a result of which the reindeer may graze in peace during those parts of the year when this is most essential.

Data from the reindeer lists compiled for the years 1945-19652) enable us to follow the fluctuations in the numbers of reindeer in the different Sami communities. These data show that all the communities, except Talma, at some time or other exceeded the rational number of reindeer, two of the communities in fact exceeded this number very considerably. Apart from this, the six communities had experienced a fairly similar pattern of fluctuation.

This pattern is furthermore confirmed if we trace figures only from those years when a census of reindeer was taken, which was done for the twenty year period 1931-1951. 
The way in which people choose to live is also a form of adjustment to ecology. Since the fully nomadic pattern is abandoned when permanent houses are built, each community now consists of one or more main settlements. This pattern of habitation varies somewhat within the region. In the three northernmost communities, the main settlements are situated in the winter pasture area, where groups of houses have been built in the small peasant villages along the main roads. The church village, Karesuando, is the largest, but it has the smallest number of reindeer Sami households, only four. The other villages are suijavaara, Kuttainen, Mertajärvi, Idivuoma, Lannavaara, and the two Soppero villages. The Samis traditionally migrate through these villages in winter, and thus it was natural for them to settle here during the process of adaptation to a more settled way of life. Now they have service institutions such as shops, post office, telephone etc. close at hand, and they are also close to public means of communication. The main road is generally used for migration to the Norwegian districts and for shopping expeditions to Kiruna. ${ }^{3)}$

The three southern Sami communities, which took up this trend much earlier, chose instead to build their houses in the autumn/ spring pasture districts, with the result that purely Samish hamlets were established. Rensjön in Rautasvuoma is the largest of these - all the Samis of Rautasvuoma live here. In Lævas a different pattern was adopted - here the Samis chose to retain the separation of the community into groups comprising a limited number of households, according to earlier practice, in spite of the fact that they practise joint reindeer herding during the period of pasture on snow-free ground. Årosjokk and Holmajärvi lie by the road between Kiruna and Nikkaluokta, while Vuonajokk is isolated. This latter settlement is thus not unlike the isolated settlements of Talma, Laimoviken and Vuoskojaure. A few, recently arrived Samis in Talma have settled at Vassijaure, by the railway between Kiruna and Narvik. Apart from them, the Talma Samis are now the most isolated of all the Swedish reindeer Samis. During parts of the year, it is impossible to cross Lake Torne - the crossing in small motor-boats is generally a difficult undertaking. The Samis of Rautasvuoma and those of 
Lævas have excellent communications with the town of Kiruna, by means of railway and road respectively, and they are the least isolated in our region.

In this connection, certain variations in the pattern of migration should be noted. We find that Lainiovuoma has adhered most closely to the nomadic form of life: Lainiovuoma has the greatest number of family migrations from season to season, followed by Könkämä. Apart from these two communities this type of nomadism is of secondary importance only, with the possible exception of Talma. This process of change, a result of several factors, among them the selective adjustment to a modern way of life, has gone farthest in Saarivuoma, where only the reindeer herders themselves migrate. The transition from intensive to extensive reindeer herding has rendered female labour unnecessary in reindeer husbandry. Moreover, when the dwelling house took the place of the mobile tent, those members of the family who were not directly involved in reindeer herding found themselves with new opportunities of choice. In some ways this change may also be seen as a result of intervention by the authorities, especially in the case of Könkämä, which has recently lost several districts of summer pasture in Norway. The Samis had old, established settlements in these Norwegian districts, and when they were moved to new districts, they found great difficulty in establishing themselves; as a result, the members of the reindeer herders' families are now forced to live in the winter villages all the year round. Such a way of life is obviously not without consequences for the active reindeer herders or for their families. This adaptation to a totally settled form of life was not voluntary, and the social costs for the people concerned were considerable.

The Samis of the communities further south do not depend on specific pasturing districts, as they dispose of the entire mountain area belonging to the community in summer; thus the transition to a more settled way of life was much smoother and easier here. In the Kiruna communities, we find that the tendency for members of the family to move to the mountain settlement in summer together with the active reindeer herder has increased in recent years. Some families have, in fact, started 
to build huts also in the mountains, to replace the earlier tent. There is no such possibility of choice on the Norwegian side of the border. There, according to the regulations set up by the authorities, only small huts to be used by reindeer herders may be built, and families can hardly be accommodated in these. Thus the pattern of migration has changed in different ways in the various parts of our region. In some cases, this change has taken the form of a voluntary adjustment to a modified way of life, in others that of a forced adjustment to a totally settled way of life. The latter aspect will be discussed in more detail in the chapter dealing with conditions of pasture in Norway.(See chapt. VII).

In winter, the reindeer herd of a Sami community is divided into several smaller units, which graze separately. This division into siidat varies, first and foremost according to the size of the community. This kind of division is essential, as the amount of pasture available demands a great increase in the intensity of grazing. A sii'da must not have too large a number of reindeer, for it requires daily attention. The three northernmost communities operate with 5 - 7 siidat, while $2-3$ is a sufficient number for the others. We might add that the number of such winter groups was greater in the past, but it has been reduced as a result of the transition to modern methods of work. ${ }^{4}$ Winter herding is highly intensive, and therefore the reindeer herders must live near their herds. The Samis from the three southern communities thus have to live away from the main settlement for about five months each year. As a rule they take lodgings at the houses of settled people at the villages Jukkasjärvi, Svappavaara, Vittangi, Vettasjärvi and Parakka. Every household normally maintains old, established relations with some household in the winter village. Some of the Talma Samis have during recent years built their own houses also in the winter settlement, but they form the only exception.

This part of the ecological discussion elucidates the natural conditions necessary for reindeer herding. On them, the Samis' adjustment to as profitable a way of reindeer husbandry as possible is based. This adjustment is affected by natural limitations, in part also by socio-ecological restrictions. 
Greater isolation may lead to proportionally better conditions of pasture, for the various disturbances caused by the wider society will then be insignificant; in part it may also lead to a low degree of frequency of interaction with the outside world, and to less possibilities of varied consumption.

Finally the utilization of the other traditional resources, hunting, fishing and so forth, is dependent on the adaptive pattern of reindeer herding. During poor pasture conditions more time may have to be devoted to herding, e.g. and in areas where lakes and rivers are affected by hydro-electric constructions the amount and quality of fishes decline considerably.

\section{B. The ecological niche of the wider society}

Apart from reindeer pasture, the ecological resources of the region comprise cultivable land, forest, waterfalls and ore. These are primary resources, and they are exploited exclusively by the wider society - in part by farmers (land and forest), in part by the industrial society (waterfalls and ore, but also forest).

The percentage of agricultural land in the region is very small, 0,05\% in Kiruna. In the past, agriculture was the only way in which the region was exploited by the wider society, but today it is of lesser importance, constantly decreasing as the farms of Lapland are abandoned. Pasturing of farm cattle in the outlying land and haymaking used to lead to some problems for the reindeer herders, but as so many farms in the region have been abandoned, the area of reindeer pasture has now increased somewhat.

In Norway, on the other hand, such pasturing of farm cattle still presents a factor of competition, as northern Norwegian agriculture is increasing rather than decreasing. Cattle, sheep and goats graze in the fertile fjord valleys and mountain glens, frequently coinciding with grazing reindeer. All the Norwegian districts, apart from D $\phi$ desfjellet and Salvasskaret are affected by the presence of agriculture. The permitted number of reindeer in the Norwegian districts also corresponds well with the units of sheep in a given district. In other words - in Sweden agriculture no longer forms a limiting factor, while in Norway it is a limiting factor, significant in part. 
Forestry is, to some extent, connected with agriculture. Deforestation can make reindeer pasturing more difficult, certain lichen areas may disappear as a result of mechanized forestry. During certain periods, this work may assume such dimensions that it affects the number of reindeer kept. In our region, however, the Kiruna communities alone experience any problems caused by forestry.

The exploitation near Vettasjärvi, which greatly affects the pasturing conditions of Lævas and the neighbouring community of Norrkaitum clearly illustrates this problem. Here the forest industry of the state has adopted new methods of preparing the ground so that large areas are now ploughed and harrowed. All that remains of the forest terrain now is sand and gravel, intersected by $40 \mathrm{~cm}$ deep furrows, about $2 \mathrm{~m}$ apart. Most of the Samis affected consider the outlook to be hopeless, and they do not think it likely that any forest should grow there again during their lifetime.

The important aspect of the Vettasjärvi region is the fact that it consisted of dry pine moors, the best possible winter pasture. The reindeer were traditionally always turned loose here after the migration down from the mountains, and when the area had been completely grazed, the herd was moved to Vettasrova. The reindeer are thought to do particularly well in these two areas which are, moreover, the only true winter areas at the disposal of this Sami community. Now one of these two available pastures is being impoverished considerably, so that the other is taxed all the heavier. As the winter pasture is the decisive factor for a Sami community's economic possibilities within reindeer husbandry (see p.28), any encroachment at this topographical level will lead to far-reaching consequences.

This is not merely an economic matter, even though the economic aspect is the most important. The problems arising from a possible increase of reindeer to the optimum number are already being discussed: even if the community was to be able to keep the rational number of reindeer during the whole part of the year when the ground is free from snow, it would be almost impossible for the reindeer to survive the four winter months. Moreover, there are also social consequences: it has now become much more 
difficult to adhere to the traditional sii'da system of division in L., the number of siidat varied from 3 to 5 during the winter season.

This case, which is as recent in date as 1971, is particularly interesting in view of the fact that the Samis affected knew nothing about the scheme until the preparation of the ground had been completed - one reindeer herder happened to go down to the winter quarters, and then he saw the damage that had been done. Once it had been discovered, the mass media immediately focused their attention on the matter, and as a result, a similar scheme in Vettasrova - already planned - was stopped. The area in question is of roughly the same size as that in Vettasjärvi, $2 \mathrm{~km} \times 1 \frac{1}{2} \mathrm{~km}$. If the Samis had lost this pasture as well - and that might well have happened, had not coincidence been on their side - the Lævas Samis would have been completely without any useful winter pasture. Winter migration would have become impossible, and reindeer herding in its present form would have come to an end. This would have affected their way of life considerably, and the economic consequences would also have been extremely severe.

If there is an end to winter pasture, then there will be an end to my life as a Sami. Then I shall perish, that is what is happening now.

We should here stress that, although compensation is paid for most forms of exploitation, the Samis do not receive any in cases that refer to forestry, a fact which impairs their position still further. This matter is causing very deep concern among the rank and file of the Samis, as appears from the open confrontation between them and the Commissioners of Woods, Forests and Land Revenues (the official organ directly responsible); this took place at the SSR national meeting in 1973. On that occasion a Samish speaker described the actions of these commissioners by means of the comprehensive and almost untranslatable Samish term árji gál'gan." "The Commissioners had not contacted the Samis at all, they had merely árji gál'gan." The symbolism here

\footnotetext{
*As a rough translation, one might say that årji gal'gan refers to work done simply to save one's own reputation, so that one cannot be accused of not having done it.
} 
employed in a situation of confrontation is very striking for those who speak Samish. One was here particularly concerned with drawing the attention of all the Samis present to the importance of this problem, so that they could on later occasions be mobilized collectively for the purpose of preventing any possible recurrence. (See also the discussion at the national meeting 1972, with the resolution passed on this subject. See also chapt. IX.) $)^{5}$ But forestry does not entail only competition. The construction of roads for forest vehicles may be of advantage also to the reindeer herders. But the effect of these roads is not exclusively favourable - they run across reindeer pasture and may split the herds. This causes a certain amount of disturbance in the pastures. Various new features in the terrain can upset the rhythm of grazing, which may lead to essentially more work for the Samis.

We should also add that extended forestry may frequently offer temporary work to the reindeer Samis, and this fascilitates their adaptation to a combined form of economy.

Water power is exploited exclusively by the industrial society. This infringement upon nature is an outcome of the growing need for energy experienced by the wider society. But the reindeer Samis to some extent make losses as a result of such measures. As a rule, the pasture land lost is not extensive, but the pasture lost is of high quality, for the snow melts first along rivers and other waterways. These pastures are of great moment in spring, particularly during the calving season. Moreover, the work of herding the reindeer becomes more difficult - often to a very large extent - and traditional encampments have to be abandoned. Fishing, whether for household use or for sale, is also impaired, and both these forms of fishing are essential ecological resources for the reindeer herder's household.

But the region with which we are concerned had experienced only one instance of this form of exploitation - the regulation of Altevatn, which affected conditions in Talma and Saarivuoma. We should add that the Kiruna communities are at present being threatened by the planned exploitation of the Kalix river, which would impair the winter pastures radically, especially those of Lævas . 
The Kiruna area has rich deposits of iron ore, and an expansive mining industry has arisen here. This development started around the turn of the century, and it is still growing at an undiminished rate. During the 1960's, for example, two new mines were established - Svappavaara and Nokutus. Many natural routes of migration were eliminated when all these mines were opened, and many areas of night pasture were lost. These encroachments have greatly impaired the Kiruna Samis' chances of profitable reindeer husbandry, and a greater burden of work is now to be put in.

As a secondary effect of the exploitation of the ore deposits, large communities and towns have grown up around the mines. The demands made by the inhabitants of these communities for recreational areas and for facilities for hunting and fishing are a new factor of competition affecting the adaptation of the reindeer Samis.

There are also some secondary factors which should be considered, factors that also express the ecological adjustment of the industrial society. Communications and settlements can render reindeer husbandry more difficult, although they will not have a lasting effect on the number of reindeer kept. Railways and roads lead to direct losses, as reindeer run over may in special cases affect the number of animals kept. The reindeer fences set up during recent years, however, have reduced these losses considerably. But the effects of these factors are not only negative - good communications make an adjustment to a modern way of life much easier.

Another factor with the same kind of two-fold effect is tourism. In some cases it may lead to inconveniences for the reindeer herder: people or unsuitably placed tourist sites disturb his work, often seriously. Rautasvuoma and Lævas are most seriously affected by the negative aspects of tourism, for the main routes run through their summer pastures. This factor is confined to the region south of Lake Torne. - The advantages of tourism include the possibilities of making an extra income by, for instance, selling handicrafts and various reindeer products, such as antlers and hides, and also the provision of increased service. In other words - the tourist stations can also be used by the Samis whose needs for varied consumption can thus be met 
in summer.

The ecological factors for which we have accounted above, all of which emanate from contact with the wider society, have a limiting effect on reindeer husbandry. Rautasvuoma and Lævas are seriously affected by pressure from the wider society, Talma and Saarivuoma also feel this pressure to some extent, while Lainiovuoma and Könkämä hardly feel any such pressure, except for that of the problems connected with the Norwegian pastures. (Cf. Sv.N. RBK, 1967:367).

Most of the encroachments we are talking about in this context are of such nature that the reindeer herders have no hope of regaining the ground for pasture again. Consequently the environment on which the Samis base their particular way of life will be transformed from containing renewable resources to nonrenewable resources, an extremely important distinction in general ecological analysis put forward by Greenwood and Edwards. (Greenwood \& Edwards, 1973:123). In this way the two groups appearing within this eco-system differ, because the Samis have always considered that natural resources are and should be renewable. Their entire ecological adaptation is built on this pre-requisite.

On the grass-root level this brings us to the question of reindeer management. In a cogent analysis of herd management Robert Paine has presented a model in which a minimal balance between the three basic factors for ecological adaptation, pasture, herd and personnel, is obtained by herding and husbandry activities. This model is depicted as an equilateral triangle. The point is that if a change occurs in one of these factors then the other two must be changed accordingly in order to retain the balance for optimal gains. (Paine, 1972). However, when external pressure, as has been discussed above, constantly causes damages on one of the factors, pasture, it will be extremely difficult for the Samis. to sustain this ideal balance. The Samis have to develop special forms of political means, formerly not utilized, if they are to succeed in profitable reindeer management. As has been stated by Daniel Bates local equilibrium in ecological terms cannot be reached without sources of power from the outside. (Bates, 1971). The political development of the Samis and especially their legal strategy 
is aiming at this important objective, a change of the power relations between the Samis and the larger society.

The conflictive aspect of the relationship within the ecosystem is all the more important if we are to understand the minority situation of the Samis. In a recent article I have presented a more extensive account of this analythical perspective. (Svensson, 1976).

Another consequence of this situation of increasing conflict is the appearance of new opportunities of a more differentiated adjustment for the Reindeer samis. The rationalisation of reindeer husbandry and the emergence of a more modern pattern of residence have increased the costs of running considerably, so that more capital is now required per household? But rationalisation has also resulted in more spare time, and this may be used for other remunerative work. If the opportunity for combined occupations is large, more people are able to remain within the reindeer herders' community than would otherwise have been the case. This again helps to maintain viable local communities. The opportunities for combined work are greatest in the Kiruna region. Here work on the railways - temporary and more permanent various kinds of road work, driving tractors and heavy snow mobiles in mountain terrain and also different service occupations for women in the town of Kiruna contribute to a favourable adaptation to new economic conditions. The northernmost communities lack most of these opportunities. There is at times a certain amount of work for the official board of the labour market; apart from this, the only possibilities are making handicrafts, hunting and fishing. Of these catching ptarmigan is the most profitable occupation, and this is carried out throughout our region.

Summing up, we may say that the northernmost communities are, as result of their isolation, not disturbed to any significant extent by pressure from without. On the other hand, those living close to expansive villages and towns may derive new economic possibilities, essential for their new, more expensive way of life, such as we have seen in the case of the Kiruna communities. But if we take all the ecological factors into account, the position of the northernmost communities emerges as the most favourable. 
1. SOU 1966:12, the Norrbotten survey 1960, and the SwedishNorwegian Reindeer Grazing Committee 1967. The most rational number of reindeer is based on calculations made by biological experts.

2. The reindeer estimate is a joint, annual estimate made by the administration together with members of the Sami communities. Since it is not based on the reindeer census, which is made every third year or more, the figures are not exact. In general the estimates are rather on the low side, but the relative differences between communities as well as between different reindeer owners within a community become quite clear.

3. This process of change has also been studied in detail by I.Ruong and I.Whitaker in the Jukkasjärvi and Karesuando areas respectively. (Ruong 1956 and Whitaker 1956).

4. This relationship between eeology and organisational structure has been studied in great detail, both by Pehrson, 1957, and Whitaker, 1955, in two monographs from Karesuando, and by Paine in a number of articles. See in particular Paine 1964a, 1964b and 1972. Paine, taking a different approach, has mostly presented the conditions of the Kautokeino in Norway, but has also compared these with Karesuando.

5. It can be noted that this matter was taken up in the Riksdag, Autumn 1972, when the Minister of Agriculture, in reply to a question, maintained that he regarded land preparations of this sort as illegal. Many Riksdag members are of the same opinion, and base this on the reindeer husbandry legislation. The Swedish Forest Service, which is primarily responsible for these land preparation actions, does not agree that these actions are illegal. Here they are arguing from a political, labour market point of view; i.e. if there are no land preparations there will be increased unemployment in Norrland. (See, amongst other things, the debate in DN August 1973 and SET $1973: 1-2$ ).

6. The increased economic costs in reindeer breeding can be critical for the household viability as has been shown by Pelto, Linkola and Müller-Wille from studies in various parts of Finnish Lapland regarding the snow mobiles. See particularly Pelto's monograph of the subject matter, The Snow Mobile Revolution, which in great detail analyses social change brought about by a single technological innovation. (Pelto, 1973). 

$0_{3}$ 


\section{Structural premises}

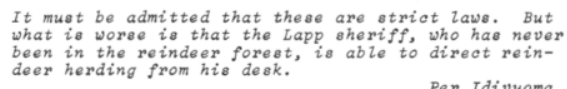

deer herding from his desk.

Per Idivuoma

Characteristic of the minority situation here discussed is the difference between the foundation of power enjoyed by the two parties. All interaction between the two ethnic groups - the Swedish majority on the one hand, and the Samish minority on the other - is based on this difference in their resources of power. The foundation of power of the wider society, officially codified in legislation, consists of certain offices and institutions and of a special system of laws. The main task of the officials is that of controlling the reindeer Samis and fitting them in as part of the wider society. The special legislation - the Reindeer Pasturage Law (RBL) - has authorised this aim. The specific foundation of power at the disposal of the wider society must also be regarded as a structural element by means of which the general conception of values in Swedish society is canalized. This may be summed up as follows: welfare for all, equality before the law.

As the Samis' sources of power have not been legally codified, and as they are largely forced to act on the premises of the wider society in any interaction of conflict, their chances of realizing certain given political aims are greatly restricted. A systematic account of this difference in the foundation of power will help to make clear the further chances and restrictions which affect the ethnic minority in the matter of realizing their own, characteristic culture against the background of adjustment to the ecological conditions discussed in the preceding section. The collective term administration here comprises the structural and legislative elements given above. The foundation of power 
enjoyed by the wider society is expressed by means of this special administrative apparatus, now known as the Reindeer Husbandry Office (Rendriftsväsendet). The administration is represented both at the regional and the national level.

In the following, we shall consider the administration mainly as a prerequisite for Samish interaction. An account will be given of the administrative structure, and of the relationship between this and the local Samish unit, the Sami community. These accounts are supplemented by examples of various initiatives regarding modernization in which the administration played a part. The two latter aspects elucidate the relationship between the administration and the reindeer Samis as a group; this relationship may be viewed as a special form of social organization, characteristic of ethnic minority situations. The discussion must be regarded as a systematic description of the second premise of the specifically Samish form of action with which we are here concerned, not as a special sphere of problems.

The part played by SSR in various ways is also illustrated in this chapter. For this reason, we find it proper to give a brief account of this institution here: SSR consists of all the Sami communities and includes also some other categories of Samis. Its policy making organ is the National Meeting held anually, to which all the communities send representatives. The resolutions of the National Meeting express the joint policy of the Samis, and they are all in some way aimed at the wider society. The political potential of the Samis has increased considerably since the foundation of SSR. ${ }^{1)}$

\section{A. The administrative structure}

On the local level, the administration affects the activities of the Samis through the agency of the Reindeer Husbandry Office.

\footnotetext{
The administration here described was in effect until July 1971 , i.e. during the entire period with which this paper is concerned, and we have therefore retained the present tense throughout. However, we must at this point make it clear that a new form of administration was established in 1971. This change will be dealt with in chapter VIII.
} 
Every county administration within the reindeer region has a special staff of civil servants. The county of Norrbotten, which is the largest in the region, is divided into three administrative districts, northern Norrbotten, southern Norrbotten and eastern Norrbotten. The region under consideration here forms part of the northern district, which comprises nine Sami communities in all. The management of these is headed by a lst inspector, who works at the county administration office. A number of instructors attend to the more continuous contact with the Sami communities. ${ }^{2}$ ) These instructors are as a rule recruited from one of the hamlets where the reindeer Samis spend the winter. Karesuando and Svappavaara are traditional recruiting sources for the holders of these appointments. Every instructor is responsible for three Sami communities. The direct contact is often handled by the instructor and the community headman (byordningsman - BO). One of the instructor's most important tasks is that of effecting the exchange of information between the Sami community and the lst inspector.

This administrative system is represented on the national level by the Department of Agriculture, to which questions of reindeer husbandry belong. In 1962 an advisory council - the Reindeer Husbandry Committee - was attached to the National Board of Agriculture. It consists exclusively of Samis, ${ }^{3)}$ and its importance is increasing steadily; as a rule, the National Board of Agriculture consults the council in all important matters relating to reindeer husbandry, and its resolutions are influenced by the advice given by the council. Thus the Samis have now acquired a limited influence at the national level.

An account of the legal situation is called for after this survey. It consists of internal legislation, and legislation dealing with the mutual right to pasture reindeer in Norway and Sweden respectively, the so-called Reindeer Pasture Convention. This legislative complex constitutes the formal framework of the administration of reindeer husbandry. The internal legislation consists of the Reindeer Pasture Law (Renbeteslagen - RBL), the Reindeer Marking Act and the Community Regulation. This legislation applies exclusively to the reindeer Sami minority, and its main purpose is that of regulating reindeer husbandry. 
A more detailed discussion of this law is not in place here, for in 1971 it was succeeded by a new law, which involves great changes. I shall therefore confine myself to a few brief comments on some of its most important sections. It opens with a stipulation of the boundaries between the different Sami communities, and gives the optimum number of reindeer permitted per community and per person and family. Criteria as to membership of the communities are also given. \$\$ 4-10 of the Community Regulation consists of detailed provisions concerning the methods to be employed in reindeer husbandry, specifying the dates when the different pastures are to be grazed during the different seasons, methods of herding, number of herders per number of reindeer, reindeer migrations, marking and slaughter.

This strict regulation of reindeer husbandry leads to restrictions which make a flexible adjustment to changing ecological conditions difficult. The officials from the Reindeer Husbandry Office control that the law is obeyed, and in the final resort it is the responsibility of the $B O$ to see that the provisions of the law are adhered to. True, $\S 3$ of the Community Regulation states that the Samis themselves are to decide, in assembly, how joint work is to be carried out, but this right is not unconditional, for they must always adhere to the provisions of the law.

RBL also includes economic restrictions, as $\S 14$ of the Community Regulation specifies the purposes to which the community funds may be put, as well as stipulating a maximum sum of Sw.kr. 750,- per item. The community funds consist in the main of income from the sale of unmarked reindeer. These funds may be used for various lesser joint enterprises. As examples, we may mention the investigation of conditions of pasture, rewards for killing beasts of prey, and payment to cover'the expenses of joint meetings. Eight different items list the purposes for which the community funds may be employed. (Community Regulation 1946)

If the amount exceeds the stipulated maximum, or if one intends to use the money for purposes other than those specified, such expenditure must be approved by the county administration. Thus the Sami communities are subject to severe restrictions as concerns the use of their own funds according to their own wishes. 
This has served as a stringent limitation in the Samis' chances of adaptation to new conditions.

In one of the communities, $k r$. 750,- of the community funds had been used to pay for air transport to the place of reindeer roundups in the autumn. An application for this expenditure was made to the county administration, but it was turned down on the grounds that the community funds could not be used for annually recurring herd removals. However, the community resolved to submit the matter to the Lord Lieutenant. The administration took no further measures against the community. This according to the community meeting, 30th June 2960.

In oommunity $X$, the inspector made the same statement in 2968 as he had made the previous year, in the matter of individual fees to SSR. These the community had paid from its funds. This is not correct, the fees are to be collected from the heads of the households. Bo replied that the community had resolved to pay the fees in this manner. The inspector overruled the resolution, but no countermeasures were taken.

One of the most important sections of RBL is $\S 5$. This gives the state the right to unrestricted exploitation in districts previously utilized exclusively by the Samis. Moreover, the state is empowered to decide how any compensation paid is to be used. The Samis do not have the right of veto in this matter; in a later chapter we shall show how this section has affected the situation of the Samis.

The wider society makes increasingly greater demands on the natural resources of the mountain areas. The mining industry is being developed, and the exploitation of hydro-electric power has led to appreciable losses for the Samis, losses for which they can hardly be compensated. Many other factors are also affecting the Samis' chances to continue their life as an ethnic group: the expanding network of communications, industrialized forestry, and the ever-increasing tourism. The ecological niche on which Samish culture is essentially based is being restricted more and more by these constant encroachments into the mountains.

Thus $\S 5$ is of paramount importance in the following analyses of the situation of the minority, as it has very appreciably affected the chances enjoyed by this group of asserting their own interests. Compensation is of no use when the ecological prerequisites essential for the maintenance of viable local communities no longer exist. Naturally, the effect of this section 
varies very much according to the geographical situation of the community concerned. The Kiruna area experiences constant intrusions disturbing the natural resources essential to reindeer herding; Karesuando, on the other hand, is more isolated, and the wider society's interest in this area is no more than peripheral.

\$ 56 deals with the consignment of certain usufructs, first and foremost with the right to enjoy hunting and fishing, but other benefits, such as the right to build cabins, are also included. An important point of this section is the fact that these usufructs must not inconvenience those engaged in reindeer herding. It is explicitly stated that any samis who may be thus affected must be consulted before the usufruct in question can be granted. If grants are constantly made, the conditions of reindeer husbandry will obviously be affected. This applies particularly to the Sami communities in the vicinity of Kiruna. According to this section, the Samis have a legal guarantee limiting the granting of such usufructs; but we should note that there are many cases of usufructs having been granted without the consultation of the Samis. As an example of this we would point to the tourist establishments which have been built in the Kiruna communities without the Samis having been consulted at all. From the Samis' point of view, several of these establishments are extremely inconveniently situated, for they affect ecological conditions essential to the reindeer herder. Had the Samis been properly consulted beforehand, these establishments could have been built in strategically less important places. The administration. ought to accept responsibility for such omissions.

An example from Levas will serve to illustrate this problem. At the community meeting in 2963, it was stated that STF intended to extent the tourist station at Allesjaure. However, the already existing cabins there lay right in the way of the migration route, so that they were a serious obstacle when the reindeer herd was on the move. The route had to pass this position, for here there is a convenient ford across the river. The main obstacle lies not in the cabins, but in the people living in the cabins. The first cabins were raised here early during the I930's, and had the Samis been consulted then, STF would certainly not have been allowed to build at this precise spot. This is the only place where the river may be crossed in a reasonably convenient manner. 
The problem consists in keeping the tourists inside the cabins when the herd is passing. They pass here when the calves are being marked, a time which coincides with the high season for tourism, and therefore there are very many people here then. If the superintendent keeps an eye on the tourists, no harm is normally done. But often the tourists come running with their cameras, and the frightened animals scatter straight away. "Sometimes we manage to pass here at night without their noticing anything at all; then they are furious, but, of course, we are happy." The community meeting disapproved the proposal to extent the establishment, proposing instead - with the support of the inspector that the existing cabins be moved at least one $\mathrm{km}$. But this proposal was ignored: the existing cabins remain in their original positions, and new ones have been added. In 2968, the author was able to observe in the field how difficult it was to pass this place with a gathered herd of reindeer. Ignoring the superintendent's strict instructions, a few campers came running with their cameras, and they almost ruined several days' work. With great difficulty, and with many oaths referring to the thoughtless tourists, the herders succeeded in moving their herd this time.

As tourism has increased greatly during the past 20-25 years, the old ford can no longer be used. In the summer of 29?0, a new attempt at crossing the river here was made, for this fitted in well with the reindeer work in hand, but it was unsuccessful. The animals did not dare to pass the establishment, which was full of inquisitive tourists. The whole herd turned and scattered, and the Samis had to round them up again - several days' extra work had to be done before migration could continue. Now the Samis therefore use a ford $3 \mathrm{~km}$ higher upstream, which means a detour of $20 \mathrm{~km}$ steep climbing along the Passajokk river. Three extra men are now required for pursuing this particular herding task.

This upstream ford is not as suitable for reindeer crossing. Difficulties are apt to arise, especially when the herd is being moved westwards. The animals refuse to be led towards the ford, preferring to enter the river immediately below the ford, where a small spit of land projects. But here the river is very rapid and there are steep and slippery cliffs on the opposite shore. Many reindeer have drowned here, especially calves. The most recent, albeit minor, accident occurred in 2972.

We may add that STF is now considering plans to move the entire tourist establishment. This is a result of constant pressure exerted by the Sami community. As the organization of the Sami communities has improved considerably, as a result of the reindeer husbandry legislation of 2972 , they can now negotiate directly with STF, without the intervention of any administrative intermediary. And thanks to this stronger organization, an objegt long desired by Levas is on the point of realization. 
I have dwelt on this case at some length, as it illustrates particularly clearly how far-reaching the consequences for the Samis involved may become. These deteriorating conditions need never have arisen if only the Samis' point of view had been considered at an early stage. The administrative system here discussed was not effective enough in making possible such contact between the different groups of interests. Another example concerns the rights to fishing in Rastojaure - this illustrates the extreme restrictions governing the actions of the Sami community.

\begin{abstract}
In 2953-54 the Kiruna Hunting and Fishing Association acquired the right to lease the fishing in Rastojaure, which concerns the communities $S$ and La. This is the only good fishing available to these two communities and, moreover, their spring pasture lies on either side of the lake. In other words, in this case the Sam is had vital interests to protect. At the community meeting of one of these two communities, the Samis turned down the application with $2 l$ votes to 9 . In spite of this olear majority, the county administration approved the application. (SET 2954:3)

At the 2955 community meeting, this matter was discussed again. On this occasion Kiruna Hunting and Fishing Association had applied for permission to fish with dibbing gear in several waters, including Rastojaure. This case was considered to be of fundamental importance. Some of the members of the community rejected the application, white others considered that it might be approved, but only on specific conditions. After a new vote had been taken, the application was approved, but its validity was confined to the months of March and April. (Minutes 29/2 (955)
\end{abstract}

Usufructs concerning the erection of cabins have also adversely affected the conditions under which the Samis live. ${ }^{5}$ ) It thus appears that \$56, which connotes certain guarantees for the Samis, can lead to restrictions in their adjustment to new conditions, unless it is always consistently applied. However, one can hardly avoid conflict when trying to satisfy two opposing interests. ${ }^{6}$ )

But RBL is not without its positive aspects. \$36, for instance, prescribes certain cases of protection under the law. These indicate, first and foremost, that the Samis are to be enabled to work with their reindeer without undue disturbance, and that the reindeer are, as far as ever possible, to be allowed to 
graze undisturbed. If the Samis suffer any loss under these headings, they are entitled to compensation. In this connection we should add, however, that it is very difficult to prove responsibility for such damage. Finally the members of a Sami community have certain special privileges, such as the right to taking timber in the forests, and the almost unrestricted right to hunting and fishing. Thus these sections should be regarded as being favourable for the Samis, and they may be included among their assets.

Thus we find that the special legislation intended to protect the Samis mainly leads to restrictions in their interaction with the wider society. The restrictions considerably exceed the opportunities in this respect. This fact must be born in mind when considering the arguments below.

\section{B. The Administration in relationship with the sami community}

The community meeting, or annual assembly, is the most important element through which the contact between the Sami community and the administration is expressed. Once a year a meeting is held in the main settlement in the community; here the first inspector presides, while the instructor acts as secretary. All the heads of households are summoned to the community meeting. other interested persons, such as women, youths and old-age pensioners, are also entitled to attend and to express their views; the vote, however, is confined to heads of households.

It is, of course, very important that as many heads of households as possible should attend. For this reason these meetings are normally convened at a time when the reindeer require a minimum of attention. Until recently, few people showed any interest in these meetings, but a new attitude prevails now. The increasing contact with the wider society, and the consequences resulting from this contact, call for a more intensive protection of the vital interests of reindeer husbandry. The author attended six such meetings, and at only one of these less than $50 \%$ of the heads of households entitled to vote were present.

Two types of matters are discussed at these meetings: (lst) matters directly affecting reindeer husbandry and local matters 
affecting the community, and (2nd) matters that concern the community's contact with the wider society. The first of these includes, for instance, the audit of accounts, checking of the reindeer list, new reindeer earmarks registered, constructions connected with reindeer husbandry, e.g. reindeer fences, etc. The other type are matters such as various forms of exploitation, and applications for certain usufructs. Matters of the first type the Samis can influence greatly by their resolutions, while their influence on matters of the second type is greatly restricted.

In the past, the Samis had no influence at all in such matters, but their position is improving somewhat now. According to the administration, it is difficult to consider the interests of both ethnic groups at one and the same time.

In a district such as Kiruna one must be realistic and understand that the claims of the population of Kiruna for opportunities for recreation are justified. At the same time, the interests of reindeer husbandry must not be negleoted; as a result, the county administration has an extremely difficult task. The inhabitants of Kiruna complain that their demands are not met, and the Samis complain because some of the demands of the inhabitants of Kiruna are met to some extent. The county administration must also consider interests other than those of the Samis - co-existence is necessary.

But the pressure emanating from Kiruna has been so heavy that the effects of this balance of interests have, in the long run, proved negative from the point of view of the Samis; their reindeer herding has been severely effected. The authorities realized at far too late a stage that the Samis must be allowed a veto when occasion demands. This right of veto they did not possess until SSR took the initiative in this matter, resulting among other things in a Jo notification in 1963. 7) The concomitant Jo report, which was submitted in 1966, deals particularly with a critical analysis of the actual application of $\S \S 5$ and 56 of RBL. (See also page 62).

The Samis' opportunities of protecting their interests are restricted by the fact that the only meeting at which such localpolitical matters are discussed is led by a public official. In the past, no Sami ever saw the minutes of the meeting, which were merely approved by the administration and then filed at the county administration office. Thus it was impossible to check that the 
majority opinion of the Samis really did appear in the minutes. In several cases, Samis concerned discovered long after the meeting that applications for usufructs which the community meeting had turned down were granted - this they discovered when cabins were built, when fishing rights in a lake were exercised, etc.

As concerns more serious cases of exploitation, of the type Kiruna airport or the railway between Kiruna and Svappavaara, the Samis were informed only when the authorities had resolved that exploitation was to take place. The Samis of the Kiruna district have experienced many such blows as far as lack of information is concerned. The administrative system, supported in particular by RBL $\$ 5$, has in this way been able to neglect the interests of the Samis. As far as the Samis are concerned, they were not in the first place concerned with attempting to prevent exploitation, but merely with gaining some influence in such matters, so that they might be able to direct a project in such a way that it would not be harmful to reindeer husbandry, thus preventing all unnecessary damage. Moreover, they wished to negotiate for reasonable compensation. These aims they have been able to accomplish only during recent years, after the Samish political form had been developed.

The next point to be considered is that of the regular contact between the authorities and the reindeer herders. Under this heading we shall discuss various forms of conducts and attitudes employed by the authorities; these questions are often controversial. We shall deal only with examples involving matters of principle; other incidents arising from the conduct of the authorities will not be discussed.

The way of life of the reindeer herders has undergone a gradual change since the 1930's. The Samis themselves have modified their nomadic way of life, adjusting to more permanent customs of living. They have abandoned their tents and turf huts in favour of houses with two or three rooms and kitchen. The methods of migration have also changed. Instead of the traditional migration by pack-reindeer, any means of transport available is now employed, be it a private car, a bus, train or, occasionally, air transport. 
There is also a redistribution of personnel. In the past, all the members of the family took part in every annual migration; now it is first and foremost the reindeer herder himself who migrates with the herd, and he is only at some occasions joined by some of the members of his family.

Not infrequently this adjustment has led to conflict between the authorities and the Samis. When, for instance, the northern communities gave up migration with pack-reindeer in about 1939, the authorities regarded this as a death-blow to the Samish culture. Long speeches were held, insisting on how errant this change was; only a few years ago, the following statement was heard: Why can we not have the fine, old form of reindeer husbandry back - this would solve all economic problems.

Similarly, when migration eastwards was cut short in the winter of 1950, the administration complained, expressing the view that this migration ought to continue, thus preserving the fine, old reindeer husbandry. The main reason for this change was the fact that the hamlets along the route from Vittangi to Karesuando had been chosen as the sites for building houses, moreover, the pasture is often poorer in the lowlands, owing to heavier falls of snow.

When some of the Samis became really destitute, partly as a result of the increased cost of living, partly because of the deterioration in the pasture conditions, the administration could offer only one solution: the old, intensive methods of reindeer husbandry should be taken into use again, for in this way all problems might be solved.

Another example of the process of adjustment being impeded is the opposition with which the administration for years viewed the building of houses. When some Samis began to build houses during the 1930's, in spite of protests, they did so under the threat of their being torn down. But in the end the administration had to abandon its negative attitude, and it was forced to accept the preference of the Samis in this matter. In recent years the state - and, in some cases, also the local authorities - have proved their positive attitude by offering the samis favourable terms for mortgages on the houses they were building. This applies particularly to the northern communities. ${ }^{8)}$ 
Matters affecting reindeer husbandry more directly form another aspect of this process of change. RBL empowers the authorities to force people to move. If a district had too many families for the total number of reindeer, some families had to move to a different district or Sami community. Those who refused to move had to pay heavy fines. In the northern communities there are families who have paid fines for years for this reason - an expensive procedure, but they preferred paying to leaving their traditional homes, which would involve heavy social costs. ${ }^{9}$ )

Further, the administration attempted to impede the preference of the Samis in the matter of the Norwegian pastures. In the early 1960's, several heads of households decided to move to Tamok-Rosta instead of the traditional but cumbersome Lyngsdalen; the administration reacted by threatening to sell their entire herds, hoping in this way to frighten them into making for the traditional district. But these Samis persisted - and the threat was not carried out.

The intensity of the conflict between Sami community $X$ and the administration may be illustrated by the following case, taken from a session of the court of justice in Troms $\phi$ in 1949:

As we Samis considered that we were being subjected to pure dictatorship when fines were used as a threat to compel us to return to the old pasture districts in Norway, we relied and based our actions on that democratic liberty which all groups of workers enjoy, but from which we samis are apparently excepted.

This sums up the Samis' cause in this case of confrontation. Later, the representative of the administration gave the view of the Swedish government:

The Samis used to move to their districts before the war, and there were no difficulties at all then, there was no poverty, and everyone enjoyed a sound economy. The Samis ought to show respect for the authorities and for the law, and they ought to obey without any contradiction, for the law was designed to uphold and preserve an ordered society.

When the lawyer representing the ten Samis who had been sued asked the representative of the administration why the fines were so heavy, the official replied:

As the law does not allow of penalties more severe than fines, these must be high enough to ensure that the Samis realize the importance of respecting us and the law. (SET 1950:1). 
In a reply in the next number of SET, the official made these theses still clearer:

The fine, old system of autumn and winter pasturing in small groups, on good pasture land, is now in danger of coming to an end. If reindeer keeping in these areas is to improve, the regulations stipulated in the Reindeer Pasture convention regarding the distribution into various districts must be adhered to. These regulations were drawn up with the good of reindeer husbandry in mind, and they are the result of a great deal of very painstaking investigation and careful consideration. The Swedish and the Norwegian authorities will aid and support the samis in every way possible in the pursuit of their work. They are by no means unfamiliar with the fact that the methods of work are being modernized in several respects. But in the matter of the utilization of the reindeer pastures, the old order must be retained. (SET 1950:2)

It should be noted here that the official investigations on which both RBL and the Swedish-Norwegian Reindeer Pasture Convention are based were drawn up entirely without Samish participation. Thus the practical view on questions of reindeer husbandry has had very little chance of asserting itself. This may well be an important cause of the constant growth of Sami opposition to certain sections of the law. These sections were largely formulated without the experts essentially involved - the reindeer herders - having been consulted.

The most recent case occurred as late as in 1968. At the community meeting of community $\mathrm{X}$, fines amounting to Sw.kr. 20.000,were discussed; these had been imposed by the Norwegian authorities for illegal grazing during the previous winter. Characteristic of the winter of 1967 was the remarkably poor pasture, and for this reason most of the reindeer were pastured on the lower slopes of the mountains for the greater part of the season. This involved a considerable risk of the animals straying over to the Norwegian side of the border. And in fact many of them had strayed into Norway prior to the legal date for Norwegian pasturing, the lst of May.

But the attitude of the authorities had grown considerably milder in the course of the years that had passed, and at the community meeting a promise was given that the government would be prevailed upon to pay up to $75 \%$ of the total fines. The inspector felt that the situation was comparable to that of other Sami 
communities, who had been granted financial aid to enable them to provide emergency fodder for their reindeer. This is a problem which affects particularly two of the northern communities.

The social system for which we have accounted above provides set conditions for official actions which prevent the Samis from attaining the possibility of a flexible adjustment. The reserve area forms a similar problem. The Samis wanted to have a possibility of utilizing this area freely when necessity arised, and in fact they did so. The administration, however, opposed their utilization of this land, and for several years heavy fines were imposed on the Samis for breach of this section. This resulted in a lengthy conflict between the two parties.

The matter was discussed at every community meeting during the 1950's, but after the community meeting in 2962, the Samis had grown tired of this state of affairs. They convened an extraordinary meeting the same evening, and there resolved to consult SSR. This resolution was a direct result of a statement made by the representative of the administration at the community meeting that day - he did not consider the time ripe for a repeal of the section of the Community Regulation dealing with the reserve area. The meeting unanimously commissioned the Sami community's elected representative to present the following at the annual meeting of SSR: "The heads of households of the Sami community strongly urge that $\$ 4$ mom. 3, which in recent years has proved a serious moment of irritation to the reindeer husbandry of our community be repealed from the Community Regulation at the earliest possible date." $(20 / 2$ 296l)

SSR approached the county administration directly, and already a month after the annual meeting, the Samis received dispensation from the provisions of this sections. Before this, some Samis had already approached the county administration in writing, but individually. The pasture farther east had grown so poor as a result of the expansion of forest reindeer husbandry that it was not expedient to let the animals graze there. For this reason it was essential that the reserve area might also be taken into use. The administration appears to have taken no notice of this appeal.

One more example illustrating the inflexible attitude of the administration; this one concerns the reindeer census. According to $\mathrm{RBL}$, a reindeer census is to be taken regularly; the provisions of the Swedish-Norwegian Reindeer Pasture Convention require the northern communities to take a census every year. However, sometimes this may be very inconvenient, as a result of ecological 
conditions which make such work impossible.

In 2955, the authorities insisted on such a reindeer census, in spite of poor conditions of pasture. The Samis had raised objections to this. Already at the community meeting on Feb. 29th they had pointed out that a reindeer census would be highly inexpedient. During years of poor pasture conditions, such a census is of little significance, partly because it is extremeIy difficult to round up all the reindeer, and partly because a census may lead to great losses for the owners of the reindeer, as compulsory slaughter may be erroneousIy enjoined, for such slaughter is made on the basis of the reindeer $i_{i s t}$. Many reindeer die when they are driven over long distance in a year when their condition is partioularly poor. In this case, the samis demanded a $20 \%$ deduction after the census, a request which was conceded.

The provision about the optimum reindeer herd of a Sami community can hit individual reindeer owners especially hard when the authorities order compulsory slaughter. If this section is adhered to all too literally, it can effectively reduce the economic basis for such families, who already are in a difficult financial position.

The matter of compulsory slaughter must surely grate on many ears when we realize that a family of seven persons, who owned 280 reindeer, was forced to slaughter 80 of them. Another who owned 225 had to slaughter 40 , while a bachelor was forced to slaughter 20 of his 80 animals. It is an obvious injustice that small reindeer owners, whose animals do not even provide them with a minimum existence, should be compelled to slaughter their indispensible breeding animals, and that at a loss. This must, in the end, lead to economic misery for the small reindeer owners. (National Meeting in Arvidsjaur 2954)

On another occasion, particularly severe compulsory slaughter was to be enforced. Nilsa and his father, for instance, were to slaughter 600 reindeer. Nilsa gained knowledge of these plans beforehand, by way of a top-secret document, and thus he was able to prevent this drastic measure, possibly because he was already then, at the beginning of the 2950's, a member of the board of SSR; thus his status might act as a check on particularly spectacular actions on the part of the administration.

Finally, as concerns the process of modernization, the administration has on several occasions opposed adjustment to a combination of occupations. After the catastrophic winters of the mid1930 's, many families found it necessary to find some other source of income, as their small herds of reindeer could not provide them a living for several years to come. In the southern communities - 
these were hit hardest - people looked for work on the iron railway. The administration, however, was greatly opposed to this, and thought that the Samis ought to occupy themselves exclusively with reindeer keeping. The number of animals will increase again, it is merely a matter of waiting. But the station-masters thought differently, and engaged all the Samis who sought employment there, thus offering them a chance of making a living. The railway between Kiruna and Narvik, mainly based on iron ore transport, has very heavy traffic and requires constant maintenance, and therefore there is always a need for extra labour. Since that time, the reindeer Samis have therefore utilized this opportunity of making a cash income at times when their reindeer require a minimum of attention. Moreover, permanent work is constantly available here for those Samis who for some reason, economic or otherwise, are no longer active reindeer herders. The advantage of this adaptation is that those who leave the community membership may still live in their own, local hamlet, and continue to be part of its cultural community. The social costs involved on leaving the Sami community membership are minimized in this way. At the same time, the local communities do not lose any personnel, a fact of advantage to the continuity of the Sami. community as a collective unit.

The attitude of the administration has undergone a gradual change. Nowadays projects which provide work for Samis are supported. This applies not least to the comprehensive mobilization of the northernmost communities, effected on the basis of a number of reports from the county administration during the 1960's. This matter will be discussed separately at a later stage of this chapter.

However, even today the administration gives its approval to a combination of occupations with certain reservations. Small scale enterprises, for instance, is not considered acceptable.

In one of the communities, two brothers have set up in business with two snow weasels for winter transport. In 2957 they had applied for a loan, which was granted by the municipality. But before the money granted was paid out, the municipality also consulted the administration; as a result, the application was now turned down. The reason was said to be that the administration did not want the brothers to expose themselves to the 
risk of a bankruptoy. But the brothers were able to borrow the necessary amount elsewhere, they started work with one machine and have now expanded to two, and their business is doing quite we 2 . The Reindeer Administration, however, competes with the brothers, acquiring their own weasel after the brothers had set up in business, which means that the brothers have considerably less work than they would otherwioe have had. They had, after all, counted on constant jobs for the Reindeer Administration. Moreover, it seems natural enough that transport required by various reindeer keeping oonstructions, fences, coralls etc., should be carried out by Samis, who possess superior knowledge of looal conditions. The administration explained the steps it had taken by saying that it was an advantage to have one's own weasel, so that one need not rely on the open market. By purchasing their own weasel, it would be available whenever necessary. The Samis concerned, however, consider this explanation to be pretty weak, seeing that reindeer husbandry constructions are usually planned far ahead, and thus it should not be difficult to secure the transport required if only it is ordered in time.

In other words - as this Samish initiative far exceeds what is considered correct and permissible for reindeer herders, the administration decided to put difficulties in the way of the brothers. At first, the administration proved to be a very keen competitor, but their attitude had become somewhat less harsh, especially after the community meeting in 1968. On that occasion, the two brothers brought considerable pressure to bear on the officials present concerning this matter.

This new form of adjustment proved so successful that another reindeer herder in the same Sami community has also started with this kind of enterprise.

This work was absolutely essential for the three men concerned. Even though they have only a few reindeer, they and their families can remain in the community, and share the basic values characteristic of the reindeer Samis. This possibility of choice is of vital importance for the Samis. From an economic point of view their new work is so important that reindeer keeping has, for them, become an ancillary occupation - it provides them with less than half of their total income. But the expenses involved are so great that they do not know how long they can continue contracting. This is a mode of adjustment 
based on Samish initiative, and as such, it has many advantages; as one of these three men put it:

As a combination of work, one might call this ideal, for we are not confined. We accept the orders which we can manage, and adapt this work to that of reindeer herding. A permanent, full-time job, for instance with the railway, cannot be combined with reindeer hording. This enterprise can easily be adapted to the needs of reindeer herding, just like fishing, but it is far more remunerative, of course.

From the above we may conclude that the administration has on many occasions obstructed the Samis' attempts at adjusting to new conditions. The process of modernization which they themselves have chosen, however, has all the time proved sufficiently strong to overcome the opposition of the administration. The closer and more frequent the contact with the wider society becomes, the more essential will adjustment of this kind become. And in the light of this, it is the more surprising that the administration appointed by the wider society attempts to obstruct every Samish initiative. Such initiatives are not accepted by the administration until they have been put into practice in spite of persistent official opposition. Many of the difficulties under which the Samish minority is labouring today are largely an outcome of the static attitude which has dominated the Sami administration for far too long.

The increasing pressure from the wider society is gradually making it more and more difficult to carry on profitable reindeer keeping. In the Kiruna district, where such pressure is felt more keenly than in any other Samish district, special demands are made on the administration. But the vital interests of the reindeer keepers have not been effectively taken care of, as appears from the section dealing with political case studies.

In the end the Samis of both the Kiruna communities lost patience and reported the matter to the parliamentary commissioner, (JO) On Oct. 3lst 2963 the Samis' solicitor $T$. Sandgren, submitted a letter on their behalf. Both the Sami communities had added a memorandum to this document, listing in detail the various intrusions committed by the wider society, which had affected the conditions for reindeer husbandry. Then the county administration was given the opportunity to express its views; their statement was supported by several national and municipal authorities. Next, the Samis issued a new 
document, by way of a reminder; this was followed by a new statement from the county administration. A final reminder from the samis concluded this flow of papers. After this, Jo worked out a report, which on Jan. 24 th 2966 resulted in an official proposition to the Government. This Proposition contains important legal views on the situation of the Samis, and these have since frequently been cited in support of political actions by the Samis.

Thus this local initiative was to gain fundamental importance for the interaction between the Sami minority and the wider society. As a first result of the action, the relationship between the parties was frozen completely. The inspector, for instance, avoided direct confrontation by not taking part in any community meetings during the first two years, instead sending a colleague from a different administrative district. The proposition by J0 led to serious admonitions being received by the administration in connection with certain, concrete cases, and its later actions clearly show a changed attitude to the situation of the Samis, a situation which is often extremely problematic. By means of this unique action, the Samis thus proved that it pays to take the offensive when special circumstances call for such an action. According to many informants this notification to Jo was submitted at least twenty years too late. All damages had already occurred.

The relationship between the administration and the Samis is not, however, without positive aspects. In certain respects the administration can be of advantage to the Samis, an asset in the matter of achieving certain aims. The official representing the administration has expert knowledge which may at times be valuable and important. In various matters concerning reindeer constructions, such as reindeer herder's huts, enclosures, fences and slaughter-arrangements, specialized knowledge of the building material needed and marketing experience are required, and as a rule, the Samis lack such knowledge. When such affairs are being arranged, it is worth while undercommunicating the conflict angle of the relationship. This is important, in view of the fact that the economic resources for such schemes are provided by way of the administration. In other words - one can attain certain advantages by being on good terms with the Reindeer Administration. Well-founded criticism can also be converted into 
pressure in order to gain advantages, for the official concerned will as a rule meet the Samis part of the way, in order thereby to improve the relationship obtaining.

\section{Measures of modernization}

During the 1960's, a series of measures were put into effect, intended to improve in various ways the conditions under which the reindeer Samis live and work. These measures illustrate different forms of interaction between the Samis and the administration. Some of them were taken on the initiative of the authorities, some on that of the Samis. Characteristic of these actions is the fact that where the Samis had some say in the matter while the measure was still in the course of preparation - especially through the agency of SSR - the result of the action is positive. This applies to the Reindeer Committee Report of 1960 and the AMS action for the northern community of 1964 (Arbetsmarknadsstyrelsen - the Labour Market Board). But where the authorities have acted entirely alone, the result is negative, seen from the point of view of the Samis. The clearest example of this is the Norrbotten plan of 1967. In fact, the more closely the various official organs cooperate with SSR, the better the prospects of attaining a result favourable for the Samis. These measures will be discussed in greater detail below.

Case I. The initiative for the Reindeer Committe Report was taken by the authorities in 2956. The committee also included two samis, but they had not been appointed by SSR. The report, which was submitted in 1960, included proposals for improving the organization of the Sami communities as weil as a revision of some of the most obsolete sections of $R B L$. It was, for instance, proposed that in future the sami community should be empowered to act as an independent juridical person. Committee of deputies should also be appointed following the provisions of $R B L$. In addition, community meetings with a committee and auditor should be introduced. Finally, the administration was to have the right to participate in the deliberations of the community meetings, but not in their resolutions.

Later, $S S R$ started an informative campaign, during which most of the Sami communities were visited. At the National Meeting in 296l, SSR's submission to the proposal was drawn up. SSR accepted the proposal in principle, as it contained many positive improvements. 
In 2962, the Parliamentary Bill on this matter was introduced, Bill No. 68. Some of the committee's proposals had been oliminated, but some important changes were put into effect. Committee of deputies were to be appointed, and thus the need for a committee was also covered. The sami community was now to be able to appear as a juridical person, in accordance with the legal case of Malmesjaure in 2967. Finally, the titles of the officials of the administration were changed, and the changes in their spheres of work were also specified. Their work was to continue to be largely of an advisory nature. In 2962 a new resolution was submitted at the National Meeting of SSR, on March 27th, to the effect that $S S R$ demanded representation in the assembly of the Board of Agriculture in all cases where general questions of reindeer husbandry were discussed. The immediate result of this was a Parliamentary motion submitted 27/3 2962, which included most of the points from the SSR resolution. The motion was supported by six members of the First Chamber and nine in the Second Chamber. The motion called for at least two Samis being included in the meetings of the Board of Agriculture, as specified above. The proposal was, however, defeated in both chambers, in the First Chamber by a vote of $54-42$, in the second by a vote of $86-85$. This action brought about on the initiative of $S S R$ shows that Samish influence can make itself felt on the level of national policy. True, the motion was defeated, but in the long run the status of the Reindeer Husbandry Committes was acoentuated, as a result of this action. It appears, in fact, that the influence of the Reindeer Husbandry Committee on the resolutions of the Board of Agriculture is by no means negligible.

Case II. At the National Meeting $23 / 3$ 2964, SSR presented a resolution dealing with the problems of employment, partioularly in the northernmost communities. As a result, AMS convened a conference, which took place already on April 26 th. It was attended by the county labour directors and delegates from SSR. Following the conference, the county labour office of Norrbotten was instructed to report on labour conditions. On July 20th, the county administration convened a new conference, to which $S S R$ was again invited. Now the administration submitted a memorandum which included most of the demands of SSR. This conference resulted in a submission to AMS, dealing with a series of measures to be taken immediately. A number of reindeer constructions were to be erected, partly in order that reindeer keeping in this area might be rationalized, and partly so as to offer possible sources of income to many of the small reindeer owners. A close cooperation between the county labour office and SSR was to put the suggested schemes into practice. This action has had a positive effect on conditions in the northernmost communities, although the problem of an exessive population remains. This is another instance of successful cooperation between the two parties. 
Case III. The Norrbotten plan is the result of an initiative taken by the authorities alone. The proposal implied strict rationalization, especially as concerns the population. The point of departure was the Samis' Low material standard of living, which was to be raised considerably. However, the authorities of Norrbotten regard this problem as a pure reindeer keeping matter, whose only solution lies in reducing the number of reindeer sami households in all possible ways. This, it was thought, would raise the economic standards of the remaining households to such an extent as to become comparable with the standard normal in swedish society as such. This change was to be wrought inotwo stages: first $29 \%$ - $52 \%$ were to be eliminated, in about 2975, a reduction of $52 \%$ - $66 \%$ of the present population would be achieved.

This aim does not agree with the Samis' own preference as to the solution of the problem. A number of articles in "Samefolket" show how critioally the samis reacted to the whole Norrbotten plan; in their opinion, the plan puts too much and too one-sided emphasis on the economic aspect of the problem. They point out that an exhaustive investigation of various altornative means of support should have been included - reindeer keeping represents only one possible way. Moreover, the chase for a higher standard of living should not be exaggerated in this manner. This is an ethnocentric point of view, which does not necessarily agree with the opinion of the Samis. Charaoteristic of the whole plan is the fact that the Samis were not consulted - the entire plan is an artificial product of officialdom, with an obvious undertone of a politico-economical way of thinking.

The problem of population is particularly acute in the northern district of Norrbotten, for here very few reindeer keepers have abandoned their occupation. In some of the communities in the region investigated, this state of affairs has taken a favourable turn, while others have experienced a highly unfavourable development. This is illustrated in the following table:

Table

Number of reindeer Samis

$\begin{array}{lrrr} & 1945 & 1958 & 1965 \\ \text { Könkämä } & 202 & 147 & 137 \\ \text { Lainiovuoma } & 144 & 174 & 165 \\ \text { Saarivuoma } & 197 & 225 & 211 \\ \text { Talma } & 38 & 75 & 63 \\ \text { Rautasvuoma } & 82 & 68 & 55 \\ \text { Lævas } & 114 & 84 & 68\end{array}$


The simplest solution of the precarious economic situation of the samis, on the basis of the above figures, is an adequate reduction in the number of people. And in the Norrbotten plan, the authorities have chosen this, the simplest solution. But an action such as this can only meet negative reaction on the part of the Samis. Thus this example shows the importance of Samish influence regarding proposals for any changes concerning the future conditions of the Samis.

These examples illustrate a particular aspect of the relationship between the Sami minority and the wider society. In as much as the Samis have, in this way, been able to achieve some political and administrative influence on their own affairs on the national level, this is a fairly new development, one which is essential to the Samis in their efforts to improve their position within society. This development will be discussed in more detail in the chapter dealing with SSR.

It thus appears that the factor of administration may be regarded partly from a structural aspect, partly from a relational aspect. Both these aspects illustrate the function of the administration as a premise of action for the Samis.

From a structural point of view the administration is, firstly an administrative apparatus which at the local and the national level handles various types of matters affecting the everyday situation of the reindeer Samis. Secondly, it includes a special legislation. The legal system serves as a legal framework to which the Samis must constantly adapt themselves. This framework forms an entity together with the administrative apparatus. The constant adjustment of the Samis to modern conditions appears to have been greatly restricted by the structural features of the administration, because these features can be affected by manipulative devices to only a very slight extent. Such manipulation becomes possible only as new political forms of organization are developed.

The possibilities emanating from this factor are, in other words, not very comprehensive. This is true also of the relational aspect. The institutionalized contact by means of the community meeting, as well as the continuous contact, mark the difficulties the Samis have long experienced in defending the 
vital interests of their group. The reason why the relational aspect has so restrictive effect on the Samis is to be found in the structural features which represent premises for action, not only for the Samis, but also for the authorities.

With these conditions in mind, it is hardly surprising that interaction between the two parties is in so large a measure marked by conflict. The attack on the administration, in the form of the JO report, as well as new instances of a limited form of cooperation in certain measures of modernization are examples of Samish attempts to modify the structural restrictions.

The relational aspect, to which we have attached primary importance in this account has, as we have seen undergone certain changes, which in part explain the change in the political form. In the following chapter we shall examine the local-political form in detail; this must be regarded partly as an adaptation to ecological conditions, partly as a result of the restrictive influence of the administration. 
1. See Chapter $V$ for a detailed discussion of this form of organisation. The political potential of this organisational form is related in detail in Chapters VI, VII and VIII.

2. The title of Zappfogde (Lapp sheriff, an officer in charge of Lapp affairs) was used for this position until 1962. It is a medieval term that goes back to the time of Gustav Vasa and which was reintroduced after the first modern reindeer husbandry legislation in 1886. In 1962 the title lapptillsynsman (Lapp supervisor) was changed to instruktor (instructor). These official titles were changed in accordance with Government Bill no. $68,1962$.

3. The Reindeer Husbandry Committee is made up of 7 Samis appointed by SSR. This body came into being after Government Bill no. 68,1962 and was intended to have 15 members, of which 7 were to be Samis. After pressure from SSR the Reindeer Husbandry Committee was reorganized as a purely Sami body.

4. The Sami community has proposed that the cottages be moved $1,5 \mathrm{~km}$ downstream with a bridge over the rivelet. In this way the nature trail for tourists can be located on the east side of the valley, which would mean that the luxuriant grass on the west side could be much better utilized for reindeer grazing. The grazing is poorer on the east side. Better working conditions and additional grazing will result if this change is carried out. The Swedish Tourist Association (STF) is wholly in agreement with this proposal but must have economic support from the government in order to carry it out. Both the Sami community and STF have separately applied for a grant from the National Labour Market Board, but these applications have not yet been approved.

5. A more detailed description of the giving up of rights and the effect of this upon the conditions of the Samis, has been given in Samernas Politiska Organisation (The political organization of the Samis - stencilled undergraduate thesis 1964) and to a certain extent in the article De renskötande samernas ställning $i$ Sverige (The position of the reindeerherding Samis in Sweden) in the book Svenska Minoriteter, 1966 .

6. The Jo has drawn attention to these conditions in a note dated 24.1.1966. What is particularly remarkable is that the RBL, apart from a particular clause in paragraph 56, lacks regulations concerning the way in which matters dealing with the rights of the Samis are to be treated. There are on the whole no instructions that give any information about the way in which these matters are to be dealt with, According to the JO this is a serious omission in the legislation. 
7. $\mathrm{JO}=$ the Ombudsman of the Riksdag, an institution that private individuals or groups can turn to in order to obtain an objective legal examination of an important matter that has to do with the administration.

8. In the 42nd paragraph of the RBL are given, amongst other things, the following restrictions concerning the erection of cottages.

2) On other Crown Lands buildings may only be erected after special permission, granted at the time of application, by the County Governor, when areas above the limit of cultivation or used for reindeer grazing are concerned.

$\ldots$. , and that it is not made larger than is necessary for its purpose as a home for a Sami, who is looking after reindeer in the area, as well as other regulations concerning the state and use of the building.

9. In one of the Sami communities fines of $6.000 \mathrm{Sw} . \mathrm{kr}$. were enforced in 1947, and $15.000 \mathrm{Sw} . \mathrm{kr}$. in 1948. These are large amounts for a reindeer herding area, where a monetary economy has hardly developed. The reason for the fines was illegal grazing in Norway or disobedience of legal instructions, which resulted in conflict arising between the community and the authorities during the early years of the 50's. (SET 1950-1954).

10. The lower figure is based on a labour requirement of 1 per 350 reindeer, while the higher figure applies to 1 per 500 reindeer. A degree of rationalization should be achieved so that the latter figure applies. All this is to increase the efficiency of reindeer husbandry and to increase the earnings of those engaged in it. Nothing at all is said about well-being. 


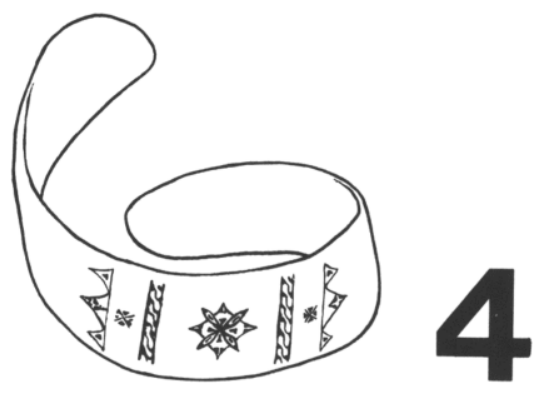




\section{The local political form}

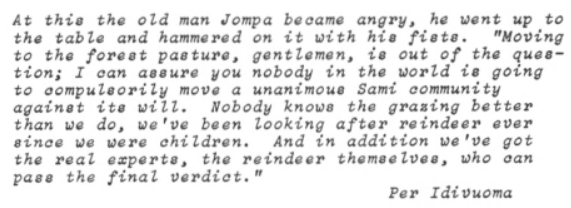

The form of local politics which has developed within the entity of the Sami community may be differentiated, in the first place, into a Samish institution and an institution determined by the wider society. Both of these may be regarded as adaptive expressions referring to ecological and administrative conditions respectively. The Samish institution has its roots in the historical background of Sami culture. This holds true not only of the reindeer Samis but also of groups of Samis with a different ecological pattern. The other institution consists of status positions imposed upon the Sami communities from without, by means of resolutions adopted by the authorities.

These two institutions will be discussed under separate headings below. If we are to give a complete account, we must also discuss those forms of expression which are not institutionalized: forms which belong to neither of the two institutions, but which nevertheless play an important part in local politics. SSR as a political body is discussed in a separate chapter; for this reason we shall not include the local aspect of this organization here. (See chapter V)

\section{A. The Samish Institution}

In order to understand the political form which illustrates the various phases of the minority situation of the Samis, we must first investigate those aspects which may be considered to be genuine. The sii'da institution, which is still practised today, has its traditional roots in the culture of the Samis (E. Solem 1933:184): this is a form of cooperation between several households. It is concerned with reindeer herding, while 
the management aspect of reindeer husbandry is the responsibility of each household (Paine, 1964a). The different conditions obtaining in the various districts lead to different ways of dividing the siidat during winter pasturing. During the rest of the annual cycle - the time when the ground is free from snow - the reindeer usually graze together, and all tasks are carried out collectively by all the households. This division into siidat is due to ecological reasons, as the animals must graze on restricted and clearly defined areas in the pine forests. Intensive herding is called for by this arrangement, and this is facilitated by the herd being divided into separate, smaller units. In the present context, however, we are most concerned with the political aspect of the siidat, since a great many moves within local politics are expressed through this institution.

The sii'da is not a corporation in the more restricted sense of the word (Pehrson 1957), but a group formation whose span of life may vary. When the reindeer are separated in autumn, before the winter migration, each household unit can freely choose a sii'da within its own Sami community, according to the Samish view. However, the pattern of separation tends towards stability, a stability which may on occasion last for several generations. This applies particularly to those households which form a nucleus for the remaining members of the sii'da.

In the region investigated, for instance, the sii'da organization was extremely stable during the period 1950 - 70. To what factors may we attribute this regularity which, as we have seen, is unconnected with the assignment of rights characteristic of corporations? Kinship is one of the most important factors. Social relations of this type are based on the bilateral principle, which allows of recruitment on the basis of kinship in most cases. As a result, if a man has no brothers, cousins, second cousins or brothers-in-law are regarded as the equals of brothers. - Another principle is that of the individual attitude to reindeer keeping. People with a similar attitude tend to keep together, because they share the basic standards of value and knowledge necessary for successful reindeer husbandry. (Cf. Whitaker, 1955) A sii'da which consists of capable and industrious 
reindeer keepers is as a rule loth to admit an unskilful, lazy herder, regardless of any ties of kinship, as long as the group is already ideally composed as regards personnel and number of reindeer.

But this social system is not without variation, mainly as an outcome of ecology, but also influenced by the administration (cf. chapter III). When the conditions of winter pasture are especially poor, the Samis are compelled to rearrange their siidat. In extreme cases, there will be no separation at all, for then the entire reindeer herd of the Sami community grazes freely on the lower slopes of the mountains, and it is impossible to keep them separated at that topographical level. These conditions occur during winters when ice forms in the snow in the pine forests areas.

Another restrictive factor is the location of the herder's permanent home. This means that one cannot join any sii'da of one's own choosing in winter - the choice is restricted to the few possibilities offered by one's own home hamlet. This is a result of the transition to permanent settlement, which makes a flexible social adjustment impossible (Whitaker 1955:65).

When several families leave a winter hamlet and move to another, the effect on the $s i i^{\prime} d a$ organization of the whole Sami community is great. One of the Sami communities experienced a large-scale move of this type during the 1960's; as a result, two of the four siidat in the original home hamlet were dissolved, and the remaining two had to be reorganized. In the hamlet to which these people moved, one of the old siidat was revived, while the remaining families are trying to find new alliances within the siidat of their new hamlet. This change has also had another effect: conditions in those pastures which may easily be kept separate are becoming pretty cramped, and this again calls for a certain regrouping of the original siidat.

The other restrictive factor is the administration. Those authorities which have been charged with the management of the Samis can, whenever they find it convenient, enforce changes, regardless of the views of the Samis. For instance - one of a Sami community's summer districts in Norway may be closed, as a result of which a group who previously had their own, separate herd of 
reindeer all the year round, will no longer be able to maintain such a separate herd. They are then compelled to move into a larger district with typically extensive reindeer husbandry, and this renders the continued existence of the group impossible. They will no longer be able to experience their old sii'da fellowship, not even in winter. A greater effort of work than this small group can muster would be required to separate their own animals from the total herd and keep them apart for some time. Thus they are forced to become members of a large winter sii'da, like the other members of the Sami community.

In other cases, the households within the accessible districts may have been regrouped - such a change is based on the optimum number of reindeer which a district is permitted to have. Such decisions of the authorities also affect the existing $b i i$ 'da organization (see also Whitaker 1955).

It will thus be seen that the sii'da is a stable form of organization, but at the same time one with a certain flexibility. It is not a corporation in the true sense of the word, although it has certain of the criteria typical of such a group: a stable composition of member households over a long space of time is frequently found, and definite principles of recruitment are practised, even though these are not explicit. The sii'da as an institution renders possible adjustment to an optimum formation of the group, seen from the point of view of the most successful form of reindeer husbandry possible. Ecological conditions and the relationship with the administrative bodies appointed by the wider society affect the stability and the changeability of this form of organization.

Each $s i i$ 'da has its own leader, sii'da-ised. This is not an office to which one is elected; persons with special sources of influence fill this post. There is fairly general agreement among our informants as to the nature of these sources of power. ${ }^{1)}$ The sii'da-ised must first and foremost be a skilful and industrious reindeer keeper, and he must own many reindeer. But he does not have to own the largest family herd of the group.

These two factors often coincide among the Samis. It is not, as a rule possible to own many reindeer if one is not skilful and industrious in the work of tending them. Furthen - the ised 
should be able to mobilize many people for work, and there must be no question as to their loyalty towards their leader. This means that he ought to have many close relatives who will support his decisions. Brothers and several adult sons are considered to be a great asset, but less close relatives may also serve, as pointed out above. Persons who do not possess these social resources will never become ised.

Characteristic of ised succession is a gradual and smooth transition (cf. Whitaker 1955). Some years before the change of leadership is to take place, the group selects a suitable candidate. Agreement is in the common interest, for a capable sii'da-ised is essential if the group is to be as productive and successful in its reindeer husbandry as possible. Thus one of the qualities the ised ought to possess, according to Samish opinion, is that he must put the interests of the sii'da before his own. This is one of the explicit duties of this status, and this he must acknowledge, while the heads of household must accept his leadership.

The situation may become somewhat ambivalent for the two persons involved. The elder ised may, for example, not yet have realized that he is no longer ised, and - partly for this very reason - the younger has not yet taken over completely. The duration of this period of transition may vary. The ised's sons, particularly the eldest, occupy a favourable position from the point of view of succession: in the region investigated, linear succession was by far the most common form. It was also fairly common for the ised to be succeeded by a son-in-law, brother's son or younger brother.

The ised's influence is limited in that it applies exclusively to the people's activities in connection with reindeer herding (cf. Pehrsson 1954). In the past, his authority in this sector was practically absolute. The sii'da-ised might, for instance, go out into the forest where the reindeer were grazing, accompanied by one of his sons or some other helper, and start to move the group's herd without consulting any of the other members of the sii'da. They were merely expected to realize what was happening, and in practice ised's decisions were frequently not communicated to the other members of the sii'da. Nor were the 
sii'da-ised's decisions ever questioned, for he was looked upon as being the most knowledgeable and wisest of the reindeer keepers (cf. Solem 1933, Lowie 1945:452, Whitaker 1955). He decided when the herd was to be moved and where it was to be moved to. He also allocated the work among the members of the group. Consultations between the ised and the other members of the group would occasionally take place - today this is common practice.

In the main, the sii'da institution is governed by the households' economic interests, and there is therefore general agreement within each sii'da. The member households realize that they are, in confrontation with other siidat, together in the same opportunity situation of ecological and competitive conditions. But fairly constant conflicts may obtain between different siidat. Such internal conflict within the Sami community is often due to different attitudes towards various methods of reindeer keeping: industry and skill may vary greatly, as may also the reindeer keeper's respect for the property of others and his attitude to more modern methods of work as opposed to more traditional forms of reindeer husbandry and herding.

The concrete expression of these conflicts may be observed in the microlevel social relations which are manifested in the work with the herd in the large corrals. Cooperation takes place first and foremost within the sii'da, but between rival siidat there may be sabotage of various kinds. But not all cooperation is confined within the boundary of the sii'da - when these limits are crossed, working relations are based on kinship and on similar basic sets of values.

Thus the political functions of the sii'da appear on two levels. Internally, it is limited to a pure working organization which competes with other siidat, but such competition cannot become so keen that it seriously impedes political cooperation at the Sami community level. This is due first and foremost to those premises which are derived from the place assigned to the minority group within the wider society. Most decisions of a political type must be made by the entire, united Sami community or at a still higher level, such as SSR, if they are to have any chance of success. 


\section{B. The Institution Effeoted by the Wider Society}

The Samis, in their capacity of reindeer keepers, were juridically incorporated into Swedish society at the end of the nineteenth century, the time when the first specialized legislation came into force. ${ }^{2)}$ Among the provisions of this legislation was that laying down the boundaries of the communities, which were from then on known as Sami communities. In the present context we shall confine ourselves to accounting for the positions which this organizational complex has imposed upon the Samis.

The most important of these is the status of BO. Every Sami community has a community headman (byordningsman - BO), elected for a term of six years by the heads of households in the community. Their choice of BO must, however, be approved by the administration before any appointment can be made. In other words - the administration can readily influence the Sami community's choice of formal leader. As a result, the BO finds himself in a dilemma of divided loyalties: he must look after the interests of the heads of households of his community, a position of trust to which he has been elected, and in his capacity of paid public official, he must attend to the interests of the administration, which mainly involves controlling that reindeer keeping in his Sami community is carried out according to the regulations of the valid reindeer husbandry legislation.

Thus the authority of the BO is strictly limited. His political activities are restricted to leading the work of reindeer herding for the entire Sami community. He represents the community in confrontations with external bodies, and he serves as a connecting link between the various siidat within the community, at the same time canalizing information between the siidat and the administration. In fact, if we study his role we shall find that it is hardly political in the true sense of the word - rather, the $\mathrm{BO}$ is a kind of pseudo-administrator in the local community.

The BO's duties include that of guaranteeing that all the reindeer belonging to the Sami community leave the Norwegian summer pastures within the prescribed date, and also that of controlling that no reindeer cross into Norway before the authorized period of pasture starts. Moreover, he supervises the 
marking of the animals as well as a number of similar working operations. In other words, a very great responsibility rests with the BO, but this is not compensated by equally great rights. His only formal privilege is the protection to which a public servant is entitled by law - this he enjoys only in case of attack by the heads of households because of unpopular measures connected with provisions of RBL. His status may, in fact, be described as being unbalanced, comprising as it does many duties but few rights. ${ }^{3)}$

These, then, are the general implications of the BO status. If we investigate the gradual incorporation of this position into Samish culture as such, we shall find certain regular features. The material shows that kinship is an important factor in the matter of succession, in spite of the fact that the BO is elected. In each of the two northernmost communities, a son-in-law succeeded his father-in-law as BO; in these communities, the sii'da-ised was also succeeded by a son-in-law. In both these cases, uxorilocality was a factor important to the attainment of a position of leadership. Virilocality is otherwise more normal in Samish society.

In another case, the BO status alternated between two groups which were often in long-lasting conflict with each other, and which also maintained separate local centres within the Sami community. This sequence came to an end when a member of yet a third sii'da was elected BO: we might add that the local conflict has subsided considerably since this appointment was made.

The following example, which occurred in the latter community, illustrates not only the possible aspects and consequences of such local conflicts, but also the weak position of authority actually enjoyed by the BO:

During the summer pasturing season in 2957, the BO had decided that we were to turn loose the reindeer in a partioular direction; our group was none too pleased at this decision, because it would be difficult to keep the animals there. We discussed this in secreoy in our phalanx, and decided that we would somehow contrive to let the reindeer drift in "our direction". Piettar, who had a very good reindeer dog, said that we should not turn loose the animals before he had come to the slope at $P$. - then he would arrange the rest. Then he sneaked away without being seen. And the BO was very surprised when we turned loose the reindeer and he saw 
that they made for the opposite direction. We were pleased of course, but the Jokki group was very bitter. But at some time they might use a similar manoeuvre against us - it was often like that then.

In most cases, the $\mathrm{BO}$ is, at the same time, sii'da-ised. Thus we ought to consider the position of ised as a source of power on a par with kinship relations. In local matters, such as leading the work of reindeer keeping for the entire community, alliances based on kinship are of great importance. It is only in extremely exceptional cases that a BO is elected without support of this kind. Skill and industry in reindeer keeping are also important qualities. A BO who spends too much time on organizational work of various kinds, so that he comes to the reindeer pasture land less and less frequently, is considered unsuitable by many members of the local community. A BO must first and foremost be interested in reindeer herding and husbandry, otherwise he loses the basis on which support for his status rests. Important resolutions must be made jointly, and sanctioned by a formal leader. If this formal leader is hardly ever present, communal decisions can scarcely be realized. This may result in a form of anarchy, which leads to serious economic consequences. The above shows that the status of $\mathrm{BO}$ has become so important to the Sami community that the viability of this local community is clearly affected by it. A great number of reindeer is another factor, although this is not decisive. The authority of the BO is, however, enhanced if he owns many animals.

The difficulties connected with the BO-status are well illustrated from the Sami community $Y$ when they held their last election before the new reindeer organization came into use in 1971. In that election the 31 votes cast were split between as many as 7 different candidates according to these figures: $\mathrm{BO}=9, \mathrm{~A}=8, \mathrm{~B}=5, \mathrm{C}=4, \mathrm{D}=2, \mathrm{E}=2$, and $\mathrm{F}=1$. Apparently this Sami community is in great trouble trying to unite behind this kind of formal leadership, which many consider rather un-Samish. Different values and opinions towards Samish politics and reindeer herding are the main reasons for this internal multi-division. Most certainly the re-election of $\mathrm{BO}$ 
this time gave him such a meagre authority base that it was next to impossible to fully consummate the status of $\mathrm{BO}$ in the years to come. In $\mathrm{Y}$ the opinion differed quite a bit regarding who was in charge with what. Many of the heads of households did not recognize $B O$ as the one in charge of reindeer herding e.g., and severe internal problems leading towards more or less anarchic conditions were the immediate result of this voting manifestation. This is not a regular pattern, but nevertheless it illustrates the problems that could emerge upon introducing strange, un-Samish statuses.

As contact with the wider society increases, the BO acquires another function, and for this other sources of power are important. He must now have a knowledge of the Swedish language, for he must be able to read and comprehend reports from various public committees etc., as well as keeping posted with the mass media. Moreover, the BO must frequently represent his community in confrontation with other parties, such as diverse public bodies and various private exploiters - a working knowledge of Swedish is essential here. And this limits the choice of person to be elected BO by a community. Other factors connected with the above are experience in organizational work and an active interest in external matters.

Various kinds of expertise, such as craftsmanship and theoretical knowledge, may also be employed as resources for attaining authority. Charisma is another resource, which is often manifested in cases where the formal leader is not, in fact, the functional leader (Svensson 1969a).

The administration may also be regarded as a resource. When necessary, the BO can claim support in RBL; he may also appeal to the county administration if the other heads of households should sabotage his actions. But otherwise RBL and the relations with the Reindeer Administration constitute first and foremost a restrictive factor. It is also extremely important that the BO's basic views should be shared by the majority, for otherwise a distrust of his authority is often expressed. These basic views may include his attitude towards more modern methods of reindeer herding, his attitude towards and his experience of reindeer theft. 
Finally, we should also mention that it is generally thought proper for the wife of the $B O$ to remain passive in the communal matters concerning the Sami community. A wife who shows too active an interest in her husband's work as BO seriously hampers his authority. ${ }^{4}$ )

The BO's opportunities for action within local politics and the restrictions under which he labours in this respect are reflected in the interaction of the above sources of power possessed by the individual incumbent. The greater the number of sources of influence supporting the actions of the BO, the stronger will his position be.

In summing up, we may describe the status of the BO as an interhierarchical role. ${ }^{5}$ ) $\mathrm{He}$ is at the top of the inferior structure and at the bottom of the superior, while functioning in both. As is so often the case where this type of role is found, the divided loyalty involved frequently leads to a role dilemma. (Svensson 1973b).

According to RBL, every community must also have a committee of deputies. Their function is that of representing the community in external matters. As a rule, the committee consists of the BO and three other deputies, but some of the larger communities have four other deputies. They are usually elected in such a way that most of the siidat are represented. They need not, however, be ised, for the qualities required for this position are different from those demanded of the ised. Experience of organisational work, another political status and a knowledge of the Swedish language are the most important qualifications, since the function of the deputies is largely concerned with external matters, especially such as concern the relationship with the wider society.

The committee of deputies meets when necessary - three to four times a year is usual. They meet partly in order to prepare their annual meeting with the officials from the Reindeer Administration, partly when a particular measure of exploitation is threatening and negotiations with those responsible for this measure are called for. In other words, the committee of deputies is fully authorized to act on behalf of the community, and the importance of its function increases in proportion with 
the contact with the wider society. Another external function is that of maintaining the relations with the neighbouring communities - this tends to be easier and more effective when common problems are discussed by a few deputies rather than by all the members of the community. Some projects of exploitation may affect several communities, and then a discussion of their common policy is essential. Naturally the heads of households are informed at a meeting of the actions planned by the deputies, and also of the results of their negotiations concerning, for instance, projects of exploitation. Thus the committee of deputies is responsible to the members of the Sami community for its actions. The policies resolved at the meeting of the community - a meeting at which the administration is not represented - are always effected by the committee of deputies.

In certain, extreme cases the deputies may also act as substitutes for the $B O$ in matters of reindeer herding. This happens when the BO as well as the VO (viceordingsman) for some reason cannot be present at the active work of reindeer herding. Someone must then be responsible, and it is natural that this responsibility should be assumed by a person of local-political status.

The other heads of households have accepted this new function, and in this way the Samis have thus redefined a status so that it now applies also to internal matters. This reflects the process by which roles of this new type are adapted to the culture of the Samis. It is surprising that this redefinition has been expressed most clearly in that community which was most strongly opposed to the institution of the committee of deputies. ${ }^{6}$ )

The local authority of the committee of deputies may vary greatly. For instance, an attitude towards a form of reindeer herding not shared by the majority within a particular Sami community may form a clear limitation of the deputies' authority. If they pursue their views too far, they may in the end lose the confidence of the community. They must therefore act extremely cautiously and be alive to the feelings of the majority, for the majority constitutes a controlling factor as regards the committee of deputies. 
In another Sami community, the committee of deputies consisted of experts in local politics during the last two terms, and they formed a very homogenous group. At the last election, several of the deputies did not wish to stand for re-election, and three new deputies were therefore elected. But they lack most of the qualifications for this position and they are, moreover, traditionally in conflict with the only remaining former deputy. Previously they had frequently criticized the actions of the committee of deputies - now they themselves must accept responsibility. The majority within the community considers it a good thing that responsibility should be distributed in this way, for criticism of the external policy of the community is thereby neutralized. This limitation may increase the authority of the committee of deputies in cases where there are very slight chances for the committee to act in concert. But in critical situations former deputies may offer unofficial support to the general line of local politics which they themselves have been instrumental in bringing about. Such a mobilization of support is effective, because the committee of deputies is constantly responsible to the community. The system of deputies is a fairly new institution. It has, however, been incorporated in various ways into the regular patterns of activity in the Sami community. As the above examples show, this incorporation is not achieved without difficulties, but such difficulties may be regarded as entirely natural when foreign types of role are to be adapted to a traditional form of culture.

The opportunities of exerting influence at the disposal of the Sami community have gradually improved since the institution of the committee of deputies as a functioning body. This did not come about until an indication had been issued in proposition 68 to the Parliament in 1962, and SSR had brought pressure to bear. The late date of the institution is regrettable, since it has changed the entire process of resolution in a positive way. In the past, the BO alone was bound to account for the community. He occupied a subordinate position in an authoritative system under which the administration officially represented the Sami community in confrontation with those responsible for a measure of exploitation. Now the Sami community can negotiate directly 
with another part, by way of the committee of deputies, instead of going via the county administration; this gives the Samis greater freedom of action. The institution of a functioning committee of deputies is, in other words, an important step towards improving the situation of the Samis within the wider society. The responsibility for the late date of the institution, in spite of the provisions of $\mathrm{RBL} 1928$, must rest with the authorities. We may regard it as a conscious attempt on the part of the authorities to maintain as unequal a balance of power as possible. Diagram I shows the political implications of the structural change brought about by the institution of the committee of deputies, which represents a significant phase of the general process of change dealt with in this study. The main difference is this: in the past, the administration simply made all decisions concerning the population of the Sami communities in external matters. Now the deputies participate in all such decisions, joined by some party representing the wider society, depending on the matter in hand. And thus the administration is reduced to one such party. - Another difference concerns the election. The administration controls the election of the BO, on the authority of RBL; the election of deputies, on the other hand, can take place without the interference of the administration. The authority of the deputies is thereby enhanced. ${ }^{\text {) }}$

The Larger Society

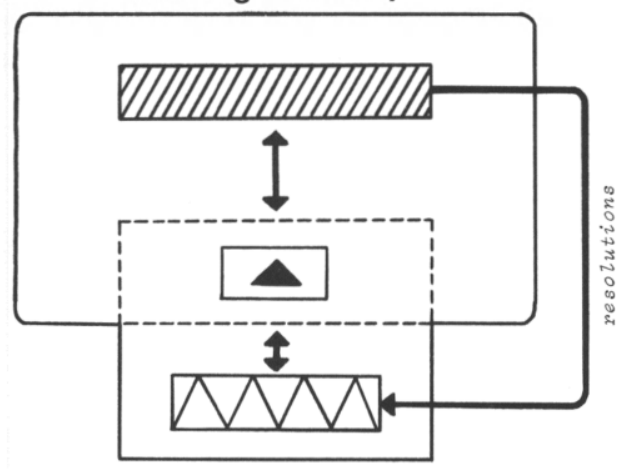

The Sami Community
The Larger Society

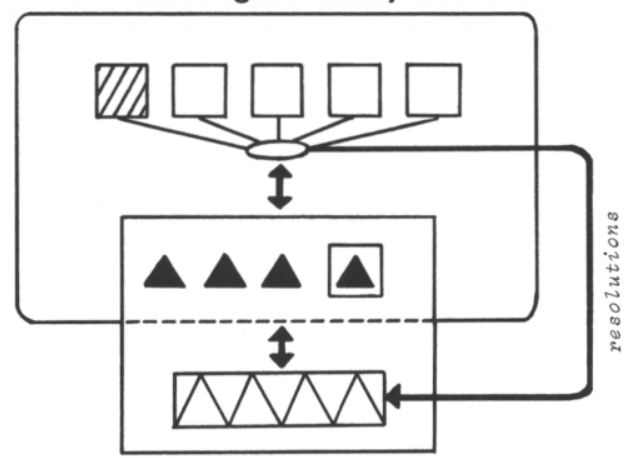

The Sami Community
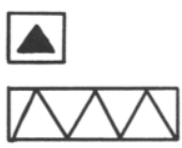

heads of household

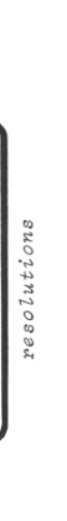


Head of household is the third type of role imposed upon the Samis by the administration. Naturally, every actual head of a household holds this status, but there may also be other active reindeer keepers within the household who enjoy the same status, for instance a brother or grown sons. The most important criterium for recruitment to this status is the number of reindeer owned, but age is also significant. ${ }^{8}$ ) officially the decision as to who is to receive this status rests with the authorities, but often the other heads of household take the initiative to have some young reindeer keeper entered on the reindeer list as head of household, or to have some old man, who is no longer an active reindeer keeper, struck from the list. Thus the situation is somewhat ambivalent, which makes for rather a slow transition. As a result, a situation may arise in which former heads of households, whose names have been deleted from the list, do not necessarily realize that they have thereby lost the right to vote.

This type of principle of recruiting may also lead to instances of unfairness, for a son aged twenty, a member of a family who own many reindeer, may acquire this status, while a son aged thirty, whose family do not own many animals, is denied it. The older man is at least as actively engaged in reindeer keeping, and he is far more experienced, but he cannot participate in decisions made by the community. As a further illustration we may cite the example of a fairly inactive man who has a mere fifteen reindeer, but who still holds the status of head of household in the community, while an active reindeer keeper aged thirty-two, who owns more than 80 animals, does not have this status. The status of head of household is relinquished when pensionable age is reached, i.e. when a man is no longer actively engaged in reindeer herding and husbandry, and also when he takes up some other permanent work instead.

At the 1971 Community Meeting in Sami community Y, the reindeer list was radically revised in this respect. Four young reindeer keepers, aged 20 to 27 , were introduced as heads of households, three of them taking over the status from their fathers. The fourth recruit comes from a town, and is closely related to a family once prominent in this Sami community. We may add that only one of his parents (his mother) is a Sami, but this was 
sufficient to stimulate him into making this choice of career. In this way his family again became part of the community, a fact of which the majority approve.

At the same time, seven men lost the status of head of household. Some of these were reindeer keepers who, because of their advanced age, had gradually reduced their active participation in the work of reindeer keeping, while others had rarely participated in this work during recent years, as they were engaged in other employment. The revision was carried out by the BO, who read through the reindeer list and struck out all the names which ought to be deleted from the list. Then the inspector read out the proposal, which was adopted after some discussion. One of the proposed deletions was not agreed to by all this concerned a very capable reindeer keeper, 55 years of age, who was no longer able to take part in any of the reindeer work except for working within the enclosure, as he suffered from severe asthma. As he was probably the best lasso thrower in the entire Kiruna region (famed in local circles) his present limited capacity was yet significant. Many felt that he ought to keep his status as head of household, as he had done so much for the community in previous years. But they were not numerous enough, and so the original proposal was adopted. This has led to a certain local schism within the community. As a result of this conflict, the later adjustment to the form of organization laid down in RNL 1971 became more difficult. - There was complete agreement about the new recruits.

Those who have taken up some other work, and who thereby lose their status of head of household, also forfeit membership of the Sami community for themselves and for their families. Thus they also lose the special privileges which depend on such membership. But these persons view their own, changed situation in the correct light. When one has deoided to work permanently on the railway, one is not entitled to be head of household at the same time. Now Nila will be herding our reindeer, and it is only right and proper that we should pay him for this work. But we do not want to give up our reindeer - the contact with reindeer keeping is part of the life of the samis. By continuing to own reindeer a man may, when occasion arises, still take part in the collective work of reindeer keeping, and thus one expresses a community of 
values which is independent of the official status of head of household. The members of the Sami community are agreed about. this community of values.

Finally, we may add that most of those who lost their status of head of household on this occasion, have taken the consequence of this and do not attend internal meetings of the community.

Such change of status has a certain economic significance for the individual concerned, for a head of household need not pay for having his reindeer herded, even if he is no longer active himself. For this reason, perhaps rather than for reasons of local politics, the community itself takes the initiative for a change of status when this appears justified. In Sami community $X$, some elderly former reindeer keepers were deprived of their status as heads of households on the initiative of their own relatives. It was considered proper that these old men should now do as one was entitled to expect of them, by paying for having their reindeer herded, as they no longer took any part in the work of herding the animals. The community considered it a good thing that the change should have been brought about on the initiative of relatives.

The status is officially defined in RBL, Community Regulation \$12.9) Here the formal function of the status is made clear, and the fact that this is an important status, well worth while striving for, is emphasized. No one except the heads of households has any influence in matters of local politics. This appears clearly whenever a decision or resolution is proposed. At such internal meetings where important schemes of work are planned, or the community's reaction to some external matter is discussed, some of the active reindeer keepers are excluded. And yet they will frequently have to carry out the work decided on at the meeting,for instance rounding up the reindeer. In other words the fathers decide on behalf of their adult sons, who accept their decision without a murmur; and they show their lack of interest by not attending the meeting. In fact, they can see no point in attending, as they are not entitled to vote. Out in the reindeer pasture land, on the other hand, they are on a more equal footing with their elders, and here the distinction between heads of households and other reindeer herders is less marked. This hier- 
archical form retains a certain remnant of patriarchalism, for all influence is in the hands of a group of senior members whose participation in active reindeer keeping is but slight, while a larger group of active workers largely lacks all influence, even having to take orders from the first group. ${ }^{10)} \$ 12$ would seem to support this hierarchical form.

The above types of role are manifested especially in certain social situations, such as meetings of various kinds. For instance - the BO presides at all meetings of the community, at which internal and external matters are discussed. Only the heads of households participate in these meetings. Moreover, the BO leads the meetings of the committee of deputies, which deal exclusively with external matters. In the practical work of reindeer keeping, in the pasture land and in the enclosures, the differences of status do not appear as distinctly, but the authority of the $\mathrm{BO}$ is, as a rule, accepted.

\section{Non-institutionalized Forms}

We also find certain non-institutionalized forms in local politics, such as, for instance, informal leadership. We are here referring to persons without any formal status who are active in some way or other, and who are looking for support for their actions. Religious leaders may at times convert their position into a source for political actions. Economic contracting may also constitute a basis for informal leadership.

As a result leadership of this type, may at times form factions within the local community. These factions are situational groups, i.e. they become topical in connection with a certain political issue, and they are observable in this context only. Recruitment cuts right across more permanent links such as kinship, neighbourhood relations and $s i i$ 'da relations, but they do not affect the existence of these, in various degree, corporational relations.

The main reason for the formation of factions is to be found in diverging attitudes towards basic sets of values. This applies, for instance, to the attitude towards various methods of reindeer herding - whether a traditional or a more modern form is preferred - or to the attitude towards the property of others - whether one 
considers reindeer theft morally inexcusable, or whether one accepts it in principle. The local attitude towards SSR and the Reindeer Administration respectively may also result in distinct differences of opinion, which may lead to the formation of factions.

Factions are groups in conflict, and they are observable in situations of conflict. ${ }^{11)}$ Where there are discrepancies in sets of values, conflict is extremely likely to arise. The effect of such conflicts on the local community may be of varying duration. The daily routine of work in the reindeer pasture land may be affected, for instance by some form of sabotage. These conflicts may find various expressions: one party may, for instance, decide to put as many difficulties as possible in the way of the work of separating the reindeer by refusing to confirm to the formal rule to the effect that all unmarked reindeer are to be incorporated into the BO's herd. Or one may turn loose one's own. herd, so that the animals mingle with the herd belonging to the other group - if one then omits to herd the reindeer effectively, the two herds cannot be kept apart. In such a case one trusts that the other group will, in their own interest, carry out the necessary work. There is a local term for such sii'da behaviour: speaking of beasts of prey, the other group in this community are also beasts of prey of a kind. A woman related to the BO's sii'da made this still clearer: They cannot understand that they have to help, and now our men have to stay up in the mountains all the time and herd the reindeer. It is always like that. If the $B O$ were to say anything, he would get a flogging! Conflicts such as this can also set their mark on the meetings of the community, with the result that the entire Sami community will experience great difficulty in reaching joint decisions. Everything depends on the leader of a faction, on how actively he conducts his politics.

As an example we may choose the Sami community $X$. The $B O$ of this community is very active within SSR, and his attitude towards methods of work is decidedly modern. He also conducts a great deal of propaganda for his ideas within the community. But now the support for his views is gradually decreasing as a result of the increasing influence of one of the informal leaders, Anta. Anta often visits the others in their homes, 
provoking them against the $B O$ and against the danger resulting from his ideas of modernization. He spends a great deal of time on this, and he knows that his success in persuading the others to agree with him is increasing. At meetings he speaks persistently advocating his own cause, thus putting diffioulties in the way of proposals for reforms. At the annual meeting with the administration in 2968, for example, the $B O$ and the deputies had together worked out a proposal to the effect that reindeer herding should be assigned by rota. The pasture was poor that winter, and therefore the entire herd of the community was being pastured in the mountains. The proposal ouggested that five or six men should herd the reindeer at a time. In this way there would be a greater regularity of work and - the main point - a fairer distribution of work would be achieved. But Anta immediately opposed the proposal, saying that he thought this acquired a smattering of reindeer keepers' association. He was against anything and everything oonnected with associations, and would defend the most important value in the life of the reindeer keeper - his personal freedom. This freedom was now being threatened. A lengthy debate between the two main opponents ensued, and more and more people were convinced by Anta as the debate progressed. Even the depu $\bar{\imath}_{2}$ ) ties began to waver, and the proposal was not accepted.

This example from $X$ is not unique - similar cases have taken place repeatedly. It is important to note that informal leadership of this type plays an important part in local politics, as successful leaders like Anta will always constitute a constraining factor which the BO and the committee of deputies must take into consideration in their strategies.

Such factions are most often caused by sii'da matters. Thus in localpolitical dynamics, the sii'da institution is frequently in conflict with the more official type of institution - this may lead to a durable dilemma for the community. Even though such conflicts are initiated by individuals, they would hardly thrive except for the contrast between these two institutions.

The localpolitical entrepreneur should also be mentioned in this connection. Because of the constantly increasing contact with the wider society, new forms of expert knowledge are called for in order that the Sami community may function optimally in defending its own position. This requirement is met by persons with long experience in reindeer keeping, who have since chosen other occupations within the wider society. After they have completed their higher education, they settle to work in towns or 
other larger societies close to their home community. From there, they return to their original Sami community, where they are active in local politics, not so much for the sake of their own prestige, but first and foremost in order to help. Such work they find highly rewarding, for in this way they can continue to manifest their cultural identity. There are also cases of people who have used local politics as a stepping stone by which to reach a position enabling them later to work for the Samish cause as such.

There was recently a protest action in Sami community $Y$. The protest, which was aimed at an official report, was sent to the government. The brain behind this scheme, a former reindeer keeper from this community - Jouna is now a professional man. He had returned to the community before this incident, and he had quickly become aware of the intense debate which was going on about the proposal in the report. The local unrest and criticism, practically all of which concerned this proposal, inspired Jouna to make use of the mass media to bring this matter out into the open. Now the flame of protest in $Y$ blazed up. Everyone, even in the neighbouring communities, read his article, and some of the heads of households took the initiative for further action by way of legal channels - a writ of protest addressed to the government was to be prepared. Jouna was asked to attend to this, and he found no difficulty in oollecting signatures, for everyone was familiar with the matter, especially after his newspaper articles had appeared. This action had a cumulative effect, for when other Sami communities began to realize the import of the report they, like $Y$, demanded that the proposed legislation be postponed. They were succsssful in this. (Appendix III)

As the heads of households as a rule lack the ability and practice to express their ideas in speach and writing, expert knowledge is required to publish important local debates which would otherwise be of no avail. Therefore Jouna is willing to repeat his actions, if the need for this should arise.

His strategy for many years has been this: after finishing his education, he would apply for work at some central place in the samish region, where he could establish a basis for political action on bohalf of the Samis some of the work was to be of looal character, but he was more concerned with general Samish politios as such. He has been aotive at such a town since January 2972 . His activities in the local press are increasing all the time. He feels that it is of strategic importance to make his name as widely known as possible, and this can be achieved by articles in the local press. It is important that the Samis should know him, but at least as important that 
those in the administration eto. Who deal with Sami matters should also know his name. He has recently attained other positions, all of which enhance his political status: he is now chairman of the Samish cultural organization "Same Atnam", for a few years cashier of SSR, and member of the board of the Samish Folk High School, and a delegate in the "Sami Fund" designed for cultural measures. These commissions of trust give him the legitimacy he requires, as well as stimulating energetic political action. (See also Chapter VIII, Sequel).

Another entrepreneur in a different community has also been active with regard to this report. One will frequently find that specific situations occasion this new type of activity. Many Samis consider it important that men who have left the community should return in possession of new expert knowledge, which the community sorely needs. But activities of this type may often lead to a certain conflict between the formal leaders of the community and the entrepreneur. This is very obvious in the two communities to which we have just referred. We should add that these entrepreneurs need not necessarily be people with a particularly high education; - this role is not confined to professional men, engineers, teachers, etc. - mine-workers with experience in trade union work also possess expert knowledge which may well become just as important.

It thus appears that local politics have gradually developed a greater complexity. This development was set off by the introduction of the modern administrative apparatus, which imposed a number of foreign status positions on the Sami community - BO, deputy and head of household. At a later stage, these positions were incorporated into the organization of the Sami community, some easily, others with more difficulty. But during the process of incorporation, the traditional form of organization, the sii'da, remains. This change involves a bureaucratization of the local units of the Swedish reindeer region. Thus the boundaries of the Sami communities are firmly defined for the first time, a.legal system which includes a special staff of officials has been introduced, and the above local roles have been established.

This bureaucratization has as its political consequence an increased influence of the wider society over the Samis. The 
Sami communities are more closely bound to the sphere of influence of the state apparatus. The increasing competition within the same environment requires, however, that incorporation should be optimal from a local political point of view, like the community committees of deputies. When bureaucratization has developed too far, at the same time as almost paralysing the political activities of the Sami community, a niche for various forms of informal leadership arises. As a rule, such informal leaders appear as a reaction against the increasing formalization of the organization of the Sami community, and thus they may be said to be more closely related to the traditional form of organization than to the status positions discussed above, which are foreign to the culture of the Samis.

But if the local communities are to retain their viability, political organizations on the national level are also essential. The following chapter will deal with the development towards such a form of organization. 
1. This is also confirmed in Solem's study of the legal rights of the Samis, as well as by Pehrson and Whitaker with contemporary empiricism from the Sami communities in Karesuando.

2. The first Reindeer Pasture Legislation (RBL) came into being in 1886. This was then revised in 1898 and 1928. The latter legislation was valid during the whole time this study was carried out. After thorough revision it has been replaced by new legislation in accordance with a 1971 Government Bill. (See further Chapter VIII).

3. The paragraph in the RBL that designates the limitations to the role of the BO is particularly interesting and merits being quoted in its entirity.

$R B L$ paragraph 23.

1. In a Lapp community there is to be a community headman who is elected from among the reindeer herding Lapps themselves at a meeting held in the presence of the County Council officer in charge of Lapp affairs or the distriat police superintendent depending on who has been appointed by the county Governor.

The County Governor is to be immediately informed of the election by the person in the presence of whom the meeting has been held. The county Governor is to assess the elected person's suitability for the post, and should he be considered suitable, to appoint him or otherwise to demand a new election.

The headman is appointed for a period of six years and has the right after two years, or even earlier if there are valid reasons, to be released from his duties by the county Governor. He is, however, obliged to oarry on his duties until another headman has been appointed by the County Governor.

The headman may be removed from his office, should circumstances warrant this, before the end of the stipulated period, by the County Governor.

2. The headman should see that the laws in force regarding reindeer herding as well as the Lapp community are observed, and in addition he should follow directions issued by the county Governor. The headman enjoys the protection and is bound by the responsibilities laid down in the regulations concerning civil servants. The headman is to be reimbursed from public funds in accordance with current regulations.

4. In one of the Sami communities the BO's authority has to a large extent been undermined because the heads of households could not accept the wife's active interest in the leadership of the BO. Now that a new BO has taken over he immediately explained to his wife that she was not to interest herself 
in men's affairs because that would weaken his position in the community. With regard to authority see also Svensson 1969 a that, amongst other things, deals with the interplay between formal and informal leadership and their implications for the BO.

5. Different types of middle-men occur in many colonial and post-colonial contexts, particularly in Africa. In addition to Max Gluckman, who has written quite widely on this subject, in particular 1965:165 and 1968, F.G.Bailey has developed this theme, most recently in the book Stratagems and Spoils, 1969. Faller's article from 1955 should also be mentioned as well as the joint statement of Gluckman, Mitchell and Barnes in 1949.

6. This proposal had already been put forward by the BO at an internal community meeting in 1957. On that occasion the matter raised scant interest and many felt that such a body was unnecessary since it would only result in more officials. In addition the heads of households would lose all rights of determination.

At a community meeting in 1962 the matter was discussed again after having been instigated by Government Bill no. 68, 1962 . After intensive discussions the votes cast for the committee of deputies numbered 21 and against 20 . Of the remaining people entitled to vote 4 abstained and 4 were not present.

At the 1963 annual community meeting the matter was, for the first time, put to the vote officially. The voting was 17-9 against the proposal. One of the reasons for this opposition was that it was thought that the committee would have too much power and there was general opposition to the concentration of power.

The lst inspector (chairman of the meeting) urged the community to reconsider this important question and try to reach agreement on this question of representation in accordance with contemporary demands.

The following year the proposers for the setting up of a committee won by $11-9$ with one abstention. The low number of votes cast at this annual meeting, approximately $50 \%$, was remarkable. On this occasion the SO (Sami ombudsman) was also present and spoke of the importance of the committee.

7. See further note 3 on RBL paragraph 13, section 1, second paragraph.

The committee's authority is limited, however, by the following clause in the Community Regulations' 13th paragraph, where in the last paragraph it states that If the County Council officer in charge of Lapp affairs or supervisory offioer is present when the committee meets, he takes the chair. This formal restriction can be avoided by ensuring that all meetings take place when the administration's officers are not present. 
8. The majority become heads of households at marriage or when they establish their own household. Others can become this when they are adult sons in a household owning many reindeer. It can, in some cases, take place at the death of a father or mother, or more unusually when a father retires.

9. Community regulations 1946, paragraph 12. At the election of a community headman or committee deputy, it states in paragraph 13 that in questions concerning reindeer herding and the administration and disposition of the community's funds, those allowed to partioipate in voting are samis who, either as head of household, or through members of their household, carry out reindeer herding.

10. In one community with only 9 functioning heads of household, four of these have adult sons and none of these are heads of household. One of the sons is over thirty while the other three are 25 years old. The fathers, who are somewhat passive reindeer herders, have complete influence over the community's decision processes. In addition the community has a further six passive heads of household, half of them pensioners and the other half occupied in other trades. The practical consequences of this is that many of the community's active labour force do not have any opportunity of influencing the elections to such important positions as the BO or the committee.

11. According to Nicholas this is one of the main criteria of factions. Factions are confliot groups. In fact, it is during social conflict that factions emerge out of a sociologically undefined background to give the observer a view of their personnel. (Nicholas, 1965 and 1966). This view goes back to R.Firth's definition at a symposium on factions. (Firth, 1957).

12. During this debate the BO made 11 contributions, of which two were very long. Anta made 14 contributions, many of these in anger and with a great show of temperament. A further 13 contributions were made supporting Anta's position, while only one head of household with three contributions participated on the BO's side. During the debate, which went on for several hours until the lst inspector thought that the matter had been sufficiently discussed and that the meeting could continue, several of the heads of household went out into the corridor every now and then. At one stage 8 people were outside discussing in the corridor. It was also there that the committee members explained to the other heads of household that they did not support the extreme view of the BO. They held the opinion that he had gone much further than the agreement that had been reached earlier. 



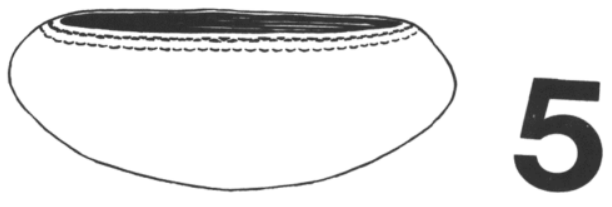




\section{The developed political form}

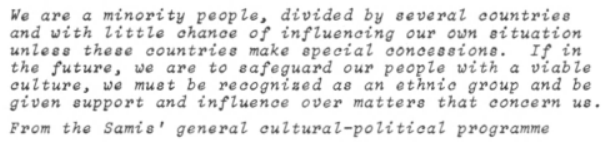

As the contact with the wider society grew, the system of which the Sami minority formed part proved to be increasingly ineffective, especially for the purpose of safeguarding the interest of this minority. On their own, the individual Sami communities were not sufficiently strong to be able to enforce their demands. Moreover, it was extremely difficult to canalize such demands and problems to the national level. Such attempts were made, by individual persons and by the Sami communities, but as a rule they were referred back to the respective local administration. In other words - there was no effective means of circumventing the local and regional administrative system. As the pressure exerted by society grew heavier, thereby essentially changing the ecological conditions on which remunerative reindeer keeping is based, channels allowing of constant contact with the national authorities had to be established. An organization uniting all the Sami communities would be the best way of solving this problem, and in 1950, Svenska Samernas Riksförbund (The Swedish Sami Union - $S S R$ ) was therefore founded. Its foundation was, however, preceded by a long and arduous struggle. Below, we shall first give a brief survey of the events preceding the foundation of SSR. Next, the structure of the organization, as well as its recent political development will be studied in two separate sections. Finally, we shall discuss some of the most important features of the ideology which SSR represents.

\section{A. Historical survey ${ }^{l)}$}

The prelude may be divided into two stages, the first of which is marked by the authorities' extreme opposition to any 
form of organization, while the second saw a gradually more positive attitude on the part of the authorities, especially at the national level.

The first association of Samis, the Vilhelmina-Åsele Sami Association, was founded in 1904. Its foundation was a result of the increasing pressure, exerted particularly by the settled population. Several attempts, in the form of individual writs to the Government, had been made at criticizing the development taking place, which was extremely serious from the point of view of the Samis. But these actions simply faded out after having been caught up in the bureaucratic machinery; and it became clearer that no result could be achieved in this way. The organizations and unions which grew up in the rest of Sweden during the latter half of the nineteenth century now inspired the Samis to form a local association. This initiative met with immediate opposition, and two of the leaders were before the Lord Lieutenant, who urged them most seriously to abstain from forming an association. ${ }^{2}$ )

The committee which had been appointed consisted of seven persons - two reindeer owners and five younger people intending to train for various professions at a later date. Two were later to become teachers, one a lawyer, one a clergyman and one a Salvation Army officer. These people were to form a nucleus for the further struggle for Sami organizations; all of them were to become members of the board of Lapparnas Centralförbund (The Central Union of the Lapps), and some of them continued into SSR.

The first national meeting was held in Ostersund in 1918. A member of the Swedish Parliament, Carl Lindhagen, who felt that the Samis ought to have the chance of jointly expressing their view on the 1917 proposition concerning RBL, took the initiative for this meeting. At the meeting it was resolved that a national union be formed, Lapparnas Centralforbund. A Samish newspaper, Samernas Egen Tidning - The Samis' Own Newspaper SET was also started, with one of the members of the board acting as editor. Two prerequisites were absolutely essential if the Central Union were to be able to exist and work: it required economic aid from the state, and active support from the Samis themselves. For five years, intensive work was carried out in order to further the cause of the union, but it became clear already in 1923 
that a national union was an impossible proposition. The Samis were simply not interested enough: there was, for instance, not a single Sami association north of Arjeplog. Moreover, the authorities refused all applications for economic aid.

The result of the 1918 initiative may briefly be summed up as follows: SET survived the crisis - it still appears today, under the name Samefolket (The Samish People), and nine Sami associations had been formed at that time.

The second stage started with the official Sami investigation of 1930, the report of which was submitted in $1935 .{ }^{3)}$ Just as had been the case on earlier occasions, no Samis were included in the committee responsible for this report. A second national meeting was therefore called in 1937, at Arvidsjaur, to give the Samis an opportunity of expressing their views on the report. The committal reply given by the Samis after this meeting led the authorities to realize that the proposal must be revised. The Parliament then resolved that a new committee be appointed, the Berlöf Committee of 1939-44. The proposals of the report prepared by this committee included one to the effect that the Samis should be given the opportunity of expressing their views at general meetings on matters of general importance to them, and this was later ratified by the government and the Parliament. In this way the wider society lent a certain legitimacy to further attempts at establishing a nation-wide organization.

The national meeting also appointed a committee of three persons, who were to attempt to create a national organization. Two of the members of this committee had worked for the cause since 1904. No result was achieved, however, and the committee was dissolved in 1940, when one of its members died. But several more Sami associations had been formed in the meanwhile, and the idea was beginning to gain a foothold also in the northern districts, for instance Jokkmokk, Gällivare, Jukkasjärvi and, finally, Karesuando.

Another national conference was held in 1948. The occasion was the 1947 report on meat inspection. The editor of SET acted on his own account in this case, as he had by chance got hold of the stencilled report. At extremely short notice he called a national meeting for February 26 th and 27 th, and a committal 
reply was ready before the time limit stipulated - March 15th with the result that the proposal could be stopped in the Parliament. This was a matter of general interest to all the Samis, and it was only by pure chance that they were able to contribute to the framing of a legislation which would be better adapted also to their interests. This occasion confirmed that the Samis needed a joint organization which would constantly watch over their affairs at the national level.

A new committee was therefore appointed at the 1948 national meeting, the Samish people's working committee, which consisted of Gustav Park, a clergyman who was editor of SET, the nomad minister Arvid Kaddik and the principal of the Sami Folk High School, Lennart Wallmark, teol. kand. - the latter is not a Sami. It will be seen that the committee was entirely dominated by religious representatives, and this was to some extent manifested in its ideology right from the beginning.

This working committee was to function until the next national meeting. Its work included propaganda, in the field, for a national union. This time the propaganda was started in the Sami communities, where the BO was asked to support the cause. After this, a statutory proposal was drawn up on Oct. 5th 1948. Two additional members had been co-opted for this purpose, I. Ruong, inspector of nomad schools, and N.P. Stenberg, reindeer owner. The next national meeting, which was held in Jokkmokk in 1950, resolved to establish itself as Svenska Samernas Riksforbund. It also accepted the statutory proposal, although with some modifications. The union was to consist of Sami communities and Sami associations, and its work was to cover four important sectors: the economic, social, administrative and cultural sectors with we quote, special regard to the continued existence and sound development of reindeer husbandry.

Now the struggle to establish an organization had met success, and the first step towards asserting the position of the minority had been accomplished. The following section deals with the structure of the national union. 
The Structure of SSR

The board of SSR consists of seventeen members and the same number of deputies. It forms the executive and administrative body of the union, and its members are elected for a term of three years. They, in turn, elect the leaders of SSR, the chairman and vice-chairman, from among their own number. Further, there is an executive committee ( $A U$ ), consisting of the chairman, the secretary, and two other members of the board. ${ }^{4}$ ) A three-day national meeting, at which important sami problems of a general type are discussed, is called every year. The Sami communities and Sami associations send delegates to these meetings, at which the right of decision rests with the assembly of delegates. This assembly thus also lays down the policy to be effected by AU and by the board during the period between meetings. The initiative for such policy is, however, as a rule taken by $A U$ and the board, after which it is confirmed or rejected by the delegates.

This, then, is the general framework of SSR. If we study the persons who have held various positions within the organization, we shall be able to trace the changes which have taken place since the formation of the union. The general tendency is that leadership has passed from educated people with religious connections to educated people with secular professions, and then to reindeer keepers. In 1967 SSR was still led by an academic and two teachers - today reindeer keepers dominate the picture. All except one of the four chairmen are reindeer keepers, and the one who is not a reindeer keeper has remained on the board from an earlier term.

This is an entirely logical development. The main concern of SSR is that group of Samis who are involved in reindeer husbandry. This aim was already formulated in the first declaration of programme in 1950. (See above). Thus it is only natural that the leading positions within the union should be occupied by reindeer Samis. This became possible when an increasing number of reindeer Samis joined SSR and thus gained experience of organizational work. The people who occupy the leading positions today are autodidacts, with little formal schooling. This change in personnel is important as concerns making official Sami politics known at the local level. This status of reindeer keeper is often empha- 
sized at the national meetings, as shown by the following brief quotations :

I am a reindeer owner myself, from a small Sami community. I am very interested in this matter, as I am a reindeer owner.

We who work in reindeer husbandry are very concerned ....

As I said yesterday, I am a reindeer owner myself, and I work at reindeer harding every day. I have also experienced severe wolf years, when we had to keep watoh day and night, so I understand these problems.

As an active reindeer herder, I should like to put forward some brief views on tourism.

We who work at reindeer herding ....

At the same time, the formal status is undercommunicated. (Goffman, 1959:141). This marking of status is certainly important when a policy is to be endowed with legitimacy. But the possession of such formal status positions is marked in another way - the incumbents wear a strict grey suit, instead of the Sami costume. When these people were still delegates or members of the board, they always wore the Sami costume during the national meeting, but now they wear it only very sporadically. This is entirely situational, and adds to the overcommunication of the status of reindeer keeper. In this way, a certain visual difference between the presidency and the assembly of the delegates is also made apparent, for the majority of the latter wear the Sami costume. As many Samis consider the members of the presidency to be men only carrying brief cases, this overcommunication is called for.

The board is elected by the assembly of delegates. Each group of three Sami communities elects a member and a deputy, and three other members are elected by the Sami associations - these represent those Samis who are not concerned with reindeer keeping. The region investigated is thus represented by four persons in an influential position in SSR.

Recruitment to the board frequently takes place as follows: first a person becomes well-known as a delegate, and then he is elected deputy-member or member of the board. The composition of the board is fairly stable, especially as concerns the regular members. During the period 1961-1970, seven out of seventeen were elected three times, and from 1964 to 1970, another six were elected twice. The deputies are not as constant - only two of them remained on the board throughout the longer period and three were re-elected during the period covering the last two electoral terms. 
The turn-over is greater among the reindeer keepers than among the other members: for instance, the seven regular members who were active throughout the 1960's include all the three non-reindeer Samis - these, moreover, constitute an older elite within SSR. We may add that two of the regular members and two deputy members have been active on the board since 1950 .

The policy of recruitment is designed to produce as strong a representation as possible. Towards this end the election of representatives from communities which have shown little interest is encouraged, for in this way a closer link may be established between the Sami communities and SSR. A stronger personality and a better organizational representative may be sacrificed in the process - this happened in one of the norhternmost communities. The deputy from the next northernmost electoral district in $\mathrm{X}$ was not re-elected, because it was considered more desirable that an active interest in SSR should be aroused in community $Y$. This latter Sami community seemed to be on its way out of SSR, and in this way one hoped to be able to bind them to the union. This was a conscious strategy, intended to make SSR into a united organization of all the 44 Sami communities - various other strategies have also been employed in the hope of achieving this aim. But the above measure was not a success: the deputy elected from $Y$ has shown only very little interest in the national meeting, and the Sami community as such is still not particularly interested in SSR and its work. In the end it was therefore felt that it would be better to have the representative from $X$, for he was an asset to the board. Community $\mathrm{X}$ is traditionally extremely interested in SSR. When the board was elected in 1970, a representative for the southern electoral district was again to be appointed. The time was now considered ripe for including the representative from Sami community $X$ as a regular member. But the representative from $Y$ was retained, and an experienced and very interested member of the organization, from community $Z$, thus had to leave the board. The same also occurred in the other electoral district, where the representative of community $\AA$, which has a positive attitude towards SSR, was superseded by a representative from $\AA$, extremely passive in these matters. Thus it is not merely a case of procuring the best possible persons - representation must be 
as broad as possible, and this end it is at times difficult to attain.

Finally, local representation is manifested by every local entity sending delegates to the national meeting. These delegates are elected for three years. Only one of the six communities in our region has a poor frequency of attendance at the assembly. On the eight national meetings held between 1962 and 1970, Sami community $Y$ has been represented at only four. Three of the communities have taken part in all the meetings, most of them with two delegates. The two remaining communities have been absent once each, but they too have on several occasions been represented by two delegates. We might add that the Jukkasjärvil Kiruna Sami association has participated on six occasions, being represented by more than one delegate at half of these. Thus we may regard the active interest in SSR in the region investigated as being very great - with one exception.

Criteria important in the election of a delegate are competence in the Swedish language, an active interest in the work of SSR and representative capacity - i.e. the delegates to the national meeting must represent the attitude of the majority in their home community. Another criterium is the status of head of household. One of the six communities had a delegate without this status for two electoral periods: this is unique in the entire Samish region, and leads to certain status discrepancies. But it does not involve statutory breach, and offends only against established practice. Such a delegate thus has the formal right to represent his community at the national meeting, while he is denied the right of participating in the internal resolutions of the community.

It may be an advantage to elect a member of the board as delegate, as he will be very familiar with the preparatory work for the national meeting. In one of the communities, the representative on the board wanted to refuse candidature as delegate, but the majority asked him to stand for election. The other delegate pointed out how important it was that Inga should be elected, as his expert knowledge as member of the board would give also him a stronger position, as he would then be able to obtain Inga's support in difficult matters during the whole national meeting. 
The members of the board usually take an active part in the election, in order to make sure that the people best from the point of view of SSR are elected. They are, in fact, tactically acting for the right delegate. If they take exception to the result of the election, they may even, by means of various manipulations, have it declared invalid. At times it may even seem preferable not to be represented at a national meeting rather than represented by an unsuitable delegate. The administration may also be employed as a resource when election takes place at a Community Meeting. One can then speak to the chairman of the meeting beforehand, and ask him to be quick with the mallet so as to prevent the election of the wrong persons. $\left.{ }^{5}\right)$

In other cases, younger people have been substituted for older ones. Another tactical move is that of trying to appoint local leaders of different types, for instance a BO who is not interested in SSR or the leader of a faction, in order to neutralize their local authority in matters concerning the relations with SSR, if their attitude towards the organization should be negative. It is important for the Sami community that these people should be kept up to date, so that they may learn to see the problems of the Samis in a wider perspective. Further, it is considered important that the turn-over of delegates should be fairly rapid. In that way, this new form of communal feeling feeling for ethnicity in the wider sense of the word - is spread, and that is still fairly new among the Samis. (Eidheim 1971).

There is not, however, complete agreement as to the desirability of a rapid turn-over. A delegate with long experience has routine and an exclusive expert knowledge. He knows the channels by which information between the board and the local community should be transmitted, and he has initiative in the matter of activating his own local community. He is therefore disinclined to renounce his status. - At a meeting of a community, held in a tent at the summer quarters, the agenda included the election of delegates. There was some discussion about various candidates - everyone, except one of the two delegates then serving, took part. He had staked a great deal on the extraordinary national meeting in Ostersund that year, and counted on representing the community on that important occasion. He was taken 
completely by surprise when his name did not come up during the discussion, and he therefore chose to sit through the meeting in silence, whittling at a piece of wood and giving the appearance of being completely indifferent. (Reindeer Samis resting in the tent or by the camp fire usually whittle a piece of wood without any special purpose.) The individual in question chose on this occasion to find a kind of back stage, and that is not easy to find in a tent crowded with people. (Paine 1970).

Many delegates wish to continue this work, partly because it gives them a certain prestige to represent their community every year, partly because they find it very pleasant and interesting to travel to the national meeting and meet people whom they would never see otherwise, to exchange views and experiences. The interaction on the micro-level, in the corridors, at lunch and in the hotel rooms, is at least as important as the actual sessions, for in this way one may gain many new impulses to be passed on to the local community. As the importance of the traditional church holidays decreases, the wider significance of the national meeting increases, not least as concerns the young Samis, and these are now getting more and more interested in attending the meetings. The Sami dance, for instance, which is always held in connection with the meeting, is important for young delegates and old. The growing interest has led to that steadily more people attend the national meeting at their own initiative, even taking part in the discussions, although they obviously cannot vote. Thus the national meeting is important not only from a political point of view - it is of great social significance for the participants.

Generally, we may say that the national meeting is the parliament of the Samis. All SSR measures of general interest must be approved by the national meeting after an open debate. The work carried out during the year must also be checked by the assembly of delegates. Finally, the individual delegates may, on behalf of their Sami communities, propose motions at the national meeting and thereby enjoin to united action. Thus, as a body the national meeting forms a significant resource for the Sami community in its interaction with the wider society. Every national meeting results in a number of resolutions, which are then passed to various national authorities; and by way of the national meeting, the possibilities of direct contact with the important authorities of the wider 
society in matters of Sami concern have been institutionalized this is a new feature in the political organization of the Samis. The Samis themselves took the initiative for this attempt at establishing a platform for a more effective protection of the position of the minority. The national meeting is, therefore, an important component of the changed political form.

\section{Organizational Development of $S S R$}

At the beginning, SSR was not a politically strong organization. Various attempts at political activity were restricted, mainly by the authorities, but also internally. The restrictive intervention of the authorities is a result of the view, then obtaining, that SSR was an unpolitical organization, i.e. a body which by definition was precluded from taking part in this game for power. The lukewarm interest shown by the Sami communities during the introductory phase also added to the difficulties of the national union.

This restrictive aspect may be illustrated by the following example: In $1954 \mathrm{SSR}$ convened a committee consisting of four reindeer keepers, the appointed representatives of SSR, to investigate and report on the question of slaughtering. In 1956, the authorities intervened, and reformed the committee so that persons with relevant expert. knowledge, veterinary surgeons etc., and a couple of bureaucrats now constituted the committee, together with two reindeer keepers. The Samis considered the composition of the new committee acceptable, but they also pointed out that the two reindeer keepers should be selected from those on the SSR committee. ${ }^{6)}$ - This case illustrates the authorities' lack of confidence in SSR as a body representative of the Sami minority. The administration always reserved the right to select even the Sami representatives. This method of appointing representatives for investigations and reports was repeated many times, most recently in 1964, in connection with the important Reindeer Husbandry Expert Committee. (See chapt. VIII).

The aspect of internal restrictions may be illustrated by the case of the committee of five, appointed by SSR in 1955 in order to investigate and report on the matter of water regulation. The purpose of the committee was that of safeguarding the 
interests of the Samis, and it was to be empowered to prepare and act in court cases concerning hydro-electric exploitation. But no authority had been received from the Sami communities, by 1956, and thus the committee was unable to function. The intention had been that the Samis should act in concert through their national union, and not as individual Sami communities, for on several previous occasions unfavourable agreements had been reached between the $\mathrm{BO}$ of a community and representatives of the Swedish Hydroelectric Company. Their later consequences were far-reaching, as the legal status of the Samis could not be adequately upheld by such private agreements. This example illustrates the difficulties SSR had in order to work through its ideas to the grass-root level during the initial stage of its existence.

But in some cases SSR constituted an asset even at an early date. Conditions in the two northernmost Sami communities were extremely precarious at the beginning of the 1950's. Communities $\mathrm{Kä}$ and La therefore commissioned one of the delegates to the national meeting to try to get SSR to take up the matter. The help of SSR and of the national meeting was essential if a solution were to be found reasonably quickly. The representative proposed a motion in 1954 and one in 1955, and he was extremely persistent. In 1955 SSR appointed a committee, which was also sanctioned by the authorities. A proposed solution was submitted in 1956, and this local initiative had thus confirmed the capacity of the national union as an institutional asset in the matter of realizing certain local measures.

But SSR was only to a limited extent instrumental in improving the legal status of the Sami minority. Such improvement could not be fully achieved without constant access to legal experts. The Samis realized this at an early stage, and at the national meeting at Arvidsjaur in 1948, they demanded that a counsellor be appointed; (Minutes Arvidsjaur, 1948:74-75) the appointment was not, however, effected until 1962. In that year a legal counsellor, SO, was attached to SSR; at the same time the Stockholm office of the national union was also established. ${ }^{7)}$ Thus SSR is now able to keep an eye on all events at the national level which affect the life of the Samis directly or indirectly. This is extremely important. Moreover, the legal status of the 
Samis in all cases of exploitation of any significance can now be tried. Thus a new phase in the history of the Samis had begun, one involving the development of SSR into an influential organization. ${ }^{8)}$

Ideally, the $S O$ is a person who acts on behalf of SSR or of any individual Sami community. The official policy with all details is determined by $\mathrm{AU}$ in accordance with the resolutions of the board and the national meeting. We must add that the so takes part in the continuous work of AU, and therefore his status is not non-political in the sense that he lacks all influence in the decision-making process.

Most important is the So's strictly legal work, which will be discussed in more detail in the section dealing with the political processes. But his work also has a general aspect, and various actions and initiatives connected with this demonstrate the importance of this institution with regard to the relations between the Samis and the wider society.

The following example will serve to illustrate a new form of interaction institutionalized by the $\mathrm{SO}$. The relations between the two Kiruna communities $R$ and $L$ and the town of Kiruna were in the past always attended to by means of direct contact. The Samis were always in a weak position in such negotiations, and they had great difficulty in asserting their own interests. These relations became more complicated when the so had been appointed. In the mid-1960's special measures to secure the future of the Samis in the Kiruna district were required because of the expansion of the town, and it was important that agreement should be reached on these measures; a committee of two was then appointed on the initiative of SSR, in order to enquire into the conditions then obtaining. This committee was then in constant contact with the SO and with representatives of both the Sami communities concerned. The so also maintained direct contact with the appointed representative of each of these Sami communities, men who were also active in SSR. The committee supplied the so with data before negotiations between the SO and the appointed representative of the town of Kiruna were entered upon. It is quite obvious that this new form of interaction considerably improves the position of the individual Sami community in confrontation with as strong a party as the town of Kiruna. 
As concerns RBL \$56, the SO wrote a letter to the Lord Lieutenant of Luleå on 29th May 1967, pointing out certain deficiencies in the practice of this paragraph by the administration. Further, the SO wished to attend the Community Meeting when important matters of usufruct were to be discussed. In this way he would be able to assist the Sami community when important resolutions of legal significance were involved. This is of particular importance in the Kiruna district. A series of actions of this type shows that the Samis are no longer passive in confrontation with the changes caused by the wider society - now their attitude is on the offensive. Not only is their power as a group enhanced by this, that of each local community is also increased. These examples illustrate the significance of the $\mathrm{SO}$ as a resource potential in local politics, but his status is still more important as an asset on which to base joint actions of Sami politics.

The strategic position of the SSR office in Stockholm makes effective lobbying possible, and it also enables the union through so to maintain a constant contact with certain members of the Riksdag who may submit motions serving the interest of the Samis, and with the central bureaucracy. The latter is extremely important, as relevant information must always be obtained at a date sufficiently early to permit of action; in this way, one can also keep the bureaucracy informed of the actual conditions under which the Samis live.

All Sam is do not agree with the placement of the SSR office. Many Samis have therefore repeatedly suggested moving the office to some town in the nuclear Samj area. In that way the office for executing Sami policy would geographically be closer to the Sami grass-root level. This point is certainly valid regarding the possibility of increasing folk mobilization; the draw back thereof is, however, diminishing opportunities for lobbying etc. at the national political level. (Cf. Minutes from the National Meetings 1971-1976).

A new political form has thus been established, one differing radically from its predecessor. For the first time the Samis are able to maintain effective channels of information with all levels of the wider society. This strengthens the position of SSR, and 
as a result the support from the local communities increases.

It will be seen that the work of the SO has been successful, although it has led to a certain shifting in the internal distribution of power within SSR. Today the SO is very influential, and he frequently acts on his own initiative, informing/consulting the board after the event. This is mainly an outcome of his superior expert knowledge. Moreover, he alone is at the centre of events, where he can constantly keep an eye on all occurrences that may affect the relationship with the wider society.

The matter of his dominating power position was discussed in much detail at the most recent national meetings. (See agenda 1970, 1971). Some maintained that other sectors should, in scope, be placed on an equal footing with the legal sector. The so, supported by the majority, defended himself by saying that the legal struggle must be given priority, as it had been for the past ten years. He maintained that this was the only way in which one could continue to act effectively also within other spheres.

As SSR is gradually able - perhaps mainly by means of legal actions - to exert greater influence than previously, the Swedish majority has become more aware of the Samis as a group with a claim to their own rights. In this way it will be possible for the SSR office to expand its field of activity, increasing its personnel with various kinds of expert knowledge. Many consider it obvious that the recruitment of Samis with the desired expert knowledge is an asset. Such recruitment of experts is at present possible as an increasing number of Samis experienced in the basic Samish occupations now choose to study. This trend may be regarded as an adjustment to the general expansion of education in Swedish society, an adjustment which must, however, also be interpreted as having been enforced by the increasingly difficult conditions under which the reindeer keeper works. The effect of this adjustment is propitious, for in this way the Samis as a group gain diverse expert knowledge from among their own ranks. Thus the Samish minority as such will in future have a better opportunity of asserting its ethnic characteristics in continuous interaction with the wider society.

Another form of criticism aimed at the $S O$ emanates from local conditions. The Sami communities want more contact between the 
So and the individual Samis - such contact they consider to be not only desirable but in fact essential. The so himself has declared the dilemma thus caused, for instance in an exhaustive interview published in 1972, which dealt with the SO and the SSR office (SET 1972:4). The SO is hardly in a position to fulfil these demands of the communities, for his main work as legal counsellor takes most of his time - $75 \%$ of his working hours are spent in dealing with court cases.

The strategy characteristic of SSR's new activities may find various expressions. In some cases, for instance, SSR attempts to neutralize unwelcome criticism from the Samis themselves. Further - SSR is working to have a professorial chair in reindeer research established; this should ensure authoritative testimony for the Samis in lawsuits. Another new feature is the travelling engaged in by members of the board who, like the so, now take part in various Community Meetings. In some cases they can be of assistance to the heads of households in matters of principle, before any decision is made.

At the 2968 Community Meeting in $z$, Nilsa attended in his capacity of representative of SSR. In this capacity he intervened in a discussion concerning the erection of a TV pylon. Nilsa maintained that legal action should be avoided if possible, and that one should instead demand that the Board of Telecommunications contact the Sami community.

"At a Community Meeting one must not pass resolutions requiring the support of the administration. I am intervening because this is a matter of principle. The exploiting party must investigate and report on the damages, and the community must stipulate conditions which will prevent any disturbance in the work of reindeer keeping. At meetingssuch as this I must, as the representative of $S S R$, try to settle questions like the present one, so that lawsuits may be avoided. One must work with this end in view right from the beginning."

He was immediately supported by the member of the board of SSR from Z. The heads of households were persuaded by Nilsa's words, and resolved to support the proposal he had submitted.

In this way the whole Sami community learns to tackle new problems in a strategically advantageous manner, which is important in the Samis' gradual adjustment to participation in the wider society.

A brief account of the national meeting especially the forms 
of action and expression that characterize this institution at present is also called for at this stage. Since 1963, all the debates at these meetings have been recorded on tape, from which the minutes are then printed. As a result, most of the process leading up to a resolution can now be documented. Resolutions are arrived at in the following manner: First the board prepares the matter in hand, which is then subjected to a general debate by the assembly of delegates. Not infrequently the board may modify its proposals after this debate, but often the proposals of the board are accepted rather too quickly, which is largely due to the fact that the members of the board are infinitely better prepared than the delegates. True, the convening notice together with the agenda is now sent out about a month before the meeting, so that the delegates in fact have plenty of time to study the matters to be discussed, but they frequently lack the resources necessary for gaining information on complicated matters, and so they appear at the meeting more or less with a blank mind. This is one of the main problems of SSR - how is information to be canalized between the board and the local representatives? In principle resolutions are passed by the delegates, but as relevant expert knowledge is required to prepare the resolutions, one will in practice frequently find that the assembly of delegates accepts the proposals of the board. The influence of the board is therefore very great. ${ }^{9}$ )

This influence extends also outside the assembly room, for some of the members of the board try to influence the individual delegates in the corridor and elsewhere. The matter in hand may be the preparation for some election or other, for instance to the board; but some other particularly important matter, for example that of the attitude to be adopted on the new Reindeer Husbandry Law, may also lead to activity of this kind. This is an expression of a strategy connected with the idea of a united national union. Of course it is in no way unique; this practice is in fact common in all organizational activity. The interesting aspect lies in the fact that here, too, the Samis have copied forms of conduct belonging to the wider society. (Cf. G.Heikka, Antropolognytt, 1969, Vol. 7:4). 
The national meeting as an institution is of particularly great importance, and it has added vitality to the Samis' general minority policies in many ways. The Samis therefore argue that their meeting should be given official recognition, like the parliamentary assemblies of the Faeroes and of $\AA$ land. This type of argument, which places the Samish complex of problems into a wider, international perspective, is also fairly new. A similar strategy has been employed in attacks on the Kammarkollegium, the Treasury Board for the rating of Government Property. The fact that this Board represents the Samis in the matter of their rights to land and water is considered to constitute a violation of the European Convention of Human Rights, for this convention states that everyone shall, when his civil rights are to be tried, be entitled to a fair and public hearing by an independent and impartial tribunal, and no one must be denied the rights defined by the convention because of his membership of a national minority.

The UN action of the Gällivare Samis must also be considered in this context; although it was not effected through SSR, it adds still more emphasis to this process of internationalization. ${ }^{10}$ )

The national meeting can also act as a stimulus to the formation of new political forms of action, as exemplified by the communal cooperate institution which was established in Kiruna in 1973. The first formal contacts were established during the national meeting of 1971, which was held in Kiruna. One of the main topics discussed here was the problem of the Samis in Kiruna, and the greater part of the debate was devoted to this question. This cooperate institution includes all the Sami communities in the district of Kiruna (i.e. the six communities discussed in the present work and the forest Sami community of Vittangi), and the numerically strong Kiruna Sami association. It is still too early to assess the importance of this institution, but the Samis consider such a body to be essential for close interaction with the wider society in the future.

We pointed out above that SSR is also striving to influence the political parties. No one party is traditionally favoured; but if a party chooses to concern itself more seriously with the Sami question than others, the Samis consider this an asset, first and foremost because the result may be a general debate in the 
Riksdag. This development of the political organization is important, and SSR cannot accomplish it alone.

SSR took a lead in this direction in the spring of 1970, on the occasion of an attendance on the government, who were asked directly whether the Social Democrats, as a party, were willing to include the Sami problem in their platform for the 1970 elections. But the government dismissed the idea, for its policy was in principle designed to arouse the interest of as large a majority as possible. The matter was in its entirety reported in the press, upon which one party - Folkpartiet (The Liberal Party - FP) - reacted. On the initiative of its leader, G. Helén, FP appointed a committee in the summer of 1970, who were to prepare a report on the topical problems of the Samis. The committee consisted partly of members of FP's Riksdag group, partly of Samis, a total of thirteen persons. Seven of these were Samis, four of them reindeer keepers and three younger professional men. We may add that some of the Samis also belonged to the elite within SSR. Half a year later, in January 1971, the committee submitted its report. The title was: The Samis - A Forgotten Minority, and it consisted of twenty stencilled pages. In content it agrees with the policy programme of Samis passed by the extraordinary national meeting in Ostersund, 1968 (SSR minutes 3rd 5 th Oct. 1968). This is hardly more than one would expect in view of the personnel of the committee.

By means of this action the Samis have demonstrated that they are willing to try many different ways of canalizing their politics up to the level of the Riksdag. The most important aspect of this committee is the fact that one may now expect FP to be willing to follow up the intentions published in the report. In the future work of the Riksdag, the other parties, and especially the party in power, will thus be compelled to express their attitude to this matter. This will result in a Riksdag debate which may well prove to be of the utmost importance for the minority situation of the Samis. In this way SSR has brought about a break-in into the Riksdag, thus supplementing its legal strategy.

A policy cannot be effective, nor can general political work concerning minorities be successful unless one has capable politicians. From this point of view, the recruitment to the elite 
is particularly important. Great attention is here paid to the expert knowledge available. A study of typical careers of members of the elite is of interest in this connection.

From the individual's point of view, this is a matter of adaptation. Special expert knowledge is required if one is to be able to act in the context of the wider society with a minority status. By means of a relevant education - social science in this case - either as a formal education for a particular profession, or in the form of courses if one should choose to retain the status of reindeer keeper, one may gain this theoretical expert knowledge. But theory must be supplemented with practice, i.e. one must strive for a status in the political system of the majority society, starting with local politics. Thereby one will also acquire the informal rules of politics.

I was a looal politician, a Social Demoorat, for eight years. I have learned the dirty game of politics, which always takes place behind the soenes. $X$ and $Y$ know that, and so do all the other Social Democrats in Kiruna. Therefore they are a bit careful when dealing with me. They know that ordinary, plain conduot is not enough. I can hit back. One has to learn all the ins and outs of the political game if one is to be able to act and to achieve one's aims.

The important decisions are made behind the scenes, more or less in secret. I have learned that too, and therefore I act as I do. If one is to get anywhere, one must choose a way that works, that is effective!

When such an individual adjustment is successful, it becomes an important asset for the continued interaction between the minority group and the majority society. In this way SSR is able to present its policy, and to look after political resolutions on the local and the regional level. This is of vital importance for the individual Sami community as an organization unit.

We have dealt with the development of SSR into a politically important organization. Not until this aim was realized was it possible to improve the position of the Samis to any noticeable extent. The authorities, local as well as regional, have now increasingly begun to accept this change. The distribution of influence in matters concerning the situation of the Samis is thus becoming less unequal than before. A more complete view of this development requires also an account of some of the main features of the formulation of SSR's ideology. 
When minority groups gradually tend to take the offensive in interaction with the dominant system of society, an effective ideology is essential. Characteristic of such an ideology is reaction agains existing conditions. One is opposed to exploitation and to various forms of wardship on the part of the majority society. This formulation of ideology is common in post-colonial situations in general. (G.Balandier 1967).

As a rule, the elite takes the initiative for the formulation of an ideology which is to fuse the group together by means of symbols of unity and arguments for unity. Such an ideology thus acquires two functions, that of contributing to the communal identification of the group, and that of forming a foundation for external political action.

It is the elite within SSR; and before SSR was founded some individual leader personalities who have contributed to the formulation of the ideology, the outcome of much lengthy work and of discussions at many national meetings. It was not until 1968 that an explicit political programme, Samernas Samepolitiska Program (The Policy Programme of the Swedish Samis), was adopted (the national meeting in Ostersund 1968). This programme comprices the minority politics at present being conducted by the Samis in Sweden. The essence of these politics may be condensed to the following four main points.

1. The Status of the national meeting.

The national meeting is the only institution representing the Samis in Sweden. Cooperation with the authorities is to be effected by means of this institution, but on equal conditions. The national meeting must therefore be recognized by Swedish law.

2. The Sami question is a cultural question.

For the Samis, culture and economic life form an indivisible whole. A Swedish Sami policy must find bonds of union between the reindeer Samis and the urbanized and other non-reindeer Samis. Young Samis must be given the chance of making Samish choice in their life career. The Sami question is therefore first and foremost a cultural question. 
3. The Samish people as a national minority. The Sami's must be ensured the choice of many different occupations. A combination of occupations is the most advantageous solution. This is based on the individual household, not on the individual person. The aim of the work of reform should be that of ensuring the highest possible income for each household, not that of onesidedly furthering reindeer husbandry, which is then abstractly conceived as an independent occupation. In this way a policy devoted to the cause of the Samis will be attained.

Some of the features of this point are derived from populism, but it is also closely related to traditional ecological adjustment, which is here merely expressed in new terms.

4. The samis' battle for justice. The battle for justice is of very great importance to the Samis as an ethnic group and to samish culture. It makes for increased self-respect, and self-confidence which constitute a base for active participation of the Samis in the progressive work. As RBL is merely a regulative measure which provides no guarantee whatsoever of any civil rights, the institutionalized resources of power are in the hands of the opponent, in this case the state. The aim of the battle for justice is that of changing this situation, and it represents a common goal for all Samis, regardless of the category to which they belong. This battle is essential if the pressure from the authorities is to be reduced, thus achieving a distribution of influence more favourable to the Samis. The utmost objective of this battle is the opportunity for samish youth to "choose Samish" in their life.

There are also other points, not directly included in the programme of Samish policy. In the present context it will suffice if we mention two of these points, both of which have been brought very much to the fore in recent years. The first of these we may call the ideology of unity. This means that one aims at attaining the most substantial support possible for the 
external policy of the union, thereby rendering it legitimate. The right of decision in the matter of originating lawsuits of principle lies with the sami community concerned. But in all previous lawsuits of principle a resolution from the national meeting has been received, implying that the national meeting will provide resources to support the suit, and also that the samis will commit themselves to the matter, as a Sami national movement. This is very important, for instance in that it influences public opinion. (SO, national meeting 1970:57).

It is also important that all Sami communities should be members of SSR. This has been stressed at many national meetings, and also in other contexts. One Sami community in particular remained outside the union for a fairly long time, but it has now joined again. (National meeting 1970:70-71).

The identification with marginal depressed areas in general is a new ideological expression, and it deserves our attention. This identification provides a basis for joint action across the ethnic boundary in certain important matters.

All those living in marginal areas - and particularly the inhabitants of the marginal areas of Norrland - are today compelled to pull together against those tendencies of the economic development and the structure of population which are a threat to them all ... Miners, Samis, farmers and others in the samish region have very great interests in oommon, and they ought to find ways of jointly attending to these common interests. (National meeting 1971:3).

The samis want to cooperate with other groups of people living in marginal areas, and also with other groups of society, however, with proper consideration of the special minority viewpoints which apply to the Sami question. (Resolution A, 1971).

This form of identification was clearly expressed during the intensive struggle against the exploitation of the Vindel river. Here we should stress that it is in concrete situations that such communal identification across'the ethnic boundaries may become significant.

If an ideology is to be effective, it must be supported by the majority of the people. Only then will the political activity involved possess sufficient authority, and this is essential if interaction with the wider society is to be politically effective from the point of view of the Samis. In other words - it is essential that the elite transmit this ideology in various ways. The policy programme of the Samis is communicated to the 
communities - by way of their delegates - by being printed in the minutes of the national meeting. ${ }^{12)}$ A similar effect is obtained by reporting the main points of the programme in samefolket. Yet another medium is the Samish radio programme, sami sagat. The cumulative effect of this process of communication, in which the delegates and the members of the board ideally play an important part, is the following: local discussions are initiated, and on these later local-political leads in contexts of confrontation are based. Thereby the aim of the formulated ideology is realized - its fundamental contents must reach the Samis at every organizational level.

Thus the elite formulates the ideology, which must then be effectively communicated to the people for whom the elite works. But the ideas and opinions, as well as problems of principle, on which this ideology is based, emanate from the everyday situation of the people. A modification of the ideology currently held is also motivated by a change in that social reality which represents the people. Therefore the formulation of an ideology is an example of an on-going process, in which the elite and the people continually influence each other in order that the ethnic group may attain an optimum basis for political action.

Our next concern is the question of how ideology is employed in actual practice. This may take various forms. Of course the national meeting is one arena in which the participants make explicit use of the joint ideology. The following example comes from the national meeting at Umeå, 1970:

The national union enjoys more recognition than before, and surely much of this is due to its democratic structure centering around the national meeting. Now the time should be ripe for recognition of the national meeting in swedish law .... It is evident in minority politics all over the world that it is essential that bodies which represent minorities should be institutionalized.

Those Samis who are not concerned with reindeer husbandry have never received any recognition, be it cultural or occupational. Today, at least $2 / 3$ of the Samis are not concerned with reindeer husbandry. Young samis have to leave their home community, but they are not willing to renounce their origin. A sami is a Sami, even without reindeer.

SSR has stated that one must have a combination of various sources of livelihood in order to maintain sufficient means of subsistence to support a sami population which reproduces itself and continues to live on. (National meeting 1970). 
In connection with speeches made during debates at the national meeting we would refer the reader to the text of some of the resolutions adopted by this forum and later employed as a means of pressure against the authorities.

Delegations appointed to call on members of the government for various reasons find these occasions opportune for a clear articulation of the basic ideological view held by the majority of Samis. The call on Prime Minister Palme, mentioned above, is an example of this form of procedure. The remarks made by the chairman of SSR on this occasion included the following:

There are two lifferent images or visions of the future of the Samis in Sweden and in Eenno-Scandinavia. One of these is a vision of decline, which is at times clearly evinoed even by persons in exalted positions. The other is the vision held by the samis themselves, and by their popular movement. It centers around the young samis' natural wish to "choose" Samish in thoir life. Samish youth is greatly concerned with this, the Samis' own vision. - Now a new Reindeer Pasturing Law is to be laid before the Riksdag. It is particularly urgent that a oorrect image - vision - of the Samis should be expressed in the proposition and the resolution of the House. A severe rationalization of the samis, compeling about a third of the reindeer keepers to renounce their livelihood, must be out of the question. Instead, various combinations of occupations must be tried. The aspects of Samish culture and of option - true equality - must override all technocratic aspects. The Riksdag must lay down basic rules for the practical work of the Board of Agriculture, safeguarding the sami culture and the option for Samish youth. The Samis' vision or image of the future forms part of the policy programme of the samis. (SET 1970:5-7).

This ideological argumentation is aıso aimed at public committees and investigations. In committees set up for the express purpose of investigating the conditions under which the Samis live, such articulation may be brought about either by the Samish members of the committee, or when a committee in the course of its work consults a group of Samis with common interests. This occurred in the autumn of 1972, when the Sami Enquiry 13) visited the Sami Folk High School in Jokkmokk. The purpose of the visit was that of obtaining information enabling them to form an opinion on the future of the Folk High School, to be expressed in their report. Teachers and students, as well as other samis in Jokkmokk, tried in various ways to explain the Samis' own point of view on this matter. The following excerpts will serve to illustrate this: 
Reindeer keeping is a way of life, not merely a livelihood. And for those engaged in traditional forms of handicraft this is also a way of life, not merely a source of income. (A teacher).

The language is going to disappear, even among the reindeer keepers, unless more Samish is taught. The teaching of the language must be related to other cultural activities, so that the people may gain a perspective of their own situation. By providing more teaching of the samish language, we can delay the process of Swedification. (A teacher).

I am an active reindeer herder, and I should like to stress the problems of the sami communities. The school can prove to be of great importance to them, with regard to the new organization of reindeer husbandry. I can also add that the meetings of the community are traditionally held here, in the school. The new organizational structure needs administrative resources, offices etc. I consider the school to be very important, if one thinks of reindeer keeping not merely as a means of livelihood, but as a way of life. And I should like to add that it does not suit us to attend courses of eight months' duration here. We need short courses, in stages, if you like. I know that the reindeer herders are interested, and without such interest we cannot survive.

I hope the committee will think about what I have said, and draw up plans which will suit us. (A reindeer herder).

As regards public committees dealing with matters concerning the situation of the Samis, SSR now has access to the important right of submission on the measure in question. In this context it will suffice to refer to the very comprehensive submission given by SSR on the new Reindeer Husbandry Legislation of 1968 . (See also chapter VIII).

This right of submission and attempts at directly influencing the work of a committee - e.g. The Sami Enquiry - illustrate some of the routine possibilities of influencing resolutions from an ideological point of view now at the disposal of the Samis.

Apart from press conferences and minority-political opinions canalized by way of the various mass media there are two other forms of action tinged by ideological argumentation. We are here thinking of lawsuits and of lobbying. The purely juridical argumentation in the skattefjall Case ${ }^{14)}$ attempts to internationalize the problem by referring in very strong terms to the European Convention of Human Rights and to the UN statute against racial discrimination. In line with this, parallels found in the conditions under which the North American Indians live were also 
adduced. In order to lend support to this argumentation, Sweden's leading expert on legal matters of this type, Lord Justice G.Petrén, was called in as witness.

When the state called in the regional chief administrator as witness, the Samis made use of the situation by asking a whole series of questions. The aim of this manoeuvre was mainly that of throwing light on the administrative system before the court and, as a direct result, on the Samis' powerlessness in important matters of principle. The existing administrative system will always be an object for attack in all minority conflicts, for no change in the distribution of influence between the two parties can be achieved until the status of the administrative system has undergone a change. As the struggle for justice is considered to be part of the policy programme, it is natural that this part of the ideological framework should be adduced in legal procedure.

Lobbying is carried out in connection with resolutions passed by bodies of the central administration, such as the Board of Agriculture etc. The formulation of Samish ideology is also beginning to make itself felt at another level, in motions of the Riksdag. Here we may refer to two motions from 1971, one proposed by Moderata Samlingspartiet (the Conservative party), the other by Vänsterpartiet Kommunisterna (the Communist party). In other words, these two motions emanated from directly opposed poles within the Riksdag, a fact which stresses the penetrative power of the Samish ideology and the efficiency of SSR's lobby activities.

A formulation of their ideology is essential for the Sames as a minority group if they are to be able to achieve a change in the distribution of power. Such an ideology must be shared by the majority of the people, and it must serve as a framework for political action on the level of the elite and on that of the local organizations. In this section we have demonstrated in detail the various forms of action in which the Samis apply the ideological framework. As a result of such a community of ideology the opponent, i.e. the wider society on various organizational levels, gains a more correct view of the vital problems of the Samis, and thus the Sambs can by degree gain a better hearing for their claims and wishes. In this way the section 
on the ideology of SSR illustrates the pattern of interaction developed between the minority group and the wider society.

The ideological framework is in many ways connected with the basic set of values held by the Samas. For example - in many ideological initiatives a specially Samish way of life is referred to; reindeer keeping must not be regarded merely as a means of livelihood, but as a way of life; handicraft is not merely the pursuit of an artistic craft, it is a way of life. The catchword combination of ocoupations adds to the idea of a special way of life. The Samis constantly stress these points in their political articulation. This, in turn, leads up to the general view that the Samis must be regarded as a national minority, i.e. as a group whose political struggle aims at ethnic plurality. As a national minority group, they must also clearly mark the ethnic boundary towards the outside world. This marking is achieved partly by stressing the points referred to above, partly by emphasizing the importance of the Samish language. Added to this we have the ideology of unity which is making itself felt more and more as an outcome of the organizational growth of SSR. This popular movement also promotes a clearer definition of the boundary separating the two ethnic groups.

Fredrik Barth has emphasized the significance of focusing on ethnic boundaries when studying poly-ethnic contexts. These boundaries are primarily social rather than territorial. In this way we are able to define the particular group for an investigation, because emphas is is laid on interaction between different ethnic groups, in which various symbols and signals are utilized in order to include/exclude people.

In this study I have tried to follow this general approach viewing the Samis not so much as a discrete group but as a group performing in a special pattern when interacting with members and institutions of the wider society. (Barth, 1969:15).

These ideological points, derived from the common basic set of values of the Samis, also lead to a gradual change in the foundations of this set of values. These changes, or modifications, of values are a result of changed opportunity situations. As explicit examples, we may cite the feeling of identification 
with others living in marginal sparsely populated districts, and the ideology of unity. The importance to the Samis as an ethnic minority of the position of their own language and of language instruction was not fully understood until recently. Now this question forms a very important point of the ideological programme of action.

This ideology is in contrast with another opinion of values, which may in concrete cases of confrontation restrict the penetrative power of the Samish ideology, as appears clearly from the chairman's statements when in attendance on Prime Minister Palme. In that case the Samis expressed clearly a conscious realization of the discrepancy of values which obtains between the wider society and the Samis. (See p. 124).

Samish ideology at the highest level was formulated at an inter-Nordic Sami conference in Gällivare, 1971. The general cultural-political programme states what the Samis are, what they are at present attacking and, finally, what they hope to achieve. According to this programme, the Samis assert that they are one people, with their own region, their own values and traditions, and with a pronounced feeling of solidarity. They are first and foremost on the offensive against political domination which, combined with the present educational system and with innumerable cases of exploitation, has long made the Sami.s' chances of maintaining their own ethnic character extremely difficult. As the pressure exerted on the minority increases, it is felt that the majority population must now recognize the Samis' ancient right to their own region, and their right to decide how the various resources of that region are to be used. In this way it will be possible to establish a basis for the development of Samish culture. This is vital if the Samis are to be able to achieve a self-evident identity within modern society. Increased self-government, influence on the use of natural resources, better legal rights, development of occupations available to the Samis - all these are points of the utmost importance if the feeling of security for the culture and future possibilities thereof is to be achieved. Questions such as that of cultivating and developing the Samish language into a modern means of communication, preserve and refine the handi- 
craft, partly as a characteristic form of art and partly as an important ancillary source of income to supplement reindeer keeping or other occupations, are also of central importance. Nor must we forget the verbal forms of expression, such as the specific type of song, yoik, and Samish literature. All these factors will contribute to an increased feeling of self-respect, of the value of being a Sami. (See also the 7 th Nordic Sami Conference, 1971).

In the 1970's a new form of ideological expression has grown up, especially among the young Samis. They use the three letters CSV as a symbol for joint identification. XSV stands for the theses We are Samis and wish to remain Samis against all economic and cultural pressure from the wider society. The symbol urges all Samis in Same Ätnam (the land of the Samis) to unite and recognize their cultural heritage and from this basis to develop a feeling of community. Major political actions should be strongly attached to this new solidarity of the Sami group. The symbol is now used as a slogan at meetings, when greeting fellow Samis and even in specially designed sweaters or T-shirts. Small silver jewels worn with the traditional Sami costume can also be engraved with the symbol $\mathrm{CSV}$. Since its start the general ideology behind XSV has frequently been presented in the Sami periodicals and newspapers. (See especially Nordkalotten and Samefolket).

When the national union has developed into a powerful instrument in the sphere of minority politics SSR, will, from the point of view of the local community, increasingly become a premise for interaction, in the same way as ecology and the administration. Seen from the local point of view, and particularly from that of the individual Sami, the national union is not only a resource in some cases it may also be a limiting factor. This development forms part of the gradual integration of SSR into the complex social system in which the Samis are assigned a place, a state of affairs which may be illustrated by examples already mentioned. SSR is first and foremost a resource, as appears clearly from the account on page 111 and from that dealing with the activities of the so. The realization of local political interests may, however, be obstructed, as was the. case at the national meeting in Östersund in 1968, when some delegates, with a mandate from 
the majority of those they represented, were prevented from presenting their arguments in the way they intended. Thus SSR can also act as a restricting factor on local politics.

Another characteristic feature of the process of development discussed in the present chapter is ethnic incorporation, i.e. the creation of an internal basis for communal action. This basis comprises aims and strategies of action, and it is essential if the identity and self-respect of the group are to be strengthened. (H.Eidheim 1971).15)

On an inter-Nordic basis we have Nordiska Sameradet (The Nordic Sami Council) which was established in 1953 and calls a conference every three years. This is first and foremost a pressure group, which acts in vital questions likely to affect the interests of all the samis. If, for instance, the samis in one country feel very constrained in a particular situation, support from the other Samis may be sought by way of the Nordic Sami Council. This enhances the position of the Samish nation. The term Samish nation here refers to a view on Samish solidarity, regardless of national affiliation. This is a Samish verbalization which must be regarded as an expression of an ideological symbol, i.e. the Samis are conscious of the fact that they are not a nation according to the terms of international law. They do not constitute, and they have never constituted, a separate state, but as a people they are striving to attain equivalent rights. The Samis employ this symbolic expression first and foremost for purposes of political articulations, as appears from many articles in the Samish press and from minoritypolitical programmes.

The resolutions worked out at the conferences of the Nordic Sami Council are canalized to the Nordic Council, which then passes them to the national parliaments concerned. Thus they clearly contribute towards influencing public opinion. The Nordic Sami Council musț therefore be regarded as an important complement to SSR. At one of the most recent conferences, which was held in Gällivare in 1971, agreement about a common culturalpolitical programme was reached, as pointed out above. This programme is also an ideological guiding line for politicians, as appeared clearly at the confrontation between The Sami Enquiry 
and the Samis of Jokkmokk, where it was made perfectly plain that the Samis expected the committee's report to follow the cultural-political programme closely. During the press conference on the Skattefjäll case in November 1972, the Samis again articulated views taken straight from this programme.

As this chapter shows SSR, the organization established by the Samis, has essentially contributed to the development of the new political form. This form has led to a better balance in the distribution of power, whereby the position of the Sami minority is improved. Characteristic of this process of development are the initial difficulties which are now being overcome, especially since juridical strategy has been taken into use. The agreed ideological formulation is also closely connected with many aspects of the struggle for justice and right. The Nordic Sami Council, as well as many other non-institutionalized actions of the same type as the UN action, supplement the form of the minority-political activities of the Samis.

The primary aim of the first part of this study is that of explaining the political form now obtaining. To this end I chose to apply a limited diachronic perspective. Typical of the change is not only the constantly increasing complexity, but also the increased influence enjoyed by the minority group. As we have seen, however, the latter could not be realized without strong opposition.

The Samis themselves are thus principally responsible for this change. In the second part of the book I intend to show by the extended case method what this changed political form in practice means to the people concerned. This case material will be employed to illustrate the significant aspects of this process of social change. ${ }^{16)}$ 
NOTES TO CHAPTER V

1. This is mainly based on Gustav Park, Samernas Organisationssträvanden $i$ Sverige, in Samiid Dilit, 1957.

2. According to Per Otnes, 1970, this Sami association also called itself the Lapp Central Association (Lapparnes Centralförbund). As there were few members outside of the core area around Vilhelmina, this association was only nominally a united Sami organisation. An organisation of this kind did not appear until the first national meeting in 1918 . (Otnes 1970:107-111).

3. This enquiry was to make a thorough compilation of the problems that were involved with the evacuation by the authorities of the Samis from Karesuando to different districts south of lake Torne, and to put forward proposals.

4. After 1967 there is a chairman's collegium consisting of the chairman and three vice-chairmen. These four, together with a secretary, are now included in the executive committee. Since then nobody from the remainder of the board is appointed to the AU. But it is possible, when required, for a board member to be temporarily appointed to this body.

5. For some reason or other, one of the siidat was not asked to be present at a community meeting when a representative was to be elected. In several people's opinion the wrong representative was chosen, which resulted in the absence of the sii'da being used in the appeal against the election to get the administration to declare the election invalid, which also occurred. This is surprising since only 6 out of about 35 heads of household were absent.

6. The two that have now been summoned are certainly excellent persons, and from an athletics point of view well-known, but it is questionable whether they have the judgement, insight and independence that is necessary for them to successfully represent the reindeer samis' points of view on the delicate and difficult problems that we are dealing with now. (SET 1956).

7. The so and its office is financed partly from funds from the government Lapp Fund (after 1971 called the Sami Fund) and partly from the Samis themselves.

8. It can be additionally noted that the $\mathrm{SO}$ is a non-Sami and has previously had long experience from the Crown Lands Judiciary Board, which is the government body for Sami questions. This is additional expertise which is available to SSR. 
9. It can also be noted that, after 1973, SSR has developed the contacts between the board and the representatives' assembly, as well as other interested groups at the local level, by allowing the SK to travel around and hold preliminary meetings in the different urban areas in the reindeer herding area, for example in Gällivare, Jokkmokk, Kiruna and Karesuando. These meetings have been held well before the national meeting and their main purpose was to help prepare the representatives for the meeting. A few Sami communities had started similar preliminary meetings even earlier in order that the community representative would be able to go to the national meeting with a clear majority backing and line of action.

10. In 1970, 96 Samis from the Kaitum area in Gällivare, sent a note of protest to the United Nations. In this note they demanded that the UN should try to make the Swedish government desist in the further development of hydroelectric power in this area. Through a series of earlier encroachments, the maintenance of the Samis' particular way of life has been seriously impaired. Gällivare, together with Jokkmokk, are the most seriously affected areas so far. The reason for such drastic action is the feeling of helplessness in dealing with such a powerful opponent as the Swedish government.

This action was not sanctioned by SSR that referred to it in quite critical terms in an editorial in samefolket. It closed by adding, however, that the Swedish government should listen to the Kaitum Samis' arguments in matters concerning hydro-electric power development. (SET 1970: 10-12). See also Appendix II.

In the Spring of 1971, the Samis received a reply from the UN Committee on Human Rights in which it stated that attention would be given to the Samis' note. This meant that the Swedish government would be required to comment on this question. (SET 1971:4-5).

The Riksdag has decided, however, that this threat of development is unlikely for the time being. The UN action contributed in part to this reaction, even though public opinion had the greatest influence, on decision makers. The action itself was regarded in official sami circles as a marginal effort that was most likely inspired from outside, i.e. from non-Samis. Should this action be repeated in particularly critical situations, this marginal form of action will, however, be transformed into a more regular form of expression, in spite of the fact that even in the future it will lack the positive sanction of the official Sami body.

11. This is one of the few rivers in Lapland that has not been exploited for hydro-electric power. The Samis, as well as a large number of those living along the river and others interested in nature conservancy, joined forces and thanks to an intensive campaign supported by important section of the mass media, a Riksdag decision against further development was finally achieved in 1970 . 
12. The task of the representative is to act as an intermediary concerning the main points at the national meeting, as well as to see to it that as many as possible in the communities read the minutes.

13. This investigation was started on the initiative of SSR in 1970 and consists of five members, of whom two are Samis. The purpose of the investigation is to look at the Sami question in its entirity. More about this in Chapter VIII.

14. The Skattefjälls case, which includes conditions in Jämtland, is the most important trial case in the Samis' history. In this case the Samis are primarily demanding improved territorial and water rights.

15. Eidheim summarises this process as follows:

While the behavior suitable for people seeking assimilation takes the form of individual strategies and is strictly prescribed by conventions in some districts down to the most subtle details, the process of ethnic incorporation is innovating, unifying and public. Those who define the group goals and strategies seek to organize inter-ethnic confrontation and aim explicitly at a new design for an ethnically composite society. This design is based on complementary ethnic statutes with recognized relevance for those seotors of activity which are vital to a future existence for the Samis as an ethnic group. Consequently this implies an attack on the mechanisms and valuations which promote assimilation. (1971:72).

16. J. Van Velsen has argued for a similar method. In the study of social processes, structural analysis is not sufficient and situational analysis should be included. Situational analys is is another term for extended case method. It is the actual social processes that take place within a structure that are of interest. It is important that case material is integrated with descriptions of social processes. Finally, the cases that are to be represented are to be situational. (Van Velsen, 1967). 
6 


\section{Cases of exploitation}

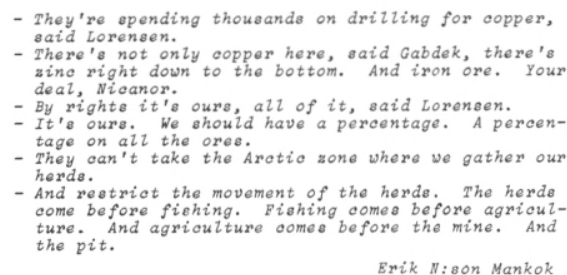

The cases discussed in the present and the two following chapters are examples of the political confrontation between the Samis and the Swedes. We shall also deal with the strategy of the minority, the dominating position of the majority, and the political potential of SSR. All the events described belong to a specific type of goal-orientated activity. These goals, aiming at the realization of Samish native rights, are of such a nature that the majority of those affected are prepared to take an active part. They may therefore be termed public goals, and thus they all clearly have a political import. Each such event consists of a sequence of phases, which take place over a short or longer space of time. In political anthropology it has been argued that we should focus on events rather than on structures and functions. (cf. Swartz, Tuden and Turner, 1966 and Swartz, 1968.) In the present study I have taken a similar position. To me it is apparant that by going through a limited number of important cases we will get a better understanding of real political life among the Samis. In this way we are able to explain the change that has taken place in the power relations between the minority and the dominant society, and consequently obtain a fairly accurate picture of the Samish minority situation. Due to the explicit emphasis on politics in the cases chosen, it is my conviction that such a procedure will bring the analysis of this particular minority situation a bit further compared to earlier writings. (cf. Eidheim, 1971.) In the article The Lappish Movement: An Innovative Process Eidheim seems to consider this movement as a-political. (Eidheim, 1968.) Without treating ecology and its relationship to the actual power relations between the two ethnic 
groups I do not think it is possible to give a true picture of this significant change. This statement is moreover congruent with the general theme of this study. For the purpose of the discussion below, the phases of the events discussed have been reduced to three: the prelude, the phase of confrontation, and the sequel. The resources that are mobilized and the persons acting will be analyzed separately for each of these phases. In this chapter we will confine ourselves to two different projects concerning the regulation of water courses, examples of a confrontation finally resolved in court. These two cases involve far-reaching consequences affecting the life of the reindeer Samis. The pattern of behaviour evinced by the Samis is similar in the two cases, thus illustrating the regular form of action which has gradually developed in the politics of the Swedish Samis. The rapid development of industry has led to an increased demand for energy on the part of the wider society, and this has resulted in an increased number of hydroelectric stations. Most of the hydro-electric rescurces come from the rivers and waterways in the traditional land of reindeer keeping. Frequently such regulation leads to far-reaching encroachments on the way of life of the reindeer Samis, and the effect on their economy and well-being is negative.

The area here investigated is not one of the most seriously exposed in this connection, although during recent years some of the Sami communities have been affected by this type of exploitation. The two cases discussed below illustrate two measures of exploitation, one very extensive, with very farreaching consequences, partly for the two Sami communities involved, and partly for the Samis as an entire group; the other is a lesser measure, which affects one Sami community only. We should add that the cases discussed belong to two common variants of this type of exploitation, represented throughout the entire Swedish reindeer keeping region.

\section{a. The Altevatn Case}

Altevatn is a large lake in northern Norway, situated in the pasturing district which is utilized by the Samis of Talma 
and Saarivuoma during the summer. This lake was regulated for the production of hydro-electric power by the Norwegian WaterPower Board during the late 1950's, and as a result, large areas of pasture were flooded. Moreover, fishing for domestic consumption became considerably more difficult, nor must we omit the fact that the Samis were forced to abandon their traditional camping sites and move to other, less convenient spots. The deleterious effects also include an increased burden of work for the reindeer herders. This case may be divided into three phases, the first concerned with the way the minority was manipulated by the wider society, the second with the minority group attacking this manipulation, and the third with the general political implications of this case as experienced by the minority.

\section{Prelude}

The first measures for the regulation of Altevatn were taken in 1958. When this came to the notice of the Swedish administration in Luleå, lawyer $\mathrm{X}$ in Troms $\phi$ was appointed as solicitor to represent the Samis and look after the interests of reindeer keeping in the district concerned. The administration informed the Samis of Talma and Saarivuoma of the project. Instead of taking legal action, the solicitor with the approval of the authorities - preferred to employ negotiation in order to reach an agreement. In 1959 and 1960 meetings were therefore held between the parties, lawyer $X$ representing the Samis and lawyer $Y$ representing the Norwegian Hydro-electric Company. The head administrators of the region concerned both of Sweden and Norway also took part in the discussions. Agreement was reached in 1960: a fund of N.kr. 250.000 was to be established, to be used for various measures of improvement concerning the reindeer keeping in the district in question. This fund was to be administered by the governor of the county of Troms, and it was intended as compensation for lost reindeer pastures. The question of fishing was decided in April 1960, the Samis being granted N. kr. 125.000. This sum was to be added to the above fund. 
From an economic point of view this compensation was considerable, N.kr. 375.000 in all. As the agreement goes, the Samis affected will receive none of this money. Every time the Samis wish to use the fund they must, as a local Sami community, make an application by way of the normal bureaucratic channels, so that the Swedish and the Norwegian administrations are brought in in every case. The compensation applies to the district in question, regardless of whether the Samis engaged in reindeer keeping there are Swedish or Norwegian. Thus the agreement may be said to have eliminated by skilful manoeuvring, the people concerned. This was certainly an advantageous strategy, especially from the point of view of the Norwegian authorities who expected to take over several districts, including Altevatn, for Norwegian interests, as a result of the report on Swedish-Norwegian pasturing conditions then impending. We must also note that the Samis affected did not take part in the matter throughout this phase. They did not have the opportunity of attending any of the meetings, nor did lawyer $\mathrm{X}$ attempt to contact his clients during this phase, but confined himself to obtaining the information he considered necessary from the Swedish administration. This manipulative behaviour is not supported by RBL and contrary to an official statement from 1873 the solicitor was not authorized by the Samis. Due to this it was impossible for the Samis to influence the outcome of the negotiations. (Kungl. Brev 1873). We may add that SSR received the written agreement for consideration, and even approved of it. However, at this time SSR lacked legal experts able to judge the matter and for this reason the Samis later considered this statement to have only limited value. From the point of view of the Hydroelectric Company, however, this statement served as a document verifying that the Samis had once accepted the formal agreement. By adopting the technique of forcing the Samis to give their opinion on a difficult and complex issue in a short time, the larger society can also be said to act in a manipulative way. SSR is fully aware of the constraining effect of this proceeding and has also criticized it on several occasions. 
Thus it appears that the Samis have no opportunity whatever to influence the outcome of the first phase. Supported by the special Sami administration, including RBL, it was possible for the wider society to manipulate aside the Samis. As we have shown above, however, a new epoch in the organizational history of the Samis started in 1962, when a legal expert was attached to SSR. As a result, the conditions for Samish political influence changed entirely, and the basis for an attack on the part of the Samish minority in the Altevatn case had thus been attained.

\section{The Phase of Confrontation}

One of the first measures adopted by the so after he had been appointed by SSR was that of a renewed enquiry into the Altevatn case, partly because the matter was of great importance on the grounds of principle - not least in view of the fact that the report on a new Swedish-Norwegian Reindeer Pasture Convention was imminent - and partly because the case was so recent that it was not yet too late to bring the matter into court, thereby legally testing the Samis' rights to land and water in this particular case.

First the So contacted lawyer $\mathrm{Z}$ in 0 slo, in order that he might appear on behalf of the Samis in this matter. A Norwegian lawyer is required to appear in a Norwegian court of law. In the forthcoming proceedings the $\mathrm{s} O$ and lawyer $\mathrm{Z}$ formed a team which was to act as solicitor for the Samis of Talma and Saarivuoma. In contrast to the events of the first phase, the Samis affected were now immediately informed about the matter. Already in April 1962, the very month when the So took up his appointment, he notified the BOs concerned that SSR, represented by the SO, had taken the initiative for a renewed trial in court of the Altevatn case. Later, in the summer, the so visited the heads of households in the district for the purpose of preliminary discussions between the solicitor and his clients. The Sami consultant (SK) then attached to the SSR also visited the district and studied the area in question together with some of the heads of households. 
Acting on the instructions of the SO, the SK later prepared a memo based on these local contacts. This was later used during the legal proceedings and - apart from the so's contacts in the district - it was largely as a result of this memo that local influence could make itself felt from the very beginning of the action. ${ }^{1}$

This chance of active participation was further enhanced through the important meeting held in Kiruna in the autumn of 1962. The participants included in all nine heads of households, most of them deputies, as well as the two solicitors and the chairman of SSR. At this meeting the Samis were for the first time informed in detail of the course of events to date. A discussion of measures which might possibly be taken followed. The Samis attending the meeting were not, at first, in favour of becoming involved in a lawsuit, for their experience told them that this was not likely to prove worth while. But they agreed to the proposal made by the solicitors when they realized the possibilities inherent in a counter-attack of this kind. A head of household from each of the two communities was appointed as contact, A and B. Contact between the solicitor and his clients was to be effected as follows: $Z$ was to be in constant touch with the $S 0$ who, in turn, would inform $A$ and $B$ respectively of the development taking place. $A$ and $B$ were then to be responsible for informing their own Sami communities .

It is clear that there was a great difference between these two phases from the point of view of the Samis. First of all, they appointed their own solicitor during this second phase. $Z$ was authorised by all individuals considered to be a party to the case to act on their behalf. Secondly the Samis could contribute to the successful outcome of the legal proceedings by their thorough knowledge of the ecological conditions for reindeer herding and the transmission of oral tradition referring to cultural historical contexts. In this initial stage a continuous flow of ideas and know-how was developed between the solicitor on the one hand and the Samis on the other. 
For the Samis the constant contact with specific persons acting in the political arena on their behalf meant that they were now not only aware of their own strategic course of action, but that they also gained a certain knowledge about important aspects of the tactics employed by their opponent. For the first time these people were now actually taking part in events of vital importance to them, and this considerably increased their self-respect.

The Samis employed resources of various types in planning the tactics by means of which they hoped to realize their aims in the case - a juridical victory. Not only did they adduce ethnographical, historical and legal written sources to lend support to their demands - they also consulted experts in various spheres, such as anthropologists, politicians, lawyers, linguists and historians as well as reindeer herders and the mass media. Thus the scope of resources mobilized by the Samis to support their legal arguments was extremely comprehensive and many-faceted. Another resource should also be mentioned here, one offering juridical support: the Skattefjäll case, which was then being tried in the county of Jämtland. As the rights of the Samis to land and water were here to undergo a decisive legal test, the Norwegian court was not bound to take earlier Swedish verdicts into consideration - they could instead arrive at an independent judgment as the Samis' rights in Sweden were sub jure at the time. This fact lent further support to the Sami action in the Altevatn case.

The Samis' action was primarily restricted by their opponent's chances of expanding. The opposing party - nominally the Norwegian Hydroelectric Company - could be stretched to include important parts of the central administration of the wider society, for example on the occasions when ministries such as the Foreign Office and the Board of Agriculture had been allowed to intervene. Thus the opponent in this case was not simply one specific exploiter, but to a great extent the wider society as such. This factor made particularly great demands on the Samis as a party to the case. 
During the preparation of the first legal hearing in 1963 the Samis on the grass-root level were on several occasions able to communicate their opinions to the so. In this way the Samis could furnish their solicitors with the data necessary to argue their cause in the matter of compensation. On the day before the main hearing an important meeting was also held at the summer camp in the Altevatn district. Lawyer $\mathrm{Z}$, the chairman of SSR and the SK all took part in this meeting, ${ }^{2}$ together with both the BOs and the local contact men of the two Sami communities and a number of other heads of households. As a consequence of this preparation the Samis could experience a feeling of active participation, that their voice was regarded and that they had a fairly good insight in the Sami tactics to be followed. For a local Sami group that has never been able to act politically concerning inter-ethnic matters this new opportunity increased to a large extent their cultural awareness. By using oral traditions and general cultural experience the Samis now realize that they can act in significant political arenas claiming native rights to land and water. Thereby they define themselves as belonging to an ethnic minority rather than to a marginal group with its particular reindeer herding interests. This reshaping of the definition of the situation is one of the most important consequences of the Altevatn case.

The legal hearings went through all three legal stages. The first law suit was brought in June 1963, and the court then conceded the Samis' right to take the case to a higher court. A factor which contributed considerably to this decision was the fact that the Norwegian Hydroelectric Company had changed its attitude since 1960, now considering that the Samis were not entitled to any compensation at all. This formed the basis of confrontation. Later in the summer, a special commission was appointed for the purpose of carrying out an inspection in the region in question, after which it was to ineet the Lapp sheriff of the county of Troms. Apart from the SK, the commission also included a representative of each of the Sami communities, and a representative of the Hydro- 
electric Company. On the basis of the material submitted by the commission, the administrator later prepared a memo specifying in detail suitable measures for the collective application of the total sum of compensation. As soon as the memo was to hand, in May 1964, the so had a sufficient number of copies sent to the Sami communities, asking for their comments. A meeting was also held in June, between the SO and the heads of households, so that they might discuss this memo. Thus local Sami participation continued all the way through this process.

In January 1965, the new hearing was held in the court of reappraisal in Troms $\phi$. The findings of this court were made public on the 29th of May. This reappraisal constituted an important victory for the Samis, for all claims for compensation they had put forward were approved. The sum did not differ from that agreed upon previously: the difference lay in the fact that the money was now being used for the benefit of the Samis affected. The compensation for forfeited pasture etc. was to be used for various measures of rationalization in the two Sami communities, while the compensation for lost fishing grounds was to be apportioned individually. The memo drawn up in the summer of 1963 formed the basis of the measures later ratified by the court. In other words - the verdict confirmed the Swedish Samis' right in civil law to land and water in Norway. It must be noted that only Samis received compensation for deteriorated fishing conditions; no compensation was granted to tenant farmers, a fact which made it quite clear which ethnic group might plead ancient rights and usage in this area. In June the so informed the Samis of the principal import of the findings of the court. This verdict had given the Samis more than just compensation for various losses. In its phrasing it represented a kind of codification of original basic rights. Naturally, the wider society could not simply accept this verdict, especially in regard to the forthcoming negotiations about a new Reindeer Pasture Convention. The Norwegian Foreign Office, 
therefore, realized the implications of principle that lie in this verdict, and thus forced the Hydroelectric Company and later also the Board of Agriculture - to appeal against the judgment. Moreover, the Hydroelectric Company had to change its solicitor as Y's work was not found satisfactory. Lawyer $\AA$ was asked to take his place.

In order to maintain the close relationship between those acting in the arena and the people concerned the so worked out a commentary on the verdict. At the same time the Samis were informed of the opponents' appeal and the latest development of oppositional expansion.

This important case was prepared for trial by the Supreme Court during the period 1965-68. During all this time, the Samis' opponents were extremely energetic in procuring new material by means of which to refute the findings of the lower courts. The special examination of four witnesses held in 0slo in 1966 formed part of this strategy. In the autumn of 1967, the report of the Swedish-Norwegian Reindeer Pasture Commission was submitted. This was to form one of the main sources on which the opponents founded their arguments, mainly because the proposal involved drastic reductions of the pasture rights of Swedish Samis in Norway. Nor did the Samis remain passive during this time. They tried, for instance, to check the effect of the opponents' examination of witnesses by calling in equally expert witnesses themselves. SSR also issued a statement on the above report, intended to make the Swedish Samis' views about this document quite clear to the court. ${ }^{3}$ Another principal document cited by the Samis was the codicil to the Swedish-Norwegian frontier treaty of 1751. This codicil is the only true codification of rights so far and has a real as well as a symbolic value to the Samis. For this reason it has been named the Samis' Magna Charta. The verdict which confirms the Samis' civil rights to land and water was based on "alders tids bruk", i.e. ancient usage. This prescription had to be extensively substantiated in the Supreme court. For this reason the Samis brought forth several valuable historical sources, which all showed that the Samis had 
paid taxes since time immemorial and therefore originally utilized this region. ${ }^{4}$

The trial was held in the Supreme Court in Oslo at the end of March 1968. The Samis were represented by $Z$, assisted by the SO, and as listeners a head of household from each of the Sami communities, together with another reindeer keeper, also a leading representative of SSR. Because the latter had also acted as Swedish delegate in the Swedish-Norwegian Reindeer Pasture Commission, his presence at the Supreme Court could serve to subdue to some extent the effect of lawyer $\AA$ 's arguments based especially on the report of the Reindeer Pasture Commission, to which both of them had been part.

The verdict of the Supreme Court was passed on 20 th April 1968 , ratifying the verdict of 1965. The significant outcome of this legal case was then immediately presented to all the Samis affected through a memo prepared by the so, reaffirming the process of communicating ideas already established.

The result of this litigation constitutes a tremendous success for the Samis, especially for those of Talma and Saarivuoma, but also for the entire ethnic group. Of special interest during this phase is the close contact with the macropolitical arena the Samis at the local level have managed to obtain during the progress of the legal action. This form of participation is fairly new, and it illustrates in many ways the potential of the new political form for each individual Sami community. The continuous process of communication between those taking part in the actual confrontation and the people affected by its outcome has established a new form of action which increases the confidence of the people and their self-respect as Samis. During the next phase we shall deal with some of the political implications of this legal verdict as they affect the minority group.

\section{Seque 2}

The Altevatn verdict was a considerable success for the Samis. First of all, the Supreme Court established that the Sami community has the right to the community district. Such a view is not entirely new; it was, for instance, implied in 
the codicil of 1751, and it is explicitly stated in Fellman's and Solem's historical works (Fellman, 1910 and Solem, 1933). This verdict has added considerably to the possibilities of action enjoyed by the Sami communities individually, for this attribution of rights expressed by the supreme court far exceeds that which the state, through RBL, was prepared to concede. Secondly - the Supreme Court also established that the Swedish Samis have a functional need of both the pasturing districts in question, Altevatn and Salvasskaret. The Supreme Court thereby rejected the proposals submitted by the Swedish-Norwegian Reindeer Pasture Commission. Thus this verdict became a resource to be employed by the Samis of Sweden in their further struggle for a favourable Reindeer Pasture Convention.

Moreover, the verdict confirms the Samis' right in civil law to land and water, for the right to fishing is based on ancient usage which has been taxed since the sixteenth century, and it is not derived from the state and RBL. This statement is considered to be of particularly great importance in any future attempts by the Samis to claim compensation during specific confrontations.

The above accounts for the verdict and for its immediate implications. For a more detailed juridical discussion, we refer the reader to T. Cramér, $1970 \mathrm{~b}$.

It is thus evident that the Altevatn verdict offers new possibilities for the Samis to act politically. Not until a political platform is founded on a legal basis can it become sufficiently effective. The Samis are today in a stronger position than they were before the Altevatn verdict, and that does not apply only to the Swedish Samis. The Nordic Sami Council stated, during its conference in the summer of 1968 , that the two legal documents - the codicil of 2752 and the Altevatn verdict - would in the future be of great importance to all the Samis in the North. (Resolution A, NU 1969:6, Pp. 12-14).

A proposal for a common Nordic Sami policy, submitted by the Nordic Council in 1970, also explicitly stressed the general importance of the Altevatn verdict to all the Samis. 
It was pointed out, for instance, that this was not merely a matter of jurisprudence. "Even though this subject is first and foremost a matter to be considered by the courts of law and not by political bodies or legislative organs, the rights of the Samis are a factor which is ever-present in the background, and which must be considered at any assessment of the situation of the Samis within the wider society." (SET 1970: 10-12).

The Altevatn verdict also created a new and more favourable situation for the Swedish Samis regarding the approaching negotiations between Norway and Sweden as to mutual pasture rights. The Samis' territorial rights had been much more seriously considered by the Supreme Court than by the Swedish-Norwegian Reindeer Pasture Commission. Consequently, the initial position had been changed, a fact that accentuated the strategic importance of the Samis' counterattack on the primary Altevatn agreement. The Altevatn verdict was to serve as an asset in supporting the Samis' attempts to improve the final Convention compared to the Commission report, and to some extent they were successful in this endeavour. (See chapt. VII). The verdict has a cumulative effect at the legal level too, particularly on other lawsuits in matters of principle such as the skattefjäll case. SSR as well as the SO, have made explicit statements on this sequel. (See e.g. the National Meeting 1969, Resolution D).

Such a verdict from a court of law also leads to special expectations and values being attached to SSR, and they, in turn, give rise to a series of new hopes and aspirations to be realized in new and similar situations of conflict. There is also another feed-back effect: the position and the reputation of SSR in the eyes of the Samis themselves is enhanced by such political results. And the authorities, in their turn are now far more likely to lend a favourable ear to the demands expressed by the Samis. This reduces their chances to manipulate, thus extending the sphere of Samish influence. 5

In other words - a gradual process has now started, a struggle aiming to achieve a politically effective position for the Samis, and this is essential if they are to continue to exist as a separate group within the wider society. 
We should also add that such verdicts - especially if a series of them is expected - will gradually lead to optimism among the Samis in their minority situation. This applies not only to the Sami communities affected by such verdicts; this new attitude has also made itself felt in other Sami communities in a particularly precarious situation. It is true not least of the young people, who frequently talk about the Altevatn verdict: this has become a theme of local political talks in many Sami communities. Probably the communication of ideas effected by SSR, partly by means of the minutes of the National meetings partly through detailed articles in samefolket is responsible for this consequence of the verdict. (See, for instance, the minutes of the National meetings of 1963, 1964 and 1968.) The Altevatn verdict has also led to a greater self-respect among the Samis of Norway. In the autumn of 1969, the Norwegian counterpart of SSR, NSR, took the initiative in having the rights of the Samis of Finnmark tested and tried in court. This action was no doubt inspired by the favourable outcome of the Altevatn case. (Otnes, 1970:209). Nils Jernsletten has also drawn attention to the general optimism among the Norwegian Samis as a result of the Altevatn verdict (Jernsletten, 1970:152).

By means of their counter-attack, the Samis have established new legal bases for action. They have demonstrated new technique by which to adapt oneself to the premises for action. As an immediate result of their action, the balance of influence between the two ethnic groups has changed. With a legally recognized right to land and water, the Samis as an ethnic group can no longer be neglected. Without such a verdict the Samis would definitely be in a much weaker position today. According to several informants the negotiations of the Reindeer Convention e.g. would have been much harder to pursue, and the Samis would also be lacking an important asset to be used in the Skattefjäll case. On various other occasions references have been made to the Altevatn verdict in general political actions of SSR as well as those being conducted by a particular Sami community. 


\section{b. The Nokutus Case}

Nokutusjaure is a small lake, north of Kiruna C. There are considerable deposits of ore in the slopes by the lake and under the lake itself, and the mining concern wishes to exploit these deposits. The lake has long formed part of the migration route of the Rautasvuoma Samis, used particularly in the autumn. Since the route through Luossajärvi was closed in 1948, the passage by L. Nokutusjaure has been extremely useful to the Samis, for it enables them to by-pass the built-up parts of Kiruna in comparative peace. The community's district is very narrow here, only about $10 \mathrm{~km}$. wide, and the topography does not offer any alternative migration route; for this reason, the exploitation of the deposits constitutes a considerable loss for the Samis of $R$. This case, which has been going on for ten years, may also be analysed in three phases.

The phase of confrontation, i.e. the trials in court, we were able to observe directly, and for this reason some of the forms of action observed there will be examined in detail, for they illustrate the general relationship between the wider society and the minority group. This is a micro-sociological method of observation, in the nature of a complement to the remaining data of the case. Erving Goffman's interaction analysis appears as a suitable method to this end, and the following account of the phase of confrontation therefore includes terms such as encounter, team and impression management. Encounter is a focused gathering, the court proceedings in this particular case; team is defined as a goal-orientated group acting in such an encounter - there may be several teams acting together, if their respective aims coincide, or they may act as competitors. Impression management, finally, is the individual communication of status; according to Goffman, this is dependent on how the situation is defined by the actors in question (Goffman, 1959, 1961). 


\section{Prelude}

The first contact between the parties occurred in 1959, when representatives of LKAB discussed the plans for the impending exploitation of Nokutusvaara with the BO of $R$ and the first inspector of the administration. The first measure was the construction of a road from Kiruna to Nokutusvaara, and this would cross the $R$ migration route leading to the winter pasture. On this occasion the BO attempted to object to the plans of LKAB, but the others present took no notice of his objections.

The opportunity situation of the Samis in $R$ was particularly unfavorable at this time. No committee of deputies existed in the local community and SSR was far from influential, mainly due to its lack of legal expertise. The BO with his rather dubious and weak power position, therefore, had to act alone on behalf of the entire community. As he could expect no assistance from the administration, the outcome of these preliminary discussions was predictable. In 1964 and 1966 new meetings were held, between the community committee of deputies - which had been appointed the previous year and LKAB. Now the Samis could meet numerically stronger, and, with the aid of SSR, they were also able to present firmer arguments for their cause. As a result the parties agreed that the migration route of the Samis should be spared, and that LKAB was to prepare a new route in the event of the deposits being exploited on a large scale.

When the road had been constructed and the necessary test mining carried out, the LKAB applied in 1967 to be allowed to drain Nokutusjaure completely. $R$ was also contacted by the mining concern at an early stage, so that agreement as to compensation might be reached. From this time on the so started to act on behalf of the Sami community.

LKAB was primarily interested in a speedy decision in the matter, as it was urgent from their point of view. They wished to start effective mining at the earliest possible moment, and wanted therefore to avoid a legal action if at all possible. This attitude was based mainly on their desire for 
economic expansion. The ore in question contained unusually large amounts of phosphorus, and phosphoric iron ore was exactly what many of LKAB's customers abroad demanded. Thus this measure of exploitation formed an important part of the general expansion of the company, and any obstacle to exploitation was therefore unacceptable. We mention this because many of the Samis of $R$, when the time for confrontation approached, expressed a desire to prevent all future exploitation affecting the last natural migration route of the community.

On the 3lst of July and the lst of August the parties met in Kiruna, partly in order to confer, and partly in order to survey the land. The Samis present at these meetings were three heads of households from $R$, a reindeer keeping expert from SSR and the SO, while LKAB was represented by lawyer $X$ and two engineers. LKAB had also called in the Ist inspector, which seems to have been of strategic importance. This appears clearly from a letter in which lawyer $X$ urges LKAB to summon representatives also from the administration. (letter 26/6) The Samis had no desire to have the administration represented at these important negotiations, and therefore experienced this manoeuvre as a new constraint.

The purpose of this meeting, from the point of view of LKAB, was that of achieving agreement between the parties, so that a law-suit might be avoided. If this were achieved, LKAB would have realized their principal aim, that of starting work on the scheme of exploitation without delay. The conferences led to a proposal for settlement, which LKAB later sent to the SO. The proposal provided that l) a migrating route 50 meters wide should be cleared and to this construction should be added fences, a corral with catching arms and a telephone; 2) after an acceptance in written form a sum of 100.000,- was to be paid to the community as a compensation to the reindeer herders and for future maintenance of the new constructions. According to the suggested restitutions for the losses $R$ should refrain from any further demand regarding the Nokutus case. Besides, LKAB had set an August 3 lst deadline for $R$ to react. As we find, LKAB is 
pressing very hard to complete these negotiations, and the Samis are left with little choice. They constitute an obstacle which cannot be allowed to delay the way to full exploitation for this big company.

However, the Samis found this proposal unacceptable, especially as concerns the financial compensation. Towards the end of the Kiruna negotiations, it had been proposed that the sum of $\mathrm{kr}$. 100.000 should be paid out once and for all, but this proposal was not based on any detailed investigation, it simply involved an arbitrary sum. As the total damage resulting from the encroachments could hardly be assessed on such vague grounds, the Samis were unable to accept this proposal. They asked for secure guarantees, ensuring that they would de jure be compensated for the losses incurred. In order to achieve this, the Samis demanded that the opponents should investigate the damage resulting from increased work due to more difficult conditions of migration, economic losses due to an increase in the number of animals straying etc. However, this demand was firmly rejected by LKAB, a point of view supported by the court.

The Samis found it best not to make any further reply to the proposal, but instead to wait for the chance of drawing up their own proposal. The discussions between the so and the heads of households which must of necessity precede the framing of such a proposal could, for various reasons, not take place until the 19th of September. For these reasons and also in order to gain more time in which the Samis might prepare their suit - the so had repeatedly tried to have the case deferred. But the Water Rights Court had rejected all these appeals, and in fact supported the opponents in their desire for a speedy hearing. That this really was the case appears clearly from LKAB's correspondence with the court:

We contest the demand for a respite in order to prepare the suit. $R$ has had sufficient time for this purpose.

LKAB is opposed to the case being deferred because the community has not yet stated their claims in this matter. (Letter 28/8) 
At the meeting on 3 lst July the so had the opportunity of conferring with the community, moreover, he was informed by us, at his request, as early as 9 th June. The fact that the so, in spite of this and in spite of a separate communication from the judge, dated 2 lst August, still fails to express himself on the matter must be interpreted as an attempt at delaying proceedings rather than as representing a real need for deferment. Other engagements do not constitute an excuse. Moreover, as LKAB pointed out in their application, this is an urgent matter. There is therefore nothing to prevent the negotiations beginning now, which clearly appears to be what the so also anticipates at this stage. (Letter $24 / 9$ )

The Samis had, however, made a preliminary statement as early as on the 2lst of June. Not until the end of September was the so able to submit three documents, two of them extremely detailed and well-founded accounts of the Samis' views on this matter. They were accompanied by a copious report prepared by a legal historian for the Skattefjäll case, but its principles apply also to other Samish districts.

At this stage the Samis had no reason to aim for a rather fast solution of the conflict. They knew from earlier experience that they needed vast material to support their cause in a court trial. For this reason sufficient time in preparing the proceeding encounter had a very high priority. This illustrates some of the strategic considerations the Samis have to make in current conflicts, mainly due to the prevailing power relations.

The Samis have now, a very short time after the case started, produced exceptionally exhaustive evidence concerning the rights of the Samis. Further investigation concerning the taxed land and the disposal of the crown forest lands is also required, however. (so, letter 22/9)

The attitude of the samis in this matter is entirely defensive. The case concerns a clash of interests between a large industrial concern with enormous capital at its disposal and a poor, exploited minori$t y$, who are nevertheless the original owners and proprietors of the land. There is a veru great difference in the resources available to the parties. Seen against this background, it would seem to be correct that the main hearing be deferred, so that the Samis may be given sufficient time to prepare their suit. Accordingly the samis herewith submit their demand for a deferment of the main hearing. (SO, letter 29/9) 
A meeting was held at the community centre, Rensjön, on the 19th September. Nine heads of households attended, as well as the SO and the SK. Also present were a former head of household, now employed as engineer by LKAB - his expert knowledge is fairly frequently made use of by the Sami community. As a result of this meeting, a specified list of $R^{\prime}$ 's demands was prepared; later, on the 22nd of September, this list was sent to lawyer $X$. This counter-offer stated 312.500,- as monetary compensation based on annual working days, furthermore a corral and a hut for the herders, constant supply of emergency fodder and fences along the artificial migrating route. But these demands were financially so far-reaching that they resulted in an immediate breakdown of negotiations, and consequently a legal confrontation was unavoidable. Already on the next day after LKAB's rejection of the Rautasvuoma proposal, the court announced that the case would be heard on the 5 th of October. The different strategic moves and various resources used by the two parties in this preparatory stage outline the preconditions for the participants in the specific encounter to follow i.e. the hearing of the case.

\section{Phase of confrontation}

The participants may be regarded as representing various goal-orientated groups or teams. These teams represent highly different interests, a fact which makes the situation conflictive. One of the parties is a large concern, of such a size that it is of great importance even in the context of national economy. Thus the financial amounts at stake are very large, and for this reason LKAB mobilized sufficient resources to enable them to attain their object. The other team represents local reindeer keeping interests. They are the party suffering losses in this case. This team represents a very small group of people, no more than about fifty. Their main source of income will suffer serious damage as a result of the new measures proposed.

As LKAB is a state-owned concern, one of Sweden's largest, the differences in economic values involved also represent 
differences in the balance of power between the wider society and the ethnic minority. The structural connections characteristic of the relationship between the Samis and the wider society are here displayed within the restricted dimensions bounded by four walls: the court room. The hearing took place at the head office of LKAB in Kiruna, which appears as an arena of a competitive interaction typical of the present minority situation of the Sam1s.

The participants defined the situation in different ways. The Samis present at first adopted a modest attitude, and they spoke in extremely low voices in the corridor just before the hearing started. This attitude coincides completely with the defeatist view of the case which they expressed in the cafeteria a few hours earlier. The battle seemed lost already - there appeared to be no chance of preventing LKAB being authorized to carry out the measures of exploitation.

As a result, the Samis had only very slight chances of pressing those demands for compensation which they considered to be an absolute minimum. As the court had done so little to accomodate them, the Samis were at a great disadvantage when the proceedings started. They were clearly aware of this, and their behaviour reflected this knowledge.

We may add that the Samis had chosen to undercommunicate their ethnic identity by not wearing the Sami costume. They avoided acting just for effect, and preferred to come to court in everyday clothes, thus to some extent overcommunicating their status as reindeer herders. The matter in hand was first and foremost one affecting reindeer herding, and therefore they decided to appear in court as reindeer herders. But as the Samis of this region normally dress in this way, except on special occasions and festivals, they communicated by these clothes also the current cultural identity. This was by no means a festive occasion, and thus the Sami costume was irrelevant. This form of impression management is a clear expression of the Samis' definition of the situation. By contrast, the representatives of LKAB were very open 
and natural in their demeanour, and they showed great confidence. They wanted to be on an informal and good footing with the Samis, and from the first moment in the corridor they expressed the feeling that we'll manage this, and we'll come to some kind of agreement to everybody's satisfaction. Thus at first LKAB's attitude towards their opponent in court was without any formal distance - with one exception - lawyer $X$. He maintained a distant attitude towards the opponents throughout the trial, and his manner was relatively cold. He had, moreover, defined the situation in such a way that he deliberately tried to influence the bench. During the intervals, he sought out the representatives of the bench in order to exchange confidences: The so is trying to make an important case of this, but you people of the Water Rights court must be accustomed to far more important cases. Thus we can establish that $\mathrm{X}$ on several occasions during the proceedings tried to influence the bench. For the so, on the contrary, it was sufficient to try to convince the court in the courtroom.

The bench, which consisted of five members - four of them jurymen - may also be regarded as a separate team in this situation. During the preliminary stage, the bench was not entirely impartial. They were conducive to having the hearing speeded up, for instance, and in spite of repeated appeals from the so they were unwilling to defer the main hearing. Thus from the very beginning the bench adopted a fairly negligent attitude towards the Samis, and was in several respects more willing to meet the demands of LKAB. This attitude was made clearer by the manner of the bench during the hearings, and was further emphasized by the onesided fraternization between one of the parties and members of the bench during the intervals. Such observations add to our impression that the bench had made a point of externating the matter right from the beginning. Ideally, a court of law, as an institution, is supposed to be impartial. However, the court system is a state institution, and in specific situations, therefore, it may be close to the interests 
of another state institution, LKAB. The preliminary stages as well as the actual proceedings indicate that such a displacement of the ideal attitude had actually taken place.

One more team must be mentioned, even though this is quite marginal from the point of view of the action taking place here. This is the Reindeer Administration, represented partly by a lawyer from the Treasury Board for the rating of Government property, partly by the first inspector together with an instructor from the regional administration in Lulea. In their own opinion they represented only the interests of the Samis, and they took their seats on the Sami side of the court room. But their activities were nevertheless somewhat ambivalent, which appeared from a certain form of interaction between the administration and the court or LKAB, but never between the administration and Rautasvuoma. But it was their pre-defined aim that they should contribute towards creating a balance between the parties, and this is confirmed first and foremost by their interaction with the bench. This aim at acting as an intermediary can be shown from the following example.

The demands of the Samis included fencing on both sides of the proposed corridor, an enclosed pasture for fodder, and a reindeer herders' hut in connection with this enclosed pasture. In his concluding speech $X$ made the following comments on these demands:

Fences are not essential, they might even do more damage. The only time when they could possibly be of use is during autumn. In spring they would seem to be an obstacle. It would be better to use a snow mobize for making tracks along the route of the reindeer, perhaps also before the autumn migration. We are also opposed to an enclosed pasture, and question the value of this. If no such enclosure is granted, there will be no need of a herders' hut either.

On being questioned directly by the bench, the lst inspector made the following remarks on the matter:

Fencing is a point open to discussion. The enclosure, on the other hand, is essential. We may look upon it as compensation for deteriorating conditions, and LKAB should therefore not oppose the demand for such an enclosure. The pasture along the new route is not as good as that along the old route. In my opinion, the 
proposed clearing should be sufficient. I think it may be possible to provide a good route also without fences. But a wide route must be cleared, not merely a $50 \mathrm{~m}$ open road through the thicket.

This team also represented the state, and the status relevant to this situation may thus imply an approach to the side of the state. In any case, this official status restricts the activities of those acting in the situation. The main reason for their presence was that part of the proposed compensation was to be paid to the State Lapp Fund, not to the Sami community. The Administration can therefore hardly be considered a resource for the Samis, as their claims tended rather to subdue the Samis' chances of influencing the court in their favour.

We are opposed to the Lapp Administration being summoned as an expert in this matter, when a trial period is to be carried through. The persons who represent the Lapp Administration are biased in favour of our opponents in this case.

The report of January 1966 by the jo (cf. page 62) constitutes a severe judgment on the Lapp Administration. The county administration of Norrbotten has, since it was instituted in 1810, obstructed the samis more than the county administration of either of the other two reindeer keeping counties. (SO)

In this way the Samis chose to inform the court of their basic attitude towards the administration.

Thus the position at the time the confrontation started was the following: three teams represented the state, although in varying degrees, and one team represented the ethnic minority. This illustrates clearly the uneven distribution of power resources. The position of the ethnic minority in such situations is very weak, and it would have been still weaker but for the so.

The methods employed by the two lawyers differed considerably, and this also reflects the general relationship between the majority and the ethnic minority. In situations of this kind the ethnic minority is always at a disadvantage, and is therefore compelled to work considerably more thoroughly and mobilize more resources to support the legal arguments they submit before the court, whereas a state concern as large as 
LKAB can take matters much more easily. To cite an example: the so had collected abundant information from various sources, and this he enclosed with his letters to the court. Apart from the meetings held with the Samis, he also contacted them immediately before the hearing, consulting them and asking as many of them as possible to be present at the proceedings. The Samis who attended the proceedings assisted him in court. Finally he had called three witnesses in order to illuminate as many aspects of the matter as possible. First and foremost, he had called the BO, who was to give a concrete account of the migration in question. By choosing the BO, the So overcommunicated the ethnic identity of the Samis, for the BO's knowledge of Swedish was so poor that his testimony had to be given in Samish, which lent a certain dramatic effect to the examination of this witness. At the same time, matters were made more difficult for the court, for they were obliged to find an authorized interpreter. In this particular case the so might just as well have used a different witness to give exactly the same testimony, but hardly with the same effect. The second witness had been a reindeer herder and teacher in the Sami school system. He is now employed by the regional Sami administration in Gällivare, his home municipality. He had been active in SSR for several years, as vice-chairman and as temporary SK and consequently his political views were very similar to those of the So. He had now given up his SSR work in order to devote himself to a research project, the collection of data concerning various reindeer herding methods by way of the Samish idiom. He is therefore considered to be the theoretically most highly qualified expert on reindeer herding and husbandry in present-day Sweden. In addition, he has ten years' practical reindeer herding experience. This man was to give an account of the principles underlying reindeer migration - a complement to the BO's concrete description. Finally, the author was also called as a witness, in his capacity as social anthropologist, having done field work for a longer period in the Sami community in question. This testimony was to go one step further - it was to be in the nature 
of an analytical presentation of the effects to be expected from this case. In other words, the problems were to be interpreted in a broader context, not merely technologically. The methods employed by the competing teams were governed by clearly defined goals. LKAB was concerned tc get off in the cheapest possible way - to bargain as much as possible in the hope of having the compensation reduced. For $R$, on the other hand, this was a matter of being granted the highest possible compensation, in the form of technical measures such as payment for fences, enclosures etc., and in the form of financial compensation for the increased work caused. The controversy was first and foremost concerned with these points, and not with whether LKAB should be allowed to drain the lake or not. The Samis realized from the very beginning that there was no point in trying to prevent LKAB's exploitation: RBL does not offer sufficient backing for such a veto. The hearing of the case was therefore largely determined by these structural restrictions.

The regular interaction within the two teams, which took place partly during the hearing and partly during the intervals, further underlines the importance of the resources mobilized. The principal speakers had at all times access to experts from whom they might obtain relevant information, and they availed themselves of this during the juridical discussion. The most interesting form of interaction, however, was that which occurred between the bench and the administration. Whenever one of the members of the bench wished to know more about some matter, he turned to the Reindeer Administration for information, thus consulting a pre-defined expert. This occurred so often that one might well suspect that the bench had summoned these persons in order that they might give an expert opinion. LKAB deliberately acted in this manner too, repeatedly seeking the support of the Reindeer Administration. The triangular interaction between these three teams was manifested not only verbally, but also by means of gestures. This interactional pattern confirmed the uneven distribution of teams acting in the arena. The last type of interaction is 
that which took place between $R$ and the administration. The traditional antagonism which prevails between these two parties was clearly in evidence here. The so tried in various ways to locate the lst inspector on the side of the opponent, whereas the lst inspector, by way of defending himself against this attack, tried to make it clear that he rightly belonged on the side of the Samis.

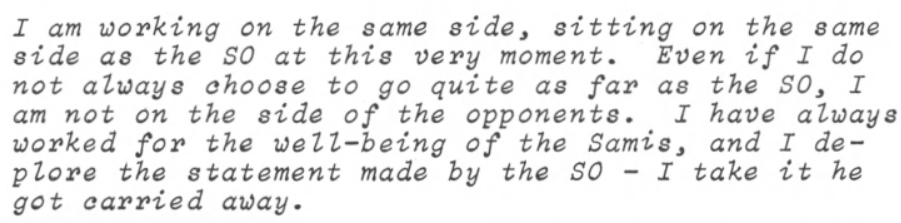

At times the attacks were really severe, and the inspector tried several times to appeal to the Samis present for support, but in vain. The Samis simply turned their backs on him. They knew only too well, from their own experience, that the administration is very apt to lack understanding for the Samish cause, and therefore they were not tempted to express any kind of sympathy. The inspector then chose to appeal to the Treasury

Board for support. The lawyer representing this Board did not condescend to give the Samis as much as a second look once he had met them. In this case one may well speak of extreme nonchalance.

We should also note an observation which emphasizes still further the forms of behaviour accounted for above. The following occurence was observed in the dining room of the Standard Hotel, after the first day's hearing: The so, together with two of the witnesses, came into the dining room first, and sat down in the otherwise completely empty room. After a while, LKAB's lawyer, together with another man from LKAB, arrived, and after exchanging a few words at the so's table, they sat down in a different corner of the room. Some time later, the lawyer from the Treasury Board entered, together with the lst inspector - they made straight for the LKAB table, where they sat down. This shows clearly in what way the administration worked as a team throughout this encounter. Their definition of the situation was also confirmed by this choice of action. 
Rather more than two months after the main hearings in Kiruna, a partial verdict was published. This verdict complied with the Samish claims only to a certain degree, and the so therefore lodged an appeal against the verdict on the next day, in order that the case might be continued at the higher Water Rights Court. ${ }^{6}$ )

That brings us to the end of the Phase of confrontation. Characteristic of this phase is the consistent state of subordination in which the Samis found themselves throughout, a situation which became especially perceptible as a result of the constellation of teams which developed. The fact that such constellations can develop, rendering the Samis' chances of realizing their own defined goals more difficult, makes extra demands on the SO and his strategies. The Samis' struggle for their own rights is still a new feature of the process of development of their minority politics: the Nokutus case, with the special expressions of conduct found in this case of confrontation, illustrates some of the difficulties to which the Samis must adapt in order to attain success in this struggle for their rights. How the Samis themselves conceive of these difficulties is apparent from the so's final statement reproduced in Appendix II.

\section{Sequel}

In January 1968 the LKAB made their first contacts with the SO for the purpose of investigating whether there was any possibility of bringing about an agreement on principle in the matter. If this proved possible, it would considerably improve the atmosphere pertaining to the negotiations between the parties. But a condition was stipulated: $R$ must be prepared to renounce the claim for fences along the newly cleared route. The so immediately contacted the Samis community - the latter agreed, in order to make sure of the constructions connected with the migration route in ample time before the winter migration of 1968 was to take place.

The matter was discussed at the community meeting on 5 th June 1968. Two representatives of LKAB were also present at 
this meeting, at which the main subject under discussion was that of the principles on which the further negotiations were to be based. The community was requested to prepare a proposal after internal discussions; this could then be used as a basis for the negotiations between LKAB and the committee of deputies a week after the Community meeting.

Although it is a fact that the administration presides at Community meetings, the chairman of this particular meeting made it quite clear that there was no reason for the Reindeer Administration to intervene. Instead he emphasized that this was a matter entirely between LKAB and $R$. Thus we can notice a switching of attitude compared to the court hearing some eight months earlier. Apart from this, the administration formed a resource at this meeting, for the instructor made it clear to some of the heads of households that he was prepared to work out an offer on their behalf. His knowledge of the line and his extensive experience with exactly this type of construction work made his offer extremely valuable to the Samis, who immediately accepted it. As the instructor was to act as LKAB's special consultant with regard to these, $\mathrm{R}$ could count on the offer they submitted being supported by the LKAB's consultant. Thus we find that in certain situations the administration may well be a resource supporting the Samis'efforts to realize specific goals.

At a meeting between the two parties it was confirmed that the Samis were to fix the price, that they were to carry out the work and to provide their own foreman, the BO in this case.

Being able to negotiate directly with external bodies such as LKAB, thereby avoiding the intervention of the administration, is of the utmost importance for the Sami community, and in fact the institutionalization of this type of organ for collaboration is among the general aims of Samish politics. As a result of the Nokutus case $R$ has now been able to realize this aim - this we may regard as a positive aspect of the case.

When the new route of migration was taken into use in the autumn of 1968, no undue obstacles to the work were experienced. According to the reindeer keepers of $s i i$ 'da $\mathrm{A}$, in which migration I took part, this could be explained by the small quantity 
of snow and fairly good pasture along the route. Due to very poor pasture in the preceding years the herd had diminished to an extremely low level at the time, a fact facilitating the hard work of migration. The normal number of reindeer for this community is, however, estimated at three times that number, thus there will be no guarantees that the new artificial migration route will function in any given situation.

In the years after 1968, migration along this route was still comparatively free from obstacles. During years of particularly poor pasture, for instance, one may find it impossible to round up the herd in order to drive the reindeer over the mine road between Nokutus and Kiruna, which lies fairly high up. Under such conditions it will be necessary to migrate along the Kurravaara route, and this is inadequate for autumn use, as the ice is never safe here until January. The inconvenience of this alternative was confirmed by the $R$ winter migration of 1967. Even though this migration took place as late as the end of December, the Kurravaara passage proved extremely difficult to pass, and many of the animals disappeared - they may have roamed to Talma, the neighbouring community, or returned to the mountains. This led to great economic losses for the reindeer owners. As $R$ no longer has any alternative route of migration when the natural conditions of migration vary, the loss of the Nokutus route is very appreciable.

In 1970 the road had to be closed for more than an hour when the reindeer repeatedly tried to use the old route. Such interruptions are expensive for the mining company, and therefore fencing leading to the route was erected by LKAB. In this way another measure claimed by the Samis at an early stage was realized.

The trial period was at an end in January 1973. Now the initiative lies with the Samis. The case will be taken up again when the time is opportune for such a measure, but the Samis have until 1976 to consider the matter. But other interventions have occurred in connection with the new route. The most serious one is the 1972 decision of the mine-inspector, granting LKAB the right to dump dead rock along the migration 
route. The Sami community attempted to oppose this decision, as it would affect migration. The main problem is that of night pasture, as the area in question has only $50 \%$ lichen pasture. The proposed change would mean that a large area of night pasture, about 100 hectars, along the present route would be lost. This, in turn, would necessitate some detours. As the days are so short during winter migration - about 4 hours of daylight in December-January - the effects of any prolongation of the route are serious. The Samis offered LKAB another area nearby instead, a swamp, but this was refused. As their reason for refusing, LKAB stated that it would be far too expensive to use the swamp. SSR took up this question and sent a protest to the Crown Lands Judiciary Board, but this was also without any result.

The joint committee met in Kiruna in the autumn of 1972 , and the Samis presented their points of view at this meeting. They emphasized that the community would prefer to keep the route which they had used since the exploitation of Nokutus had started; the most serious consequences of this proposed dumping of waste rock would be that they would sooner or later have to find a new route, which would have to lead north of the drained L. Nokutusjaure. Two new enclosures would then be required, with overnight stopping places, and fencing would have to be put up along the Torne river, to prevent the animals mingling with those from $T$. The risk of such straying and mingling would increase considerably, as such a route would be closer to the community boundary.

Because of these additional encroachments on the last remaining migration route available, $\mathrm{R}$ still feels its very existence threatened. For this reason the Samis applied to the Regional Agricultural office in 1972 , requesting a ratification of the new route of migration; this was, however, turned down. Thus the Sami community is still without secure guarantees. Since then $R$, with the support of SSR, has protested to the Agricultural Board. In this connection we may add that both the Kiruna communities intend to bring a law suit of principle against the state, dealing with conditions generally prevailing in Kiruna, an action similar to the Skattefjäll case. 
Nokutus will also form part of this large-scale confrontation. Thus it seems very likely that the exploitation at L. Nokutus will be further discussed in relation to this wider context.

It appears from the above that the sequel was marked by several new measures, brought about on the initiative of the Samis. The relations between the two parties are now considerably improved, but even so, when LKAB finds that new measures are required, the concern is not even now prepared to show consideration for the interests of the Sami community, as is clearly illustrated by the matter of the waste rock. In this crisis the Sami community found it better to act on a broad juridical front by means of a case of principle, rather than to let the matter dwindle away in a specialized court of the type represented by the Water Rights Court. This point of view represents a strategic choice based in the main on the experience gained by the Sami community in this particular case. Another consequence of great importance during this phase is the fact that SSR has put the Nokutus case to use in several matters of principle. In 1969 and 1970 SSR issued statements regarding a number of new bills which had been proposed, such as the one concerning a new Reindeer Husbandry Law (SOU 1968:16) on which SSR remarks i.a.:

Any grants or conveyances of reindeer pasture
should be attended to by the Samis themselves.
The Crown Lands Judiciary Board should not be
concerned with the legal surveillance of the
rights of the Samis. The Code of Procedure
is formulated in such a way that all parties
must represent their own interests by their
own efforts. It is the responsibility of the
court to make a distinction between the par-
ties. In several cases the Crown Lands Juri-
dioiary Board has tendered propositions detri-
mental to the Samis, for instance in the Aitik
case in Gallivare and the Nokutus case in Kir-
una. In an action in which the Samis are in-
volved, the presence of such "persons represen-
ting the Samish interests" is not, from the
point of view of the Samis, desirable.

A revision of the Water Law and the Mines Law has also been proposed. The following quotations from SSR's comment on these two proposals emphasize the fundamental importance of the Nokutus case. 
The question of the return of the water areas to their original state is of importance to the samis. As an example we should mention L. Nokutusjaure in Kiruna, whose level has recently been lowered because this was found desirable by the mine... In cases concerned with water it appears that the present law is not interpreted as including provisions to the effect that the level of Nokutusjaure should be restored, as the ores under the lake are being mined. Such provisions are now required.

When the Water Law is revised, it is essential that deferment of compensation to Sami communities and individual Samis, as well as to the Lapp fund when this is involved, must be prevented. In cases of encroachment in particular, impossible situations are likely to arise when the decision as to the responsibility for the encroachment can be deferred. The Nokutus case provides an excellent example of this...

After the trial period is over, it will be impossible for the samis to prove that the encroachment is a result of $L K A B^{\prime} s$ intervention. LKAB will presumably protest that they are not responsible for the damage, but that the damage was done by one or more other interests opposed to the Samis. (Comments sent on the Water Act report, 10th April 1969.)

The Nokutus case does not represent a success for the Samis to the same extent as Altevatn. But Nokutus has already had one positive result: for the first time the Samis of Kiruna have been able to take part in a confrontation of this kind and obtain some of their claims. The most important matters, those of financial compensation and fencing along the route of migration, may still form the subject of a trial in court. Thus R, as a local community, has by means of this lawsuit improved its position in a relationship of continuous competition. This has increased the self-respect of the people involved, and provided them with new strategic tools. They know now that in any future cases of exploitation one important choice of action is to defend the vital interests of their community by means of a trial in court. Many also feel that the Nokutus case, in spite of its outcome, had another still more important result: this, the other positive aspect, we have touched upon above. We are here referring to the development of a functioning organ for collaboration between LKAB and the Sami community. 
Nokutus is not as far-reaching or comprehensive a case as Altevatn. By comparison, its fundamental importance is rather marginal. But in conjunction with one another, these two cases are very illustrative of the dynamics of the changed political form.

The two case studies here presented illustrate a number of common features, all of which are typical of the new form of action. In both cases the opponent is represented by extremely great economic interests, a fact which made additional demands on the Samis. Samish participation in the course of events was manifested partly by numerous meetings between the so and the heads of households, partly by other types of communications, especially by letter. Such participation in important events is new, and it is of tremendous importance to the developing selfrespect and ethnic awareness of the Samis. Another phenomenon which should be observed is that of the expansive force regarding resources which the Samis are now known to possess. This mobilization of resources forms part of the Samis' adjustment aiming at the most favourable possible outcome of every case of confrontation. Part of the minority-political potential of SSR is reflected thereby. This change, which on the whole dates from 1962 , the year when the office of the SO was established, is characteristic of the growing political form. Among other social situations shedding light on the potential of action of the political form we should mention official enquiries. The next two chapters deal with two such cases of official investigations and reports, which are of particularly great fundamental significance to the Samis and their future situation. They will be penetrated in a similar manner. 
1. The intensity of the second phase of these micro-processes that occurred between 1962 and 1968 is illustrated by the fact that the exchange of notes between the SO and $\mathrm{Z}$ amounted to 95. In addition they had 6 meetings. The SO and $T+S$ exchanged 27 notes in addition to having 4 meetings including the Kiruna meeting.

2. The chairman of SSR, who is both a linguist and an ethnographer, and the Sami consultant (SK) were to be heard as expert witnesses at the main hearings. The latter's testimony was very important as the Swedish Samis need for Norwegian grazing had to be emphasized. After a general description, partly historical, partly contemporary, of reindeer herding the SK went through the distribution of different rock types with the aid of geological maps. Lichen grazing is to be found on the primary rock formations while grass is found on the sedimentary deposits. North of the lake Torne there are only primary formations with the exception of the most northerly area of $\mathrm{Kä}$. This is the reason why the demand for Norwegian grazing is so great, and this was the main reason for holding this trial. In addition the two local representatives were also called as witnesses.

3. In this 17 page statement, dated March 6th 1968, the Samis state, amongst other things, the following:

That a national delegation presented an ultimatum during the final phase of the negotiations, and threatened to tear up the results of the negotiations unless specified concessions were made, is incompatible with the intentions of the enquiry. Such an ultimatum, however, has been given by the Norwegian side concerning, amongst other things, the Altevatn district. That just this district was chosen, most probably has a direct link with the trial between the Norwegian government and the Swedish Samis $T+S$ in the HR. This appears from the statements of lawyer $A$ who has had the opportunity of participating in the Norwegian delegation and as the Norwegian representative at the trial. The whole master plan concept has been diverged from because of this ultimatum.

4. The sources were the Egil Saga from the 1220's, the QvigstadWiklund collection of historical documents of 1909 , and finally two articles by Ræstad which deal with Sami legal historical questions. (A detailed commentary on these documents and how they were used can be found in Svensson,1973a:131-132).

5. At the beginning, the Swedish authorities tried to play down the importance of the Altevatn verdict in different ways. It was a success for $T+S$ but nothing more. However, it has gradually become apparent that the verdict has general importance. Of course, an explicit statement of to what degree is avoided. The problem is delicate because the Swedish authorities were to negotiate the text of the new Swedish-Norwegian 
convention, while at the same time the government is one of the parties involved in the Skattefjäls case and other important legal confrontations. On the whole the authorities act more cautiously now, and whether or not they try to play down the importance of the verdict, they have been influenced by it. During the $70^{\prime} \mathrm{s}$ this change has become apparent in concrete situations.

6. First, the court gave permission to this activity. The reasons given for this were that it cannot be considered that reindeer husbandry will suffer particular damage. Neither can it be considered that the living conditions of individual samis will substantially deteriorate as a result of this activity.

Second, the following compensation was awarded to $R$; a new route without fences is to be opened before drainage work commences. An enclosure, with paths leading to the start of the route is also to be provided, in order to make movement more effective, as well as a watchman's hut complete with telephone. LKAB was not, however, required to finance the provision of feed in the enclosure. 



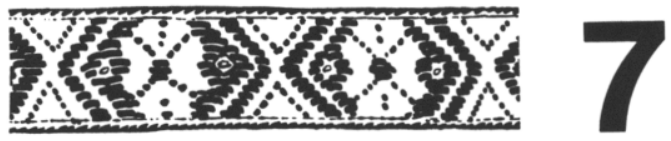




\section{Samish pasture rights in Norway}

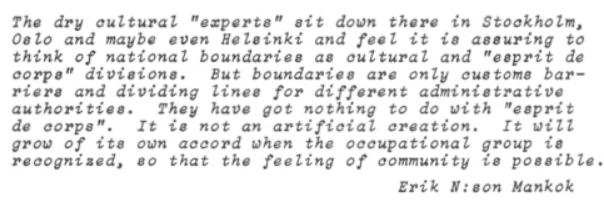

As I have stated in earlier parts of this work the activities of the Samis as an ethnic minority are to a large degree constrained by a legal framework set forth by the larger society. In order to change this premise for action a new legislation is required by the general political institutions, i.e. the Riksdag and the Government. Legislation of this nature is, as a rule, preceded by official enquiries that map out the present conditions in detail and propose improvements. This is a common procedure in all political life of Sweden, something the Samis as a minority have to adopt themselves to. By this parliamentary practice, however, it is possible for the Samis to bring about changes which increase their frame of political activity.

There is a clear difference between such enquiries that have been initiated by the authorities and those which have come about as a result of persistent pressure from the Samis. Because both kinds of enquiries form the basis for Samish minority political actions in the future, I think it is important at this stage to select a couple of current cases, as an amplification of the cases of exploitation. In this way it is possible to elucidate the minority political position of the Samis from an interactional point of view. The cases chosen are first the one that has to do with Norwegian pasture rights and second the introduction of a new Reindeer Pasture Law. Both these enquiries were carried out during the 1960's with a limited participation from the Sami side, and as they led to new legislation in 1972 and 1971 respectively they may, like the cases of exploitation, be regarded as complete po- 
litical case studies. By going through, in great detail, these extensive events I hope to indicate clearly the political potential which the extended political form has acquired. These events are political, and they are oriented towards political gains, which mean a change of the existing power relations. At the same time both these cases illustrate from direct situations of action how restricted the political influence of the Samis is and that in general the power relations have been altered only in a very small degree. The cultural consequences of the power relations between the Samis and the wider society will, however, be clearly elucidated by a thorough account of these sequences of events.

The Samish right of pasture across the national frontier providesa good example demonstrating the palpable interference of the wider society with the vital life conditions of the Samis. This right is deeply rooted in tradition, and it is largely determined by the ecological conditions. The pasture land on the high mountains, which has been essential to the Samis since reindeer keeping first developed during the fifteenth century, ${ }^{1)}$ lies practically entirely on the Norwegian side of the border as regards the four northernmost communities. South of L. Torne, too, the reindeer have been pastured on the other side of the border, for the national frontier does not by any means form a natural border from the point of view of reindeer herding.

The first codification of this practice dates back to the 1751 frontier treaty between Norway and Sweden. This treaty has a codicil about the Samis, providing future guarantees for their rights to use these regions. This chapter is not intended as an exhaustive discussion of the entire complex concerned with the relationship with Norway - it is mainly confined to the present situation. A Swedish-Norwegian enquiry, the Swedish-Norwegian Reindeer Pasture Commission, submitted in 1967 a proposal for large-scale change. This report forms the subject of the present chapter.

On the macro-level the prelude of this particular case illustrates some divergences of attitude between the acting 
parties. The existing convention between Norway and Sweden is unilaterally attacked by the Norwegian authorities. In the late 1950's Norway found it unacceptable to prolong the reindeer pasture convention, mainly due to the lack of reciprocity regarding the favors offered to the Samis in the two countries. This aggressive attitude is further emphasized by the attack on the codicil, the oldest legal codification of the Samis, and the announced threat to punish severely all illegal Swedish reindeer pasturing in Norway.

At this stage the Norwegians carried out a very active policy aiming at specific goals such as a new convention implying large reductions of the pasture rights presently held by the Swedish Samis in addition to the abolition of the codicil, which document long has been considered injurious to the sovereignty of Norway. In contrast the Swedish authorities maintained a passive attitude and acted extremely yieldingly.

But the Samis, who soon became aware of what was about to happen, started to act according to their limited resources. In 1962, for instance, the matter was discussed at the Nordic Sami Council, which stated that they could not simply stand by as disinterested spectators while the interests of the Norwegian and the Swedish Samis were being played off against each other as tokens in a game of national considerations. On request of the Nordic Sami Council the Nordic Council urged the two governments to prepare a new reindeer pasture convention which was in accord with the interests of both Sami groups and which ought to be worked out with Samish participation. Most important from the point of view of the Samis, however, was the appointment of the so in the same year. Because the Swedish authorities remained rather passive, the Samis realized more and more clearly that they had to have their own legal experts. Therefore SSR could demand that the so should act as their representative in the delegation which was to take part in the preliminary negotiations.

Otherwise, SSR made great efforts to mobilize the people on the micro-level. This was done by the so and the SK who 
held some meetings in the local communities most concerned in order to inform the people there about the issues at stake and to make them commit themselves to the case. Moreover, SSR argued that the official motives for making changes were incorrect. In this respect they put forward a kind of ecological reasoning. It is a well-known fact that winter pastures constitute a minimum factor for both Swedish and Norwegian reindeer herding groups. There is, however, no competition between them over this type of pasture. The summer pastures in county Troms, on the other hand, are so ample that they should certainly suffice for both Swedish and Norwegian Samis. If the question could have been confined to these two Sami groups with little or no influence from the wider society it was believed that they most likely would have found a sensible solution to the problem. Many Norwegian Samis gave their support to the argument of SSR. This idea was, however, firmly rejected by the authorities in both countries.

Considering the delicate situation at hand, it was important for the Swedish Samis to act with great caution during this introductory phase, as they realized the significance of avoiding serious clashes with the Norwegian authorities. The Samis' actions were all the time restricted by the threat of acts of retaliation, a fact that made it extremely difficult to act at all.

In February 1964, both governments appointed their delegations to the Reindeer Pasture Commission. This commission was to work out a proposal for a new convention. This decision was the end result of a political game at the macrolevel between the central political and bureaucratic bodies of the two countries. The Samis' opportunities to interfere and to influence the outcome of this game were constrained mainly by the aggressive attitude held by the Norwegians and by their own powerlessness in all macro-political contexts. In cases like this the position of an ethnic minority is inevitably weak. This will be confirmed even further when we discuss the specific enquiry both concerning the process of enquiry and the report. 


\section{The Specific Enquiry}

a) The process of enquiry

It should be kept in mind that this enquiry primarily was an affair between the two national states. With the aid of diverse expertise Norway and Sweden were to work out a proposal for a new convention. The political pressure on the Swedish delegation was particularly noticable because the Norwegians persisted in their harsh attitude. Besides the measures mentioned before, in the final phase of the process of enquiry Norway issued an ultimatum threatening to thwart the result of the discussions entirely unless Sweden agreed to certain concessions. The Norwegians were thinking first and foremost of the Altevatn district and the ultimatum was announced while the Altevatn case was still being tried in the Supreme court.

For the Norwegian delegation it was opportune to act in this way. They did also possess the right prerequisites for action, because the solicitor representing the state in the case against the Samis at the Supreme Court was also a member of the Norwegian delegation. This Norwegian move far exceeded the mandate to which both governments had once agreed. The Swedish party could therefore not act as freely as desired and this delegation was forced to remain rather passive and pursue a wait-and-see policy until the Altevatn case was concluded.

As regards Samish influence and participation it was mainly limited to two representatives who entered the Swedish delegation. They were appointed by the SSR and were to work in the pasture group, while the reindeer group mainly consisted of representatives from the administration. The narrow authority base the Samis could plead was even further weakened because the Norwegian Samis only to a limited degree were brought into the process of enquiry. In this way the Samish representatives were forced into so obvious a minority status that they were unable to assert the interests of the Samis effectively.

This shows that the two macro-structures had defined the 
situation somewhat differently; to Norway this was more a question of national concern than a matter that had to do with the Samis, while Sweden, at least in part, attempted to look at this controversy from a Samish point of view. This divergency in the definition of the situation also affected the ability of the joint delegation to bring about a common proposal for change.

The So was also cut off from direct participation, and during the process of enquiry could only act indirectly, partly through the elected Sami representatives and partly through lobbying. In addition to this the Swedish delegation held only one informative meeting in the three year period and that already in 1964. This meeting was confined to the four northernmost communities. Apart from being informed about which pastures etc. the Norwegian adversary might deprive them of, the Samis were also given the opportunity of stating their own views about pastures in Norway.

The restricted capability of the Samis to influence a process of structural change, is quite apparent. First the contact and exchange of ideas between the delegation and the people who are directly affected seem to be rather meagre. Second the Samis in the delegation are outnumbered and too powerless to assert their cause. This is made clear not least by the reindeer-keeping representative's separate statement, which took the form of a supplement to the report. ${ }^{2}$ )

\section{b) The report}

The proposals for changes included far-reaching restrictions in the Swedish Samis' right to pasture in Norway. Map II shows the losses which the Swedish Samis were likely to incur if the proposals were accepted. Changes of this type do not lead only to economic consequences - the social organization is also affected.

Kä, for instance, has since the 1949 revision of the convention made use of six different districts. The proposed change would leave the community only two of these. Two of these six districts, Lyngsdalen and Marknes, have been 
surrendered for purely practical reasons. The Norwegians claimed that Nordnesset had also been surrendered voluntarily, and Norway therefore immediately wanted to take over this district. This was, however, a gross oversimplification of the actual facts. The sii'da which had traditionally migrated to Nordnesset was compelled to discontinue doing so, as they lost far too many reindeer every summer. The Norwegian group in the adjacent district, Skerfavagge, employed a method common in Finnmark - they gathered together all the reindeer, regardless of the owner's mark, before the autumn migration. The Swedish Sames applied to the authorities for help to build a border fence. There was already such a fence on the Finnish side of the district. A fence about thirty $\mathrm{km}$. long would have sufficed, and it would have formed an effective boundary between Nordnesset and Skerfavagge. At first the Swedish administration promised to have such a fence built, an attitude which was changed later, with the motivation that it would be too expensive. The Norwegian Samis did not want to have a fence, and therefore it was easy for the administration to arrive at an agreement which did not serve the interest of the Swedish Samis. The Samis of this sii'da did all they could before they finally gave up this excellent district. The reindeer were tended daily in order that one might avoid them mingling with others, but the nature of the terrain makes it impossible to avoid such mingling.

During the final phase, eight heads of households with about 2000 reindeer migrated to Nordnesset, while six heads of households migrated to skerfavagge. Two of these six, the Kemi brothers were related to the leading group of brothers at Nordnesset, and for a long time they had migrated with the Swedish Sam is to the winter pastures in Kä. Because of this close relationship (they were cousins) they had also been allowed to pasture their animals at Nordnesset in summer. During recent years, however, the Kemi brothers had chosen to stay at Nordnesset also in winter. As neither any of the other Skerfavagge heads of households nor the Kemi brothers were willing to gather in large herds of reindeer in order to separate them to- 
gether with the Swedish Samis, the latter lost an important possibility of controlling their own private property. In accordance with the convention, all the unmarked reindeer thus became the legal property of the Norwegian Samis, especially of the Kemi brothers, who had the full support of the Lapp sheriff when they set their own mark on all the unmarked animals after the following lst of May.

Another factor to be considered is that the Finnmark Samis gathered frequently in small groups in different reindeer enclosures in order to mark and separate the animals. It was practically impossible for the Nordnesset group to keep an eye on all these enclosures. Moreover the Norwegian Samis slaughter reindeer throughout the summer, as distinct from the practice of the Swedish Samis, who suspected that Swedish reindeer were being slaughtered. Evidence of organized theft was to hand - this refers to an incident during the summer of 1958/59, when the entire Nordnesset group was in Karesuando, where they attended a funeral.

The relationship between these two groups has deteriorated more and more, and in the end the Nordnesset group were forced to realize that it had become impossible to continue this traditional migration. This was made quite clear by the fact that the Swedish herds at Nordnesset decreased every year, while the Norwegian herds increased.

When they realized that the administration - and especially the Norwegian Lapp sheriff - supported only the Norwegian Samis and their interests, the Swedish Sami.s felt that they had been slighted. They therefore felt compelled to leave the district. But the majority of them were opposed to migrating to a large district, and they applied for permission to make use of some smaller districts, including Lyngsdalen, which was vacant at the time. Their application was, however, refused by the Swedish administration.

The conduct of the Swedish administration in this matter was highly detrimental to the interests of the Swedish Samis; in fact it lent more strength to the position of Norway at the time when the negotiations for a new convention were to start. 
1962 saw the last migration to Nordnesset, and in 1964 a Norwegian note demanded that Norway should transfer 2000 reindeer from Finnmark to Nordnesset. Instead of defending the interests of the Swedish Samis, the Swedish state yielded to the Norwegian demands, and thus another district had been manipulated away by the wider society.

The social implications are perceptible. This sii'da, which had practiced reindeer keeping on their own all the year round, was now compelled to enter a strange district, one with a more extensive type of herding. Moreover, the families could no longer accompany the heads of households on migration, for they had no alternative to move to - it takes time to establish the relationship with the settled people required for life on the summer pastures. ${ }^{3)}$ The niche provided by tourism was also lost: these Samis used to pitch camp near the road, where they could sell reindeer products and handicrafts to the tourists passing that way. The women tried this during the following summer as well, but they were driven away by the Norwegian Samis, who considered that the Swedish Samis no longer had any right to trade with the tourists as they had no longer any reindeer grazing there. The perceptible losses also include the eleven small houses which had been built by Galgojaure as well as three calf-marking enclosures and a separating enclosure, which the members of this sii'da had built at their own expense. The Swedish Samis have not received sufficient compensation for these losses from the Norwegian state.

I have dwelt at great length on Nordnesset, because this example illustrates particularly well the manipulations carried out by the bureaucracy at all levels. The Samis affected by this matter would still today dearly like to migrate to this district, as statements made by both men and women show. Some of them did not realize until long afterwards that they had lost the district forever, as a result of the bargains and compromises made by the two Foreign Offices. ${ }^{4}$ )

The fact that the Swedish authorities agreed to give up Nordnesset resulted in still greater demands from the Norwegian authorities. Thus Sweden was on the defensive right from the 
beginning. The Samis tried to exert their influence on the Swedish Foreign Office, and sent a memo which described the conditions in Nordnesset in great detail. This document, based on the initiative of the SO, was worked out by him in collaboration with the SK and the $s i i$ 'da-ised of Nordnesset. But when the Foreign Office was to take a stand on the matter in 1964, they ignored this memo completely. ${ }^{5}$ )

Conditions in Rendazen are similar. According to the proposal, this district was to be used in summer by two families from Finnmark. The sii'da which had migrated there some of its households for generations - wanted to retain the district, and they continued to migrate to Rendalen while the enquiry was in progress. Now they can no longer do so. The older reindeer, however, continue to stray there on their own, and some of the members of the $s i i$ 'da were thus forced to continue to camp by Lyngseidet, the site traditionally used by these Samis. According to several informants it is much better that the reindeer should be in a separate district in this way, nather than that the entire reindeer herd of the whole Sami community should graze together in one large district. Such a practice leads to difficulties when the calves are to be marked. It thus appears that these small groups suffer economic consequences from changes of this type, for they find difficulty - especially during the initial stage of transition - in adapting to the new ecological situation enforced by the authorities.

The following restrictions of the rights to pasture reindeer on the Norwegian side of the border were proposed for $R$ and $\mathbf{l}$ : a large part of the Norwegian pasture land is forfeited (see map II 2; further, the time of pasturing is reduced from $2 \frac{1}{2}$ to $1 \frac{1}{2}$ months. These restrictions were also designed to benefit the Norwegian reindeer keepers.

It is obvious that the commission did not consult the Sami communities affected by the matter at all in this case. The heads of households of both $R$ and $L$ have called attention to the fact that it is crucial for their reindeer keeping that they should be allowed to use the Norwegian pastures until the 
15th of September. During July, on the other hand, these pastures are not as vital. For L, however, the Norwegian pastures are vital, and they are not prepared to renounce them voluntarily. Especially during hot summers the reindeer tend to move to the Norwegian grass pastures, which lie at a much higher level than the Swedish pastures. $R$ does not depend quite as much on the Norwegian pastures, but the Samis of $R$ want to ensure an effective boundary. In this way, a few families could be moved from Finnmark to Troms, in Kä for 1100 reindeer and in $\mathrm{T}$ for 1500 .

\section{Sequel}

The report was published in November 1967. Because the Samis' possibilities for influencing the enquiry had been so constrained, most Samis on the grass-root level had very little idea about the changes at stake. It was, therefore, felt to be very urgent to offer these people extensive information about the matter. At the request of SSR the administration sent four copies of the report to each of the Sami communities. SSR also demanded that all the Sami communities should be personally informed by the proper authorities as to the content of the report. This form of direct contact between the experts who were responsible for the report and the people affected by the suggested changes is essential, for most Samis have great difficulties in understanding the highly formal language employed in documents of this kind. Such a move also gave the Samis a chance of reacting and of conveying their views on the proposal to the representatives of the Swedish delegation. The so also took part in the informative meetings convened for the northernmost communities, and after the Community Meetings he had individual conferences with the Samis. He informed them of certain tactical lines which would be adopted in future, and the Samis supplied the so with important local arguments pertaining to the matter. The so also read to them the draft for a commentary on the report.

The proposed changes came as a shock to many of the Samis. They had realized that the Norwegians were on the offensive, 
and that they would claim some of the Swedish districts, but they had by no means expected the results of the enquiry to be so far-reaching. In many ways the Samis felt that they had been out-manoeuvred by the authorities. The Samis in L, for instance, where nothing had been known beforehand, were very bitter. They were especially surprised by the remarkable fact that a commission which had worked for three years had not once during that time visited the people concerned, but had instead chosen to formulate a proposal for change without consulting the Samis themselves. At the meeting the impression was also conveyed that there was no point whatever in the Samis making any seriously meant comments, seeing that the matter had already been decided at the national macrolevel. This was confirmed by the officials present who stated that during the entire process of enquiry the pressure from the Norwegians was felt very strongly and that no effort had been spared in trying to protect the interests of the Swedish Samis. Due to this it was not likely that any important change could be made in the report. This rather submissive attitude was disquieting to the Samis.

We saw the report for the first time now at the meeting. When one reads it, one gets the impression that $L$ does not need any Norwegian pasture at alz, and that is quite wrong. When someone is unfinching and hard as bone - and this $X$ has been right from the beginning - whatever is the point of coming and asking us? Our views are surely without any sense at all in this case. Things are so bad that if this report is approved. I shall either move or give up reindeer keeping. One can no longer stay here. The whole month of August can be hot, and then we must be able to use the Norwegian pastures we have now, for the Swedish pastures are not enough. During the last years we have spent weeks in Norway gathering in the reindeer, in order to get them out by about the roth of September. One can hardly call this a sound enquiry - they have worked for almost three years without even once consulting us before publishing their report. Then it is about time?

The final commentary for consideration was worked out by the board of SSR. This did not give any detailed criticism of the actual proposal but confined itself to principles. The mandate of the committee and the methods employed during the 
enquiry were questioned. The main reason for this criticism was that the mandate implied that the committee must avoid all legal appraisements. This greatly impaired the situation of that group of Samis on which perceptible losses of land were imposed, in this case the Swedish Samis. Furthermore, the commentary stressed the difference in the attitude officially adopted by Norway and Sweden respectively towards the Samis as a group; as a result of this the Swedish representatives had been working at a serious disadvantage in the course of the enquiry.

The Norwegian motives for changing the allocation of pastures were criticized. The Samis meant here that the problem of over-population experienced by the Norwegian state in Finnmark, especially in Kautokeino, could hardly be solved by depriving the Swedish Samis of a few districts which could then be made available for all-the-year-round reindeer keeping in Troms. The families which might then be moved would be far too few to have any noticable effect, whereas the effect on the lives of a great number of Samis in Northern Sweden would be highly detrimental. The Swedish Samis also found reason to call attention to the ultimatum issued by the Norwegian authorities towards the end of the work of the commission.

Finally, great attention was also devoted to the Lapp codicit of 1751, and a detailed scrutiny of the principles of this document was presented. The character of this codicil, as the first document codifying the rights of the Samis, was emphasized particularly strongly. Strong objections were therefore raised against the attacks which had been made on the codicil, particularly by certain sections of the central bureaucracy in Norway.

As we find from the above, in the commentary the Samis chose to canalize a position founded on principle and left it to the local communities to react in detail regarding the allocation of pastures. The points put forward in the commentary were in close consonance with the Samis' general political ideology. 
The phase that followed then was particularly important. On the basis of the proposal submitted, a Norwegian and a Swedish delegation were to negotiate a new convention text. In the composition of the delegations we notice the continuing discrepancy between the two nations regarding Samish participation. The Norwegian authorities were content with having only one Sami. member in the group of five advisors that were to assist the negotiators. In Sweden, on the other hand, SSR had achieved two essential demands: firstly that the SO as an observer was to attend all internal meetings held by the delegation; secondly that the delegation during the process of negotiations should remain in contiuous contact with a group of experts, consisting of four Samis besides the so. This group could fall back upon SSR as their formal authority base.

This difference in basic views on the macro-level, which already at the process of enquiry was apparent, was stressed even further in this latter phase. The problem at stake deals directly with the life conditions of a definite category of people, the Samish minority. Furthermore, it is a matter of reindeer herding. The Swedish delegation consented to five Sami representatives, three of which were reindeer keepers, who would assist them in their negotiation work, whereas the need for the Norwegians was covered by one representative, a university trained Sami.

It seems rather unlikely that officials who differ so much in fundamental views on this particular point should be able to obtain an agreement that would pay due attention to the interests of both Norwegian and Swedish Samis. The positions of the delegates were from the very beginning blocked by this divergency of values, and the Swedish Samis were, therefore, constrained in their effort to acquire political gains, i.e. a change of the original proposal.

After having made this point clear we can now relate the work of the Swedish delegation, thereby illustrating in what way the Samis were able to influence the matter. According to the relationships established, the Samis at the local level were now able to convey their concrete views of the issue, 
partly through the group of Sami experts, partly through the separate participation of the SO. This contact flowed both ways, since the representatives of the group of experts and the SO through SSR continuously were able to keep each local community informed about the progress of the events. These channels of communication facilitated the maintenance of direct contact between the distant delegation acting on the macro-political arena and the Samis on the grass-root-level. The established flow of ideas also generated a local engagement for a central-political case, something which at the time must be considered extremely unusual among the Samis.

The driving force of this development was SSR, and on the initiative of this organization a local conference was convented in Troms in which Swedish and Norwegian Samis were to discuss common pasture conditions.

The matters discussed in particular detail included that of Falsnesfjellet, a mountain which is the subject of rivalry between Swedish and Norwegian Samis. The Samis from Könkämä would have preferred to keep the entire district. However, as this district has lichen pasture, it is of great importance also to Norway, and therefore the interests of the parties concerned diverged greatly. The Kemi brothers formed one of the Norwegian groups at the conference, and the Norwegian authorities were fully aware of the long-standing antagonism between these brothers and Kä. Now the Norwegians could turn this antagonism to their advantage. The Kemi brothers argued that they needed more land, and the Swedish delegation, together with Kä, pleaded that Kä required, and should be allowed to retain, the entire Falsnesfjellet district. The Kemi group hardly needed more pasture land than they would gain as a result of the report. But for the tactics of the Norwegians, the mobilization of this group was of great importance in this connection; the Swedish Samis present realized with sufficient plainness that Norway intended to move other Samis to this district.

Investigations in the field had shown that the proposed border was unacceptable. Attempts were therefore made now to have this border moved slightly, in favour of $\mathrm{Kä.} \mathrm{Moreover,} \mathrm{all}$ 
parties agreed that if the district were really to be divided, a fence must be erected, for otherwise a considerable degree of mingling would be unavoidable.

Further, Saarivuoma stated that they wished to continue using Dividalen, a claim against which the Norwegian Samis affected protested. They were planning to carry on all-theyear-round reindeer keeping, and this would not be possible if $S$ were given access to the whole of Dividalen. But no one from $S$ was able to concur with this assertion, since the reindeer graze on different plants at different times of the year. Visits to the districts of Altevatn, D $\phi$ desfjellet and Falsnesfjellet were also carried out in connection with this meeting, which supplied the Swedish delegation with information new to them on some of the controversies and problems arising from the report submitted; at least SSR felt that they should be able to make use of this newly acquired insight in the subsequent negotiations.

In order to stress the importance of the statements made at this conference the four Sami communities issued written declarations. S, the Sami community most seriously affected, for instance, sent the most copious statement. The reaction of this Sami community constituted a severe attack on the report, an attitude shared and supported by the three other communities.

The report of the commission, dated 24 th February 2967 , in practice proposes the liquidation of the Sami community of Saarivuoma. The reindeer were to be transferred to districts other than Altevatn and Dividalen. As a result $S$ would in practice be eliminated. Mr. Per Idivuoma has submitted a strong reservation against the proposal of the commission. The report of the commission would surely have been more favourable towards the Swedish Samis and $S$ if the verdict in the Altevatn case had been published and known at the time the commission submitted its final report. The verdict of the court of reappraisal was, however, known. But the Swedish experts participating do not seem to have considered it likely that the Supreme Court should really defend and protect the legal rights of the suppressed Samis. Not until long after the supreme court verdict had been given did the highest authorities of Sweden acknowledge that the civil rights of the Samis had existed for generations, and that they continue to exist. While the commission was at work, Norway had pursued the case with particularly great severity, in the hope of being able to use the report of the 
commission as an argument against the Swedish Sami communities $S$ and $T$ in the Supreme Court. Supreme Court lawyer $A$ actually did cite this report on behalf of Norway, but the Supreme Court overruled this attempt at influencing the bench by means of administrative measures. The sami community of Sarivuoma wishes to retain the Norwegian districts to which the community, according to the findings of the highest Norwegian court of law, is "entitled". (Communication from Saarivuoma, 5th December 1969.)

Another example of local comment was the written statements made by the same four communities regarding the codicil. This document was considered to be of such great significance to the Samis both for political reasons and for its symbolic value, that they wanted to make this view-point clear to the Swedish authorities. At the same time even the so made a statement similar in content. The Samis referred to the Altevatn verdict in support of the significant status of the codicil. This verdict also made possible the argument that the Samish rights could be put into practice also by modern methods, with the aid of modern technology. The articulation of this point was essential, as the Norwegian delegation tenaciously insisted that the Samish rights applied only to traditional reindeer keeping, according to nomadic methods. This conservative attitude on the part of the authorities had been rejected by the supreme court. The Samis stressed the point that both in Sweden and in Norway they wanted the codicil to remain irrevocable, mainly because this document had such great general value to the Samis, serving as their own Magna Charta. Through contacts with influential Samis in Norway it was possible to work out a firm agreement on this point, stating that: without the codicil there will be no convention. This unified action supported by a resolution from the Nordic Sami Council in 1968 and a statement made by the Swedish Attorney General in 1970, weakened the attack on the codicil made by the Norwegian delegation. (See also T.Cramér, 1970a).

If we sum up the discussion so far we may state that the frequent interactions between the $\mathrm{SO}$ and the local communities on the one hand and the specific group of Sami experts assisting the delegation on the other, illustrate some of the dynamics within the developed political form. This latter ad hoc 
group forms an extremely important element of the highly intricate interaction connected with the reassessment of SwedishNorwegian reindeer pasture relations. We must keep in mind that the Samis had been practically entirely excluded from the work being done at previous conventions. The fact that such ac hoc groups can now participate in processes of this kind is also a result of the political form developed, and it may be regarded as a supplementary element thereof.

Furthermore, the SO maintains a significant role in most local political actions. He often initiates and selects the right opportunity for measures to be taken; he assists the Samis in articulating their arguments in the most efficient way, and, finally, he acts as an intermediary in the relations between the Swedish delegation and the local communities. Thereby the so together with the Sami communities concerned form a situational team directly supported by SSR. The joint actions which emanated from this team illuminate the power potential of the political form now at hand. These types of team constellations have to a limited degree increased the influence of the Samis in specific situations of enquiry and legislation that are relevant to their life conditions. This represents something new in the political organization of the Samis.

In 1971 the negotiating delegation presented its proposals for a new Reindeer pasture convention. Quite soon afterwards the Sami communities were informed of the proposals, partly by SSR to the assembly of delegates at the national meeting the same year, partly through special meetings arranged by the delegation in the Sami communities. This information later formed the basis of the ensuing Sami actions.

The political result of the work that the Samis had put into the negotiating period was that a further two districts could be secured for the Swedish Samis. These are Anjavassdalen and Havgavuobmi that were allocated to Saarivuoma. In this way the relocation of a large number of families from $S$ to $\mathrm{T}$ was avoided. That this objective was achieved by the $\mathrm{S}$ Sami community and SSR was due to a large part to the Altevatn verdict. This verdict, that confirms the civil law rights of 
amongst other things the $S$ in Norway, served in this case as an effective obstacle to the threatened elimination of all the grazing rights the Sami community had in Norway. The Samis in Sweden have in this way, shown that the Altevatn verdict can be used as a direct resource.

With regard to the negotiating situation at the time it is inconceivable that the Swedish Samis would have been able to obtain further concessions, over and above those proposed in the report of the Reindeer Pasture Commission, without access to a new power source. The Altevatn verdict in HR is a good example of such a power source, that came into being after the investigation was concluded. But even this resource has a limited value, since the Altevatn district was lost. From the Swedish Samis' point of view it was assumed that Altevatn would be relinquished as a result of the favourable verdict. As a consequence, more importance was attached to other districts during the negotiations, such as Dividalen. The Altevatn area was, however, one of the few districts that had lichen pasture, which meant that all-year-round reindeer grazing could be established and this was, from the Norwegian point of view, the most desirable type of ecological zone. In, for example, Anjavassdalen, there is only summer pasture and summer pasture being what the Swedish Samis needed it was easier for them to get their demands accepted there. The consequences of this loss is that all the compensation measures, for example 14 bridges and other constructions, that were granted to the Swedish Samis by the Altevatn verdict now lie outside the convention boundary and as a result cannot be utilized by S. Fishing is also located outside this boundary. The question is, however, whether the Swedish Samis can be prevented from making use of these fishing rights that have been established by the Altevatn verdict, and in fact they still make use of them.

If this verdict carries as much weight as has been made out in several cases, the Swedish Samis should, by judicial means, be able to demand considerable compensation for the loss of that district. As a consequence these compensation demands should also include all the other losses occasioned by the new 
convention. Rights within the Altevatn district ought to be equated with rights in all of the Norwegian grazing districts.

According to several representatives of SSR the private judicial rights of $S$ in Norway have not been conceded. The convention is only a treaty. The community has chosen (after a series of decisions) to go to court in order to get this officially recognized. Should they win it ought to be possible for $S$ to reclaim the Altevatn district. The Altevatn question therefore continues to be a conflict that may have judicial repercussions for the whole of the reallocation of grazing that came about with the new convention.

A further improvement is that $K a ̈$ will be able to continue using the former Falsnesfjellet district, now called Rieppe, during a limited period of $1 \frac{1}{2}$ months a year. This right of use is to be enjoyed during a transitionary period of five years. Since this is an area of high mountains that are covered with snow until quite late into the summer, it is, however, debatable whether this area can be effectively used before 15th June. If access to the area had been made available for an additional month, this would have had great importance for $K a ̈$. It is conceivable that the primary reason for removing Rieppe from Kä was the planned water control of Lake Rieppejaure. From a Norwegian point of view it is necessary to avoid future litigation and the Norwegian Hydro-Electric Power Board has made it clear that they will not pay compensation to Swedish Samis. Similar conditions are to be found for $L$ with the Sjoumen project.

During the Autumn that preceeded the final discussions in the Swedish Riksdag the Samis made a number of moves. All the 25 Sami communities that were affected made a declaration of principles, via the so, that formulated the Samis' general attitudes to the convention proposals. This statement then served as an ideological framework for the ensuing discussions. What was given greatest emphasis however, was the importance the Altevatn verdict could have had, had this been available before the investigation put forward its own proposals. In addition it was emphasized that the compensation question had not been considered. This question must be seen as being of 
great importance for the side losing territory.

In this case the compensation question was regarded as the most central issue, and it was therefore important to make clear to the politicians, well before a decision was made in the Riksdag, that the Sami communities in Sweden would unwillingly accept that their ancient land rights in Norway, established by HR, would be frittered away in the negotiations between the two governments. Should this happen, the Sami communities would put forward far-reaching compensation demands.

At this point SSR considered it pretty hopeless to once again attempt to adjust the district boundaries. It was necessary to quickly choose a line of action that would give the greatest possible political returns. In order to prepare for this important question SSR set up a committee consisting of 5 persons who would negotiate with the government primarily about compensation questions. So was included in this committee and the committee also had access to experts of their own, a firm of development consultants, who were to appraise the value of the land areas denied to the Swedish Samis. SSR also held special meetings with heads of households both in Kiruna and Karesuando in order to go through the compensation demands in greater detail. In the statement later submitted by SSR on the convention proposals a compilation of the Sami committees' demands was consequently included, in addition to the two memoranda from the development consultants. In this way a local commitment could, once again, find channels to the national political level.

An example of the way in which, from a local point of view, it was necessary to act independently was likewise the initiative taken by L. This district turned directly to the Norrbotten County Agricultural Board and pointed out that the summer grazing in Norway was essential for reindeer herding in the district. It was also pointed out that earlier it had not been necessary to watch the Norwegian side of the boundary as this consisted of natural barriers. But with the new boundary lines much more work would be entailed in arranging watching. As a result the compensation demands that were made for giving up these areas, were much higher than those suggested by the authorities. The following statement from one of the 
heads of household in $L$ further emphasizes the formal expression of these opinions:

We really need the mountain grazing. At the moment there's enough, but if we are to achieve a rational number of reindeer, approximately 6.500 , then there won't be enough at alz. We have very poor summer pasture compared with $R$. But these experts, they know everything. They don't understand that our grass grazing can't be used since it's too warm where the grass grows.

I've been to three meetings during the preparations for the convention proposals, but by the time I came along it seemed to be too late to try to influence the matter. My grandfather lived in Norway and moved to the Swedish side in winter. The autumn camp was then at Allesvuoma. Now it is our summer camp. My father did the same up to 2929, when he had to stop. In those days they reckoned that what we are using now wasn't even worth using for summer pasture. It's often very warm and full of insects. The Samis have therefore traditionally called the area cuoi'kavuomos, "mosquito valiey", and it's a pretty unattractive summer area. And in addition there are all the tourists that pour through the valley which hardly makes for peaceful grazing.

Through these persistent pressures from the local level it was possible to arrange economic remuneration for the extra work involved by means of increased watching amounting to Sw. kr. 13.000,- per annum over a period of thirty years. According to the reindeer herders affected by this, the compensation was not sufficient to offset the loss of the Norwegian summer grazing areas. It can therefore be pertinent to ask what the Norwegian delegation's motive was in withdrawing this spatially insignificant area from Swedish reindeer management. It had been said earlier that it was going to be used by Norwegian Samis. But since there is not any winter grazing this argument falls apart. The only people who can use this area are the Swedish Samis, as without access to Swedish winter grazing this ecological zone cannot be utilized.

Up to 20-30 reindeer can be kept, but even these can be lost when conditions are difficult. I had a relative on the Norwegian side who died some years ago. He had farming as a mainstay, but kept a few reindeer at the same time. Other reindeer never came to that herd, because it's unnatural for reindeer to wander in, there's nothing to attract them there. He would 
have been a good witness to disprove the talk about year-round reindeer herding to any extent.

This comment illustrates how conscious the Samis are about effective ecological boundaries. Unfortunately the Samis frequently have difficulties in putting forward to the authorities the insights that they have attained by experience. This situation is further illuminated by the fact that, the grazing expert employed by the survey, had concluded that $\mathrm{L}$ has such good pasture on the Swedish side that the community did not need any summer pasture on the Norwegian side. The community's members who have a life-time experience of grazing conditions, had however, a completely different opinion.

of course, there is plenty of grazing pasture on the Swedish side, it's just that the reindeer can't get at it because it's often too warm there. Its accessibility that's the crux. As soon as we've reached the normal number of reindeer again, it'll be a real problem now with the new convention boundaries. But this expert, we've never seen him before, he's just a name on a paper. He's never even spoken to us, as far as we know he's just flown over the area and seen that grass grows there.

Since the convention was adopted there is no longer question of moving families from Finnmark to this area. The Samis themselves are of the opinion that the sjoumen project was the main reason for the Norwegian delegation to adhere to L's demands for grazing on the Norwegian side.

The Sjoumen fjord area has recently been developed by the Norwegian Hydro-Electric Power Board and to avoid a new Altevatn case it was important to remove the Swedish Samis from Sjoumen. L was not satisfied with this and began taking proceedings agains the Norwegian Hydro-Electric Power Board in Autumn 1973. The same lawyer that had represented the Samis in the Altevatn case was to act in this new lawsuit, and the same reindeer-herding expert, who had been called upon in many similar cases, was retained. A preliminary meeting to formulate strategy was held in Stockholm in May 1972 between a representative for the community, SO, lawyer $Z$ and the reindeer-herding expert. This action from L's side is particularly interesting since it is not clear, since the new convention, whether the community has the right to plead. This question 
will be determined by the court and will, obviously, become a precedent for other Sami communities. At the same time the case will be a test of the legal strength of the Altevatn verdict. The political significance of the latter has been clearly recognised by the Norwegian authorities through their actions concerning L's border grazing and the Rieppe area of the Falsnes mountain zone. These actions refute all the earlier statements about the Altevatn verdict, that were aimed at restricting its general implications.

SSR's five-member committee even had discussions with the Minister of Agriculture, before his motion was presented in the Riksdag, about the principles for estimating compensation, in order to avoid the loss of legal rights. This question came up again in the statement from SSR that was presented in a somewhat dramatic form at a meeting attended by over 70 samis in addition to the SO. The meeting continued for a whole day and primarily concerned the question of compensation. The calculations made by the authorities were compared with the Sami's own surveys, and the question was therefore investigated in depth in front of the responsible minister shortly before the Riksdag discussions.

In the actual 15-page statement, weight was given to the principles involved and the ideological framework was clearly expressed. The general argument, directed as it was towards the loss of land and demands for compensation, was based on references to the Codicil, the 2968 Sami political programme and the Altevatn verdict in addition to an international comparison with Indian politics in USA, with special reference to the Indian counsellor Vine Deloria Jr. (Deloria Jr, 1969). All the Sami communities as well as the Same-Atnam association also made statements about the convention proposals. It was also possible for the Samis to express their opinions through other consultative bodies such as, for example, the County Agricultural Boards and the Swedish Board of Agriculture. As a result of the 1971 Reindeer herding legislation a united number of reindeer-herding Samis are included in the two advisory boards that fall under these bodies (see chapter VIII). During the discussions in the Riksdag the Samis were 
also able to put forward their ideological viewpoints. Firstly, this took place through the SSR's statement of facts before the Agricultural Committee which was the Sames' last opportunity to influence the Riksdag's resolution.

Secondly, two motions, one from VPK (communists) and a joint one from FP (liberals) and M (conservatives), were brought before the Riksdag, that were closely aligned in their arguments to the question that SSR had pointed out in its statement. These two motions prove once again that it is possible for SSR to influence debates in the Riksdag by means of lobbying activities. The two motions together with SSR's statement formed a combined attempt, by means of a debate in the Riksdag, to achieve maximum advantages for the Sami.s before the final legislation. The Report of the Agricultural Committee also clearly shows the imprint of the arguments put forward.

After the convention was finally accepted and ratified by the Riksdag and the Storting an exchange of notes of fundamental importance also took place between the two governments. This exchange of notes, initiated by the Swedish Foreign Office, was to serve as a guarantee for the continued Sami use of the necessary grazing rights in the neighbouring country. It is worth noting that the term way of life in an official context such as this was used collaterally with the term livelihood. This serves to illustrate the way in which sami ideology is gradually permeating the establishment from widely different directions. The codicil will also remain as a document that supports the basic viewpoint expressed in the exchange of notes. It is, however, no longer nonterminable. The Swedish delegation, with the backing of SSR, and with the insistency of some Sami communities, have successfully achieved their objective of retaining the codicil's status in spite of unrelenting attacks by Norwegian opponents. As has been described earlier SSR has, ever since its statement on the Reindeer Pasture Commission's report, given a great deal of time to the codicil and its importance. That these efforts have been successful is of intrinsic value to the Sami minority's continued survival in the larger society. 
The preservation of the codicil is to a large extent an achievement that affects the Samis as a whole. And even if it is the Swedish Samis that have primarily achieved this beneficial result, the codicil probably means even more to the Norwegian Samis. The reason for this is that the Norwegian Samis still lack a court ruling that confirms the ancient rights of the Samis as explicitly as the Altevatn verdict. Since both the Samis in Norway and Sweden wish to maintain the codicil it is no longer a problem that the passage referring to the non-terminability of the codicil has been removed from the text of the new convention. There were, of course, frequent contacts between the Samis of both countries to consolidate agreement on that point. It was not until then that the Swedes could meet the Norwegian demands that the clause concerning the codicil be removed from the Karlstad convention. In this way the Norwegians, who for a long time had regarded this clause as an infringement, could be appeased. It is therefore expected from the Swedish side that in the future the Norwegian government will not take steps on its own accord that would be contrary to the wishes of the Norwegian Samis. There are no written guarantees for this apart from those explicit in the exchange of notes mentioned earlier between the respective Foreign Offices. The question has, however, been observed at an international level, which should deter unilateral attempts to alter the agreement.

The exchange of views at the highest political level, that terminated the interaction between Sweden and Norway in this particular case, illustrate the extent to which the political groundwork of the Samis has reached the central political core and found expression in concrete terms. The differences here in the participation of the Samis are particularly great compared with the earlier occasions for negotiation, for example in 1919 or 1905. Had the codicil been put under the same pressure then as during this period, this important document would long ago have lost its value as a resource of political power for the Samis. This time, through the combined efforts of the Samis in both countries they fought to retain the codicil principally because of 
its ideological symbolic value. This was achieved in spite of strong opposition, or passivity, from the macro-political level. Naturally the basic prerequisite for such a struggle was the developed political form.

In order to ascertain how the new convention operates in practice, a permanent committee has been set up comprising three members from each country, of which two are reindeerherding Samis. The idea is that this committee will serve as an additional guarantee for any Samis affected, which means that in the future an individual Sami community will be able to refer to the committee problems that have arisen because of the new convention. It can be noted that $L$ has already referred to the committe in order to examine the possibility of extending the convention boundaries. It has in fact even been suggested that there is a willingness to forego the allocated compensation in order to obtain a more acceptable boundary. The creation of this additional body, which has been written into the convention and therefore cannot be dissolved, is regarded by the Samis as a positive result of the negotiations.

According to the new convention the Swedish Samis also lost certain grazing areas on the Swedish side, that are to be used solely by the Norwegian Samis for winter grazing. The Samis maintain that the relinquishment of these areas is a special case and want a court ruling on the question of compensation. So therefore took the initiative at the beginning of 1973 of starting new legal proceedings on the question of principles using Maunu in Kä as a test case. The decision of the court is extremely important for the Swedish Samis and will create a precedent for all comparable Norwegian winter grazing areas. In the same way the ensuing Skattefjäll case in Jämtland, as well as the Kiruna case, will also be trial cases. An accumulation of similar cases forms the core of the Samis' political strategy at the moment, and the Altevatn verdict is the instigating element. The officilal investigation that has been examined here has, apart from its immediate result in a new convention, also created a new trial case. The latter, the Maunu case, 
forms an important element in the general political minority strategy, the objective of which is to alter the division of power between the larger society and the Sami minority.

What I have tried to show with this example is that the official investigations that preceed the drawing up of new legislation offer suitable case studies for the illustration of particular political forms of action. The process of investigations is, as a rule, so complicated that the parties involved need to mobilize a whole arsenal of resources to achieve their specific goals. This is particularly the case where an ethnic minority is involved. We have been able to see how the Samis, together with SSR and SO, have acted, what forms of conduct have been chosen; and finally what sources of power have been used in different contexts. We have also been able to present empirical evidence showing the actual potential of the developed political form. Different power sources and symbols have been illustrated, such as the Altevatn verdict, the Lapp Codicil, the Nordic Sami Council, and in addition the extension of Sami identity over national boundaries has also been illustrated. In the combined negotiations with the larger society these resources have been deployed at different stages of this particular confrontation. Specific sources of power, symbols and Sami identity have also been strengthened by their use. Not the least noticeable has been the ideological development at the local level, within Sami communities. Their often well thought out and articulate actions bear witness to the effect of the stream of ideas that have developed. The distance between those affected by legislation and those who determine it has thereby shrunk.

The individual Sami community is no longer totally outmanoeuvered. The reason for this is the developed political form that not only consists of SSR together with the so but also includes specific ad-hoc groups that can be mobilized for particular occasions, as well as lobbying activity that opens channels to the central political arena. The SwedishNorwegian Reindeer Pasture Convention demonstrates not only the multi-faceted character of the political form of action, 
but also the feed back effect such long term confrontations have at the Sami grass root level. Through being forced to participate in a struggle for the very existence of their cultural life style, their own ethnic identity is reinforced. Should several similar confrontations with the same adversary, the larger society, develop simultaneously or one after another, this will serve to weld together the Samis as an ethnic group. This is imperative since the Samis are a numerically weak group with an extremely wide geographical spread. It is therefore not untrue to state that the long term confrontations that characterize the general situation of the Samis during the sixties and the first half of the seventies have contributed positively to the ideological consolidation of the Samis as an ethnic group and of the specific political forms of action that they have developed. Confrontations of this kind, in the same way as cases of real exploitation, are included as dynamic elements in the adaptation to the particular minority situation that the Samis find themselves in at present. They are important for the continued development of minority politics the predominant aim of which is ethnic pluralism. 
$+++\downarrow$ national border

- community border and district border

border of Norwegian pasture according to the new proposal

ఒ eastern border of summer pasture

border of the old pasture right
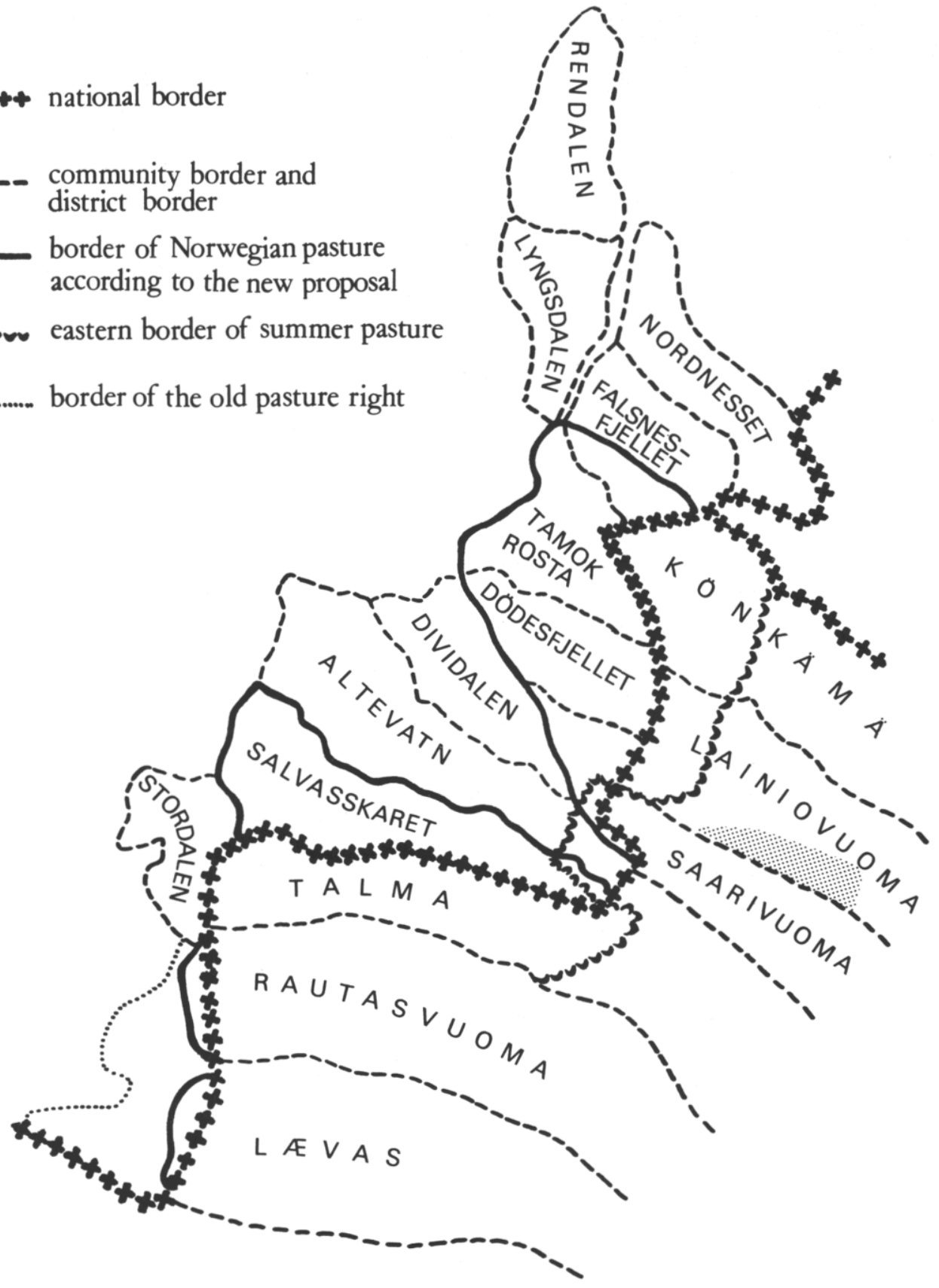
1. See Sommarström's article in Kulturhistoriskt Lexikon. See also K.B. Wiklund, 1908, where two Swedish manuscripts from 1498 refer to traditional, regular migrations over the Norwegian-Swedish highland boundaries.

2. Special statement made by Per Idivuoma about the Saarivuoma Sami community:

Since I have a lifetime's practical experience of reindeer herding, and reindeer grazing conditions in the northern Sami communities with their summer grazing in Troms, I cannot agree to the Commission's proposal concerning the Saarivuoma Sami community, they'll be shut off from the age-old use of summer grazing in Troms and will now be forced to use other areas.

The most rational solution, from a practical reindeer herding and grazing point of view, would be that even in the future, this sami community is retained as a unit by using the southern parts of the Altevatn and Dividalen summer grazing districts, where there is plentiful grazing as we 27 as snow-clad highlands for the reindeer during hot and dry summers.

3. The Swedish Samis have traditionally established relations with Norwegians living in villages in the reindeer grazing district. Each family has a special place to go to, its verde (host). The latter often visits its Sami verde in Sweden during the winter, and the relationship is transactional to the extent that it manifests itself as a reciprocal exchange of goods and services without cash transactions. In addition the verde-relationship often extends over a long period of time, in such a way that sons on each side continue their fathers' relationships. For a fuller discussion of this relationship see Eidheim, 1966 .

To maintain these meaningful relationships, and to move families to Norway each year, giving an opportunity of changing the daily routine particularly for women and children, is of great value to the Swedish Samis. The loss of this opportunity is difficult to compensate.

4. It can be additionally noted that the Norwegian authorities have always extolled free competition for reindeer herding. Fences of the Nordnesset type are incompatible with this basic view. In other words, the principle of the strongest side was encouraged. The Norwegians are now demanding, however, that fences be put up in several places to protect Norwegian reindeer herding from intermixture which shows that, in this context, their attitude is not consistent. 
5. In this $P M$ a very detailed description is given of how conditions for the Nordnesset group gradually deteriorated in terms of failing co-operation with neighbouring reindeer herding groups. In addition it was emphasized that the regional authorities, neither in Norway nor in Sweden, had given the Nordnesset group any support. It was therefore pointed out to the Swedish Foreign office that the relinquishment of Nordnesset could hardly be regarded as voluntary.

PM July 4th 1963, Rostadalen, Norway. 



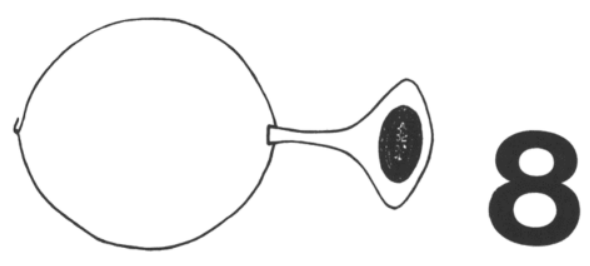




\section{Revision of the legal framework}

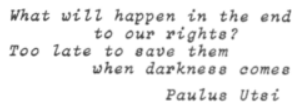

In chapter III have been discussed the limiting effects of the RBL on the actions of the Samis. This structural limitation has particularly affected the Samis when they have attempted by different means, to adapt themselves to a more modern life style. This adaptation has to do with ecological changes that have been created by different interest groups in the larger society. For a long time it has been evident to the Samis that the RBL was obsolete, and that more up-to-date legislation was required. But what particularly urged the Samis on, however, were the patriarchal relicts of tutelage that the legislation was built upon. This derogatory attitude toward another ethnic group was particularly common at the time when the first RBL came into being, i.e. during the 1880's, - an epoch that was tainted with evolutionistic ideas. Darwin's and Spencer's works had been translated into Swedish and their ideas were adopted by extensive circles within the Swedish civil service, which has had an unmistakable effect on all legislation concerning the Samis. This basic view of a nomad people's natural inferiority has not disappeared in later legislation.

The increased political awareness in conjunction with a consolidation of the forms of political action that had been developed, resulted in the Samis becoming more impatient about these points. In their daily life the Samis could no longer accept being continually subjected to a tutelage that bore the stamp of evolutionistic racial thinking. When the pre-requisites for action were made available it was possible to make direct demands on the political bodies so that a new and more contemporary reindeer grazing legislation could be brought about. 
With the coming into being of the three earlier RBL it was the authorities who decided to investigate conditions and to draw up legislation, and the Samis were left, to all intents and purposes, completely outside of what went on. This time the Samis were the active side that pointed to the need for changes, and who through their ideologically founded reasoning were also able to push through their demands that the whole complexity of reindeer grazing legislation should be investigated. SSR was promised that it could appoint a delegate to this investigation.

The advantages that the Samis had achieved in getting this investigation accepted, were however considerably reduced right from the beginning. The two sides, the larger community and the Samis, defined the investigating situation somewhat differently. Both sides were basically agreed that this was primarily a legal question, a code of rules that was to be applied to reindeer grazing and its practioners. In this particular case the government administration was of the opinion that it should itself supply the required judicial expertise whilst the necessary information about reindeer husbandry conditions should be obtained from the Samis. The Samis, on the other hand realised that if they were to have any real influence it would only come about by the mobilisation of their own legal experts. Since they would have only one member on the five-man member committee it was natural that SSR appointed the SO as its delegate. The government, however, overruled this proposal and turned tentatively to two of the leading representatives of SSR in order that someone from this circle would be included in the investigating group. Naturally it was important for the government to obtain a Sami representative who was sanctioned by SSR. In this way it would be possible to reduce the effect of future criticism of the proposed legislation.

Each of the two Samis who were asked, declined however, and gave as motives for the position they took that SSR had been unanimous that this investigation concerned legal questions and that therefore so was the only suitable representative who had the full confidence of SSR in these matters. In addition entering this investigation would mean breaking an earlier decision of SSR and would therefore result in a deterioration of 
the SSR's position amongst the Samis. For the Samis it was important to present a united front and to maintain their political definition of the question, and to avoid being drawn into the authorities'initial attempt to reduce the matter to the level of a purely economic problem.

These divergent opinions made things impossible for the government which then went outside of the inner circle of SSR in order to finally find a reindeer-owning Sami who was prepared to be proposed. He was a local representative, the BO in his own Sami. district and a skilled reindeer herder, but he lacked the requisite legal and organisational competence to play the role demanded by the Samis. In addition since he was not authorized by SSR his position became somewhat ambivalent and he did not therefore contribute particularly actively to the supply of continuous information to SSR. As a result the opportunities for SSR to act as a pressure group were considerably more limited than they would have been if the so had been included in the actual investigating group.

The outcome of this first phase of the confrontation further illustrates the actual power relations between the government and the Samis. This confrontation applies to the power conditions in general, which the Samis wished to influence to their own advantage to a large extent. This objective became more difficult to achieve when the Samis were prevented from participating with equal expertise in the investigation that was to form the basis for the future code of rules. The only thing that remained for the Samis was to attempt to establish channels through which ideological pressure could be applied outside of the investigation.

In reply to the government's outmanoevering SSR formed their own reindeer grazing legislation committee which comprised of four reindeer herders and the SO. This committee was to have the opportunity of consulting with the investigation group and during the period of the investigation a minimum of one consultation per year was held.

This regular contact also formed the foundation of the information that SSR distributed to the Sami communities and upon which SSR based its continued political strategy in order to 
attempt to influence the formulation of the report. With regard to the weak Sami representation within the investigation itself this would not have been possible without such a committee.

\section{The speoific investigation.}

\section{a) The Report}

The report that the 1964 reindeer herding experts eventually presented in 1968 contained, in addition to the new reindeer grazing legislation (RNL), quite a few changes at the organizational level. Before going into certain actions triggered off by the report it is relevant to give an account of and describe some important aspects of the proposals. In this way the actions of the Samis can be understood.

\section{The Zegislation}

The proposals put forward are virtually a complete modernisation of the RBL, but even in future exact regulations will be in force for the practice of reindeer herding. A particularly important point, on which there has not been any change, is however the question of the government's development rights, that go as far back as paragraph 5 in the 1928 RBL. Not even in the future will the samis be able to cite any legal rights if they are threatened by intensive development. Their inferior position in future confrontations therefore remains, and they have no right of veto as regards their vital land interests. This attitude of the authorities conserves the uneven distribution of power that the Samis are continually attempting to change. For this political objective to succeed only the courts remain. This is why trial cases of the Skattefjäll type are so important. If the legal demands of the Samis should command the attention of the courts then future reindeer grazing legislation would have to be adapted to this new legal foundation. This crucial question is, however, sub jure for the time being, and a government investigation can, as a result, avoid the whole problem.

With regard to the exclusive reindeer herding rights a certain loosening up was proposed. Amongst other things women were equated with men so that a woman's reindeer herding rights can 
be transferred to her husband even if the latter is not an authorized reindeer herder. In addition it is also proposed that members of the Sami community who have lost their membership by going over to other permanent occupations, shall be allowed to retain hunting and fishing rights for a period of ten years. Such persons will also be able to remain as supporting members of the Sami community by payment of member's subscriptions. In this way local solidarity can be strengthened. The previous law, the $\mathrm{RBL}$, had in this context, a negative effect since it cut very sharply through the Sami population and thereby created an artificial and undesired division. This was a particular nuisance in the Sami districts where many ex-members were able to continue living in the local community because some occupational opportunities were available, as in the communities of $L$ and $R$ in Kiruna. This modification in the legislation was therefore welcomed with great satisfaction by the Samis.

In order to illustrate this point further it can be mentioned that in Rensjön, the main location of $R$, one third of the population are not members of the Sami community. All the men in this category work on the railway and live and work in the local community as much as the official community members. Several women and also some reindeer herders' wives work in Kiruna. The differences between the two categories are therefore not particularly great. Their sense of affinity is also confirmed by frequent interaction irrespective of which category they belong to. It is here that the Sami idiom plays an important role. It should be noticed that all those who work on the line are Samis and they therefore speak Samish every day to the same extent as those who spend their day among the reindeer. Their Sami identity is therefore clearly manifested. In addition all their spare time is spent helping to look after reindeer when the Sami community needs extra labour. The solidarity of these people with the community is therefore great. Why then should a legal paragraph formulated by the authorities create a division within a limited population group that in practice is meaningless and which has a negative effect on the individuals involved? These people have through the years, in spite of their lack of legal rights, shown their loyalty to the community. It is only now that their ethnic 
identity is becoming recognized. A change such as this is therefore very important.

\section{The local organisation}

The report proposed a number of changes that strengthen the Sami community's position as a unit. The community meetings will become an internal forum where all important affairs of both internal and external character are to be dealt with. As a result, in the future the subjection to the steering of these meetings from the administration's side will be avoided. This change will obviously strengthen the community members' self esteem and they will be free to discuss their own problems. In addition the former community delegates' institution is to be replaced with an elected board that is responsible to the community assembly.

All decisions taken by the community assembly that concern external affairs are to be passed on to the County Agricultural Board. In a similar way the regional administration is obliged to allow the Sami community to express their opinions on any question that has a bearing on conditions within the Sami community. The Sami communities have thereby secured a legal right to participation in the regional decision-process that affects their own situation. This area of responsibility was formerly rather vague and it is therefore a marked improvement for the Samis that the obligations of the authorities have now been made explicit in the legislation even if this will continue to be based upon conditions laid down by the majority. The Sami community has even been given authority over the control of individual reindeer ownership and who shall be accepted as members. The flexible adaptation to varying ecological conditions is made possible in an improved manner by such self-government than was the case when this was regulated by law and the decisions of authorities.

A further improvement is that in the future the Sami community will itself be responsible for decisions concerning the use of the community's finances. An ancient tutelage directed at the community has thereby been removed and this change is probably more important on an ideological level, where it has great symbolic value, than as something affecting practical economics. 
The right to vote at community meetings is restricted in the majority of cases to members who are responsible for the care of reindeer, and relates, for example, to questions concerning reindeer management. In the case of questions such as these the right to vote is distributed in such a way that one vote represents 100 reindeer. The abuse of this right is avoided by the fact that one person may not hold more than one-fifth of the total number of votes cast. In other questions, where all members of age have influence, one vote per person applies.

An economic model, based on the 1951 Law concerning Incorporated Associations, forms the basis for these organizational changes. In accordance with the differentiated distribution of votes the distribution of costs can also be differentiated, that is to say, it is based on reindeer ownership. In this way a more equitable division of labour is achieved. The greater the ownership of reindeer, the greater the resulting costs which should therefore imply greater influence. This model, however, breaks seriously with traditional organizational principles within the Sami community. In this way the legislation has resulted in the introduction of reindeer management associations which are by no means regarded as desirable everywhere. (See further the discussion under section $b$ in this chapter.) With regard to the political implications of these changes it should be noted that guarantees against the misuse of power hardly exists. It is possible for a few large reindeer owners to monopolise the taking of decisions at the local level on such vital issues as, for example, the recruitment or exclusion of members. Such a strong position creates new opportunities concerning the binding up of client attachments when important decisions are to be made. Small and medium-size reindeer owners will thereby have less influence than before. In this way there is a risk that this difference in power can become an instrument in the effective consolidation of economic differentiation in the local community. The larger reindeer owners will continue to be wealthy and the smaller reindeer owners will continue to be poor. The opportunities for considerable changes in ownership structure that have, up to now, characterized the Sami community will thereby be noticeably restricted. 
The report has however considered this problem of the abuse of power and has therefore proposed that the county council shall act as an Appeals body. This means that individuals or groups that find themselves in a minority in the Sami community are able to appeal againstan important decision made by the community assembly. This may concern local conflicts between reindeer owning and non-reindeer owning members, between different groups of reindeer owners, between modern and traditional husbandry methods etc. That internal divisions of this sort can occur is dependent primarily upon the fact that many reindeer herding Samis believe that the traditional sii'da organisation is the most practical, when the organisation of relations between reindeer herding households are concerned.

\section{The regional and central administration}

As a result of the Sami communities achieving increased autonomy, the Samis will also participate in the regional administration by the fact that two reindeer herding Samis will be included in the seven-member County. Agricultural Board's reindeer grazing delegation. Decisions are made by this board while the reindeer grazing section of the County Agricultural Board, in contrast to the regional administration mentioned earlier, will only have an executive function.

Analogically with this system the Samis will obtain a position of limited influence at the central administrative level by the inclusion of three reindeer herders in the Reindeer Committee of the National Board of Agriculture which also has seven members.

For the Samis this will result in an improvement at the county level, since they have never been able to participate in decisionmaking previously, and a distinct deterioration at the national level. Since 1962, when the central Reindeer Grazing Administration was centered on the National Board of Agriculture, the Reindeer Husbandry Committee, an important advisory body for the Samis, has acted with considerable success. The Samis have been able to debate issues undisturbed in this Committee and thereafter present the National Board of Agriculture with expert decisions (see also page 46). Cooperation between the National Board of Agriculture and this committee has operated smoothly according to unanimous 
opinion, and the gradual institutionalization of this body has furthered the development of Sami influence at the national level. Since the Samis are only included as a minority in a body with similar functions, the positions that have already been won have now been moved backwards. SSR regard this as a serious deterioration of the position of the Samis and intend to fight hard in an attempt to retain the Reindeer Husbandry Committee. ${ }^{\text {l) }}$

\section{Economic questions}

In 1943 a fund was created based on compensation paid by development companies. This fund, which up to now has been administered by the authorities, has been used to improve the working conditions of the Samis. For a long time the Samis have regarded this fund as their own, since it is based on compensation for direct losses brought about by development. One of the most important contemporary political questions for the Samis has therefore been the enforcement of total control over this fund. For the Samis the new fund represents only partial success since their influence is limited to that part concerning cultural activities, whereas the more important part of the fund, concerning reindeer husbandry will continue to be administered by the authorities.

As we can see, the Report included proposals that contribute to strenghtening the Samis minority position. In certain cases however Sami progress has been stemmed particularly in terms of basic rights to the use of land, participation in the central administration and influence on the Sami Fund. The starting point for future Sami action has therefore been corrected. A report of this kind, perphaps the most important to date concerning the Samis in the twentieth century, naturally creates a series of actions that illustrate the various political forms of expression that the Samis have developed. In the next section we shall discuss the ways in which the Samis have reacted to this Report, what forms of actions have been chosen to influence the final formulation of new legislation, and finally what interchange of concepts and ideas between SSR and the Sami communities have been caused by the Report. 


\section{b) Activities and reaction}

This event that so actively interferes with the daily life of the Samis naturally demanded the total involvement of the Samis. In order to make local discussions as active as possible SSR decided to give information about the Report the greatest possible distribution. The national meeting that was held shortly after the Report was made public became the primary channel of information because the representatives were able to return home and give an account of events. The Sami massmedia, such as samefolket and the Samis' own radio programme sámi ságat, were also involved in the ensuing distribution of information. For tactical reasons SSR also decided not to comment on the contents of this new legislation proposal, but instead to call an extraordinary national meeting in the Autumn of the same year so that the Samis could decide on the formulation of comments to be submitted by SSR. ${ }^{2}$ ) In order to give the greatest possible authority to these submissions it was imperative that in the six month period that remained, a debate that was as comprehensive as possible should take place in the individual Sami communities. In order to achieve this it was necessary to increase contacts between SSR and the Sami communities. For this purpose SSR chose to take responsibility for the most extensive information activities in the communities. Economic support was sought to carry out these intentions and was granted by the government. Five leaders within SSR, all reindeer owners, were then appointed to distribute information in the field about the contents of the Report.

The idea was that there should be a reciprocal exchange of information and that at the information meetings with the Sami communities local reactions on the proposed legislation should be collected, which the Board of SSR could refer to in the formulation of their final submission of comments. It is important to note here that the Sami communities received information not only about the Report at these meetings but also the preliminary draft of the SSR's comments which had been formulated by the board in co-operation with the so.

The flow of ideas and concepts that were exchanged at this early stage contributed to the strenghtening of contacts 
between SSR and the local Sami communities. SSR regarded it as extremely important that the Sami communities were involved in this policy - making process right from the beginning and that they were successively informed of the SSR comments that were to be submitted, so that even this could be the subject of local discussions prior to the extra-ordinary national meeting.

At the information meeting held in Kiruna for the $R$ and $L$ Sami communities 10 heads of households, as well as a number of non-reindeer herding Samis, took part. The latter took quite an active part in the debate and showed a manifest interest in it. This in itself is not so surprising since Kiruna is the one community in the country with the greatest non-reindeer herding Sami population. Its Sami Association is likewise very active and regularly sends two or three delegates to the national meeting. By showing its interest in these events it became apparent that previous conflicts of interest now lacked importance, and that the new proposed legislation was something that concerned all Samis. Above all, solidarity was expressed with the pressed situation of the reindeer herding Samis and a willingness was expressed in assisting them to influence the proposed legislation in the most favourable way possible.
We're not so much interested in our own rights as in helping our kinsmen, the reindeer herders, to get the best possible bargain. That's why we're acting now, but Nilsa doesn't seem to understand this at all. It is completely meaningless if the reindeer herders to- tally isolate themselves as a group. They're far too few, and therefore too weak as a group, and they'll soon go under. That's what I think. We must fight together and of course here in Kiruna we have a tra- dition of good relationships between the two groups.
There's no future for the samis unless we're together. They can't manage themselves, we have to stick to- gether. We want to help: we know about things that the reindeer herders don't know about. We need each other, it's important now.

The meetings were held alternatively in Swedish and Samish which was important because much of the complicated legal texts could be better understood. The intentions of the proposed legislation would otherwise have been missed by many. In Karesuando information was given by a southern Sami and a Forest Sami, both of them without any knowledge of northern Samish, with the 
result that only a limited amount of the information was understood. In this area people were also very disappointed with the information. Swedish is perhaps least known in Karesuando. It is in addition a very isolated area, and information is needed there to a much greater degree than in other areas. The average individual has hardly had contact with the larger society. A complicated legal text of this sort is therefore quite incomprehensible for most people unless the main points are satisfactorily translated into their own language. It is important for the Samis to understand and translate the high-flown officialese into conditions in the reindeer areas and other day-today aspects of Sami life. Without this kind of appreciation of what is meant it is impossible to react in a meaningful way. Far-reaching consequences can result because this involves proposed legislation.

The discussions that began as a result of these information meetings then continued throughout the summer in the different Sami communities. In order to give greater power to this exchange of ideas a number of communities decided to obtain a copy of the Report for every head of household so that everyone could acquaint themselves with the contents to the best of their ability. The Report was the centre of discussion after work during the summer calf marking period. The local representatives, that the communities were sending to the national meetings, were particularly eager to study the proposed legislation and to get discussions started. In this way unanimous arguments and a 10cal majority of opinion would form the basis of their actions at the national meeting.

This was the most important question that the Samis had faced in modern times. With the help of SSR the debate was extended right down to the grass-root level which was extremely important if the comments that were to be submitted were to have any authority. The insights contained in the general debate and the formulation of the final submission at the extra-ordinary national meeting clearly indicates the breakthrough of the concept of local involvement.

There is therefore good reason for describing this discussion in somewhat more detail. In general the proposals were accepted, but there was criticism about certain points from different 
quarters. The idea of reindeer associations was, for example, not met with approval everywhere. This proposal was hotly debated in the far north. Many were worried that if a reindeer herder's association was introduced this would be a brutal attack on their way of life.

I'm afraid that they'll get the idea of an association into the new law and I don't like that at all.

If there's to be an association and I'm on day-labour I might just as well give the whole thing up and go into industry or down the mine straight away, because the whole point of Sami life is lost, I mean the personal freedom. We must protect Sami culture.

It is the great difference between the $s i i$ 'da organisation and the adaption of reindeer herding to a form of association that produces such arguments. At the same time the idea that the number of votes would be based on reindeer ownership was disapproved of. To many it seemed to be an undemocratic principle through which it would be possible for a minority to introduce a reindeer herding association, despite the fact that such an organisational change was to be voluntary according to the Report.

Another important point was rationalisation. If the survey's intentions were to be followed then $30 \%$ of the reindeer herding population would have to be removed in order that those who remained would have a standard of living comparable with the rest of the country. The normal salary of an industrial worker corresponds to a family owning 500 reindeer. Today there is hardly anyone in the area investigated for this study that has this number. If this objective was carried out it would have a negative effect on Sami culture. The population base would be too small to maintain a viable culture. On this subject the authorities reason ethnocentrically and they assume that the Samis want a raised standard of living of this sort. The Sami system of basic values does not however, coincide completely with those of the larger society. It is the lack of insight into the value differences between the two groups that results in these proposals by the authorities. In addition SSR has for many years maintained a firm policy concerning the combination of different occupations as a safeguard against too great rationalisation. (SSR:s submission 1968 and T.Svensson 1969 b.) 
500 reindeer per family seems totally mad. Why should they decide on the same standard for everyore, it has always been different. It's not at all certain that the Samis want the same high standard of living. You can give up a lot of things, live more simply and still live well if you want to. Freedom - which is typical for reindeer herding - is also valuable. It's natural that you can choose yourself unless you have too few reindeer, 35 to 40 , but then you can see for yourse if that it won't work. Reindeer herding depends on luck and grazing conditions vary; not everyone can have the same in the long run. There are very few now who have so many reindeer, but it works alright because there's a sort of subsistence economy - meat, fish etc. and cheap, but good, housing. This must also be included in the standard of living in order to make comparisons with industrial workers' salaries. Not everything of value can be expressed in terms of money and that's important.

That it'Il be decided that there'Il only be the large reindeer owners left is also wrong. You can't bank on this, there'll be too few people for the continued existence of our culture and there won't be enough labour when it's needed. People who don't have reindeer can't just sit by and wait for work until it suits the reindeer owners. So they have to move and then the workforce isn't sufficient. If you're going to bank on the future of Sami culture then you have to make sure that there is temporary work to put in between and then you can manage with much fewer reindeer.

All this about 500 reindeer is also undemocratic. A small reindeer owner that makes do with a simpler way of life must also have the freedom of choice to do so. People shouldn't be forced to do things of any kind.

At the extra-ordinary national meeting, which was held in östersund at the beginning of October, just before the last date for sending in submissions, the whole time was used exclusively for working at the submission. Never before had the representatives at a national meeting been so well prepared and the discussions were very intensive. Already a week before the national meeting, the SSR's submission proposals had been sent out to all representatives. In this way it was possible for the representatives to be well prepared themselves in terms of comparing the proposals with the (earlier) statement as well as informing the other members of the community of the main proposals in the statement, in order to obtain last minute reactions on these. Since the representatives were so well prepared, decision making at the national meeting has never had such wide popularity as at that time. 
The board of SSR was forced to make alterations to several points in its own statement proposals since this was demanded by the majority of representatives. Points of principle as well as concrete proposals were energetically put forward. This procedure demonstrated that SSR had become sufficiently mature as a representative body for the Samis, and the previous exchange of ideas at different organisational levels amongst the Samis formed the foundation of this. It should also be noted that an unusually large number of delegates attended the national meeting. A number of Sami communities had sent representatives as well as their deputies, since the questions about structural changes were regarded as being so important that as many as possible should be there. From the area covered by this study 12 representatives were present, in addition to a further five persons with other status, board members etc. As a result the national meeting was attended by a relatively large number of persons, which of course contributed to an intensification of the dissemination of information to members of the Sami communities.

In addition to a detailed run through of the proposed legislation the statement that the Samis finally agreed upon concerned certain points of principle. To begin with a Sami political objective was sought for in the report. Since the experts had obviously narrowly interpreted the directives of the enquiry and had not paid sufficient attention to the rights that reindeer husbandry are based upon, the proposals therefore took a rather weak official stand in terms of strengthening the Sami minority's position.

SSR was also very critical of the proposed rationalization of people and emphasized the negative effects this would have on the future viability of Sami culture if these proposals were carried out. The Samis had maintained for a long time that the most suitable way of solving the economic problem was to extend the opportunities of combining different types of work. As a result they could not accept that the economic activities of the Sami community should be limited to reindeer herding. The rights of the Sami community should, according to the Samis, also include opportunities for other economic activities on a collective basis. 
The Samis insist that this is necessary if the Sami community is to be strengthened as an ethnically identifiable community. In conjunction with this a special Sami cultural enquiry that would take up these more general questions was demanded.

In addition it was considered that future grants of usufruct rights should be made exclusively by the Sami community. Since reindeer grazing, hunting and fishing rights and other Sami rights pertain to the Sami community it was regarded as natural that the Sami communities were also allowed to determine the granting of other rights with the help of SSR. Because earlier legislation on these points was not a sufficient instrument of protection for the Samis a somewhat autonomous position was sought. This argument was additionally strengthened by the fact that it was usual for the Samis themselves to confer usufruct rights of this character before 1886, when the first RBL appeared. There was therefore an older praxis of influence that the Samis wished to recall.

In addition the reduction of the right to voice in decisions made at the national level was regarded as unsatisfactory. Since the new Reindeer Committee would replace the earlier Reindeer Husbandry Committee the Samis would lose their own institution and its power of initiative which had previously been part of the central administration. The minority position that the Samis would now find themselves in was unacceptable. Finally came the question of the Sami Fund administration. SSR maintained that this Fund would be administered by a totally Sami board, since it concerned the Samis' own money. This money is to be used exclusively for Sami purposes. Since it is impossible to carry out effective policy without recource to extensive economic resources the administration of the Sami Fund is a question of the distribution of power. Limitations in the control of these resources make it impossible for the Samis to carry out some of their political activities.

The statement that SSR finally put out forms a very important part of the Samis' general formulation of ideology. This is the first time that the Samis have methodically worked out a unified policy for future action, apart from the fact that it is a very complete and well-founded reaction to the report. The Samis have themselves raised this document to something of value in itself by calling it the Policy Programme of the Swedish Samis. All the 
resolutions from the national meetings between 1962 and 1966 , and which are collected together in the stencil entitled the will of the samis, form the basis of this statement and declaration of policy. (Samernas Vilja, 1966)

The ideological framework that developed as a result of the enquiry into reindeer husbandry legislation has already been used in a number of important actions. The reaction of the Swedish Samis concerning the Swedish-Norwegian Reindeer Grazing Convention was based to a large extent on this platform. Individual Sami communities, that during the $70^{\prime} \mathrm{s}$ had been affected by different forms of development, also show a reaction that is stamped with the same communal ideology. Different actions to influence the ongoing work of the Sami Enquiry, as well as Sami political activities in conjunction with the important skattefjälls trial case, also testify to the fact that this ideological articulation has made a breakthrough in practical terms.

The second phase of this particular confrontation has now been recounted. We have paid particular attention to how the Samis at different levels have reacted to the report. The interaction that has later become institutionalised between SSR and the local communities is clearly apparent in the preparatory work on the statement. In this way the different organisational levels have come closer together, which contributes to the integration of SSR. In addition the report has functioned as an important incentive for the Samis in their struggle to come together around a common political programme. That they have been successful with this objective is illustrated by the pattern of political action that since that time can be observed amongst the Samis. The realisation of this ideology is therefore one of the positive aspects of developments so far. Further on we will look at some of the important events that are related to the final legislation as well as some of the consequences of the new legislation.

After the statement had been presented, discussions continued in the different Sami communities. In many aspects the discussions were particularly intensive in the northern reindeer herding area. After a long series of discussions between heads of households the Y Sami community sent in a note of protest to the government, in which certain vital points in the report were 
contested. (See also page 92 and Appendix III) This local political manifestation was unique and instigated a far reaching debate in the local press as well as in samefolket between representatives for the local majority on the one side and leaders of SSR on the other. That conflict arose on certain points between SSR and the policy they wished to pursue, and the attitudes of a number of Sami communities, was given new substenance at the national meeting in 1969. SSR wanted new legislation to be brought in relatively quickly in order that the obvious improvements incorporated in the new legislation could be put into action. For $Y$ and some other Sami communities, however, uncertainty about the effects of the new legislation was so great, particularly in terms of local organisation, that they advocated postponing the legislation. After long discussions the prevailing attitude was one that had previously been maintained by $Y$, which was somewhat of a loss of prestige for the SSR board.

Postponement can have serious consequences for the Samis. I warned against a postponement and regarded the bringing about of legislative changes as quickly as possible as of vital importance. These changes involve considerable economic support measures that do not apply until the legislation comes into force. Until that time it is difficult to do anything effectively for reindeer husbandry in terms of economics. (The so)

This statement confirms the fears that the Samis in Y felt, namely that the authorities wanted the legislation to come into force as quickly as possible, and in order to achieve this economic support measures would act as an incentive. SSR had apparently chosen to conform to the government viewpoint which meant that they opted too strongly for the, in themselves, essential economic problems and took less consideration of the cultural consequences of the new legislation. It was primarily the latter that $Y^{\prime}$ 's action was intended to concentrate attention upon.

The uncertainty that was expressed was also based upon the fact that the Samis in the communities had been poorly informed. The information activities that had been the responsibility of SSR had in many aspects been inadequate. As an explanation of the decision about postponement taken at the national meeting even the following aspect was put forward. 
The contents of the report are difficult to digest and perhaps difficult to interpret and it is perhaps impossible to assimilate it in one day. In the short time that has been available we have concentrated on the information aspects. (One of the members of the SSR's information group.)

This example illustrates something quite interesting about the developed political form. The discussions in the field are now so developed that decision making on matters of particularly great importance cannot be pushed forward if the Samis themselves do not want this. The local community possesses an expertise that neither SSR nor the administration has control over, and it is this that can instigate more independent actions of this sort. This will in the long run benefit the individuals. Their opportunities of choice in terms of political action increase while at the same time SSR must, in future, take into consideration the risk that such unexpected reactions can occur in a particular Sami community and therefore limit their strategy.

As a result of what the national meeting had been agreed upon, SSR wanted to concentrate on an effective and widely spread information activity. The demand for this was apparently greater than SSR had believed at first. The only opportunity, however, of bringing these intentions into effect was by resurrecting the SK activities. In Autumn 1969 a state grant was sought in order to employ someone whose primary task would be to travel around to the different Sami communities and spread information about the legislative proposals. The government, however, did not approve this required grant and the objective that had been put forward in 1969 could not be achieved.

It was not until 6 months after the new law had been approved by the Riksdag that SSR acquired the economic means for employing a young, well-educated Sami with wide experience of reindeer husbandry and Sami organisational activity. After 1975 this post was made permanent.

The Samis, particularly those who wanted more time to go through all the intricacies of the legislation, felt that they were cheated when they realised that they were not able to avail themselves of this important information. Irrespective of how much information is received afterwards, this only goes to testify how powerless the Samis are as an ethnic group. This is a recurrent theme for ethnic minorities, that the required resources 
that would give them real influence in the decisive decisionmaking process are often withheld. In this way their participation becomes a sham. Nor do they at the moment have any means of sanction to reinforce their demands and must accept instead the relatively arbitrary treatment that they are subject to from time to time.

SSR therefore abandoned the idea of a broad dispersion of information. From that point onwards they concentrated on attempting to influence the formulation of the new government bill. This took place both in written form and in meetings with the government. In the Minister of Agriculture's speech at the national meeting in 1970 the ideas that were put forward and used to strengthen the arguments in the statement were apparent. According to this speech it was expected that several of the demands that the Samis had made on different occasions would be met with. In addition the government had agreed to set up a Sami cultural enquiry.

In order to remedy the dilemma of insufficient information the authorities took a number of steps. While the new government bill was available but before the legislation had come into force, the basic ideas in the proposed legislation were disseminated via special courses and by means of a special series of programmes on the Sami radio. The educational activities consisted of a three-week course for Sami community officials and a two-day course for all Sami community members. SSR was allowed to participate in the formulation of these courses. As a complement to this information drive the National Board of Agriculture gave out two well-illustrated brochures on this topic that were distributed to the Sami communities. Thanks to these efforts the government regained some of the prestige that it had lost by previously denying SSR the state grant for SKactivities. However, these efforts do not by any means compensate for the absence of information from a permanently employed SK.

That the Samis were deeply involved in these legislative questions is apparent not only from the separate actions such as those of $\mathrm{Y}$ but also from the May Day demonstrations carried out by different groups of Samis in Stockholm 1970. The main 
reason for this spontaneous manifestation was that they wanted to express their disapproval of the Reindeer husbandry legislation. Above all it was designed to draw attention to all the Samis that had been overlooked in this legislative context and the main theme of the demonstration was in consequence the future of the ethnic minority, a point that had been completely overlooked in the Report. It was apparent from the bilingual text on the banderols carried in the demonstration, Samicednan samiide - Sami power to the Sami land, that this was inspired by the appeals of oppressed groups of people from various parts of the world. However, this demonstration met with mixed reactions from SSR, who emphasized that it was often wiser to avoid conspicuous forms of expression.

The sami demonstration in stockholm is one expression of sami opinion. It should be respected as such, in the same way that samis who choose other methods in the discussion of the future of the samis, perhaps less sensational forms of expression and with more oarefully weighed arguments, should also be respected. (SET. 2970:8-9)

However, this is more a dispute about forms of expression than about the ideological manifesto itself, which emanated from the general political programme.

By means of its different activities SSR was at least successful in achieving the formation of a contact group which worked together with the Ministry of Agriculture during Autumn 1970 on the preparation of a Government Bill. Two leading representatives from SSR and the SO were included in this group. That an interested party was allowed to participate at such a late stage in a legislative context is, of course, completely new for the Samis and also unique for legislation in general; and this was pointed out by the Minister of Agriculture in the Government Bill. In this way the Samis had created a particular form for future action where legislation is concerned. It is beyond dispute that the Samis have hereby reinforced their position as a minority group in the larger society.

The Bill that the Minister of Agriculture presented in February 1971 confirmed that the Samis had been successful in their lobbying activities. On the minus side we find, however, that the Samis will continue to come up against effective 
constraints concerning the development of viable local communities. The Sami communities are not allowed to participate in any other economic activity except reindeer husbandry. This means that even in the future it is impossible for a Sami community to carry out commercial fishing or anything more than simple tourist activities. But in order to appease the Samis to some extent, the formal prohibition of individuals or groups in a Sami community from forming some kind of limited company for these activities has been avoided. For the Samis, however, it has been important all along to emphasize the significance of the Sami community, as the central local unit upon which contemporary Sami politics rests. It is therefore of some symbolic value for the Samis that the Sami community in this way is given increased authority. The official attitude of the authorities when they refused the demands of the Samis was that they wished to safeguard the Sami communities from taking too great economic risks which could also have detrimental effects on reindeer herding .

Again, here we have an example of the authorities' declaration of the incapacity of the Samis. The Samis have for generations developed a very careful adaptation to ecological resources. They have superior know how of the extent of how far one can go in the exploitation of resources in addition to the demands of reindeer husbandry. A multifacetted use of resources in a Sami community's area stems from that period when the Sami community had absolute control over its territory. The Sami communities of Tingevara and Siggevara in Jukkasjärvi are examples of this, and existed as late as the 17th century. (Ruong 1937) This Sami community authority survived for the greatest length of time amongst the skolt Samis, and even at the beginning of this century the community council, norraz, had in contrast to the outside world, full control over the allocation of resources between individuals and groups. (Nickul, 1948).

When the Samis really press home this point it is because they want to bring the former, autonomous community units back into operation. Sami ideology rests on the fact that the Samis, as an ethnic group, can strengthen their position only when the Sami community has regained its earlier position of strength. 
The legal struggle that is being waged at the moment, characterized in particular by the skattefjäls case, aims at forming the foundations of just such a development. In this lawsuit the Samis are demanding that the Sami community rather than particular individuals is recognised as the owner of skattefjäll. By means of this strategy the Samis have chosen to emphasize cultural continuity, which is in direct agreement with the general development towards increased and definable ethnic identification that the Samis are going through at the moment. In addition, by giving articulation to this point of view in the courts the Samis are demonstrating that they have by no means given up this question. Should their demands gain favour the Samis will obtain the required ecological basis to develop the Sami community both economically and politically. For this to take place is of vital importance for even the Sami movement as a whole.

Further, the refusal of SSR's demands that the Sami community itself should be allowed to administer the granting of, for example, fishing and hunting rights, also coincides with the demands that have become current in the legal battle. To obtain native rights to territory would mean that land would become remunerative for the Sami community. This is the recurrent topic of discussion in many Sami communities at the moment, particularly in the ones directly affected by the skattefjälls case. On the other hand the Samis have succeeded in opposing the total granting of rights in places where, in the future, they would be prevented from utilising resources. It was the much discussed usufruct rights to Lake Råstojaure in La that enabled the Samis to achieve an improvement in the legislation on this point.

In terms of economic and administrative questions the Samis, however, were able to obtain a few more advantages. On the Reindeer Committee the Samis obtained 5 representatives ( 4 reindeer owners and the SO) out of 10 instead of the proposed 3 out of 8 . At the regional level the number of Samis was increased from 2 out of 7 to 3 out of 8 , which is however only a marginal shift of power, especially since two of these will be authorised by SSR while the third representative will be appointed by the regional administration. In this way the amount of participation that was at first offered to the Samis has lately been circumscribed. 
Also in a number of cases, particularly in the Norrbotten area, the Samis have had reason to be dissatisfied with this state of affairs since the Sami appointed by the authorities has not wished to follow the communal Sami ideological formulation. As a result the Samis are forced to work in a minority position at the regional level which seriously hampers them in their efforts to influence the decision making process.

The influence of reindeer owners is limited since we are only 3 out of 8 but at least we are informed about what is going on. (A representative)

The Reindeer Husbandry Legislation has meant that it is even more difficult than before for SSR to act at the county level. The authorities at that level are markedly unmoved by pressures from SSR. Even in the Reindeer Husbandry delegations it is very difficult to find effective ways in which SSR can act. This means that representatives appointed by SSR must have effective influence in spite of their minority position. This can only be obtained by unified action and determined group conferences, even while meetings are going on, for example, by using the breaks, as well as joint reservations if necessary. (The SO, national meeting 1972)

Here the $\mathrm{SO}$ has chosen at a very early stage to explain to the assembled delegates what sort of difficulties the new administrative arrangements will imply for the Samis that have been elected to positions of trust. At the same time he points out particular tactical guidelines for future actions which are especially important for a minority group.

To act within the Reindeer Husbandry delegation is very difficult. One isn't given anything except the points on the agenda - no material at all. It's difficult to make any kind of preparation. And in addition it's difficult to argue points concerning sami communities that I don't know anything about. In our communities it's easier. At least I feel that I know what $I^{\prime} m$ talking about. But as soon as you get outside the nearestoommunities then it soon becomes very diffioult. As far as $R$ is concerned I've been able to put forward their demands quite well, but for example a problem in Kä, how am I to know enough about that? The only thing I can do is say what I've heard, but as a rule this isn't enough when we're in such minority position.

We can illustrate these difficulties with an example from L. This concerned a quartz quarry that LKAB wanted to open in 1972 . Since this affected Y's own community he was allowed a say at the meeting but was not allowed to participate in the decision making. 
The proposal was dealt with very rapidly and the community was not given the opportunity of making their views. After the meeting, however, $Y$ took the initiative of making a number of Sami counteractions.

The quarry lies right next to the migration route, which will make movements more difficult. The greatest barrier will be the new road from Highway No. 90 to the quarry because this cuts right across the sami community's territory. There's going to be a lot of traffic on it. It was because of these things that we felt that the matter was so important that we got the so up here and had discussions with him at a community meeting. We felt that we needed to make a study of the likely consequences of this proposal, which the Reindeer Husbandry delegation didn't want to do. At their meeting the proposal was simply agreed upon in spite of my protests.

Afterwards the $S O$ went to a legal expert at the National Board of Agriculture who studied the problem and as a result the Board of Agriculture criticised the County Agricultural Board for the way in which it had dealt with the case. The result, so far, is that LKAB has been given permission to develop in spite of our appeal, and that the question of compensation will be taken up later. But we haven't been satisfied with this and have appealed to the government, but we don't know how far we can get with that.

The Samis have therefore already begun to reduce these restrictions. Then the question of the extension of Kiruna airport came under discussion in May 1973. The Sami representatives were able to get the matter postponed for a while. Soon afterwards $Y$ contacted two leaders in the Sami community involved, in order that they could mark out on a map the extension that would be least detrimental to reindeer herding. If they have this sort of proposal with them it will be much easier to put forward their arguments at the next meeting. And then there is a greater chance of decisions taking Sami interests into consideration. More time must be available for the Sami representatives to act convincingly, and future tactics must be based on this. The Samis are now fully aware of this dilemma and are trying different ways of transforming having partial influence into being able also to use it. This distinction is important because it is in real life situations that influence is measured in political terms.

When the National Board of Agriculture deals with reindeer husbandry questions the Samis, in the form of one representative, are now allowed to be present. To this task has been appointed a 
person with accumulated authority from different levels, purely Samish as well as administrative. He is the chairman in his own Sami community and in SSR. In addition to his position at the National Board of Agriculture he is also the representative for Jämtland in the Reindeer Husbandry delegation and in the Reindeer Committee. This choice was particularly opportune because Sami opinion can hardy be communicated at this central administrative level if the person concerned does not have very wide ranging organisational experience.

If we then look at the economic aspects, the Samis have achieved a marked improvement in the administration of the Sami Fund. SSR had demanded a purely Sami board of directors. The authorities did not agree to this but the Samis obtained 3 representatives out of 6 for the main fund, which makes grants for reindeer husbandry, while in the more secondary fund for cultural and organisational questions the Samis have a majority with two representatives out of a total of three. In terms of making decisions about the Sami Fund the Samis have come some way towards official recognition. That there was even approval of the Fund's change of name to samefond, the Sami Fund, is also of symbolic value to the Samis.

In these comments on the text of the government Bill I should like to conclude with the problem of status. In the future, a Sami community will consist of reindeer herding members as well as members of the sami community. What is important is that individual Sami communities will be able to determine the exact distinction themselves. In principle it will be the reindeerherding members who will decide who are the reindeer herding members. The main criteria to fulfil this requirement will be that one is of legal age and an active reindeer herder. The number of reindeer owned will no longer have any significance. In this way the dilemma of heads of households will be reduced by virtue of the fact that a household group can now consist of several reindeer herding members irrespective of the total ownership of reindeer. In this way a contribution is made towards the strengthening of mutual solidarity and co-operation within the community by the fact that more persons then before can participate in the local decision-making process. 
The rules are flexible and their interpretation can vary widely, which is illustrated by the difference between the communities in Kiruna and Gällivare. In the latter district all the reindeer owners who are permanently employed by the Swedish State Railways, are included in the reindeer herding group. This decision is motivated by the fact that all their free time is spent looking after reindeer. As mentioned earlier similar conditions apply in Kiruna, but there they have chosen to retain the narrower interpretation of status transferred from the Reindeer Husbandry legislation.

The positive aspects of the legislative proposals have been established thanks to the series of actions that the Samis have been responsible for. This shows once again how useful and indispensable the developed political form is for the Samis. One of the most noticeable consequences of the process of social change that this study is primarily concerned with is that they have acquired an instrument through which it is possible to influence their own situation at the national legislative level. of course, this is an enormous improvement compared with the previous situation, when the Samis consisted solely of a group that was the object of more or less arbitrary legislation. Now it is possible for the Samis to carry on a continuous dialogue with the authorities as well as in many cases to be able in practice to influence the final legislation. In this way the Samis have changed their status of being purely supplicants to partial active participation in the formulation of structural changes. That this has occurred is shown in the SSR's actions before and after the Government Bill and by the Communist Party's and the three Conservative Liberal Parties' Bills that were inspired by SSR's general Sami political programme. Even though it had been possible in these Bills to assemble well articulated support for the autonomous position of the Sami communities they were without success because the government party kept unwaveringly to the Bill. However, because of their actions the Samis had created the foundations for increased involvement among Riksdag members, and an increase in the number of Bills that take up Sami issues in the Riksdag after 1971 is clearly noticeable. 
However, on one very important point it was impossible for the Samis to influence the contents of the proposed legislation, and this concerned the use of land in terms of RBL paragraph 5 (compare page 48). The same detrimental legal position remained in paragraph 26. After intensive discussions in the Riksdag it was agreed that the relinquishment of land according to this paragraph should at least be limited quantitatively and, in addition, be referred to the determination of the costs in court. This minimal improvement, that occurred as a result of the unstinting work of SSR on this particular question, points to the need for increased legal protection. As long as this paragraph remains, Samis wishing to follow a career as reindeer herders feel very insecure. It has been confirmed by their own actions during the discussions about the RNL, that it is only by means of a favourable court decision that this state of affairs can be changed. The legal strategy that was chosen during a particular phase of political development has therefore shown itself to be completely correct. A victory in the Skattefjalls case, for example, would pave the way for an amendment of the law on this vital point. As a result the individual Sami oscillates very much between the insecure position created by the structural limitations in terms of the RNL, and the strong belief and expectation of a favourable result from the Skattefjäls case. The latter has therefore to a very great extent contributed to a strengthening of self confidence and an emphasis of the wefeeling between Samis.

We demand that all those who want to will be able to live as Samis, and be Samis. If so, we must be given the opportunity to carry on wide economic activities. A favourable court decision is our only hope.

Our culture today lacks an economic foundation. A court deoision in our favour, that protected our territories and gave us an economic return, would be a good start for young Samis. This is absolutely necessary for the future of our oulture.

Our knowledge about our own culture has been increased and our feelings of confidence have been strengthened by the skattefjalls case. Now at last we can dare to speak out, we have a better perspective on our own situation. And irrespective of what happens, the Samis will come out of this court case as a stronger group. 
After the RNL was adopted by the Riksdag, discussions at the grass roots level started up again. The main topic of discussion was the fact that there had been too little information about all the structural changes that the new legislation would create. In the region covered by this study there was particular dissatisfaction and many statements emphasize how unprepared people felt when faced with the imminent changes.
A question as important as a new law should have been translated into our own language. A legal text isn't the same thing as a newspaper. It's very difficult to read and to understand. That's one of the reasons why we understand so little. I think there would have been more discussions in the community if it had been trans- lated into samish and if we'd had more time. As it was, it was easy to give up because we hadn't the strength to go on.
The idea about trial communities also came too late. A year is much too short, they say themselves that we know too little. We should have had at least five years. But they want to do things quickly so that we Samis don't have time to react until the new legislation is already in existence.

These criticisms were taken up at the Sami political arena when several representatives at the national meeting gave vent to sharp criticism as well as their fear, in particular of the authorities and even implicitly of SSR. These exchanges illustrate the large differences that can exist within an ethnic group that is as geographically spread out as the Samis are. SSR must have realized at an early stage that these differences of opinion are based on the ability or the will, or lack of it, to adapt to modern forms of organisation. The Sami communities that were affected should therefore have been better informed than the others. But instead no distinction was made, for example, between the Forest Samis and the southern Sami area, which have in some ways adapted to more contemporary organisational forms for some time, and the northern communities which still maintain the original sii'da organisation.

Both individuals and the communities have been given too little information. I think greater efforts must be made in the future when it concerns information to the communities, I think that two days is much too little. It is here that as much as possible should be done, otherwise it won't get out to them.

Samish is our mother tongue, it's not that easy to follow things in another language. I think that all information 
activities should be in Samish so that everyone can understand. One ought to have more than one day to go through and translate the legislation into Samish so that everyone in the community can understand the contents.

The Reindeer Husbandry Law is so far only at the drawing board stage and it's not yet been put into practice. It's only then that we can see the effects. In three weeks you don't learn anything. You get perhaps just a few ideas about the whole thing. The community officials must have wide theoretical knowledge in order to carry out the work that has fallen on them according to the new system. To begin with there should be two three-week courses for all committee members in every community and then further follow-up courses.

Of course, SSR was not solely to blame for this. For several years a state grant towards SK-activities had been applied for without success. It was not until the RNL came into force that the necessary economic resources to carry out this totally essential information drive became available. As a result it was possible for SSR to reduce the difficulties of adaptation during the first transitional phase.

Another question that is, in a way, coupled with the lack of information was the innate lack of interest in the idea of reindeer association. It was felt that the new organisational form, which was very Swedish in character, would involve such great social costs that it would be difficult to adapt to it. The opportunity of free choice, at any given point in time, to participate or not in one phase of work was now lost. The old sii'da organisation was based on this principle, and that gave a particular feeling of satisfaction at the same time as demarcating their own cultural affinity. Many Samis are now of the opinion that a reindeer herding association will weaken this distinction, that the differences between paid work in the larger society and being a reindeer herding Sami will no longer be particularly great.

I'm not pleased with this new legislation. I know one thing, we're losing all our freedom. I'm afraid of the now legislation and the herding association, we'll lose all our freedom then. Those who live of reindeer herding will be forced to carry a burden that they can't manage.

It'll be expensive to be a reindeer owner in an association, if one is only living off reindeer.

Herding reindeer in an association won't be the same as the reindeer herding we've had before. It will be difficult to keep up the sii'da division, it'll be too expensive 
to keep separate reindeer herds. I'm pretty sure that it's going to be more expensive to be a reindeer herder.

When they worked out the new legislation they've given too much thought to the economic aspects and forgotten the importance of well being. It isn't just the economic aspects that are important but the way that one gets satisfaction out of one's work.

Even if the division of labour is more equitable, working at it purely from an economic point of view, there is still a risk that such great competition for work opportunities will arise, particularly in the larger Sami communities where there is abundant labour force, that the unity of the community will be damaged. This will, of course, have an effect on well being as well as economic consequences.

I think it'll be very difficult up here in the larger communities - there are so many people here. If there are a lot of people who want to take part but only four or five are needed it will be difficult to make the choice. Communities with 8-lo households have totally different circumstances. Voluntary co-operation is better than compulsory.

An important effect of the new legislation is the loss of freedom. You can't go into the reindeer areas just whenever you feel like it. You'll be regarded as a reindeer hustler, and be regarded with suspicion. Before you could go out into the reindeer areas because it was fun to be there, one liked that way of life, irrespective of whether there was a demand for work or not. But that's all over now.

In order to go into the reindeer areas you have to have reindeer. Those that have reindeer don't go to the reindeer areas for day wages but in order to look after their reindeer. But can I entrust my reindeer to the care of the community? Those that go out, what do they do? Do they herd the reindeer as they should do, and do they mark all the calves? This isn't a question of a day's wages, it's a question of deep interest. The reindeer owners themselves have a greater interest in going out.

This massive local criticism was also expressed in an open letter in a local newspaper that a young reindeer herder in $Y$ sent to the members of the Swedish Riksdag. It was the last individual attempt to try to influence the legislators before the RNL was accepted. (NSD 30/4 1971)

In the RNL the authorities had prepared for a relatively rapid transition to the new local organisation by effectively eliminating all opportunities of choice. In the first place future state economic grants for the improvement of reindeer 
husbandry were dependent on whether the Sami community was organized according to the new principles or not. Since the Sami communities in general are dependent on this form of support they were forced to rapidly accept the association form. In addition a special clause about a manager (RNL \$72) was introduced, which acted as a form of threat to all Sami communities still undecided. This manager was to be responsible for the administration of the community if the latter had not registered itself according to the principles of an association within a stipulated period of time. The Samis who were opposed to the Reindeer herding association regarded this clause as formal blackmail aimed at carrying out hasty reorganisation.

A manager is something that $Y$ must have and they will get it if they don't form an association. That's what I've heard.

A manager is a regrettable action, it's a form of guardianship. And in this way the Sami community is forced to form an assooiation. It's a sort of blackmail. They want to force the sami community because it will be more expensive than forming an association. And now we have legislation that can be pressed upon us.

The County Agricultural Board can say, if you don't do this we'll put a manager in at your expense.

They haven't bothered at all to keep up to date up here. But if there is no community board consequently there's nothing else to do but to accept a manager. The County Council will appoint a manager who will be in charge of the Sami community's organisation, and then there'll be hard terms. Then there'll be an association but it will be much more expensive than if we did everything ourselves because we'll have to pay the official's salary. The community won't be able to manage it.

That this is a question of a compulsory clause is also confirmed by the following official statement from the national meeting.

Care must be taken to avoid getting a manager appointed, and therefore a board must be elected within the sami community. It is not difficult to appoint a board. There is the committes of deputies and it's only a matter of transferring authority to the board. (SSR's reindeer herding expert).

This thing about the manager is the absolute final way of improving reindeer husbandry in a sami community. It must rest with the County Agrioultural Board to decide that in a particular sami community they can't manage and therefore a manager must be appointed. It should be the Samis on this Board that decide that a manager is needed for a 
particular Sami community. It's imperative to have this sort of legal clause otherwise it's impossible to control everything if such a situation should oocur. (Minister of Agriculture).

It is true that it has not been necessary to apply the manager clause during the five years that the RNL has been in operation but I know of at least two cases in the Gällivarel Kiruna region, where the transitional difficulties have been so great that there were far-reaching plans to transfer the Sami community's administration to a manager who is an administrative official. This institution clearly shows that the increased authority that the Sami community acquired at first was by no means unconditional.

In the association model rationalisation has also been built in, the object of which is to increase the profitability of the individual units of production. It is the larger society's definition of profitability that is being enforced, which is by no means in accord with Sami conceptions. With economic compensation as an incentive it was hoped that voluntary winding up could be speeded up, which was rightly regarded as attempted official control of population development. The majority of Samis have also reacted against this. Amongst other things they emphasized that the adaptional difficulties would be too great for many individuals, and that the social costs would be unacceptable since they by no means compensate for the economic advantages that are entailed in a winding up. In addition a drastic rationalization of people in this way would have negative effects on unity and co-operation within a Sami community.

According to the new legislation all reindeer owners will have large herds. It will be necessary to have 500 reindeer in order to carry on. But what will they do with the smaller reindeer owners? Do they have to sell their reindeer to those who have more? And so they use money to draw people away from reindeer herding.

Now I've heard the Minister of Agrioulture say that the differences must be evened out and the Samis must be reduced: That doesn't sound too good. I was around during the hard times and $I^{\prime} m$ worried about these attempts towards equality that mean that the poor are to be moved away and only the rich will be left. It's not democratic legislation when this sort of thing can happen.

smaller reindeer owners as well as the aged have become worried. They want to remain and that's easy to understand. It wouldn't be too pleasant to be moved to the 
mines for example. There'll be questions of another language, another environment etc. This transfer is quite simply impossible to oarry out.

It's this rationalisation of people that we are against. Nobody today is prepared to carry it out. Things like this don't create unity, co-operation. It creates only a lot of worries in the sami community.

If one is born a reindeer herder then it's difficult to give it up. I can't imagine giving it up. This is why reindeer herding is not just economics.

In his Bill the minister of Agriculture also rejected the proposal from SSR to strengthen solidarity between different categories by introducing supporting members in the Sami communities. Only for those Samis that give up reindeer herding will it now be possible to keep some attachment to the community during a transitional period. By laying the foundations for a smoother transition for those, who for different reasons have to give up reindeer herding, it is obvious that the authorities are aware of the problem. Instead of deciding the question definitely it was preferred to pass on this matter to the then ongoing Sami Enquiry. As we have seen earlier a large number of non-reindeer herding Samis, who have chosen to refer to themselves as differentiated Samis, according to the terminology of the Sami author and sociologist Erik N:son Mankok, have joined the reindeer herding group on this vital problem. This is illustrated in part by the discussions concerning the new legislation and also by the recurrent mobilisation of labour for example in the Kiruna and Gällivare Sami communities. This sort of expression of solidarity is a basic prerequisite for the development of the Samis as an ethnic group, instead of the series of small groups broken up into different categories that we find now. The tendencies towards ethnic consolidation, that are not the least illustrated in this case study, are quickly nipped in bud by means of these formal rejections. Since the Sami Enquiry is not concerned with legal conditions the differentiated Samis feel that they have been overlooked in this particular case. What they wish to achieve is, for the first time, an official recognition of their ethnic status; to be formally recognised as Samis with certain minimum rights. They have therefore sent several petitions to the Sami Enquiry in order to influence it, 
in particular the newly created Norrbotten Sami Association and the numerically stronger Sami Associations in Kiruna and Gällivare. Even SSR revived its idea from 1968 by amongst other things discussing the matter with representatives from the Sami Enquiry at several national meetings and also by means of their own petitions to the Enquiry.

The Sami Enquiry which recently published its findings remains relatively cautious on this point (SOU 1975: 99-100). Since this question is still so unclear, not the least amongst the Samis themselves, it is suggested that the Sami communities are allowed to accept a limited number of supporting members during a trial period, and these should be Samis with reindeer herding rights in their own community. The Sami community will thereby have full authority over who and how many can be incorporated in the community.

This is so far a proposal that neither SSR or other Sami groupings have had time to consider. The submission stage has hardly begun and will culminate in the national meeting in June 1976. It is, however, not difficult to state that the differentiated Samis even this time will stand clearly aside. The government are laying out the framework for future Sami community decisions. But since the Sami community is a construction that the authorities have forced upon the Samis from 1886 onwards the Sami Enquiry is more likely to increase the gap between the different categories of Samis than to increase the feeling of unity between them. It therefore appears even more likely that a development towards ethnic mobilisation implies clear territorial connections. An official enquiry, irrespective of the extent of Sami participation, cannot solve such radical questions as these since the legal considerations rest on the RNL of 1971. What the enquiry proposes, after five years work, only goes to confirm how essential and right the struggle for legal rights is for the Samis and their future, in terms of the protection of the ecological basis for reindeer herding Samis as well as a favorable starting point for increased unity between all the different groups of Samis. Improvements of the Samis' situation will continue to be marginal as long as Sami legal rights do not rest on basic territorial rights. Both the enquiry that formed the basis of the 1971 RNL and the resulting 
enquiry SOU 1975: 99-100 that developed from the former, clearly show this.

Before we sonclude this example it may also be pertinent to refer to recruitement to the reorganised administration. All posts were made available in 1971 and many Samis with sufficient merits sought different posts at this time. In only one case out of nineteen was a Sami appointed. Particularly remarkable were the appointments to the posts of assistants, where none of the 16 Samis who applied were appointed. This appointment procedure has been the subject of animated comments in samefolket which clearly illustrate the bitternes that the Samis felt about this.

In one case an applicant, a Sami, who in terms of both theoretical and practical experience of reindeer husbandry, its organisation and its prerequisites, who is much more qualified than all the employees in the administration, has been completely passed over by another applicant who has no general education at all and very little experience of practical reindeer husbandry, a non-Sami. (Editorial in SET. 1971:12).

Not until the government reduces itself to the position of conceding to the Samis, is forced to accept that knowledge of the Sami language and culture is a merit for posts within the administration for reindeer husbandry, a Sami occupation - not before then will it be possible to say that the Samis have been accepted by the Swedish society. (PM Utsi, SET 1972:1-3).

To pass by a qualified Sami in this way was regarded as such an outrage that a member of the Riksdag (Vpk) took up this matter in the Riksdag and questioned the Minister. The Riksdag member stressed the fact that educated Samis, if fully qualified, should be given preference to different administrative posts concerning reindeer husbandry. Otherwise it would be virtually impossible to make a career in the service of one's own minority, a factor that weakens the ethnic group still further. The Minister replied to this important question of principle in an evasive manner, and even the central administrative level refused to give a straightforward answer. (SET 1972:1-3).

Some of the Sami applicants got together and appealed against the decision. In terms of the particularly qualified applicant that was referred to above, the authorities conceded and made available a new post linked to the same administrative section. Since then it has been shown how important this post was for the Samis in this district. They can now turn to an expert, who speaks 
their own language and has ties with their own area. Through his long experience as a reindeer herder he is well acquainted with the Sami system of codes and can therefore carry out the necessary translation of legal texts to the situation in the herding areas. Under the difficult transitional problems that the Sami communities are now struggling with, access to such expertise is of considerable importance. That this is the case is illustrated by the B Sami community. Two members of the committee spent two whole days in the assistant's office at the beginning of June 1973 in order to obtain help with preparations for the first annual meeting since the Sami community had been registered.

Another of the Sami applicants, a representative for the executive committee of SSR, has obtained a post as assistant in Umeå after it had again been made available and recently a Sami was promoted to the National Board of Agriculture.

A certain amount of Sami participation can only be achieved if Samis are able to obtain positions in the administrative machinery that deals with their problems. Through their actions and by not accepting the outcome of the first round of appointment procedure the Samis have demonstrated that it pays to agitate and to demand particular favours. As can be seen they obtain nothing gratis from the larger society, but with an active policy the Samis can achieve limited results.

Through the coming into operation of the RNL the Samis have for the fourth time had the legal framework that determines relationships between them and the larger society laid down. This framework is of great importance to the Samis in their adaptation to changing natural factors as well as to conflicts with different parties in the larger society. The Samis had therefore very good reason to try to influence the changes to this framework. If one is to test the political potential that a form of action has in practice, a thorough analysis of the processes that resulted in the RNL make a well chosen case. We find here many of the ingredients that reflect the lack of power that the Samis still experience as well as their strengthened position, compared with earlier situations, that the developed political form entails. 
SSR has in this case, perhaps more so than in the examples discussed earlier, strived to achieve a closer association between the various Sami organisational levels. A steady stream of ideas have contributed to tighten the bands between the national organisation and the different local units. Involvement at the Sami community level has been strong and, in part, critical which has forced SSR to re-evaluate or make more explicit many of their original viewpoints. The ideological formulation that developed from the work on the submission into the general Sami political programme presupposes such a close relationship.

This feed back effect has consolidated SSR and all future Sami policy emanates from this ideological platform. This is noticeable in the Sami representatives' tactical manoeuvres within the administrative sector of the Reindeer Committee as well as in the regional reindeer husbandry delegations. It is further apparent in the Bills that SSR, with increasing lobbying activity, succeeded in introducing into the debates in the Riksdag. The dominant flow of ideas that these Bills are based upon are easily recognizable from the Sami political programme. Even in the legal strategy of action in terms of trial cases as the skattefjalls case, the Samis have chosen to make extensive use of the ideological framework that was hewn out during work on the proposed legislation. And finally of course the individual Sami communities have been able to achieve more unified lines of action and forms of expression than before. It is also more and more noticeable how similarly the Sami communities act in confrontation situations. They make similar demands, they use similar procedures and negotiating techniques and express themselves according to a common code - the Sami political programme. This continual flow of ideas within the Sami group and the relatively uniform use of the ideological framework in specific situations must be regarded as just as important as the immediate improvements to the legal framework that the RNL introduced.

However, this does not mean to say the Samis stand united behind the new framework. The RNL with the new organisational forms at the Sami community level have not, as has been noted, been accepted by all parties. The negative reaction, that has now and then become apparent, not the least in the area covered 
by this study, relates to the difference between the flexibility of the sii'da organization compared with the stricter organisational form that characterizes the new legislation. With the RNL a local organisation was introduced that, seen from the point of view of the Sami community, brought about greater opportunities for external control over the individual members of the community. In this way a new way of classifying people was introduced, i.e. many Samis regard it as a depersonalization of reindeer activities and local corporate life as a result of increased internal bureaucratization. This is regarded by many Samis as a dilemma because personal freedom, which has natural links with the traditional sii'da institution, is lost. Since there will be less room for reindeer herding in small groups on the sii'da pattern, the lifestyle loses some of its uniqueness. This generally affects well being and thereby even the mutual basis of values. The introduction of the RNL and its principles of local organisation have created a certain amount of conflict of values among the leaders of the reindeer samis. That this is the case is apparent from the discussion above. This conflict of values between SSR and certain local groups can be seen as a result of this state of affairs.

The RNL is naturally, like all other legislation, not completely ideal. It is, however, much better than previous legislation for this minority group. It should be emphasized that the Samis induced this legislation at the right point in time. The National Physical Plan Proposals, which started up after the RNL came into force, will have a very strong controlling effect on the use of land. The fundamental security of the Samis'exclusive use of land, which was successfully written in to the legal text, would therefore not have been possible to get through today. When in 1963 the Samis turned to the Minister of Agriculture and demanded an enquiry in order to attain an improved legislative position, they acted at a particularly opportune moment. This is emphasized not the least by the fact that the authorities, particularly at the regional and local level now consider that the RNL gives the Samis much too extensive rights concerning the use of land. 
1. This idea was developed further in the statement by SSR. Statement of SSR on the Report SOU 1968:16, page 38 .

At the SSR's national congress in Umea 1970, the Minister of Agriculture made a speech that clearly showed that the Ministry had taken notice of the Samis' statement on this point. He agreed, in the same way as the National Board of Agriculture, that Sami representation should be increased to five members. The Samis would, in this way, obtain a comparatively strong position in the new body.

2. The reason for this decision by the Board was that SSR should be allowed to see the proposals and go through them thoroughly, that the Sami communities could examine them so that all the details could be understood, before the discussions could be started.

This tactic also reflected something new. Previously, the authorities were always anxious to obtain a Sami reaction quickly in order to safeguard themselves. We've referred it to the Samis. The Samis are now much more cautious and consistently avoid acting rashly. In this way much greater weight is attached to the statements of the Samis. This tactic differs partially from that of SSR at an earlier stage, and in particular from that period before SSR existed. Compare page 139. 



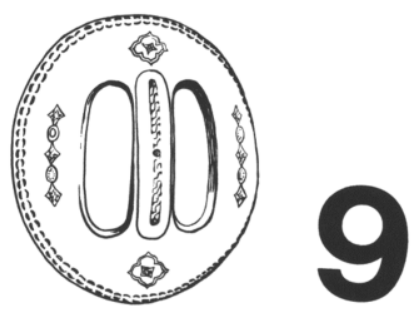




\section{Conclusions}

It ia Hietory itaelf which has taken hold of the young Samio' minde and thoughte; it has made them aware, and they now realize that as a tribe and people they have reached the end of the road. Their existence as a natural people is at an end and there io no way back. Trying to live in the past would be escapism.

Annok Sarri Nordra

This study, which consists of two parts, illustrates a particular minority situation. From a local context I have given in the first part a detailed presentation of the social system in which the reindeer Sami group forms an organizational part. The form of action, which has gradually developed, is to a large extent based on ecological and administrative conditions. The third important prerequisite for action that I take up is the basic values, not least the larger society's value system which acts as a clear constraint on Samis' ability to attain many important political objectives.

I have also pointed out the role of the political elite concerns the formulating an ideological framework as well as the initiating specific political actions. As among so many other ethnic minority groups this elite tends to be dominated by educated persons. Within the Arctic and Subarctic region this may be considered to be a common feature of political mobilization on ethnic ground. Helge Kleivan's article about ethnic identity on Greenland certainly affirms this statement. (Kleivan, 1970:211, 226-227). In this way new positions and modes of behavior were developed that were not traditionally attached to the Sami culture. Suffice it to mention here the founding of the organizations SSR, the Nordic Sami Council and the so institution with its strategically located office in Stockholm. The strategy of emphasizing ethnic identity is one of three basic choices listed by Barth referring to organizational change in situations of culture contact. (Cf. Barth, 1969:33). On the Sami local level these institutional developments have strengthened the sense of community of values and gradually 
consolidated the value base of the Samis. The frequency of minority political activities reaffirmed basic values because all actions were anchored to a Samish movement with a relatively unified ideology. Following Holloman this readaptation in order to cope with the new and more competitive situation could be named sociocultural evolution. (Holloman, 1975:29).

The role of the so clearly bears the characteristic of a broker in the way that he facilitates the Samis' communication with the larger society. As Holloman recently stated, articulation in poly-ethnic contexts, where boundary maintenance seems culturally significant, is usually brokered. (Holloman, 1975:27). The importance of the expertise of the $S O$ in any political game during the last 15 years confirms this general proposition.

Constraints on action have shown themselves to be difficult to manipulate because of the power constellation that characterizes the minority situation. In this context there is a clear difference between the Samis on the one side, and the administrative bodies of the larger society on the other. The latter have resources that enable them to attain their objectives to a far greater extent than the Samis. The majority has more or less full control over the constraints that affect Sami action, as is clearly apparent in the Nordnesset case.

The prerequisites for unified action are defined differently by the two sides. In each particular confrontation situation the Samis are forced to participate as the subordinate partner which is characteristic of minority situations. When the larger society, as a result of expanding industrial activity, extends its sphere of influence to include even areas that have previously been left as undisturbed reindeer grazing areas, the position of the Samis becomes even further weakened. It becomes more difficult for them to maintain their way of life as the economic base for this has been undermined. A possible reaction to this is a decimation of the population particularly in certain vital age groups, which in turn will influence cultural viability. From a demographic point of view, many of the local community units will be too small to withstand this negative trend.

In order to prevent this sort of development the Samis have adopted a double strategy, on the one hand by changing the social system and demanding exclusive rights, and on the other by 
accepting the premises of the majority by making more systematic demands in the courts for the rights they have by virtue of Swedish citizenship. In this way they hope to strengthen the Sami minority's position in the Swedish society. In many cases concerning the development of land the Samis are now referred to as a legitimate interested party with rights to economic compensation. By going to the courts and testing their fundamental rights the Samis have demonstrated, in a much more effective way than before, that they are in a position to act on the basis of the premises of the majority. Each recognition of their rights to compensation does not in itself entail any gain, but rather a confirmation of the legal right that they have had for a long time: as Swedish citizens, and which they have not had the resources to utilize until more recently. However, a series of successful court cases can be recorded as political gains for the Samis, in the ideological sense, since optimism, self-confidence and belief in their own political power is strengthened. One of the immediate political objectives of the legal strategy is by means of continued court actions to shed an increasingly stronger light on Swedish society's "defining away" of the Samis as a category with rights, as exemplified by the RBL and more recently by the RNL 1971. In this way the Samis are working towards a re-definition of rights, i.e. the achievement of an ethnically plural society in a political sense as well as from the point of view of minority rights.

This study places particular emphasis on this aspect. It has been necessary to give a detailed account of how ecological conditions have changed as well as the negative effect of the increasing influence of the administration. By the latter is inferred the process of bureaucratization of which the Samis have been the object for a long time and which has considerably extended the larger society's direct control over marginal units of the sort that the Sami communities represent. ${ }^{1}$ )

The basic values and the way in which these have changed form the third premise which has influenced Sami political action. An analysis of this kind of process of change cannot be carried out without reference to the interaction of these three elements. 
It is important to point out that the political activities which the Samis themselves have initiated should be regarded as a goal-orientated choice, the choice between assimilation or a plural situation. (Cf. Dahlström, 1971). The process of assimilation is counteracted by the different ways in which the Sami group is strengthened ideologically and from an organizational point of view, while simultaneously aiming their strategic actions for the final objective, i.e. a plural situation. However, there is still a very long way to go and in the meantime we shall limit ourselves to recapitulating the steps towards that objective which have been attained so far. (Cf. Eidheim, 1968).

As a first step in this development process all local units were brought together into one national organization. Ethnic identity and common economic interests form the basis of this new structural development. As a result of the elite's formulation of ideology which has developed to a large extent from the newly awakened Sami intellectual involvement, the feeling of identity and communal interest on the part of the individual is intensified. (Compare amongst others Balandier, 1967, and coser, 1956) ${ }^{2}$ ). At this point a change of attitude takes place, in such a way that individual Samis become aware of what it means to be a part of the larger society, while at the same time increasingly realizing the importance of defending ethnically distinct interests from that society. As a result of such a process the Sami group has achieved one pre-requisite for action, i.e. internal unity, which is essential if the position of the minority group is to be strengthened.

As has been indicated earlier, my material illustrates ethnic incorporation, i.e. the development of an esprit de corps around a common objective, an objective that all categories of Samis can identify themselves with. (See Eidheim, 1971). From what one can observe so far, an important element in the strategy developed by SSR to achieve this objective is the legal aspect. Rights to territory and water are proven in test cases such as the Skattefjälls case.

Similar strategies have been employed by other ethnic minorities. Here, it probably suffices to mention the James Bay 
project, a gigantic development project in the province of Quebec, Canada which affected the ecological situation of the Indians and the Inuit. On the initiative of these two groups the matter was brought to court. The first ruling of the court, on 15th November 1973, was in favour of the indigenous population to the extent that teir territorial rights were recognized, while at the same time all work on the project was brought to a stop. The Quebec government, which was the opposing legal party, has since then appealed against this ruling. Because important natural resources, such as hydro-electric power, iron-ore, timber and oil are involved, the indigenous population are no longer prepared to give up their fundamental rights too easily. On the contrary, this sort of recognition creates new economic opportunities for minority groups, who count on obtaining a part of the large profits that can be extracted. In this way an improved economic base is created for the continued existence of an ethnic group in a modern society, in spite of the deterioration of the basis for traditional ecological adaptation. (See also the Nunavut, a proposal for the settlement of Inuit Lands in the N.W. Territories in Canada, submitted in February, 1976.)

When considering changes of attitude it is important to note that SSR played an influential role in terms of furnishing politicians and representatives of central and regional authorities with information. Because of this, the authorities are in a position to make important decisions concerning the Samis from a completely different basis than earlier. They are much better informed, which is to the Samis' advantage. This change of attitude is most apparent in the latter half of the period that this study covers.

As this study clearly shows, the administrative system which the government once forced upon the Samis, was not able to sufficiently safeguard the interests of the Samis. This became particularly apparent during this century when the larger society exerted increasing pressure. The primary intention behind the introduction of this administrative system was to regulate relations between the nomadic and the sedentary population. Additionally it was intended to act as a protection for the minority group. Since the Samis lacked an effective organization at this stage, i.e. the latter half of the 19 th century, those 
affected had no opportunity of taking a stand on the way in which the administrative system was being drawn up. ${ }^{3)}$

When the Samis in some situations wish to adapt themselves to new conditions, which are largely the result of increasing cultural contact, the administration prevents these attempts. This concerns the transition to more permanent dwellings, adaptation to a combination of supplementary income sources, and the modernization of reindeer husbandry. However, far more important was the negative attitude to ethnic mobilisation, taken by authorities at different levels, when the Samis began to concentrate their attention on an organizational structure. As is apparent in the previous chapters the larger society was not prepared to accept unconditionally the type of social change started by the Samis themselves and exemplified by SSR and the Sami associations. It was not until SSR existed as a new reality, to which the authorities in their continued dealing with Sami matters were obliged to adapt themselves, that they also recognized SSR and accepted its importance. ${ }^{4)}$

From the beginning SSR represented a form of common interest organization with trade unions and other interest organizations as a model. Its political potential in the ethnic sense developed later, and is regarded today as the raison d'etre of the organization by the Samis themselves. Not even this change has been officially accepted and from many quarters the authorities insist that SSR is primarily an interest organization similar to $X, Y$, and $Z$ in Swedish society. Using similar tactics they attempt to undermine the actual authority that SSR has. This contributes to making political action more difficult for the Sami minority.

In spite of these difficulties SSR today is an organization which is primarily concerned with political activities, i.e. with power conflicts. The second part of this study illustrates these activities with a number of examples. Groups, which are incapsulated in larger social systems and which exist specifically to deal with conflicts of interest with the larger society are referred to as parapolitical structures. (Bailey, 1968). 
Many of their activities are determined by external social factors, but internally they act as if they were independent of the larger society. ${ }^{5}$ ) Structural units of this sort are apparent in certain types of conflict situations. If a minority group is to retain its ethnic identity and consequently avoid assimilation, it is forced to become involved in conflicts. (Coser, 1956). The minority position of the Samis, as described above, is largely characterised by this sort of involvement. Conflicts become the incentive to the type of mobilization on an ethnic basis that is illustrated by SSR.

There was not much demand for this kind of mobilization on a wide front until increasing conflicts developed concerning the use of resources in the Sami areas. The objective of this movement was to create internal cohesion and strength, while simultaneously externally searching for the most favourable position possible in the conflict situation, i.e. a redistribution of power to Sami advantage.

The second section of this study illustrates particular events of conflict, e.g. cases concerning land development or important legislative matters. By focusing our attention on these events we are in a position to analyse the forms of action which the developed political form has made possible. As becomes apparent from this case material, the Samis have been able to gradually strengthen their position and they have also achieved certain objectives through the improved use of the majority's own premises for action in particular confrontation situations such as land development and legislative questions. In this we can also observe the moral strategy which the Samis have chosen to employ. The prerequisites for a successful policy on the basis of these premises is the type of organizational development exemplified by SSR. An organizational basis of this sort, together with a firm expression of ideology, has had a unifying effect in an ethnic sense. In this way the Samis have been able to have an increasing influence over their own life situation. This has not, however, occurred to a sufficient extent. So long as the political objective of exclusive legal rights for Samis is not attained, the Samis lack guarantees against the effects of large-scale land development and their opportunities for action in the political arena will remain constricted. 
The frequency of land development cases has increased considerably during the last 25 years. This has intensified interaction between leaders of SSR and Sami local-level politics, particularly at the Sami community level, channelized primarily through the so. This has given the so a key position in the process of development, which has resulted in greater selfassurance and a more articulate ethnic identification amongst the Samis in the Sami communities. This development has been instigated as much by the actual land development cases as the more general legislative questions. Since the legal strategy has shown itself to be increasingly successful, cases dealing with land development have created a new opportunity situation for the Samis so that it has become advantageous for individuals to express Sami identity. This new attitude is a further addition to ethnic mobilization. (See Barth, 1971). It is probably sufficient to cite here the ruling in the Altevatn case and the ideological significance this has had for many Samis, many of whom were not directly influenced by this particular development project.

With regard to the legislative processes, we have dwelt upon two such cases which have entailed structural changes of a profound nature. In both cases the Samis have been able to demonstrate the potential of the new political form by demanding participation in order to influence the legislative results. In these cases interaction within the Sami rank and files has been intensified, which has again resulted in an increased feeling of ethnic identity. In addition new forms of action have been tested, such as the ad hoc group that successfully participated in the final drawing up of the Reindeer Pasture Convention. Since Samis are to make statements on new legislative proposals, such as those presented in more important surveys of the sou type, they now choose, before acting, to give thorough consideration to their points of view. This strategy characterizes authoritative Sami action today, and clearly differs from the period before SSR existed. The statement on SOU 1968:16, which was finally approved at the extraordinary national meeting in October 1968, illustrates this new strategy in a striking way. 
Through the RNL the Samis have achieved participation at different levels, limited participation in central and regional administration, quite a strong influence in the Sami Fund, and finally greater independence for the Sami communities as compared to the earlier situation. Taken together these can be regarded as a step towards cultural autonomy, which is essential in all plural situations. This autonomy cannot, however, be achieved unless positions are moved forward even further. The recently presented Sami Enquiry (SOU 1975:99-100) is a step in this direction. The Sami objectives in this enquiry were to strengthen Sami feeling of community. In order to achieve this, however, structural prerequisites and increased resources were required to enable Samis in the Sami communities to be integrated with other Samis. The investigation is very vague on this point and has been strongly criticized by SSR in their statement drawn up recently. (National meeting, 1976).

Another step towards cultural autonomy is the legal strategy, in particular the way it has been expressed in certain court cases. If this strategy becomes too successful, so that the minority group becomes too strong at the expense of the majority, then discrimination tendencies may be strengthened. General arguments along these lines have been put forward by Blalock. (Blalock, 1967:120). Discrimination means in this particular context inflammatory statements about the Samis qua Samis in various public fora such as political arenas as well as the mass-media. This attitude of conscious disparagement towards the Samis was not necessary to the same extent when the Samis lived as a reticent and peaceful nomadic group who did not make any difficulties or claims.

During the period that this study covers, it has not been difficult to verify the thesis advanced by Blalock. The attitude towards the Samis adopted by officials and many private individuals in Norrbotten can be characterized more and more as the discrimination of an ethnic group. In the mass-media, and in particular the local press, it is cleawly evident how critical and envious people are of the limited success that the Samis have struggled for in recent years. This is confirmed by a special study of how Sami affairs have been treated by the leading newspaper in Norrbotten, Norrländska Socialdemokraten. 
(Fredricson, 1974). This situation contrasts to a large extent with the role that the mass-media has played for samis on the national level. In the national press and on radio and television, Sami problems and, for example, the actions of SSR have been reported in a correct manner. This way of information has been spread to a wider public who cannot be said to adopt a discriminating attitude. Because of this publicity, authorities and politicians are forced to act with greater discretion, which in the long run is to the Samis' advantage.

It should also be noted that the reinforced position, in terms of minority politics, that the Samis have been able to achieve in Sweden is unique in many ways. In this respect there is a striking difference between the Samis in Sweden and, for example, in Norway. There is no office in Oslo for the continuous observation of decisions or events that affect the situation of the Samis, nor is there any so that is prepared or has the resources, to conduct extensive court cases with the authorization of a strong national union. The Samis in Norway, and also in Finland, do not therefore have access to resources that can be mobilized to the same extent as the Swedish Samis. By presenting a wide range of material, this study demonstrates the power of mobilization that these resources entail.

My analysis is built on three key concepts, resources, ethnicity, and power. There appears to be a clear interdependence between these three factors; any ethnic group (in this case ethnic minority) needs access to basic resources in order to maintain its particular way of life, its culture. Because of the new competitive situation within the ecosystem where the Samis operate, power is essential to the Samis if they are to be able to utilize resources for their cultural ends. For an ethnic minority this issue of power distribution is most crucial, because such a group by definition lacks the power needed from the very beginning. The conflicting game we are witnessing through the empirical cases here presented focuses on this ultimate aim - power for the Sami minority. This is made quite apparent from the general ideological framework as well as concrete actions in all cases of inter-ethnic confrontations. This has not always been so. Earlier the Samis viewed various forms 
of economic compensation as their main goal; now political gains, i.e. pressing their position of real influence concerning their own matters as far as possible, seem to be the decisive aim in all cases of confrontation, large or small scale. My own material confirms this general transition, which, according to Barth, seems to be a trend of change we find in most inter-ethnic contexts. (Barth, 1969). ${ }^{6)}$

Important to notice in this connection is that if an ethnic group gets involved in a continuous power game, such as illustrated in this study, it will consequently result in general cultural revitalization, moral strengthening of the people concerned and a more definite and clear cut marking of the boundary between themselves and the outside world. As has been shown from this material ecological and structural variations within the ethnic group need not impair or obliterate this boundary. (Cf. Hoetink, $1975: 24$ ).

In these conclusions a further point should also be discussed and that is the question of value discrepancies. The Samis and the authorities have diverging opinions about the solution to the problems that the Samis are now being faced with. This applies in particular to the economic situation. (See, for example, the Norrbotten survey 1967, and SOU 1968:16). According to government opinion improved material standards should become a central issue even for the Samis. In order to obtain this standard a redistribution of people will be necessary. As we have seen an extremely high percentage of the present population would have to be moved. The Samis can neither collectively nor individually accept a change of this sort. Material standards, according to current methods of measurement in the larger society, are not at all worth striving for from a Sami point of view. What is regarded as important for the Samis is to continue, and to participate in, the way of life that characterizes the reindeer pastoralist culture. If the methods that have been adopted so far should reduce the opportunities to pursue this way of life new strategies will be developed by those who wish to remain. For those who regard it as less important, or who have fallen below the relevant minimum level of existence, a voluntary move will be natural. A way of thinking inspired by liberal economic theories is confronted with value concepts of a different nature. 
The Samis form a distinct ethnic group with its own system of basic values which form the basis for, and are the foremost expression of, ethnic identity. If the authorities' intentions were followed the long-term result would be that the different local units would have too small a population to maintain a culture. A minority population should not decrease below a minimum number of persons, who are in regular inter-action with each other, if the culture is to continue to exist and be socially viable. ${ }^{7}$ The movement of people and a pro-minority policy are therefore, incompatible.

The opportunity situation that the Samis have adapted themselves to consists of, not only the value discrepancies discussed above, but also ecological and administrative possibilities and constraints. The actions of the Samis can also be understood when seen in relation to this adaptation and then one realizes that the Samis have made a rational choice in remaining in their environment with its low income potential, instead of choosing to move and to work in industry. The much higher cash income of the worker, which in reality does not lead to greatly improved standard of living, because of increased expenditures - higher taxes, more expensive housing, all consumer goods have to be bought - seems to be an insufficient incentive for movement for many because the social costs that are involved are in no way balanced by the inflow of cash.

Several studies confirm the existence of a value discrepancy of this kind and show that it in many respects hinders the Samis in their struggle to revitalize the ethnic group. The study carried out by $V$. Aubert and L. Homme among the Coast Samis in the county of Nordland in Norway clearly points to this. ${ }^{8)}$ Problems of this kind are, however, of a general nature and are not necessarily solely concerned with minority situations. Analyses of the different forms of marginal adaptation which illustrate the precarious situation that many rural communities in sparsely populated areas find themselves in, emphasize the opposition between centre and periphery, and which in many respects is similar to the relationship between an ethnic minority and the larger society. (See e.g. Brox, 1966 and Daun, 1969).9) Brox and Dahlström have gone even 
further and suggest that the future of the Samis is linked to the solution of the problem of the sparse rural areas. (Brox, 1969, Dahlström, 1973-74). The ideological statements put out during recent periods by SSR even suggest that many Samis are of the same opinion. (See for example, the minutes from the national meetings in 1971 and 1972).

As we have seen the Samis regard themselves as an ethnic group who refer to a self-evident right to direct their own destiny. Swedish society has not, however, found the cultural differences between Swedes and the Sami minority to be sufficient to vindicate, and to make concessions to, the main demands of the Samis. Sami politics have for a long time borne the consequences of this by formulating the objective of an ethnically plural society. However, in order to achieve this complementary rights for the two ethnic categories must be institutionalized. This means a recognition of the inherent values of the respective value systems. In their political actions, illustrated by the case material in this study, the Samis have demonstrated the great importance they attach to their own ethnic values being accepted as a complement to those of the majority. This would however require a new attitude to minority situations particularly on the part of the politicians and the administration. (See Goodenough, 1966:375).

Before closing let me add some general theoretical remarks relevant to the discussion in this chapter. In a recent book edited by Leo Despres (Despres, 1975) it has been argued persistently against the Barthian position as being too narrowminded. Despres and his associates strongly accuse Barth and those following him to be extremely subjectivist in their definition of ethnicity. Barth's model is considered to be basically psycho-cultural (Holloman), whatever that means, and confined to subjective phenomena. Ethnicity, however, should consist of both objective and subjective phenomena, a distinction I have difficulty in conceiving. Van den Berghe summarized this distinction with which most of the contributors of this book seem to agree:

Ethnic groups are defined both by the objective cultural modalities of their behavior (including most importantly their linguistic behavior) and by their subjective views of themselves and each other. (Van den Berghe, 1975:72, my italics). 
Ethnic boundary maintenance, the marking of cultural particularities in inter-ethnic interaction, the consolidation, ethnically speaking, of the group in order to perform various kinds of power games referring to the control of basic resources necessary for cultural viability, are all forms of behaviour that are relevant to the understanding of the Sami minority situation. Following Barth I have treated these organizational features, and I cannot possibly agree with the statement that this analytical procedure should be referred to extreme subjectivism. It is more than a slight exaggeration to consider this theoretical position as psycho-cultural, and reading through the papers in the book edited by Despres, I do not see the analytical disagreement which so tenaciously has been repeated throughout. If the basic frame of reference contains the concepts resources, power, and ethnici$t y$, as has been stated above for this particular study, and there seems to be no diversity of opinion on that point between Barth and Despres, then the theoretical disagreement about subjectivel objective viewpoints here referred to remains merely a chimera.

The distinction suggested by C. Mitchell, (Mitchell, 1974:1) between ethnicity and ethnic group may lead us out of this conceptual dilemma. According to Mitchell these two concepts both represent analytical constructs, ethnicity referring to perceptual or cognitive phenomena and ethnic group to behavioural phenomena. This distinction is much more fruitful than an argument about subjectivelobjective points of view.

Ethnicity can be seen as a set of shared meanings and values that serve the actors when mobilizing as an ethnic group. (Mitchell, 1974:14). In concrete situations where two or more different ethnic groups interact, for example the cases in this study, we observe ethnicity in this context only. It is what people actually do, their way of behaviour and so forth, that counts, not what they subjectively think. There is no subjective or psycho-cultural definition of ethnicity in this reasoning. As in most other cases we are here dealing with behavioural data observed in specific events of inter-ethnic interaction. 
To continue I share the opinion that the three concepts resources, power, and ethnicity are essential to an understanding of the Samis' current situation. To make this analytical frame of reference operational I have selected a few concrete situations, which are all power games of a kind between the two ethnic groups. Using this research strategy calls for the incorporation of a great deal of macro-data in the general analysis. My intention in this study has been to increase our understanding of an ethnic minority situation by applying such a continuous interchange between micro- and macro-level data throughout all case studies.

Finally, when examining a minority group in relation to a larger society in such detail a feeling of apprehension seems to be inevitable. It is impossible to deny the potential danger that is implied by increased insights on the minority which can make it easier for the larger society to keep the distribution of power constant when conflict situations arise in the future. These justifiable misgivings have been mentioned by, amongst others, M. Banton, who has however added that the opinion-creating effect must be regarded as positive from a minority point of view. (Banton, 1972:154). To this I will only add that I am well aware of these risks. Because of the controversial nature of this type of study I think it is important to let some few of the people being studied take part in the final stage of the research process, i.e. reading through the manuscript before it is published. In this way we do not necessarily dispel the apprehension felt, but we establish a fruitful communication of ideas between the anthropologist and his informants. In the final phase of this project a number of informants have been consulted for just this purpose. They represent local leaders and ordinary members of Sami communities of both sexes, "differentiated" Samis with positions in SSR, and others who are outside this organization while, of course, the SO has also been consulted. None of the persons contacted have had any objections to this work being made public. 
1. In an article on the relations between nomads and sedentary population in the southern Sami area of Norway, J.Falkenberg has also clearly shown the relation between ecology and administration and what this implies for social change. (Falkenberg, 1964).

2. Coser emphasizes the importance of intellectuals when systemizing and supplying an interest group with the ideological framework which is essential for all action. In this way the prerequisites for collective orientation of the individual are established, which is important in all conflict situations. Similar conditions apply to SSR. (Coser, paperback edition, 1964:116-117).

3. G.Gjessing, who has treated social change in general as well as using a long-term perspective - from archeological to historical to contemporary periods - concludes that a Scandinavian administration could very easily be established, because the Samis lacked an extensive political structure. This is obviously correct. As a result the inclusion of the Samis into the larger society took place without much resistance. Gjessing does not, however, go into the consequences of this social system, which is the main theme of the present work. (Gjessing, 1954).

4. The initial refusal of the authorities to attach formal status to the formation of ethnic groups occurs in many poly-ethnic situations. Abner Cohen has shown a similar tendency in his study of an urban environment in West Africa. With regard to ethnicity, he states that even in this context it only becomes apparent when an ethnic group organizes itself informally for political action within a larger social system. (Cohen, 1969:200).

5. The term parapolitical structure goes back to Easton 1965, but has been used for the first time as an analytical tool in a social anthropological context by F.Bailey, who analyzed local political conditions in India, in the article Parapolitical systems. (Bailey, 1968).

6. In a recent article by Helle and Tom Snell with particular reference to the Southern Samis in Norway, a similar argument is put forward concerning the Samis' adaptive responses to the new competitive situation.

Ethnic identity is converted into an organizational quality and ethnic solidarity is proclaimed to be both the integrative force to work with and the desired goal to work towards. (Snell H. \& Snell T. 1975:167 and 180). 
7. A similar argument in general terms has been put forward by Ward Goodenough, who states, inter alia, that

If the members of a community are to be aware that they have a number of sentiments in common, they must have ample opportunity to observe one another at work and play in a wide variety of contexts. To this end group activities are essential. By doing things together people are reminded over and over again of their common interests and values. By working in groups, even on tasks that require no cooperation, they reinforce in one another the values they individually associate with their work.

And he later on continues that

A community whose members have strong emotional bonds with one another through joint partioipation in traditional activities is likely to be conservative, especially with regard to any changes that they feel may threaten existing ties. (Goodenough, 1966).

8. See also T. Svensson 1968 and $1969 \mathrm{~b}$ where this argument is further illustrated.

9. The general theoretical approach that is intended here has been primarily expressed by F. Barth. See in particular Barth 1966 . 


\section{APPENDIX I}

The Samis in the Kaitum area write to the United Nations.

96 Samis signed the note. They live in the Kaitum area which is threatened by hydro-electric power development. The note is addressed to the UN Committee of Human Rights and reads as follows:

The undersigned, being Samis resident at the Kaitum lakes in northern Sweden, beg to put forward the following points of view, and respectfully request that the competent body within the UN contacts the Swedish government on this, for us, vital question.

The reasons for submitting our situation to the assessment of the UN are the following:

We belong to a small minority who live in the northernmost part of Sweden, mainly in the highland region. Our language, our culture, our traditions and our means of livelihood differ in all respects from those of other Swedes. Our livelihood and our cultural pattern have always been based on reindeer herding, fishing, hunting and handicrafts.

The reindeer is a migrating herd animal that requires large areas with special conditions. In order to look after our animals we must follow the migrations of the herd, in the Spring from the forested areas to the highlands and in the Autumn in the opposite direction. We also fish a lot in the lakes in the Swedish mountain ranges, the waters of which are well stocked with brown trout.

During the last decades, the opportunities for making a living within our traditional way of life have been severely threatened by the Swedish government's development of lakes and rivers for hydro-electric power.

An immediately impending project is the use of the Kaitum lakes and Autajaure for hydro-electric power purposes. Large parts of the reindeer grazing and calving areas will be destroyed, our communities will disappear under the water and fishing in the lakes will deteriorate. As to ourselves, we will be moved, against our wishes, to areas unknown to us. Many of the people here have already earlier in their life been forced to leave their homes and forced to move to the place where they now live.

We see this as a grave threat to our existence, our way of life and our culture, and we request that the UN initiates an independent enquiry into our situation, and if our complaints are found justified, to strongly demand that the Swedish government abandons its plans for the further development of hydro-electric power in the Kaitum area. 
Defence speech in the Nokutus case, Oct. 6th, 2967.

For too long the Samis in Kiruna have been pushed aside through the use of power. When Kiruna was established it was foreign profit interests, that together with Swedish help, just helped themselves to the reindeer grazing areas without compensating the Samis. This is true of both the iron-ore field as well as the railway (1903) which caused a great deal of damage for the Samis. Even the County Council in the Norrbotten County reacted to this and has tried for forty years to obtain compensation payment to the Sami Fund - without result.

But something new is beginning to happen for the Samis in Sweden. A lot of this is being provacatively brought out in this case. This struggle between the new and the old viewpoints has been apparent during these main proceedings.

It would be an act of self-evident generosity on the part of LKAB, the town of Kiruna and the County council if they joined forces in their efforts to take care of the Samis in a decent way. The fact is that the mine and the town were only established about 60 years ago on the territory of the Samis.

The Samis have previously not received any compensation for the encroachments they have suffered.

And what is it like today, in 1967?

When the Samis use the same criteria for compensation in Kiruna as in other hydro-electric power cases, the out of court negotiations with LKAB break down.

LKAB cannot shake off the traditionally domineering ways of mining interests.

The Norrbotten County Council has, ever since its coming into being in 1810, been much less positive in its attitude towards the Samis than its colleagues in Västerbotten and Jämtland. This one knows from research that has been done. As early as 1825, the County Council was making anti-Sami statements, and this attitude was created by the iron-ore mountain and its use. At that stage the mountain was still a completely untouched reindeer grazing area.

The County Council cannot rid itself from its traditional attitude that is based upon the phrase Lapps will be Lapps. This is clearly shown in the citing of the extremely out-of-date 22nd paragraph in the RBL during the trial.

And the town! In town the Samis are citizens for whom the community has special responsibilities for historical, cultural and other reasons. The land was mine in the past, preserve my people in the future it says on a monument in Gällivare, which has a somewhat friendlier attitude towards the Samis. The same should be true of Kiruna. Hjalmar Nystr $\phi \mathrm{m}$ understood that. 
But in this court case the town has not said a word about the importance of protecting the Samis and the destruction of their vital migratory routes by industries.

The town talks fervently about the land requirements of its skiing enthusiasts.

The town cannot rid itself from its traditional attitude.

To a large extent the fate of the Samis is decided in the courtroom. The evaluation of damages and encroachments must be raised to a realistic level, even in a mining context.

What is taking place creates serious damage to livelihoods of great importance. According to paragraph 7:39 of the Water Laws this is forbidden.

When talking about importance it is not just economics that are implied. The importance of this livelihood for the well-being and the living conditions of the Samis should also be considered. 
APPENDIX III

\section{Statement from Y Sami community to the Minister of Agrioulture.}

The undersigned, being Samis and opponents to the herding of reindeer in associations, and being members of the Y Sami community, wish to bring a very important matter to your attention, concerning the new reindeer husbandry law proposals in Reindeer husbandry in sweden SOU 1968:16.

We consider that the practical application of these proposals will mean the decline of our livelihood and our culture, because the intentions of the proposals are that the number of reindeer herders/owners are to be reduced. This means that the basis of the continued existence of Sami culture will be considerably reduced. According to the proposals, this reduction is to be carried out compulsorily. We therefore protest firmly and strongly against such a move in a democratic country such as Sweden. Compulsory legislation of this sort is not worthy of our country. We demand that greater consideration be shown to the individual and to individual reindeer owners. We wish to safeguard private reindeer ownership and the private rights of disposition over our own property.

The new reindeer husbandry proposals not only directly affect the economic and legal aspects of our livelihood, but also indirectly the whole of the Sami culture will be affected by the new proposals. The way in which the application of the proposals will, in reality, influence our livelihood and our culture cannot be clearly expressed at present, but we are deeply concerned about the proposed changes - they appear to threaten our existence.

We demand that the new reindeer husbandry proposals be directly submitted to the Sam is by referendum. All legally eligible individuals in reindeer husbandry, and not only heads of household in the Sami communities, should be allowed to express their opinion on this matter of vital importance to the Samis and their culture. The results of this referendum should be presented to the Sami communities and to the nation as a whole.

...March 13th, 1969 .

Signatures enclosed.

Note

All the undersigned are persons over 21 years old. Only two of all the heads of household that were available have dissociated themselves from this communication.

EZucidation:

What the 80 signatories are clearly opposed to is the obligatory introduction of collective reindeer husbandry within the framework of the Sami community, and not the new reindeer husbandry proposals in their entirety. The proposed referendum should therefore concern this question and nothing else. 
ABBREVIATIONS

\begin{tabular}{|c|c|c|}
\hline A.A. & $=$ & American Anthropologist \\
\hline AMS & $=$ & The Labour Market Board \\
\hline $\mathrm{AU}$ & $=$ & Executive Committee \\
\hline BO & $=$ & Community headman \\
\hline C & $=$ & The Center Party \\
\hline FP & $=$ & The Liberal Party \\
\hline HR & $=$ & The Norwegian Supreme Court \\
\hline JO & $=$ & The Ombudsman of the Riksdag \\
\hline LKAB & $=$ & Luossavaara-Kirunavaara $A B$ \\
\hline M & $=$ & The Conservative Party \\
\hline NSD & $=$ & Norrländska Socialdemokraten \\
\hline NU & $=$ & Nordic Series of Enquiries \\
\hline RBL & $=$ & The Reindeer Pasture Law \\
\hline RNL & $=$ & The Reindeer Husbandry Law \\
\hline $\mathrm{S}$ & $=$ & The Social Democrats \\
\hline SET & $=$ & Samefolkets Egen Tidning, also Samefolket \\
\hline SK & $=$ & The Sami consultant \\
\hline SNRBK & $=$ & Swedish-Norwegian Reindeer Committee \\
\hline so & $=$ & The Sami ombudsman \\
\hline SOU & $=$ & The State's public enquiries \\
\hline SSR & $=$ & Swedish Sami Union \\
\hline STF & $=$ & The Swedish Tourist Association \\
\hline VPK & $=$ & The Communist Party \\
\hline
\end{tabular}




\section{REFERENCES}

ARCTIC PEOPLES CONFERENCE. 1974. Minutes of Arctic Peoples Conference, Kфbenhavn.

BAILEY, F.G. 1968. Parapolitical Systems, in M. Schwartz ed. Local Level Politics, Aldine, Chicago.

1969. Strategems and Spoils, Blackwell, Oxford.

BALANDIER, GEORGE. 1967. Anthropologie Politique, Paris.

BANTON, MICHAEL. 1972. Racial Minorities, Fontana, London.

BARTH, FREDRIK. 1964. Competition and Symbiosis in NE Baluchistan, Folk, Vol. 6,1:15-22.

1966. Models of Social Organization, RAI Occasional papers, No. 23, London.

1968. On the Study of Social Change, A.A. Vol. 70.

1969. Ethnic Groups and Boundaries, ed. F. Barth, Univ. forlaget/Allen, Bergen/Oslo/London.

1971. Minoritetsproblem från socialantropologisk synpunkt, in D. Schwartz ed. Identitet och Minoritet. Almquist $\circ$ Wicksell, Stockholm.

BATES, DANIEL G. 1971. The Role of the State in Peasant-Nomad Mutualism, Anthropological Quarterly, Vol. 44: $109-156$.

BERGHE VAN DEN, PIERRE. 1975. Ethnicity and Class in Highland Peru, in L. Despres ed. Ethnicity and Resource Competition in Plural Societies, World Anthropology, Mouton Publ., The Hague.

BLALOCK, H.M. 1967. Toward a Theory of Minority-Group Relations. John Wiley, New York.

BROX, OTTAR. 1966. Hva skjer i Nordnorge? En studie i norsk utkantspolitikk, Pax, Oslo.

1969. Sameproblemet som utkantsproblem i NU 1969:6.

BYLUND, ERIK. 1956. Koloniseringen av Pite Lappmark t.o.m. år 1867, Geographica 30, Uppsala.

COHEN, ABNER. 1969. Customs and Politics in Urban Africa, Routledge and Keagan, London.

COSER, LEWIS. 1956. The Functions of Social Conflict. (Paperback edition 1964), Free Press, New York. 
CRAMER, TOMAS. 1966. Kodicillen av 1751 och Samernas Rätt, i NU 1965:13.

1970a. De Underprivilegierade Samerna, in A. Küng ed. Samemakt, Tema, Stockholm.

1970b. Om de svenska samernas rätt tilz renbete $i$ Norge och dess bakgrund, in Cramér/Prawitz Studier $i$ renbeteslagstiftning, Nordstedts, Stockholm.

DAHLSTROM, EDMUND. 1967a. Samerna i det Svenska Samhälzet, Sociologisk forskning, 1967:1.

1967b. Våra Samer, Forskningsrapport nr.9, Sociologiska Institutionen, Göteborg Univ. Göteborg.

1971. Sociologiska synpunkter på nationelza minoriteter, in D. Schwartz ed. Identitet och Minoritet, Almquist o Wicksell, Stockholm.

- 1973-74. The Lappish Minority in Sweden: A Macro-Sociological study, International Jrl. of Sociology, Vol. III No. 3-4:110-146.

DAUN, ÅKE. 1969: Upp till kamp i Båtskärnäs. En etnologisk studie av ett samhälle inför industrinedläggelse, Prisma, Oskarshamn.

DELORIA, JR., VINE. 1969. Custer Died for Your Sins, CollierMac Millan, London.

DESPRES, LEO A. ed. 1975. Ethnicity and Resource Competition in Plural Societies, World Anthropology, Mouton Publ. The Hague.

EASTON, DAVID. 1965. A Systems Analysis of Political Life, John Wiley, New York.

EGILSAGAN, 1220-talet. Egil Skallagrimsons Saga (svensk översättning 1930).

EIDHEIM, HARALD. 1963. Entrepreneurships in Politics, in F.Barth ed. The Role of the Entrepreneur in Social Change in Northern Norway, Bergen.

1966. Lappish Guest Relationships under Conditions of Cultural Change, A.A. Vol. 68.

1968. The Lappish Movement - an Innovative Political Process, in M. Schwartz ed. Local Level Politics, Aldine, Chicago. 
EIDHEIM, HARALD. 1969. When Ethnic Identity is a Social Stigma. in F. Barth ed. Ethnic Groups and Boundaries, Univ.forlaget/Allen, Bergen/Osio, London.

1971. Assimilation, Ethnic Incorporation and the Problem of Identity Management in Eidheim Aspects of the Lappish Minority Situation, a collection of essays, Universitetsforlaget, Oslo.

FALKENBERG, JOHS. 1964. Samer og Fastboende i Rörostraktene, Norveg Vol. 11.

FALLERS, LOYD. 1955. The Predicament of the Modern African Chief: An Instance from Uganda, A.A. Vol. 57.

FELLMAN, ISAK. 1910. Handlingar och uppsatser angående Finska Lappmarken och Lapparna, Helsingfors.

FIRTH, RAYMOND. 1957. Factions in India and Overseas Indian Societies, British Jrl. of Sociology, Vol. 8.

FREDRICSON, HANS. 1974. Samerna i Norrländskan, mimeographed paper for fil.kand degree Socialantropologiska Institutionen, Stockholms Universitet, Stockholm.

GJESSING, GUTORM. 1954. Changing Lapps, Monographs on Social Anthropology No. 13, London School of Economics, London.

1973. Norge $i$ Sameland, Gyldendal, Oslo.

GLUCKMAN, MAX, MITCHELL, C. and BARNES, J.A.1949. The Vizzage Headman in British Central Africa, Africa 1949:2.

GLUCKMAN, MAX. 1965. Politics, Law and Ritual in Tribal Society, Blackwell, Oxford.

1968. Inter-hierarchical Roles: Professional and Party Ethics in Tribal Areas in South and Central Africa, Aldine, Chicago.

GOFFMAN, ERVING. 1959. Presentation of Self in Everyday Life, Doubleday, New York.

1961. Encounters, Bobbs-Merrill, Indianapolis.

GOODENOUGH, WARD H. 1966. Cooperation in Change. An Anthropological Approach to Community Development, (paperback edition), Wiley \& Sons, New York.

GREENWOOD, W. \& EDWARDS, J.M.B., 1973. Human Environments and Natural Systems. A Conflict of Dominion, Duxburg Press, Belmont, Calif.

HANNERZ, ULF. 1973. Lokalsamhället och omvärlden: Ett socialantropologiskt perspektiv, Tema, Stockholm. 
HARDESTY, DONALD L. 1972. The Human Ecological Niche, A.A. Vol. 74:457-466.

HEIKKA, GUSTAV. 1969. Intryek och synpunkter på betänkandet SOU 1968:26, Antropolognytt, Åro. 7:4.

HOETINK, HARMANNAS, 1975. Resource Competition, Monopoly, and Socioracial Diversity, in Despres ed. Ethnicity and Resource Competition in Plural Societies, Mouton, The Hague.

HOLLOMAN, REGINA E. 1975. Ethnic Boundary Maintenance, Readaptation, and Societal Evolution in the San Blas Islands of Panama, in Despres ed. Ethnicity and Resource Competition in Plural Societies, op.cit.

HULTBLAD, FILIP. 1968. Overgång från Nomadism till Agrar Bosättning $i$ Jokkmokks Socken, Acta Lapponica XIV, Stockholm.

INGOLD, TIM. 1974. On Reindeer and Men, Man Vol. 9:523-538.

JERNSLETTEN, NILS. 1970. Varför vara same, in A. Küng ed. Samemakt, Tema, Stockholm.

JUSTITIEOMBUDSMANNENS SKRIVELSE, 1966. Till Konungen angående förhåzzandena $i$ samebyarna $R$ och $L$, Stockholm.

KARLSTADSKONVENTIONEN. 1905.

KLEIVAN, HELGE. 1970. Culture and Ethnic Identity: On Modernization and Ethnicity in Greenland, Folk, Vol. $11-12: 209-234$.

KUNGLIGT BREV. 1873.

LAG. 1928. Om de svenska Lapparnas rätt til renbete i Sverige samt Lag om renmärken, Byordningar (RBL).

1971. Rennäringslagen, (RNL).

LAPPECODICILLEN. 1751. TiZl gränstraktat mellan Norge och Sverige, Lapparne betreffande.

LOWIE, ROBERT. 1945. A Note on Lapp Culture History, Southwestern Jrl. of Anth., Vol. 1:4, 447-454.

MITCHELL, CLYDE. 1974. Perceptions of Ethnicity and Ethnic Behaviour. An Empirical Exploration, in A.Cohen ed. Urban Ethnicity, ASA Monographs No 12 Tavistock, London. 
NICHOLAS, RALPH. 1965. Factions: a Comparative Analysis, in M. Banton ed. Political Systems and the Distribution of Power, ASA Monographs No 2, Tavistock, London.

1966. Segmentary Factional Political Systems, in Schwartz, Tuden, Turner eds. Political Anthropology, Aldine, Chicago.

NICKUL, KARL. 1948. The Skolt Lapp Community Suenjelsijd during the year 1938, Acta Lapponica V, Stockholm.

NORDISK UTREDNINGSSERIE. 1969. Sjette Nordiska Samekonferensen $i$ Hetta.

NORRBOTTENSUTREDNINGEN. 1967. (mimeographed).

NUNAVUT. 1976. A Proposal for the Settlement of Inuit Lands in the Northwest Territories.

OTNES, PER. 1970. Den Samiske Nasjon, Pax, Oslo.

PAINE, ROBERT. 1964a. Herding and Husbandry, Two basic Concepts in the Analysis of Reindeer Management, Folk, Vol. 6:1, 83-88.

1964b. Cultural Demography and Nomad/Sedentary Relations of Reindeer Groups in Norway and Sweden. The VIIth International Congress of Anthropological and Ethnological Sciences, Mos cow.

1965. Coast Lapp Society II. A Study of Economic Development and Social Values. Univ.forlaget, Troms $\phi / 0$ slo/Bergen.

1970. Lappish Decision, Partnerships, Information Management and Sanction A Nomadic Pastoral Adaptation, Ethnology, Vol. IX:I.

1972. The Herd Management of Lapp Reindeer Pastoralists, Jrl. of Asian and African Studies, Vol. VII.

PAREDES, J. ANTHONY. 1974. The Emergence of Contemporary Eastern Creek Indian Identity in Thomas K. Fitzgerald ed. Social and Cultural Identity, Southern Anthr. Society Proceedings No 8, Univ. of Georgia Press, Athens.

PARK, GUSTAV. 1957. Samernas Organisationssträvanden $i$ Sverige, in Sámiid Dilit, Oslo. 
PEHRSON, ROBERT. 1954. The Lappish Herding Leader: A Structural Analysis, A.A. Vol. 56.

1957. Bilateral Network of Social Relations in Könkämä Lapp District, Indiana Univ. Indiana. (Reprinted Samiske Samlinger VII, Oslo.)

PELTO, PERTTI, J. 1973. The Snow Mobile Revolution: Technology and Social Change in the Arctic, Cummings, Mento Park, Calif.

PROPOSITION NR. 68. 1962. Sveriges Riksdag, Stockholm. Om Rennäringsförvaltningen.

PROPOSITION NR. 51. 1971. Om Rennäringslag.

PROPOSITION NR. 16. 1972. Om Konvention mellan Norge och Sverige om renbetning.

PROTOKOLL. Svenska Samernas Riksförbunds landsmöte 1963-1975.

PROTOKOLL. 2948. Landsmötet i Arvidsjaur.

PROTOKOLL. 1964. SSR:s Renbeteslagskommitté och 1964 års Rennäringssakkunniga.

QVIGSTAD-WIKLUND. 1909. Dokumentsamling II, Gröndal 으 Sön, Kristiania.

RENBETESKONVENTION. 1919. MeZlem Norge og Sverige angaaende flyttlappenes adgang til Renbeiting, Nordsteds, Stockholm.

RENUTREDNING. 1960 .

RUONG, ISRAEL. 1937. Fjällsamerna i Jukkasjärvi socken, Geographica 3, Uppsala.

1956. Types of Settlement and Types of Husbandry among the Lapps in Northern Sweden, Arctica, Festskrift till Åke Campbell, Uppsala.

RAESTAD, ARNOLD. 1928. Lappeskatten og Lappenes Rettigheter $i$ Norge för 1751, i Festskrift till J. Qvigstad, Troms $\phi$ Museums skrifter, Vol. 11, Oslo.

1930-33. Fra Stettin til Strömstad, Norsk Hist. Tidsskr., Bind 29.

SAMEFOLKET (SET). 1918-1976.

SAMERNA - 1971. En bortglömd minoritet (mineographed report $\left.f_{p}\right)$. 
SAMERNAS VILJA. 1966. SSR, stencile, reprinted in protokoll landsmötet 1967 .

SAMERNAS SAMEPOLITISKA PROGRAM. 1968.

SAMERNAS VITA BOK I. 1972. Angående ny konvention melzan Sverige och Norge om renbetning m.m.

SCHWARTZ, M. TUDEN, A. TURNER, V. eds., 1966. Political Anthropology, Aldine, Chicago.

SCHWARTZ, MARC. ed., 1968. Local Level Politics, Aldine, Chicago.

SIMONS, SUZANNE L. 1969. The Cultural and Social Survival of a Pueblo Indian Community, in Tobias o Woodhouse eds. Minorities and Politics, Univ. of New Mexico, Albuquerque.

SNELL, HELLE 은 SNELL, TOM. 1975. Samish Responses to Processes of National Integration in $\mathrm{J}$. Boissevain ed. Beyond the Community: Social Process in Europe, the Hague.

SOLEM, ERIK. 1933. Lappiske Rettsstudier, Institutt for Sammenlignende Kulturforskning, Ser. B XXIV.

SOMMARSTRÖM, BO. 1967. Renskötsel, i Kulturhistoriskt Lexikon, Stockholm.

SOU 1966:12. Renbetesmarkarne.

SOU 1968:16. Rennäringen i Sverige.

SOU 1975:99-100. Samerna $i$ Sverige, Stöd åt språk och kultur. (Sameutredningen).

SVENSK-NORSKA RENBETESKOMMISSIONEN. 1967. Betänkande.

SVENSSON, TOM G. 1964. Samernas Politiska Organisation, mineographed paper for fil.kand. degree Stockholm Univ., Stockholm.

1966. De Renskötande Samernas Ställning $i$ Sverige in D. Schwartz ed. Svenska Minoriteter, Aldus, Stockholm.

1968. Rensamerna, in Vad sker i Glesbygden?, Norrbottens Museum, Luleå.

1969a. Former forr Politiskt Liv i Samebyn, Nordnytt 1969:2, also NEFA-Debat).

1969b. Socialantropologi som Kritisk Vetenskap, Häftet för Kritiska Studier, 1969:2-3. 
SVENSSON, TOM G. 1973a. Samernas Politiska Organisation, En studie av en etnisk minoritet $i$ förhållande till storsamhället, Dr.Diss. Stockholms Universitet, Stockholm.

- 1973b. Reindeer Lapps: Ecology and Political Development, in G. Berg ed. Circumpolar Problems, Habitat, Economy and Social Relations in the Arctic, Wennergren International Symposium Series, Vol. 21, Pergamon Press, Oxford.

- 1976. The Effect of Economic Change on the Ecology, Culture and Politics of Reindeer Samis, in P. Pelto, L. Müller-Wille eds., Unexpected Consequences of Economic Change in the Arctic and Sub-arctic. In press.

SWADESH, FRANCES. 1969. The Alianza Movement of New Mexico. The Interplay of Social Change and Public Commentary, in $\mathrm{H}$. Tobias $\circ \mathrm{C}$. Woodhouse eds. Minorities and Politics, Univ. of New Mexico, Albuquerque.

TOBIAS, H. \& WOODHOUSE, C. 1969. Minorities and Politics, Univ. of New Mexico, Albuquerque.

VAN VELSEN, I. 1967. The Extended Case Method and Situational Analysis, in A.L. Epstein ed. The Craft of Social Anthropology, Tavistock, Loncon.

WAGLEY, C. \& HARRIS, M. 1958. Minorities in the New World, paperback ed. 1964, Colombio Univ. Press, New York.

WHITAKER, IAN. 1955. Social Relations in a Nomadic Lappish Community, Samiske Samlinger II, Oslo.

1956. Declining Transhumance as an Index of Cultural Change, in Arctica, Studia Ethnographica Upsaliensia XI, Uppsala.

WIKLUND, K.B. 1908. De Svenska Nomadlapparnas flyttningar till Norge $i$ äldre och nyare tid. Almqvist Wiksell, Uppsala.

WIRTH, LOUIS. 1950. The Problem of Minority Groups, in Ralph Linton ed. The Science of Man in the World Crisis, Columbia Univ. Press, New York.

YTTRANDE. 1976. Över Sameutredningens betänkande SOU 1975:99-100, Samernas landsmöte juni 1976, SSR:s Kansli, Stockholm. 




\section{STOCKHOLM STUDIES IN SOCIAL ANTHROPOLOGY}

1. Caymanian Politics: Structure and Style in a Changing Island Society by Ulf Hannerz Skr. 25:-, \$ 5.00 .

2. Having Herds: pastoral herd growth and household economy by Gudrun Dahl and Anders Hjorth Skr 45:-, \$10.00

3. The Patron and the Panca: village values and Pancayat Democracy in Nepal by Bengt-Erik Borgström Skr 25:-, \$ 5.00

4. Ethnicity and Mobilization in Sami Politics

by Tom G. Svensson Skr 35:- $\$$ \$.00

Available from

Department of Social Anthropology

University of Stockholm

Fack

10405 Stockholm 50

Sweden

ISBN 91-85284-06-8 